Portland State University

PDXScholar

5-3-1973

\title{
Die Einwirkung des Jugendstils auf Rilkes Frühwerk
}

Linda Collins Blumenthal

Portland State University

Follow this and additional works at: https://pdxscholar.library.pdx.edu/open_access_etds

Part of the German Literature Commons

Let us know how access to this document benefits you.

\section{Recommended Citation}

Blumenthal, Linda Collins, "Die Einwirkung des Jugendstils auf Rilkes Frühwerk" (1973). Dissertations and Theses. Paper 2135.

https://doi.org/10.15760/etd.2134

This Thesis is brought to you for free and open access. It has been accepted for inclusion in Dissertations and Theses by an authorized administrator of PDXScholar. Please contact us if we can make this document more accessible: pdxscholar@pdx.edu. 
AN ABSTRACT OF THE THESIS OF Iinda Collins Blumenthal for the Master of Arts in German presented May 3, 1973.

Title: The Influence of Jugendstil on Rilke's Early Peetry APPROVED BY MEMBERS OF TEE THESIS COMMITTEE:
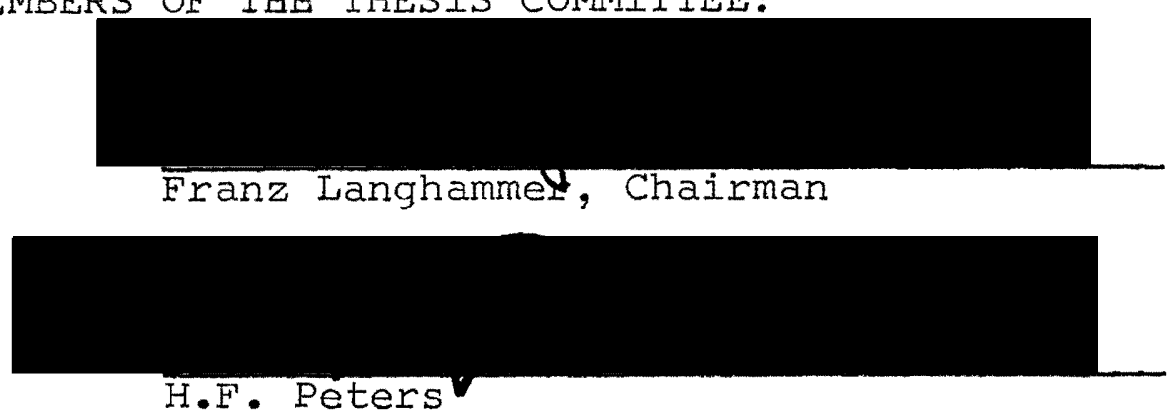

A review of the secondary literature written on Rilke's poetry reveals that his earliest work has scarcely been dealt with. This fact is not astounding considering that the poet feund literary acclaim only in his more mature period. In those cases, however, in which Rilke's first poetry has been examined, it is approached outside the contextoof later developments. This paper is based on the thesis that a vital continuous thread which begins with Jugendstil and extends into his most mature poetry, runs through Rilke's work as regards life style and art theory. Many of his most typical symbols - and he is a representative of the Symbolist movement - can be traced back to Jugendstil: Angel, Love, Dancer and Death, for example. A thorough analysis of Rilke's poetry cannot be undertaken without consideration of his early dependence upon Jugendstil especially because such symbols are newly interpreted Jugendstil themes. The aim of this paper 
is therefore the exploration of this dependence as exemplified in Rilke's early poetry thus providing a basis from which a comprehensive interpretation of Rilke's person and work can be realized.

As to the method of investigation: In order to show what exactly made Rilke a Jugendstil poet it was necessary to extend the subject matter examined to include not only his poetry and essays, but also statements made by him in letters and diezies and statements made about him by his acquaintances and to relate these to the cultural and intellectual history of the turn of the century and the Jugendstil tradition.

Rilke's poetic development begins with an inclination towards representational art, and his work is continually characterized by a pictorial manner of expression. His interest in art manifests itself in the attempt to finish a degree in Art History, in the process of which he is inevitably swept up into a circle of artists in Munich, which is at this time (1896) the center of the creative modern trend in art, namely the Jggendstil movement. Rilke was in addition attracted to this movement because its advocates were searching for cotoperation and unity in the arts in order to thus revitalize life and the whole of society. Thiscopoperation concerned Rilke in as far as he wrote poems to Jugendstil paintings, published his poetry and essays frequently in Jugendstil magazines, had his books decorated with Jugend- 
stil ornaments, established relationships with Jugendstil artists and in various ways supported Jugendstil theater. Such activities had of course an effect upon his literary production. In order to determine the Jugendstil influences in his poetry, it is first necessary to provide a general comparison of the themes apparent in Jugendstil in the visual arts with those in literary Jugendstil. This part of my paper consists of an exposition of the typical characteristics of this art tradition which distinguish Jugendstil from its contemporaries - Impressionism and Neoromanticism; namely, the particular approach to life with its new turn toward natural forms and goals and the thus resulting style of artistic expression; and finally, the elevation of art to a sacred function through which a paradise-like state of existence could be restored.

Rilke's connection to Jugendstil can be best portrayed chronologically. Having begun during the period in Prague in which Rilke composed youthiul poetry with Jugendstil themes, the development continues in Munich and leads him to the precursors of the movement - the Preraphaelites; they and the general rediscovery of the Renaissance before the turn of the century take Rilke in 1898 to Italy, its land of origin. The works which were written in Italy and shortly thereafter ate a reflection of Rilke's absorbtion of the Renaissance as seen through the eyes of the Preraphaelites and Jugendstil artists. Rilkes "Ding" concept which is so important for his later 
poetry materializes at this time and finds further development during his journeys to Russia and the sojourn in Worpswede, the actualized "artificial paradise" in order to all the faster come to an external renunciation of Jugendstil in Paris (1902), partly due to the fact that Jugendstil art shortly after the turn of the century had become to some extent a common fad. The actual life philosophy contained in Jugendstil, however, remained alive in Rilke. 


\title{
DIE EINWIRKUNG DES JUGENDSTILS
}

\author{
AUE, RILKES FRÜHWERK
}

$$
\text { by }
$$

LINDA COLLINS BLUMENTHAL

\author{
A thesis submitted in partial fulfillment of the \\ requirements for the degree of \\ MASTER OF ARTS \\ in \\ GERMAN
}

Portland State University

1973 
TO THE OFFICE OF GRADUATE STUDIES:

The members of the Committee approve the thesis of

Linda Collins Blumenthal presented May 3, 1973.

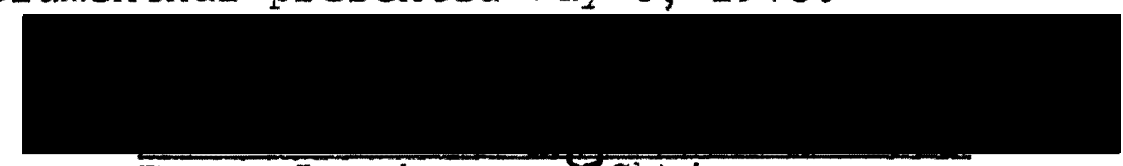

Franz Langhammer, Caicman
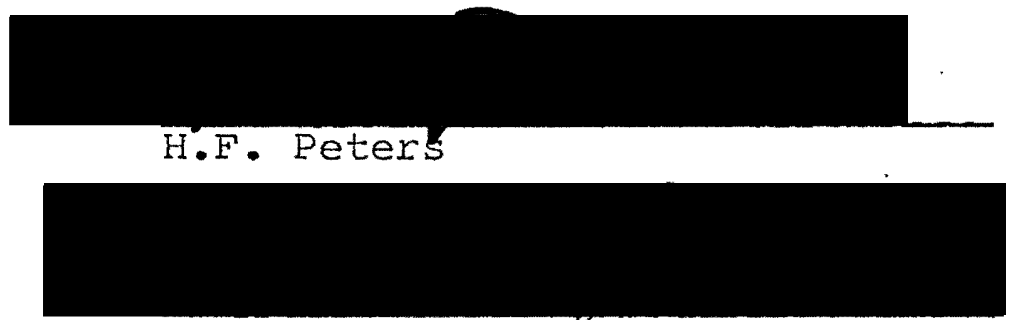

Frank F. Eaton

APPROVED:

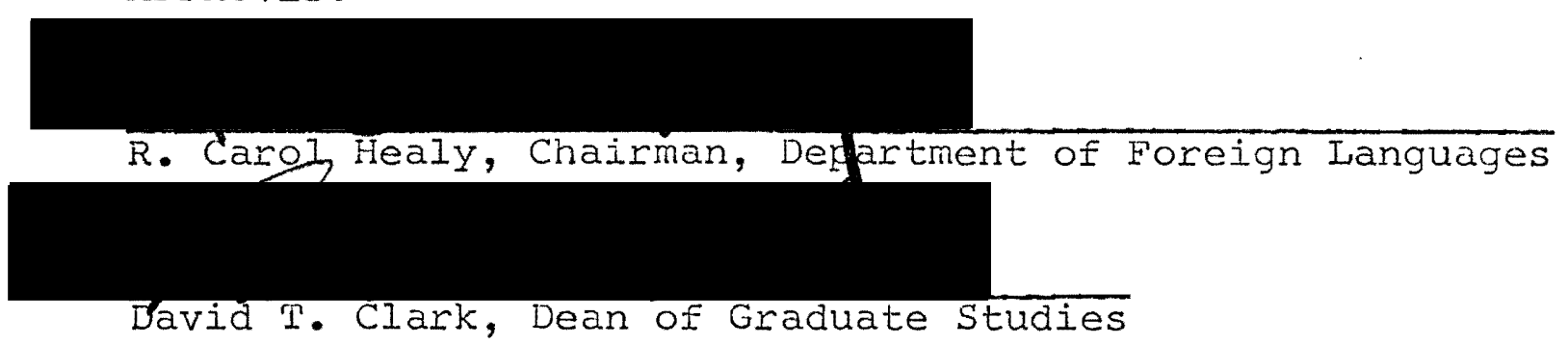

May 10, 1973 


\section{INHALTSVERZEICHNIS}

SEITE

KAPITEL

II DIE BEDEUTUNG DES SCHAUENS BEI RILKE ...... 4

III DAS KUNSTSTUDIUM $\ldots \ldots \ldots \ldots \ldots \ldots \ldots \ldots \ldots \ldots \ldots$

IV DER JUGENDSTIL ALS DIE MODERNE KUNSTRICHTUNG IN DER FRÜHZEIT RILKES ........... 12

Der geistesgeschichtliche Hintergrund des Jugendstils

Die gewandelte Einschätzung des

Jugendstils und die Forschungs-

lage

Die Frage nach einem literarischen Jugendstil ............. 18

Untersuchungen zu JugendstilElementen in Rilkes Frühwerk

$V$ PARALLELEN ZWISCHEN DEM BILDNERISCHEN JUGENDSTIL UND RILKES DICHTUNG ........... 25

Historische Aspekte ................. 25

Texte'zu-Gemälden ............... 25

Veröffentlichungen in Jugendstil-Zeitschriften

Bücher Rilkes mit Jugendstil -

Ornamenten

Gedichte Rilkes mit Jugendstil-Gestaltung

Persönliche Beziehungen zu

Jugendstil-Künstlern

Verbindungen zu den Jugendstil-Sezessions-Bühnen 
Motiv-Vergleiche zwischen bildnerischem und literarischem Jugendstil

Mystische Versenkung

Pan, Engel, Traum, Sehnsucht, Tod, Der Innenraum, Der Gottesbegriff, Kunst als Rezigionsersatz, Die Liebe, Das Frauenbild

Das kuinstiche Paradies

Der Garten mit dem Weiher, Die Insel im Meer, Die Bootsfahrt, Der Schwan

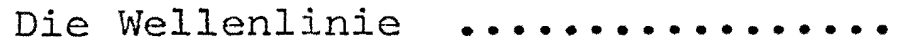

Die Musik, Der Tanz

Das Kunst-Ding ..............

Sprachmerkmale 68

Die Form der Bildichkeit ...... 68

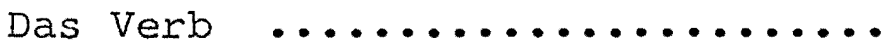

E. Hajeks These der Zeit-Raum

Entsprechung

Abgrenzung zum Impressionismus und zur Neoromantik

VI RILKES VERHÄLTNIS ZUM JUGENDSTIL, CHRONOLOGISCH GESEHEN

Die Prager Zeit

Erste Gedichte, die Rilkes Interesse an der Malerei zeigen .....

Rilkes Beitrag zum Kreis der Modernen in der Zeit vor München ...

Beispiele für Rilkes Auffassung der jugendstilhaften Vermischung der Künste

Jugendstil-Motive in Rilkes Dichtung während der Prager Zeit .....

Die Blumenmotive H.V.Preuschens, Weitere JugendstilMotive 
Die Münchener Zeit .................... 114

München als Zentrum der Moderne

Jugendstil-Motive in Rilkes Münchener Lyrik und vor der Italienreise

Motive aus der Pflanzenwelt, Das" Motiv der mystischen Versenkung, Die Wellenlinie, Das künstiliche Paradies .....

Rilkes essayistische Äußerungen zum Jugendstil . ............ 129

Der "Münchner Kunstbrief," ... 129 "Moderne Lyrik", .......... 133 "Uhdes Christus" .......... 134

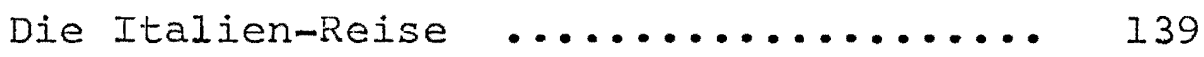

Die Wiederentdeckung der Renaissance um die Jahrhundertwende

Die im Florenzer Tagebuch enthaltene Kunstauffassung ........ 142

Die aristokratische Kunst

als Religionsersatz ....... 142

Das Vorbild der Frührenaissance und Kritik an der

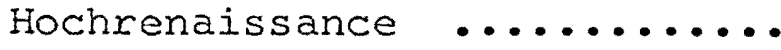

Die Bedeutung von Richard

Muthers Botticelli-Interpretation für die Jugendstil-Generation ....

Jugendstil-Motive in Rilkes

Italien-Dichtung $\ldots \ldots \ldots \ldots \ldots \ldots .156$

Die Frau als Motiv in den "Nädchen-Liedern" und

-"Gebeten"

Verschiedene Motive in der

"Weißen Fürstin" .......... 161

Jugendstil-Symbolik im "Spiel" und in den "Bildern entlang".. 164

Die Entstehung von Rilkes

Ding-Verständnis

Rilkes spätere Italien-Kritik und sein Abrücken vom Renaissancekult. 
Die Rußland-Besuche

Rilkes russische Kunst-

Aufsätze

Die im Stundenbuch sichtbaren

russischen Einflüse

Weitere Jugendstil-Themen im

Stundenbuch ind in einzelnen

Gedichten

Die. Suche nach einem neuen Stil ... 193

Worpswede

198

Die Verbindung zu Heinrich Voge-

lers Version des Jugendstils

Kunstiberlegungen in der Worps-

weder Monographie

204

Die Begegnung mit Clara West-

hoff und Paula Becker .......... 207

Rilkes letzte essayistische Beschäftigung mit ausgesprochenen Jugendstil-Themen

Rilkes Maeterlinck-Rezeption ..

Rilkes Abkehr vom jugendstil ......... 221

Rilkes weitere Verbindungen allgemeiner und künstlerischer Art zum Umfeld des Jugendstils

Seine elitäre Lebensweise ....... 224

Rilkes Bekanntenkreis in Paris .... 225

Rilkes Studium Hokusais ........ 228

Die Stilwenaung im Spätwerk ..... 232

Jugendstil-Motive im Spätwerk .... 235

VII SCHLUSSBETRACHTUNG $\ldots \ldots \ldots \ldots \ldots \ldots \ldots \ldots \ldots \ldots$

AUSGEWÄHLTE BIBLIOGRAPHIE $\quad \ldots \ldots \ldots \ldots \ldots \ldots \ldots \ldots \ldots$ 


\section{KAPITEL \\ EINLEITUNG}

Rilkes Verhältnis zur Malerei spielt eine wichtige Rolle in jeder Phase seiner dichterischen Entwicklung. Die Malerei gibt ihm wichtige Anregungen bei der Formulierung seiner Kunstauffassungen und ist eine Inspirationsquelle, die eine wertvolle Einsicht in seinen Schaffensprozeß bietet.

Man nimmt meistens an, daß die Malerei für Rilkes Dichtung erst nach 1902 während seines Aufenthalts in Paris Bedeutung gewonnen hat, denn hier werden seine entscheidenden Erlebnisse in der Malerei deutlich durch eigene Aussagen in Briefen und in den $z u$ dieser Zeit geschriejbenen Gedichten zum Ausdruck gebracht. Tatsächlich verbringt Rilke Tage und Wochen in verschiedensten Ausstellungen. Er informiert sich über die Entwicklungsgeschichte der modernen Kunst, interessiert sich dabei besonders für Van Gogh und Cézanne und erkennt das Neue dieser Richtung, nämiich die "Wendung" ${ }^{1}$ zur Zweidimensionalität, die mit ihrer gewandeltèn Perspektive das eigentlich Moderne der bildenden Kunst des 20. Jahrhunderts einleitet. Die große Wendung in seiner Schaffensweise kann als Ergebnis dieser Beschäftigung und seiner Begegnung mit Rodin gesehen werden, indem hier bei ihm neue Vorstel- 
lungen von der Dinghaftigkeit in der Kunst erweckt werden, die er dann in seine eigene Dichtung umzusetzen versucht: In den Neuen Gedichten geht ein großer Teil der Gedichte auf Anregungen aus der bildenden Kunst zurück. Durch genaue Überprüfung der Tagebücher und Briefe, durch einen Vergleich mit den Entstehungsdaten der Gedichte stellt man z.B. fest; $d a ß$ unter anderen diese Gedichte auf Bilder folgender Maler zurückzuführen sind: "Corrida" (Gaya), "Leda" (Correggio) und "Die Legende von den drei lebendigen und drei Toten" (Benozzo Gozzoli). 2 Auch die Werke, die nach den Neuen Gedichten entstehen, sind unbedingt in Verbindung mit Malern und Malerei zu betrachten. So z.B. "Die spanische Trilogie", "Himmelfahrt Maria" und "Christi Höllenfahrt", die aus dem Erlebnis seiner Spanienreise 1912-13 und des Studiums EI Grecos geschrieben werden. El Greco ist auch später wichtig für das Engelbild der Elegien. Die Kriegsjahre in Wien und München brachten Beziehungen zu den Malern Kokoschka und Klee und Stellungnahme zum Expressionismus und der abstrakten Kunst. Es war aber Picasso, der den tiefsten Eindruck gemacht hat und dessen Gemälde, "La Famille des Saltimbanques", die Grundlage für die "Fünfte Elegie" gewesen ist.

In der Periode nach 1902 gibt es also wichtige Verbindungen von der Malerei zu Rilkes Dichtungen, was in der Sekundärliteratur entsprechend untersucht wurde. Zum größten Teil

\footnotetext{
$2 \mathrm{H}$. Berendt, Rilkes Neue Gedichte (Bonn: H. Bouvier Verlag, 1957).
} 
unerforscht blieb aber die Periode vor 1902, mit der diese Arbeit sich beschäftigt. Unerforscht wahrscheinlich deswegen, weil das Frühwerk von Rilke selber nicht viel später verleugnet worden ist - wie wir sehen werden, zum Teil mit gutem Grund, denn in der Tat sind die ersten Veröffentlichungen, an seinem Hauptwexk gemessen, künstlerisch weniger wertvoll. Was hier beabsichtigt ist, ist die Entwicklung der Rilkeschen Kunstauffassung bis 1902 darzustellen, die eben durch seine Beziehung zur Malerei (und vor allem zu der Kunstrichtung Jugendstil) geformt worden ist - eine Kunstauffassung, die durchaus in Verbindung auch zum Spätwerk zu betrachten ist. 


\section{KAPITEL}

\section{DIE BEDEUTUNG DES SCHAUENS BEI RILKE}

Das Anschauen der Dinge war von Anfang an Rilkes erstes Anliegen: sehen lernen wollte er. in erster Linie. Es war diese Fähigkeit, die ihn so sehr mit der Malerei verband. Der erste Ausdruck seines Künstlerwesens waren dementsprechend Zeichnungen. Carl Sieber und F.W. Heerikhuizen ${ }^{3}$ berichten über die ersten Malversuche, die höchstwahrscheinlich von der Eitelkeit der Mutter stark unterstützt wurden. Die Lieblingsthemen des Frühwerks tauchen schon hier auf: Villen und Schlösser, Inseln, drachentötende Ritter und kämpfende, heldenhafte Offiziere. Diese Beispiele sind mit einer Stelle aus Malte Laurids Brigge zu vergleichen, wo er als kleines Kind einen "sehr deutlichen Ritter auf einem merkwüirdig bekłeideten Pferd" zeichnet. Plötzlich rollt sein Bleistift vom Tisch herunter und er kriecht unter den Tisch und sucht ihn. In der Dunkelheit erkennt er nur seine eigene, ausgespreizte Hand

die sich ganz allein, ein bißchen wie ein Wassertier, da unten bewegte und den Grund untersuchte. Ich sah

\footnotetext{
${ }^{3}$ Carl Sieber, René Rilke (Leipzig: Insel-Verlag, 1932), S. $78 f f$.

F.W. Heerikhuizen, R.M.Rilke, His Life and Work (Lon-
} don: Routledge \& Kegan Paul Ltd., 1951), S.33f. 
ihr, weiß ich noch, fast neugierig zu; es kam mir vor als könnte sie Dinge, die ich sie nicht gelehrt hatte, wie sie da unten so eigenmächtig herumtastete mit ${ }_{4}$ Bewegungen, die ich nie an ihr beobachtet hatte.

Das Traumatische an diesem Ereignis ist das Erscheinen einer großen, mageren Hand, die aus der Wand seiner eigenen Hand entgegenkommt und sie sucht. Nur mit großer Mühe kann der Junge seine Hand zurückziehen und wieder auf seinen Stuhl kommen - noch ganz bei Bewußtsein, aber körperlich geschwächt. Der Erzähler vermag dieses Geschehen nur vage wiederzugeben, aber es hat sich tief in das Wesen des Kindes eingeprägt und hat eine weiterwirkende Kraft uber ihn.

Es ist natürlich Einbildung, wenn ich nun behaupte, ich hätte in jener Zeit schon gefühlt, daß da etwas in mein Leben gekommen sei, geradeaus in meines, womit ich allein würde herumgehen müssen, immer und immer. Ich sehe mich in meinem kleinen Gitterbett liegen und nicht schlafen und irgendwie ungenau voraussehen, daß so das Leben sein würde: Voll lauter besonderer Dinge, die nur für Einen gemeint sind und die sich nicht sagen lassen. 5

Vielleicht ist es das Gefühl des Berufenseins, das Unsagbare zu empfangen und künstlerisch zu vermitteln. Der Prozeß des Aufzeichnens ist mit dem Anschauen stark verbunden - was in einem Rilkebrief an seine Frau Clara Westhoff deutlich wird. Rilke beschreibt, wie seine Arbeit sein müsse:

...wie wenn man zeichnet, den Blick auf das Ding gebunden, verwoben mit der Natur, und die Hand geht allein irgendwo unten ihren weg, geht und geht, wird ängstlich, schwankt, wird wieder froh, geht und geht

\footnotetext{
4Rilke, Sämtliche Werke. (SW). Bd. VI. (Wiesbaden: Insel, 1966), S. 795. 
tiefer unter dem Gesicht....Mir ist als hätte ich immer so geschaffen: das Gesicht im Anschauen ferner Dinge, die Hände allein. 6

Es gibt genügend Tagebuchstellen, Briefe und Gedichte auch aus der frühen Periode Rilkes, die seine dichterische Arbeit in erster Linie als Anschauungsprozeß beschreiben. Nur als Beispiel eine Stelle aus einem Brief vom 10. März 1899:

... in unserem Schauen liegt unser wahrstes Erwerben. Wollte Gott, daß unsere Hände wären wie unsere Augen sind: so bereit im Erfassen, so hell im Halten, so sorglos im Loslassen aller Dinge; dann könnten wir wahrhaft reich werden. Reich aber werden wir nicht dadurch, daß etwas in unseren Händen wohnt und welkt, sondern es soll alles durch ihren Griff hindurchströmen wie durch das festliche Tor des Einzugs und der Heimkehr. 7

Bis in die Zeit der Elegien und Sonette bleibt das "Von-sichselbst-Fortschauen" ein Merkmal seines Arbeitsprozesses. Ein Gemälde von Hans Memling, "Der Evangelist Johannes auf Patmos" auf dem Seitenflügel des Johannes-Altars in Brügge, beeindruckt Rilke so sehr, daB er am 16. Januar 1912 nach der Niederschrift der beiden ersten Elegien sagt:

Ich zögere unendlich, liebe Fürstin, nach dem Diktat, das mir hier auf diesem Patmos so stümisch eingerufen wurde, daß ich, wenn ich daran denke, meine, wie der Evangelist in Brügge im Johannisspital, mit beiden Händen geschrieben zu haben, nach rechts und links, um alles Eingegebene aufzufangen.8

6Rilke, Br.A.1902-1906. (Leipzig: Inse1, 1930), S. 83. 7Rilke, Tagebücher aus der Frühzeit (Leipzig: Insel, 1942), S. 152 .

8Rilke, Briefwechsel, R.M.Rilke und Marie von Thurn und Taxis-Hohenlohe. (Wiesbaden: Insel, 1951), S. 92. 
Auch in dem späteren Gedicht vom November 1915, "Die Worte des Herrn an Johannes auf Patmos" heißt es:

Aber du, du sieh, gewahre, sei schauender, als je ein Mann gewesen.

Und sollst schreiben, ohne hinzusehn;

denn auch dieses ist von Nöten: Schreibe! leg die Rechte rechts und links auf deg

Stein der Linke: daß ich beide treibe.

Die "Verwandlung des Sichtbaren" im Spätwerk ist dann die Endstufe dieses Schauens, "die geschaute Welt" will "unsichtbar in uns erstehen" ( $\$$. Elegie). Rilke schreibt aus Duino im März 1912:

Damals (zur Zeit Tassos) fing vielleicht das an, was wir schon so vollzogen um uns sehen, das Zurückschlagen einer im Äußeren überfüllten Welt ins Innere.... die inneren Erlebnisse waren im sechzehnten Jahrhundert im Sichtbaren draußen zu einer solchen Herrlichkeit gediehen, daß sie weiter nicht zu steigern waren. 10 $\because \cdots$

Die Aufgabe des Menschen und des Dichters insbesondere ist es, sich mit dem Sichtbaren innig zu verbinden, Abschied von ihm zu nehmen und es sich in seinem unsichtbaren Wesen anzueignen. 11 So heißt es in der "Siebten Elegie":

Nirgends, Geliebte, wird Welt sein, als innen. Unser Leben geht hin mit Verwandlung. Und immer geringer schwindet das Außen. Wo einmal ein dauerndes Haus war, schlägt sich erdachtes

9Rilke, SW. II. (Wiesbaden: Insel, 1963), S. 108. 10Rilke, Br.A. 1907-1914. (Leipzig: Insel, 1933), S. 221.

${ }^{1 I_{W}}$ Falk, Leid und Verwandlung (Salzburg: Otto Müller Verlag, 1961), S. 67 . 
Gebild vor, quer, zu Erdenklichem völlig gehörig, als ständ es noch ganz im Gehirne.12

Oder in der "Neunten Elegie":

Und diese, von Hingang lebenden Dinge verstehn, daß du sie rühmst; vergänglich, traun sie ein Rettendes uns, den Vergänglichsten, zu. Wollen, wir wollen sie ganz im unsichtbarn Herzen verwandeln in - o unendlich - in uns 113

12Rilke, SW. I. (Wiesbaden: Insel, 1955), S. 711. 13 ibid. S. $71 \dot{9}$. 


\section{KAPITEI}

\section{DAS KUNSTSTUDIUM}

Ein weiteres Anzeichen für Rilkes Interesse an Malerei ist sein immer wieder beabsichtigtes Kunststudium. Nachdem er durch Privatunterricht das. Abitur nachgeholt hatte, immatrikulierte er sich zu Anfang des Wintersemesters 18951896 an der Karl-Ferdinand-Universität in Prag und belegte Philosophie, deutsche Literatur und Kunstgeschichte. Doch sein Onkel, Förderer der Familie, der schon während der Schulzeit Rilkes Studium (in Form eines Stipendiums) unterstüzte, hatte den Wunsch, daß der junge Rilke nach einem Studium der Rechte die eigene Anwaltskanzelei übernehmen sollte; nach eifnem halben Jahr wechselte Rilke also zur Rechtswissenschaft über - allerdings ohne Begeisterung. 14 Ende September verließ er Prag und ging nach München, wo er mit Unterbrechungen bis Oktober 1897 blieb und in losem Kontakt mit der Universität stand, indem er ein bißchen Kunstgeschichte studierte, besonders italienische. Mitte Mai 1897 machte er auch die Bekanntschaft mit Lou Andreas-Salomé, die sich bald zur leidenschaftichen Liebe entwickelte. Rilke folgte ihr nach Berlin im Herbst des Jahres, wo er auch Vorlesungen besuchte

14H.E. Holthusen, Rainer Maria Rilke in Selbstzeugnissen und Bilddokumenten (Hamburg: Rowohlt, 1958), S. 19. 
und sein Studium der Iiteratur und Kunstgeschichte fortsetzte. 15 Dieses Studium war als Vorbereitung auf die Italienreise im Früling 1898 gedacht. Das Florenzer Tagebuch ist ein Beweis für diese intensive Beschäftigung mit der Kunst. Durch Lou entsteht ein Interesse für Rußđand, das zu zwei russischen Reisen führt - die erste im Frühjahr 1899 und die zweite im Mai 1900. Rilkes Kunststudium vollzog sich außerhalb des Rahmens der Universität. Briefe und Tagebucheintragungen berichten über tage- und wochenlanges Auseinandersetzen mit der russischen Kunst zusammen mit Lou. Drei Tage vor der ersten Reise schreibt er an Frieda von Bülow, die Freundin Lous:

...mein Universitätsstudium (ist) nun unvermeidlich und unaufschiebbar.... Die eigentliche Arbeit nimmt doch erst im Winter ihren Anfang, und es gibt zu$\because \because$ aächst auch nicht viel Interessantes $\mathrm{zu}$ hören. Als Hauptfach werde ich Kunstgeschichte betrachten und hoffen, daß Herman Grimms halberledigter Lehrstuhl bald gut besetzt werde. Man möchte am liebsten Muther hören; aber der ist in Breslau, und ich mag dmolesernPfirichtenezwerter Ordnung willen nicht den lieben "Waldfrieden" verlassen, in dem so gute Arbeitsstunden mir froh und freigebig begegneten. Denn, ich muß Dir nicht sagen, daß meine Arbeit die höchste Instanz bleibt und daß vor dem Blick einer schenkenden Stunde alle Eintagspflichten verstummen müssen. Immerhin, glaub ich, wir mir die Fachbeschäftigung den Weg zu manchem guten Buch zeigen....16

Diese Aussage faßt die Situation zusammen: am wichtigsten war Rilke seine eigene Arbeit - hier weiterzukommen war fast 15ibid. S. 35 . 16Rilke, Briefe und Tagebücher 1899-1902 (Leipzig: Insel, 1931), S. 10 . 
die einzige Absicht seines Lebens. Das private Kunststudium blieb im Vordergrund - auch in den zwei folgenden Jahren nach den Rußlandreisen bis zur Pariser Zeit im Herbst 1902. Denn auch in Worpswede und Westerwede, wo er zusammen mit Künstlern lebte und schon anfing sich für Rodin und Cézanne zu begeistern, kam kein ordentliches Studieren zustande. In Westerwede lebte dann Rilke mit seiner neuen Frau, der Bildhauerin Clara Westhoff, und deren materielle Notlage machte die Wiederaufnahme des Studiums unmöglich. Doch die Idee taucht immer wieder auf, und noch im Juli 1902 waren seine Parispläne unbestimmt; er hatte noch die Hoffnung, "im Oktober zu Muther nach Breslau zu gehen, in der Absicht, so bald als möglich den Doktor zu machen."17 Stattdessen übersiedelt er im August nach Paris. Im Oktober schreibt er in einem Brief aus Paris an Arthur Holitscher:

Ich wollte nach Breslau gehen, um zu lernen. Nun damit kann ich hier gut beginnen. Ich werde im Collége de France manches hören, vielleicht kommt etwas dabei heraus....18

Man sieht, er hatte die Idee eines Fachstudiums immer noch nicht verworfen, doch von einem offiziellen Kunststudium ist hier zum letzten Mal die Rede.

$$
\begin{aligned}
& \text { 17op.cit. EW VI., S. } 1435 . \\
& \text { 18op.cit. Br.A. 1902-06. S. } 53 \text {. }
\end{aligned}
$$


IV. KAPITEL

DER JUGENDSTIL ALS DIE MODERNE KUNSTRICHTUNG

IN DER FRÜHZEIT RILKES

Halten wir fest: seit seiner Kindheit war die Malerei für Rilke eine äußerst wichtige Quelle und Ausdruck für seine geistige Produktivität; kein wunder, daß in dem für uns wichtigen Zeitraum (nämlich 1895-1902) Rilke der maßgeblichen Kunstrichtung unter den jungen Künstlern - eben dem Jugendstil - sein Hauptinteresse zuwandte. Bevor ich Rilkes Verarbeitung des Jugendstils behandele, sei eine kurze Charakterisierung dieser Stilrichtung und eine Erörterung der Forschungslage eingefügt.

I. DER GEISTESGESCHICHTLICHE HINTERGRUND

DES JUGENDSTILS

Jugendstil in der bildenden Kunst ist die Epoche zwischen Naturalismus und Expressionismus. Er ist die deutsche Version der Stilwende, die sich von Chicago und New York uber Schottland, England, Spanien, Frankreich, Belgien, Österreich bis Rußland ausbreitete und in einzelnen Ländern mit verschiedenen Namen versehen worden ist (Art Nouveau, Liberty, Modern Style etc.). Er entstand als Protest gegen Historismus in der Kunst und Positivismus in der Wissenschaft, gegen den Kapitalismus und Industrialismus, die das Leben im 
Wilhelminischen Zeitalter bestimmten. Die Jahre nach 1871 und der Krönung Wilhelm II. brachten in der Tat nationale Erfolge und materielle Leistungen, ermöglicht durch die Industrialisierung und die Entwicklung der Technik, aber es erfolgte eine Vernachlässigung der Geisteswissenschaften gegenüber den Naturwissenschaften und eine Abwertung der irrationalen, seelisch-geistigen Bezüge des Lebens.

Dagegen wehrte sich eine neue jüngere Generation, die eine Renaissance der Kunst und des Lebens herbeiführen wollte Technik und Zivilisation sollten durch Kultur ersetzt werden. Statt des Realen, Wirklichkeitsnahen gewann nun das Phantastische, Märchenhafte, Romantische an Bedeutung. Die Hinwendung zur Natur und zum All, die Suche nach der Einheit zwischen Natur und Geist, Kunst und Leben, Körper und Seele und nach Gott und Mensch war eine Flucht vor der 'modernen' Zersplitterung. Man sehnte sich wieder nach vorindustriellen Zuständen zurück - kurz: nach Ursprünglichkeit.

Die Kehrseite dieser Bewegung war die Einrichtung eines Schönheitskults, der sich von den Realitäten der Gesellschaft ablöste. Schönheit war nur in der Kunst durch die Phantasie des Künstlers erreichbar, der die Wirklichkeit in einer subjektiven, intuitiven und idealen weise erlebte und umgestaltete. Er suchte Zuflucht in dieser seiner selbst erfundenen Welt, die sich nur für Träume und Sehnsüchte eignete. Welche waren die Hauptleistungen des Jugendstils im Rahmen der Kunstgeschichte? Als erstes wäre zu erwähnen die 
Überwindung des "Historismus" und die positivistisch-akademische Natur- und Genremalerei, die auf den Akademien gelehrt und besonders in der Malerei und Architektur verwirklicht wurden.19 Die Entwicklung eines eigenen Stils vor dem Jugendstil hatte dieser Generation gefehlt, man kopierte und varijerte die gesamte deutsche Kunstgeschichte bis zum Biedermeier. Man entwarf nacheinander und nebeneinander im Stil der Neu-Romantik, Neu-Gotik, Neu-Renaissance, des NeuBarocks und Neu-Rokokos in der Vorliebe für einen unechten Prunkstil, für 'Altdeutsches' mit viel Schnörkeln, Deckchen und Statuen: überladenes Interieur.

Jugendstil dagegen strebte einen völlig neuen einheitlichen Stil an, der auf allen Gebieten der Ausstattung des Alitags sich durchsetzen sollte. Insofern kann die Rede von einer Bemühung um gesamtkünstlerische Gestaltung des Lebens sein. Das Gesamtkunstwerk entstammt der Überzeugung, daß die Kunst der höchste Wert sei und in jedem Lebensbereich von Bedeutung sein müsse. Die Grenzen zwischen den Künsten wurden aufgelöst: die bildenden Künste sollten mit Literatur und mit den dekorativen künsten vereinigt werden. Diesen Gedanken hatten schon die Präraphaeliten in England entwickelt. Ihre Vertreter - Rossetti, Hunt, Burne-Jones und Maddox Brown - dichteten, malten, entwarfen Möbel, Textilien oder trugen etwas $z u$ den angewandten Künsten bei. Art

19L. Koreska-Hartmann, Jugendstil - Stil der 'Jugend' (Nördlingen: DTV, I969) S. I7. 
Nouveau (die englische Version des Jugendstils) übernahm diese Ideen, die dann endlich nach Deutschland kamen. : Eckmann, Behrens, Van de Velde, Heinrich Vogejer und zahlreiche andere waren in ähnlicher weise anfangs Maler und wandten sich dann - den Wert des 'autonomen Kunstwerks' bezweifelnd - zur angewandten Kunst und entwarfen Möbel, Innenausstattungen, Arbeiten in Silber, Glas und Porzellan; sogar architektonische Fragen beschäftigten sie. Ein wesentlicher Punkt für meine These ist die Tatsache, daß aus dèr Zusammenarbeit, die zwischen Künstlern und Dichtern stattfand, auch eine neue Buchkunst sowie zahlreiche Zeitschriften entstanden, die Jugendstilideen förderten; so erschienen in den neunziger Jahren nicht weniger als 100 solcher Zeitschriften in Europa.

Das Hauptmerkmal des neuen Stils ist die asymetrische wellenförmige Linie, die in einer peitschenartigen energieg geladenen Bewegung ausläuft. Sie stellt die stilisierten Elementarbewegungen des Wassers, des Feuers und der Luft mit schwungvoller Asymmetrie dar. Und dennoch ist die wellenförmige Linie nur ein äußeres und populäres Merkmal dieses Stiles; ihre eigentliche Bedeutung liegt in der Fähigkeit, den Gegenstand in sich aufzunehmen und zu verwandeln und ihn der Iinearen Bewegung untertan zu machen. Meistens ist die Ornamentierung symbolisch zu verstehen. Sie stellt Phänomene der Natur dar, wie zum Beispiel einen Pflanzensprößling, eine Knospe oder einen jungen Baum und betont somit eine 
dynamisch-organische Lebensauffassung. Die Motive sind in der Hauptsache botanische Motive, die sich für die WellenIinie eignen: Schwertlilien, Lianen, Seerosen, Mohn und Heckenrosen - alles mit einem reichen Blätter- und Rankenwerk; man liebte aber auch Pfaue, Flamingos und Schwäne; dem Element Wasser wurden auch Undinen und Wassernixen enta nommen. 
II. DIE GEWANDELTE EINSCHÄTZUNG DES JUGENDSTILS UND.

\section{DIE FORSCHUNGSLAGE}

Über den Begriff Jugendstil gab es immer Meinungsverschiedenheiten. Schon um 1900 verdammten ihn einige als den Inbegriff aller dekadenten Geschmacklosigkeiten, während andere ihn als Aufbruch in die Moderne begrüßten. In dieser Doppeldeutigkeit sieht man ihn noch heute, doch in der Forschung ist eine gewisse Entwicklung festzustellen. Bis 1933 interessierte man sich nur für die 'puristischen' Elemente des Stils, die entwicklungsgeschichtlich bereits auf den Expressionismus oder die Neue Sachlichkeit hinzudeuten schienen. (Michalski, Hamann). Näch der Hitlerzeit wandten sich die Emigrierten (Pevsner, Schmalenbach) immer stärker der vielfältigen Verflochtenheit des deutschen Jugendstils mit den internationalen Art-Nouveau-Tendenzen $\mathrm{zu}$, während man in Deutschland den Nachdruck mẹr und mehr auf Vokabeln wie Aufbruch, Wende, Jugend und Lebenspathos legte. Doch auch das Schwille, die innere Emigration in das Reich der Undinen, wurde gerade in diesen Jahren zum erstenmal einer objektiven Betrachtung gewürdigt. (Sternberger) Seit der Ausstellung "Um 1900", 1952 im Züricher Kunstgewerbemuseum, erlebte diese Bewegung plötzlich eine Renaissance. Das apolitische und saturierte Bürgertum der fünfziger Jahre fing an, einen anderen Jugendstil zu entdecken: die geschmackvolle villen- 
kultur um 1900, deren Reichtum an kunstgewerblichen Einzelleistungen bis heute unübertwoffen blieb. Schriften über die Innenausstattung, die Möbel, das Plakat, den Buchschmuck, die Schrift, den Bilderrahmen, die Juwelierkunst, die Gläser des Jugendstils erschienen. Man war der Kargheit der industriellen Zweckformen allmählich müde geworden. Die Kunsthistoriker (Kurt Bauch) und die Museumsverwalter (Günter Busch), die weiterhin auf der These bestanden, daß der Jugendstil eigentlich den Durchbruch zur Moderne bedeutete, gerieten ins Hintertreffen. Solche Ansichten ließen die Ästheten und Snobs dieser Richtung kalt. Vom Symbolischen (Hofstätter) und Erotischen (H. Kramer) war höchstens die Rede, und von Sachlichkeit wollten diese Kreise nichts mehr hören. Auch die Hippies gehörten zu den zahlreichen Jugendstil-Schwärmern; das Symbolgeladene, Naturverbundene und Textilscheue dieser Richtung war der richtige Ausdruck der Love Generation und Flower Children. Diese Kreise weigern sich entschieden, den Jugendstil an seinem historischen ort und damit in seiner ideologischen Problematik zu sehen, sondern benutzen ihn rein als Rechtfertigung ihrer eigenen Ideen. 20

Die Frage nach einem literarischen Jugendstil

Für die Zeit um die Jahrhundertwende gibt es eine Fülle von Bezeichnungen in der Fachliteratur: Impressionismus,

20Jost Hermand, Jugendstil (Darmstadt: Wissenschaftliche Buchgesellschaft, 1971), S. ix.ff. 
Neoimpressionismus, Neuromantik, Symbolismus und "Fin de Siècle" unter anderen. Der Begriff "Jugendstil" ist erst in den letzten Jahren dazugekommen, nachdem wesentliche Parallelen mit dieser Richtung in der bildenden Kunst erkannt und erforscht wurden. Von "literarischem Jugendstil" $\mathrm{zu}$ reden ist legitim, nachdem neben den entsprechenden Produkten der bildnerischen Kunst Schriftsteller das Ihrige dazu beitrugen, ästhetisch, politisch und sozial durch Werk und Leben diesem Begriff einen grundlegenden Gehalt zu geben. Man kann aber keineswegs die ganze Epoche mit diesem Terminus generell bezeichnen und die Begriffe sind nicht synonym aufzufassen. Jugendstil ist die Bezeichnung eines Zeitstils, den viele Zeitgenossen in unterschiedlicher stärke verwirklicht haben, der aber nicht das Zeitalter als ganzes beherrscht hat. 21 Die Besonderheiten des literarischen Jugendstils werden in dieser Arbeit am Beispiel Rilke aufgezeigt.

Die Forschungslage und Rezeption des literarischen Jugendstils ist zum ersten Mal von Jost Hermand ${ }^{22}$ gründlich dargestellt worden. Auch hat er die erste und einzige Anthologie des Jugendstils im Jahre 1964 unter dem Titel Lyrik des Jugendstils herausgegeben. Einen späteren Forschungsbericht findet man bei Dominik Jost, Literarischer

2IDominik Jost, Literarischer Jugendstil (Stuttgart: J.B. Metzlersche Verlagsbuchhandlung, 1969), S. $13 f$.

22 Jost Hermand, Ein Forschungsbericht 1918-1964 (Stuttgart: J.B. Metzlersche Verlagsbuchhandlung, 1965). 
Jugendstil, 1969. Bis auf die Literaturgeschichte von Curt Hohoff, Dichtung und Dichter der Zeit, wird der Begriff entweder bloß sporadisch verwendet oder gänzlich weggelassen, auch in den meisten neueren Literaturgeschichten. Curt Hohoff arbeitet wertvolle Kriterien $z$ u seiner Erfassung heraus; hier wird diese Kunstrichtung als Vorläufer und Wegbereiter des Expressionismus gesehen. Die erste Iiteraturgeschichte von wissenschaftlichem Rang, in der der literarische Jugendstil zusammenhängend dargestellt ist, wirdWerner Kohlschmidts dritter Band der Geschichte der deutschen Literatur sein, in der die Zeit "Von der Romantik bis zum Jugendstil" behandelt werden wird. 23 :

Andere Behandlungen, die weniger eindeutig sind, wären: Ernst Alker, Die deutsche Literatur im 19. Jahrhundert. 18321914 (hier werden Holz, Dehmel, George, Rilke, Hofmannsthal, Stehr, die Brüder Hauptmann, Hermann Hesse, Thomas Mann, Arthur Schnitzler, Beer-Hofmann, Bierbaum, Ernst Hardt, R. Schaukal und andere unter den gemeinsamen Nenner Jugendstil gebracht: ohne aber dabei den Begriff deutlich einzugrenzen. Erwähnt wird der Begriff bei Bruno Markwardt, Geschichte der deutschen Poetik, Bd. V, 1967; in Walter Höllerers Anthologie, Theorie der modernen Lyrik. Dokumente zur Poetik I, 1965; und bei Richard Hamann und Jost Hermand in ihrer Darstellung, Stil-Kunst um 1900, 1967, der ersten umfassenden Darstellung des literarischen Jugendstils als Ganzem und im Zusammenhang 
mit der ganzen Epoche.

Außer solchem allgemeinen Orientierungsmaterial gibt es eine Reihe von Einzelstudien. Wohl die gründlichste Studie über den Jugendstil in der deutschen Lyrik ist die Dissertation von E. Klein, 1957, in der sie als Vertreter vor allem Dehmel, Rilke, Hofmannsthal, George, Falke, Morgenstern und Schlaf herausgreift. Für Walter Lenning ist Friedrich Nietzsche Begründer des Jugendstils. Auch Paul Fechter, Friedrich Ahlers-Hertermann, Fritz Martini, Kurt Mautz und Siegfried Vitens haben den 'Zarathustra-Stil' untersucht und Nietzsches Sonnensymbolik und seine Idee des 'ewigen Mittags' in Beziehung zum Jugendstil gebracht. In einer schroffen Ablehnung hat Walter Benjamin den Jugendstil bei Stefan George untersucht. Für Benjamin ist der Jugendstil der Stil, "in dem das alte Bürgertum das Vorgefühl der eigenen Schwäche tarnt, indem es kosmisch in alle sphären schwärmt und zukunftstrunken die 'Jugend' als Beschwörungswort mißbraucht"; als "Regression aus der sozialen in die natürliche und biologische Realität." 24 Claude David, Jost Hermand und walter Schmähling haben ebenfalls den Jugendstil im Frühwerk Stefan Georges aufgezeigt. Die charakteristische Kontrapunktik von Todessehnsucht und Lebenverherrlichung, die Spannung zwischen Lebenskraft und Unfruchtbarkeit haben Otto Friedrich Bollnow und Hans Schwerte bei Hugo von Hofmannsthal behandelt.

24 W. Benjamin, 'RückbIick auf Stefan George.' In Schriften Bd.II. (Frankfurt am Main: Suhrkamp, 1955), S. 325. 
Thomas Manns Erzählung Tristan'ist Objekt einer JugendstilUntersuchung von W. Rasch. Frederick H. Willecke hat sich zu Herman Hesses Jugendstil-Tendenzen geäußert. Eine Untersuchung der frühen Lyrik von Karl Gustav Vollmoeller hat Klaus Günther Just durchgeführt. Als exemplarische Jugendstil-Dichter sieht Dominik, Jost im Literarischen Jugendstil, 1969, Vollmoeller, T. Mann, Wedekind, Heym, M. Dauthendey, E. Lasker-Schüler, E. Stadler, Gustav Sack und E. Stucken. Jost Hermand behandelt Gralsmotive um die Jahrhundertwende und das Frauenbild im Jugendstil bei mehreren JugendstilDichtern, die schon erwähnt wurden. In seiner Anthologie der Lyrik des Jugendstils schließt Jost Hermand Gedichte von Bierbaum, Heymel, Dehmel, Morgenstern, Stadler, Trackl, Heym, Mombert, George, Holz, Stucken, Schröder, Vogeler und E.R. Weiß unter anderen ein. Kurt Mautz analysiert das Frühwerk von Georg Heym unter Jugendstil-Aspekten. Horst Fritz behandelt den Übergang vom Jugendstil zum Expressionismus bei Dehmel. Jugendstilelemente in Ricarda Huchs früher Prosa ist der Titel einer Dissertation von Roswitha Holler-Keller. In einer Arbeit von Edelgard Hajek, 1971, über Oscar Wildes "Salome" werden neue Möglichkeiten für eine Anwendung von Stilprinzipien des bildnerischen Jugendstils im literarischen Jugendstil dargestellt.

Untersuchungen zu Jugendstil-Elementen in Rilkes Frühwerk. Zu dem Frühwerk Rilkes gibt es auch vereinzelte Untersuchungen. Ein Aufsatz von Bert Herzog behandelt den "Gott des Jugendstils in Rilkes Stundenbuch". Paul Requadt und 
E.C. Mason bringen Rilkes Interesse an den Präraphaeliten und am Jugendstil in Zusammenhang mit der Italienreise und den Werken, die dadurch entstanden sind, ohne aber einzelne Werke ausführlich zu behandeln. In dem Rilke-Gedicht "Der Knabe" hat Walter Lennig eine Übergangsform vom Jugendstil zum Expressionismus gesehen. Rilkes Frauenbild behandelt kurz Jost Hermand in seinem schon erwähnten Aufsatz. Volker Klotz schließt bei seiner Suche nach literarischen "Entsprechungen zum bildnerischen Jugendstil" auch Gedichte von Rilke ein. Erwähnt wird Rilke als Vertreter des Jugendstils in den Literaturgeschichten von Soergel-Hohoff und von Kohlschmidt. Selbst Ernst Zinn, der Herausgeber des kritischen Gesamtwerks Rilkes, spricht von den Jugendstil-Werken Rilkes, ohne allerdings darauf einzugehen noch eine Begründung zu geben. 25 Auch in verschiedenen Abhandlungen über den bildnerischen Jugendstil (Schmutzler, Seling und Hamann/Hermand) wird auf Rilke verwiesen. Es fehlt bisher aber eine gründliche Untersuchung - wie überhaupt für Rilkes Periode bis 1905. Als Grund, eine solche Arbeit zu leisten, gibt Jost Hermand in seinem Forschungsbericht an: "Erst wenn man den frühen Rilke so betrachte, das heißt als Produkt des Jugendstils, könne man ihn endlich aus der allgemeinen 'Verkultung' befreien, die seine Person immer noch umgebe." 26 Außerdem ist, wie $D$. Jost sagt, die ganze Forschung des literarischen

$$
\begin{aligned}
& 25 \text { op.cit. SW III., S. } 862,871 . \\
& 26 \text { op.cit. Hermand, S. } 72 .
\end{aligned}
$$


Jugendstils noch an ihrem Anfang und ist heute noch in der Iiteraturwissenschaft keine als selbstverständlich akzeptierte und gehandhabte feste Kategorie. Diese Situation läßt sich aus der Tatsache erklären, daß die Literaturkritik lange die Selbsteinschätzung der Autoren einfach nachgesprochen hat, die eine Jugendstil-Periode durchgemacht haben und die später zu allgemein respektierten Werken in einer anderen Stilhaltung gelangt sind und ihr eigenes Frühwerk abgelehnt haben. 27 Rilke ist hierfür ein gutes Beispiel. 


\section{KAPITEL}

\section{PARALLELEN ZWISCHEN DEM BILDNERISCHEN JUGENDSTIL UND RILKES DICHTUNG}

Man kann den bildnerischen Jugendstil mit einem literarischen Jugendstil bei Rilke auf folgenden Ebenen in Beziehung setzen: im Vergleichen der geistes-historischen Grundlagen, der Themen und Motive und der Stil- und Sprachmerkmale.

\section{HISTORISCHE ASPEKTE}

Unter historischem Aspekt sind zu untersuchen: Gedichte, die unter dem Eindruck von Jugendstil-Gemälden geschrieben worden sind, Veröffentlichungen in Jugendstil-Zeitschriften, Buchveröffentilichungen mit Jugendstil-Gestaltung, Zusammenarbeit und Freundschaften mit Jugendstil-Künstlern und das Kunststudium des Jugendstils, was alles aus Briefen, Tagebüchern und Aufsätzen nachgewiesen werden kann. Hierzu gebe ich zunächst eine einleitende Übersicht - weitergehende Ana Iysen folgen im Hauptteil dieser Arbeit, die Rilkes Verhältnis zur Kunst chronologisch verfolgt.

\section{Texte:zu-Gemälaen.}

Rilke hat als erstes die Jugendstil-Gemälde von Hermoine von Preuschen bedichtet; die Gemälde (sowie seine Texte dazu) 
tragen die Titel: "Asrael", "Evoe Bacche", und "Die Pforte der Zukunft". Diese Gedichte bestätigen seine Beschäftigung mit dem Jugendstil schon in dex Prager Zeit, also vor 1896. Das Gedicht "Pfauenfeder" entsteht aus seiner Bewunderung für Emil Orlik auch zu dieser Zeit. Dem Jugendstil-Maler Hans Thoma widmet Rilke ebenso Gedichte, mit den gleichen Themen wie dessen Bilder: "Mondnacht" und "Ritter". Zu den im Jahr 1898 im "Pan" erschienenen Bildern vom Jugendstil-Maler Ludwig von Hofmann den Gedicht-Zyklus "Die Bilder entlang." Unter dem Eindruck der Bilder Hofmanns und ihm gewidmet ist das Stück "Spiel". Auch zu Gemälden von dem in der JugendstilTradition stehenden Maler Böcklin konzipierte Rilke 1901 Gedichte: "Frühlingslieder" und "Fragmente zu 'Die Pietá' von Arnold Böcklin". In der Worpsweder Zeit wurde Rilke von Vogelers Schaffen besonders zu folgenden Gedichten inspiriert: "Begleitung zu Bildern Heinrich Vogelers I-IV" - 'Das Haus', 'Ritter, Welt und Heide', 'Der Kahn' und 'Widmung'.

Veröffentlichungen in Jugendstil-Zeitschriften

In den bekanntesten Jugendstil-Zeitschriften der Jahrhundertwende hat Rilke regelmäßig Beiträge veröffentlicht und zwar in: Pan, Jugend, Simplizissimus, Ver Sacrum, Die Insel, Deutsche Kunst und Dekoration und Avalun. Ich gebe an dieser. Stelle alle dort veröffentlichte Gedichte an. Pan: Lieder der Mädchen (April 1899); Die weiße Fürstin (Juli 1900)

Jugend: Sonntag (Sept. 1896); Nacht, Aber lieber Herr (März 1897); Purpurrothe Rosen (April 1897); Heiliger 
Frühling (Mai 1897); Im Leben (Feb. 1899)

Simplizissimus: Stelldichein (Sept. 1896); Der Bach hat leise Melodien (Juli 1897); Mühle (Juli 1897); Zukunft (Nov. 1897); Das alte Schloß (Dez. 1897) Klage (März 1898); Teufelsspuk (März 1899); Erinnerung; Das Lachen des Pán Mráz; Das Haus (Mai 1900).

Ver Sacrum: Masken (April 1898); Über Kunst (Nov. 1898); Uber Kunst (1899) Über Kunst (1899); Ein Prager Künstler (April 1900); Drei Spiele (Nov. 1901).

Die Insel: Die heiligen drei Könige (März 1900); Der Sänger singt vor einem Fürstenkind; In der Certosa; Verkündigung (April-Mai 1902)

Deutsche Kunst und Dekoration: Heinrich Vogeler (April 1902)

Avalun: Von den Fontänen; Karl der Zwölfte von Schweden reitet in der Ukraine; Fragmente aus verlorenen Tagen; Am Rande der Nacht; Der Wahnsinn; Der Tod ist groß (III, 1901).28

Bücher Rilkes mit Jugendstil-Ornamenten

Buchausgaben von Rilkes Lyrik, die von JugendstilMalern gestaltet worden sind, waren Mir zu Feier von Heinrich Vogeler, Advent von Emil Orlik, 29 Die Geschichten vom lieben Gott von E.R. Weiß und Rilkes Stundenbuch von Tiemann. Von H. Vogeler wurde auch das Buch der Bilder geschmuickt. Selbst die Schrift dieses Buches ist jugendstilhaft - es wurde in Versalien gedruckt, eine Schriftform, die um die Jahrhundertwende in der Buchkunst weitverbreitet

28 F.A. Hünich, Rilke-Bibliographie. Erster Teil. (Leipzig: Insel, 1935).

29 Emil Orlik schuf auch ein Exlibris für Rilke, das eine weiße aufrecht stehende Frauengestalt zeigt, die sich in einem Teich spiegelt, darüber schweben Leier und Gänsekiel in einem Kranz - typische Jugendstil-Motive. (Br.A. 1906-07, Anm. zu S.170). 
war. Unter anderem hat Heinrich Vogeler sehr viele Jugendstil-Buchstaben neu entworfen. Daß Rilke viel Wert auf die Ausstattung des Buches der Bilder legte, wird deutlich in einem Brief an seinen Verleger vom 7. November 1901:

Ich...lege darauf gerade die Betonung, daß Gedichte in einer großen, monumentalen, jeden Buchstaben klar für sich setzenden Schrift gedruckt werden; denn wie das Wesen der Prosa in einer langen Zeile, einem breiten Satzspiegel und still, unauffällig hinfließenden Buchstaben besteht, so wird das Charakteristische von Versen am besten ausgedrückt durch das Stehen, Monumentalwerden auch der kleinsten Worte. Es gibt nichts Unwichtiges, nichts Unfestliches da. Jedes Wort, das mitgehen darf im Triumphzug des Verses, muß schreiten, und das Kleinste darf dem Größten nicht nachstehen an äuBerer würde und Schönheit. 30

Eudo C. Mason 31 nennt dieses typisch für Stefan Georges Monumentalität, denn tatsächlich hatte dieser zu jener Zeit schon längst die Gewohnheit, seine Bücher in Versalien drucken zu lassen, ohne - ähnlich wie bei Rilke - Hauptwörter und andere Wortarten durch Groß- und Kleinbuchstaben zu unterscheiden. Das Titelblatt zu den "Hymnen" (1890) beweist Georges Gestaltung: es besteht aus drei Zeilen einer solchen 'Groteskschrift', die seiner eigenen Handschrift gleicht. $\mathrm{Ab} 1892$ schreibt er in Antiqua-Minuskeln und trennt damit erstmals auch in der Handschrift die Buchstaben tvoneinander. Ausgehend von graphischen Bemühungen Georges, Typen für eine eigene Druckschrift zu entwerfen, wird eine 'Stefan-George-

30 op.cit. Briefe und Tagebücher 1899-1902, S. 115 .

${ }^{31}$ E.C. Mason, Rilke (Edinburgh und London: Oliver und Boyd, 1963), S. 44 . 
Schrift' von 1903-1908 entwickelt. Georges Druckwerke wurden von dem Jugendstil-Künstler Melchior Lechter beeinflußt. 32 Rilkes Interesse an dem Schriftbild ist auf $1896 \mathrm{zu}-$ rückzuführen, das Jahr, in dem seine Hauptbeschäftigung mit dem Jugendstil begann. Ein wichtiges Merkmal der Stil-Wandlung ist der prägnante Unterschied in der Handschrift zu Beginn und zu Ende desselben Jahres. Rilkes flüchtige, manchmal fast unleserliche Schrift und die geringe Beachtung der äußeren Form wandelt sich zu einer gepflegten und formbewußten Schriftgestaltung, die für alle späteren Briere Rilkes typisch ist. Er schrieb mit Lettern "groß und genau", deutlich und "ein Gerechtes aussagend". Richard v. Mises, der Herausgeber des Bandes, RMR, Briefe, Verse und Prosa aus dern Jahre 1896, weist in seinem Vorwort darauf hin, 33 sieht diese Entwicklung aber nur im Zusammenhang mit der Begegnung mit Lou und mit der Änderung des Namens von Renê zu Rainer, die in dieser Zeit stattfand. Das Maß, mit dem Rilke sich gerade in dieser Periode mit dem Jugendstil auseinandersetzte, läßt aber stark vermuten, daß Lou nicht der einzige Grund dieses Stilwandels war.

Gedichte Rilkes mit Jugendstil-Gestaltung

Auch einzelne Gedichte, die in verschiedenen Jugendstil-

$32 \mathrm{H}$. Seling, Juqendstil, Der Weg ins 20. Jahrhundert (Heidelberg: Keysersche Verlagsbuchhandlung, 1959), S. 202f

$33_{\text {Rilke, Briefe, Verse und Prosa aus dem Jahre } 1896 .}$ Hrsg. Richard v. Mises (New York: Verlag der Johannespresse, 1946), S. 10 . 
Zeitschriften erschienen sind, wurden von Jugendstil-Künstlern illustriert. Ludwig von Hofmann hat Rilkes GedichtZyklus, "Die Mädchen-Lieder", der im "Pan" erschienen ist, mit der ornamentalen Randleiste eines Reigens begleitet. Der Jugendstil-Künstler Gustav Klimt illustrierte das in "Ver Sacrum" abgedruckte Gedicht "Lehnen im Abendgarten beide" aus der Sammlung Advent. Auch in "Ver Sacrum" finden sich die "Drei Spiele". Hierzu haben J.A. Auchenthaller, Wilhelm List, Kolo Moser, Alfred Roller und Ernst Stöhr Randverzierungen beigetragen - alles Jugendstil-Künstlex, der Wiener Sezession zugehörend. ${ }^{34}$ Allerdings hat Rilke in einem Brief an Axel Junker vom 21. Januar 1902 den Buchschmuck als "schrecklich" bezeichnet, wozu anzumerken ist, daß im Jahre 1902 die Jugendstil-Richtung von vielen nicht mehr geschätzt wurde.

Persönliche Beziehungen zu Jugendstil-Künstlern

Diese Tatsachen zeigen eine deutliche Zusammenarbeit mit Jugendstil-Künstlern und -Zeitschriften. Die persönlichen Beziehungen zu Künstlern sind nicht so leicht nachzuweisen, weil sehr viel biographisches Material zu Rilke in dieser Periode fehlt. Auch einige wichtige Briefwechsel fehlen: die Briefwechsel mit $H$. Vogeler und $E$. Orlik sind verschollen, genauso die Korrespondenz mit Richard Muther, einem Kunsthistoriker, der sich ausgiebig mit dem Jugendstil be-

${ }^{34}$ Hans Ankwicz-Kleehoven, "Rainer Maria Rilke und die Wiener Sezession", Wiener Zeitung, Nr.1, 1. Januar 1947, S.9. 
schäftigte und Rilke wichtige Anregungen gab. Wohl die engste Freundschaft mit einem Jugendstil-Künstler war die mit Heinrich Vogeler - Tagebucheintragungen und auch die Aufsätze und Gedichte zu oder für Vogeler bezeugen das. Hiervon wird später die Rede sein. Wie weit sein Kontakt zu Ludwig von Hofmann gediehen ist, ist schwer zu sagen. In einem Brief vom 2. April 1907 an Ernst Hardt aus Capri schreibt Rilke:

Vielleicht ist das endlich auch die Gelegenheit, Herrn von Hofmann zu begegnen, die ich mir seit Jahren schon, auf das geduldigste gewünscht habe. 35

Rilke hatte eben gehört, daß Hofmann in Griechenland sei und möchte dorthin fahren. Das heißt also, daß Rilke während seiner Jugendstil-Phase Hofmann auf jeden Fall nicht persönlich kennengelernt hatte. Jahre danach schreibt er aus Paris am 9. Mai 1910 an Clara, daß er in einer Spieloper von Hofmannsthal gewesen sei und Zuhörer seien "außer Keßler und Nostitzens Ludwig von Hofmanns, Van de Velde, Frau Osthaus... und Frau Förster-Nietzsche" gewesen. ${ }^{36}$ Die kommentarlose Erwähnung des Namens L.v.Hofmanns läßt darauf schließen, daß der Dichter zu dieser Zeit kein bestimmtes Interesse mehr an dem Maler hatte.

Daß es eine Bekanntschaft mit E.R. Weiß gab, kann man durch eine einzige Briefstelle nachweisen. Rilke schreibt

$$
\begin{aligned}
& 35 \text { op.cit. SW VI., S. } 1820 . \\
& 36 \text { op.cit. Br.A. 1907-1914, S. } 93
\end{aligned}
$$


1907 an Paula Modersohn-Becker:

Karl Hofer sah ich vor drei Jahren oft in Rom, war zu dumm, ihn kennenzulernen.....Später erzählte E.R. Weiß (der Maler) von ihm; aber gesehen habe ich kaum je etwas, ein paar kleine Sachen in der "Insel" abgerechnet. 37

Karl Hofer, von dem oben die Rede ist, war auch ein Jugendstil-Künstler, der der 'puristischen' Richtung angehörte, die zwischen 1902-05 herrschte. Nicht das Dekorative steht hier im Vordergrund, sondern die Entschiedenheit der schlichten Linie. Auch E.R. Weiß und E. Orlik waren ihre Vertreter. Der Titel zu Rilkes Geschichten vom lieben Gott, den E.R. Weiß kreierte, ist charakteristisch für den Jugendstil um die Jahrhundertwende; ein typisches Beispiel für die Verschlingung pflanzlicher und geometrischer Elemente, indem eine kurz vor dem Aufblühen stehende Tulpenblüte an ein oben eingewölbtes Glas erinnert. Damit ergibt sich eine für den Jugendstil exemplarische Formverdoppelung. Weiß war auch Schöpfer einer der schönsten Antiqua-Schriften und hat Buchschmuck für Bierbaum und Heymel entworfen, der sehr reich an Wellen und Windungen, Verschlingungen und fließenden, wiegenden Gebilden ist. ${ }^{38}$ weiß war 1895-96 Mitarbeiter am "Pan" und später bei der "Insel". Von ihm stammt das berühmt gewordene Inselsignet.

Mit Emil Orlik war Rilke seit 1896 in Prag befreundet.

37 op.cit. Br.A. 1906-1907, S. 227.

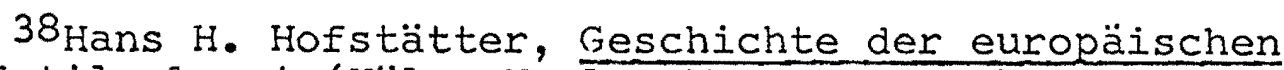
Jugendstilmalerei (Köln: Verlag M. DuMont Schauberg, 1963), S. 177 . 
Beide kamen zusammen in dem "Verein bildender Künstler" und "Concordia" 39 Diese Vereine, die aus Dichtern und Malern bestanden, waren zeittypisch für den damals aktuellen Versuch der Zusammenarbeit der Künste. Später war Orlik ein Mitglied der Jugendstilgruppe "Wiener Sezession", zu der auch Rilke Verbindung hatte. Rilkes Bewunderung für Orlik drückt er in einem Brief vom 6. Mai 1896 an Láska van Oestéren aus Prag aus: "Meiner Ansicht nach der talentierteste jüngere deutsch-böhmische KünstIer". 40 Im April 1900 war Orlik für Rilke noch bedeutend; Rilkes Aufsatz über ihn, "Ein Prager Künstler", erschien in "Ver Sacrum". August 1901 schreibt er aus Westerwede an Arthur Holitscher:

Emil Orlik haben wir Ende Juni in Prag besucht. Er hat viel Schönes aus Japan mitgebracht, hat wie es scheint, ein starkes Wachstum durchgemacht, nach dessen Stillstand sich neue Harmonien seiner Persönlichkeit ergeben werden. Jetzt ist er etwas unsicher, wie alle Heimkehrenden.... Weiß noch nibht genau, wovon seine schweren Netze schwer sind. 41

Rilke hat Orliks Japan-Aufenthalt ganz richtig eingeschätzt, der ein entscheidender Wendepunkt für seine Kunst war. Deshalb muß die Bedeutung des japanisch-orientalischen Einflusses für die westliche Kunst nach 1860 und besonders für den Jugendstil an dieser Stelle aufgezeigt werden. 1860 nahm Japan zum

39peter Demetz, René Rilkes Prager Jahre (Düsseldorf: Eugen Diedrichs Verlag, 1953), S. 67. 40op.đit. SW VI., S. 1376 . 41op.cit. Briefe und Tagebücher 1899-1902, s. 111. 
ersten Mal an der Weltausstellung in London teil. Praktisch alle Kunstgattungen wurden durch japanische Kunst beeinflußt. Zuallererst ist die Übernahme der zwei-dimensionalen Tradition Japans von westlichen Malern zu erwähnen. Indem er sich von dem flächenmäßigen Hintergrund löste, konnte der Künstler die Gegenstände freier in den Raum setzen; daneben war das Aufgeben der Mittelpunkt-Perspektive ein weiterer Schritt in die gleiche Richtung. Von großer Bedeutung für die Plakatkunst, Buch-Illustration und Schreibkunst war außerdem die Verwendung von senkeechter Beschriftung auf der Bildfläche, ein japanisches Mittel auf dem Wege zur Verbindung von Bild und Wort. Dj.esen Versuch hatte in der Kunst des Westens vor dem Jugendstil bisher nur Blake unternommen. 42

Emil Orlik ist aber einer der wenigen Jugendstil-Künstler, der die japanische Kunst in ihrem Ursprungsland studiert und sich dort die Fertigkeiten einer scharfen Stilisierung mit Kontrastwirkungen erworben hat. In späteren Holzschnitten kommt er dadurch dem Expressionismus nahe. Die erste Auswirkung des Japan-Aufenthalts macht sich ïn seinen Arbeiten für die Wiener Sezession bemerkbar, in der er seit 1902 gerade nach seiner Rückkehr aus Japan - Mitglied ist. In seinen Sezession-Arbeiten verbindet sich der wiener Schmuckstil am reinsten mit den östlichen Anregungen. Die Sezessionsausstellung zeigt von ihm eine Goldlackarbeit auf Mahagoniholz mit Intarsien von Edelhölzern, Perlmutt und

42 . Tschudi Madsen, Art Nouveau (New York: McGrawHiIl Book Co., 1967), S. 59 f. 
Halbedelsteinen. Die Synthese des Kunstgewerbes mit der darstellenden Kunst scheint auf dieser Ausstellung in letzter vollkommenheit erreicht. 43 Auch orliks Theaterdekorationen für Maeterlincks Inszenierungen sind ein weiteres Bindeglied zu Rilke, welcher Maeterlinck für die Berliner Sezession produziert hat.

Orlik war ein erfolgreicher Maler und Professor in Berlin geworden, als Rilke im August 1917 an Marie von Thurn und Taxis schreibt:

..... Ich habe in Berlin herrliche Porträts von ihm gesehen und ein gemaltes Bildnis, das in der "Freien Sezession" hängt, hat mir Luat gemacht auch ${ }^{44}$

Da Orlik zu dieser Zeit noch in Jugendstil-Manier malte, könnte dieses Zitat als Indiz dafür genommen werden, daß Rilke auch in seinem späteren Leben sich noch nicht völlig von der Jugendstil-Tradition abgewandt hatte.

Während der Worpsweder Zeit und seiner Freundschaft mit Vogeler entstehen Beziehungen zu vielen Jugendstil-Künstlern. Schon lange vorher hatte er sich mit Max Klingers Werk beschäftigt. ${ }^{45}$ Klinger war einer der stärksten und einflußreichsten Künstilerpersönlichkeiten der Jahrhundertwende. $B_{e} i$ aller Vielseitigkeit in seinem Schaffen, spielt der Jugendstil für

43 op̈̈сit. Seling, S. 158.

44 op.cit. Briefwechsel, RM Rilke und Marie v. Thurn und Taxis-Hohenlohe, -5.516.

${ }^{45}$ Rilke, "Münchner Kunstbrief" in SW V., S. $321 f f$. 
ihn eine bedeutsame Rolle; er gilt als einer der wirksamsten Anreger dés Jugendstils im deutschen Raum. Die für den Jugendstil typische Verbindung zwischen Mensch und Landschaft, wo beide zum Ausdruck einer gemeinsamen Stimmung gebracht werden oder wo schließlich die Landschaft allein menschliche Stimmung spiegelt (wie bej, Ludwig von Hofmann, Leistikow, oder bei Segantini und den Worpswedern), stammt von Klinger. 46 Durch Clara Westhoff, die spätere Frau Rilkes, läßt sich eine direkte Verbindung $\mathrm{zu}$ Worpswede herstellen, indem sie als Bildhauerin Schülerin von Klinger gewesen ist. Daß Klinger als Besucher nach Worpswede kam, als Rilke dort wohnte, taucht in den Briefen und Tagebüchern aus der Frühzeit auf.7 Von seinem Beitrag zu Rilkes Kunstauffassung wird später die Rede sein.

Durch Vogeler in Worpswede machte Rilke auch höchstwahrscheinlich die Bekanntschaft von dem Jugendstil-Künstler Alexander Schröder und dem Dichter Heymel, die durch ihre Zusammenarbeit bei. der "Insel" zu engen' Freunden Vogelers geworden waren. 48 Auch Rilkes Arbeit bei der "Insel" vertiefte die Beziehungen. Das Rilke-Gedicht "Die Liebenden" wurde eingeschoben in die Sammlung Der Neuen Gedichte anderer 46 op.cit. Hofstätter, S. 168 f. 47 op.cit. S. $89 f, 329$.

$\cdot 48_{\mathrm{H}}$.W. Petzet, Von Worpswede nach Moskau: Heinrich Vogeler, ein Künstler zwischen den Zeiten (Koln: Verlag M. DuMont Schauberg, 1972), S. 75 . 
Teil mit folgender Widmung: "An Alfred W. Heymel mit einem. kleinen Gedicht aus dem ersten Manuskript dieses Buches, herzlich: R.M. Rilke. Paris, Januar 1909.49

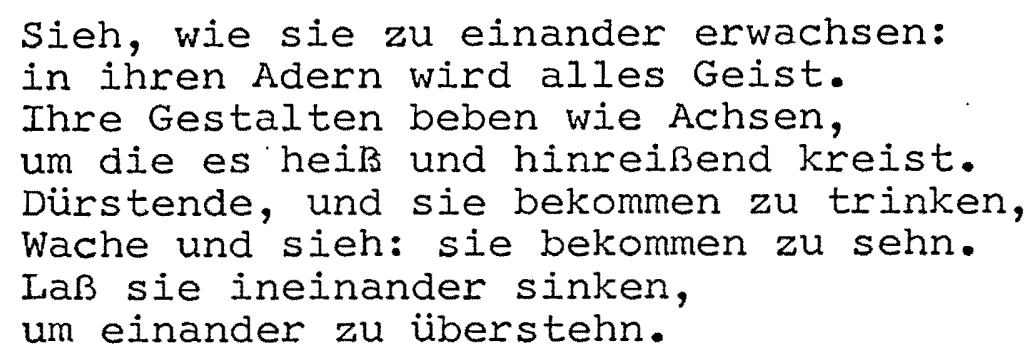

Wie viele Jugendstil-Merkmale in diesem Gedicht vorhanden sind, wird aus dem Hauptteil der Arbeit zu entnehmen sein. 1914 wurde noch einmal in einem langen Brief an Heymel Freundschaft und Bewunderung ausgesprochen: .. Lieber Heymel, was haben Sie für ein unübertreff-
iiches Jahr: Sie schreiben die schönen Gesänge an
den "Traumgeist"; Sie genesen von einer schweren
Krankheit und geben sich selbst gleich darauf Be-
weis des kühnsten Lebensgefüls. Vergessen Sie
nicht, daß Sie damit auch Ihren Freunden Anlaß ge-
geben haben, Sie besser zu lieben, und erhalten Sie
sich nun für die, die sich Ihrer Freundschaft rühmen. Aber sechs Wochen später, am 26. November, starb Heymel in den Armen Henry van de Veldes einen schweren Tod. 51

Jakob Wassermann, Redakteur am "Simplizissimus", war Rilkes Freund in der Münchner Zeit, und in Briefen aus dem Jahr 1924 nennt er Wassermann als wichtigen Anreger für seine Kunst.

$$
\begin{aligned}
& \text { 49op.cit. SW VI., S. } 754 \text {. } \\
& \text { 50 Rilke, Briefe. } 2 \text { Bde. (Wiesbaden: Insel, 1950), Bd.II, } \\
& \text { S1 } 13 . \text {.cit. Petzet, S. } 79 \text {. }
\end{aligned}
$$


Übrigens war es Jakob Wassermann, dern ich den ersten, fast strengen Hinweis auf diese Bücher (von Jacobsen und Turgenieff) zuschreibe; das lyrische Ungefähr, in dem ich mich bewegte, machte ihn, der die Arbeit und Erarbeitung im Künstlerischen schon werten und ausüben gelernt hatte, ungeduldig -, und so legte er mir eines Tages in München, als eine Art Aufgabe, diese Werke in die Hand, die er sich kurz vorher selber maßgebend gemacht hatte. Daß ich, von mir aus, so zugängliche Bücher zu finden nicht fähig war, erinnert mich an meine heillose Unbeholfenheit im

Lesen...52

1902 bespricht er in einem Aufsatz Wassermanns Buch "Der Moloch" ziemlich kritisch: Wassermann wolle zwar die Dinge erfassen, und doch sei sein Stil etwas stilisiert und künstlich - er sei Sammler "von seltsamen Zügen, Worten, Gebärden und Winken.....Sein Schreiben ist eine mühsame Handarbeit". Am Schluß empfinde man eine Müdigkeit, wie "wenn man aus einem Museum tritt". ${ }^{53}$ Rilke rechnet allerdings dessen stil nicht dem Jugendstil zu, sondem dem Pointillismus. Wassermanns Bücher

...beanspruchen nicht zu bleiben, sie gehen vorbei, ihre Worte verlöschen wie Laternen, sobald man vorüber ist. Mit dieser Vergänglichkeit behalten sie das starke Licht eines Augenblicks, die intensiye Wirkung, die sie eine Sekunde lang ausstrahlen.

Der Einfluß Georges und seines Kreises gehört auch in diesen Zusammenhang. In demselben Brief aus dem Jahre 1924 an Hermann Pongs, in dem Rilke alle wichtigen Förderer aus den frühen Jahren aufzählt, lesen wir:

52 op.cit., Briefe. 2 Bde., Bd. II, S. 462.

53 op.cit. SW V., S. 624 . 54 ibid. S. 625 . 
Von Stefan George war das "Jahr der Seele" mir von Anfang an bedeutend gewesen; es erschloß sich mir aber erst als Überwältigung, seit ich den Dichter im Lepsius'schen Kreise seine gebieterischen Verse hatte sagen hören. 55

Rilke war nämlich 1897 im Salon Lepsius bei einem Leseabend gewesen und schien davon so beeindruckt, daß er George briefIich im Dezember 1897 seine Haltung darlegt:

Indessen glaube ich nur dann die Wege Ihrer Jünger zu erkennen, wenn ich jeden Schritt zu Ihnen und den Kunstzielen Ihres Kreises verfolgen darf. Dem engeren, von den Mitgliedern erkorenen Leserkreis der "Blätter für die Kunst" anzugehören, ist der Vorzug, welchen von Ihnen erbittet: RMR5

In Florenz begegnete Rilke 1898 George durch Zufall. Georges monumentale Dichtung und seine despotische Persönlichkeit waren in jenen Jahren Vorbild und eine Art Bedrohung zugleich 57 Rilke hielt sich von näheren Kontakten zu dem Georgekreis fern, obwohl er mit Interesse und Begeisterung auch in seinem späteren Leben in Briefen und Tagebuchaufzeichnungen vom Werk Georges berichtet.

Graf Kessler gehörte vor dem Krieg zu Rilkes besonderen Unterstützern. Zahlreiche Briefe erzählen von seinen Besuchen bei Rilke in Paris. 58 Kessler war im Redaktionsstab des "Pan" und hat auch beim Insel-Verlag mitgearbeitet. Er war ein

55 op.cit., Briefe. 2 Bde., BdII, S. 462.

56 Rilke, Gesammelte Briefe 1892-1904 (Leipzig: Insel, 1939), S. 47-48.

57 7 op.cit. Mason, S. 19.

58 op.cit. Briefe. 2 Bde., Bd.I., S. 184, 255, 426. 
guter Freund von dem in der Jugendstil-Tradition stehenden Maillol, den Rilke auch bewunderte, sowie von Henry van de Velde. Sein Haus in Weimar wurde von Van de Velde einge-:.: richtet und enthält einen Wandbrunnen von Maillol. 59

Verbindungen zu den Jugendstil-Sezessions-Bühnen

Noch im Zusammenhang mit Rilkes Beziehung zu JugendstilKünstlenn muß die Verbindung zur Berliner Sezession und später zu den Sezessionen in Bremen und Wien Erwähnung finden. Nachdem der Jugendstil in München (die Münchner Sezession) schon längst Fuß gefaßt hatte, kam er nach Berlin, weil dort die konservative Kunstpolitik des Kaisers lange hemmend wirkte. Um walter Leistikow und Ludwig von Hofmann bildete sich in der stadt ein kulturelles Zentrum, und damit ist die Entwicklung zum Jugendstil schon vorbereitet. 1892 gründen sie zusammen mit anderen die Gruppe der "Elf" als vorerst noch inoffizielle Protestkundgebung gegen den "Verein Berliner Künstler", dessen Präsident zugleich der Direktor der Berliner Kunstakademie war und dem Geschmack des Kaisers huldigte. Eine Ausstellung der "Elf" umfaßt impressionistische, sozialkritisch-naturalistische, symbolistische Kunst und lyrischen Jugendstil in engem Nebeneinander. Man spricht von den "Halluzinationen eines Herrn L.v. Hofmann", und der Kaiser kritisiert diese Kunst als eine Malerei, "die weiter nichts tut, als das Elend noch scheußlicher hinzustellen, wie es

59 Ingeborg Schnack, Rilkes Leben und Werk im Bild. (Wiesbaden: Insel, 1956), S. $208 f$. 
schon ist."60 Der zweite Anlaß zur Gründung der "Elf" war eine Busstellung mit Edvard Munch, die Skandal erregte und nach wenigen Tagen geschlossen werden mußte. Aus der Gruppe der "Elf" wurde 1899 die Berliner Sezession. 61

Schon vor der Gründung der. Sezession war Rilke mit der neuen Malerei vertraut. Zur Eröffnung des Kunstsalons Keller und Reiner in Berlin im Herbst 1898 schreibt er den Aufsatz "Die neue Kunst in Berlin", worin Werke der Vertreter der neuen Richtung, Van de Velde, Riemerschmied, Endell, Leistikow, Thoma, Habermann, Max Klinger und anderer besprochen werden. Das Verdienst dieses Salons besteht in den Worten Rilkes in folgendem:

Und sie haben ein großes Verdienst, die beiden jungen mutigen Besitzer, die dem Neuen eine Kirche bauen mitten unter den Ungläubigen oder Glaubensschwachen. Sie tun mehr als das Libertyhaus für London oder Bing für Paris getan hat: sie wagen. Und mögen sie nun gewinnen oder nicht, man wird sie nicht vergessen dürfen. Aber ich glaube, es ist bald zeit, auch in Österreich und Deutschland. Allenthalben erwachen wahre und ernste Apostel der Schönheit. Und sie predigen das Heil und nennen den Namen Gottes in neuen Sprachen. Und wenn die Menschen schweigen, werden die Dinge 'Amen' sagen.'

Libertyhaus in London und Bing in Paris waren Kunsthandlungen, die den englischen Jugendstil und den französischen förderten. Rilkes Begeisterung für den Jugendstil ist hier sehr deutlich. Nachdem die Sezession begründet worden war, verfolgte

$$
\begin{aligned}
& 60_{\text {op.cit. Hofstäter, s. } 166 \text {. }} \\
& 61_{\text {op.cit. Seling, s. } 149 .} \\
& 62_{\text {op.cit. SW V., s. } 446 .}
\end{aligned}
$$


Rilke die Entwicklung mit starkem Interesse, denn es war gerade die Zeit (Herbst 1898-Oktober 1900), zu der er in Berlin-Schmargendorf seinen festen Wohnsitz hatte. Seine Arbeit für die damit in Verbindung stehende "Freie Bühne" ist in Briefen und Tagebüchern folgendermaßen dargelegt: Zwischen den beiden Rußland-Reisen im März 1900 schreibt er an Sofia Nikolajewna Schill, er habe die Übersetzung der "Tschaika" von Tschechow fertig und die Übertragung von seinem "Onkel Wanja" vor (beide Stücke waren zwischen 18951897 entstanden), um dann vor der zweiten russischen Reise diese Schauspiele bei der Sezessions-Bühne des Dr. Zickel einzureichen. Ob diese Texte angenommen worden sind, bleibt unerwähnt. Ein anderes Stück von Tschechow, "Der Heiratsantrag", wurde November 1900 hier uraufgeführt.

Im Oktober 1900 schreibt er an Frieda von Büløw:

Anfang November (unbestimmt wann) ist die Premiere meines alten Stückes "Ohne Gegenwart" hier auf der Sezessionsbiihne.

Rilke ist auch fleißiger Besucher des Sezession-Theaters; in einer anderen Passage desselben Briefs heißt es:

Gestern sah ich auf der Sezessionsbühne Hofmannsthals "Tor und.Tod" und Wassermanns "Hockenjos". Das erste war etwas zu viel für die Bühne, das zweite etwas zu wenig. Ich habe Hofmannsthal lieber allein für mich - es geht bei der Bühne viel von seiner Pracht verloren, besonders bei "Tor und Tod." Aber vielleicht gibt es noch was Gutes zu sehen, bis $\mathrm{Du}$ kommst. Die Kunstsalons sind voll schöner Bilder. ${ }^{64}$

$$
\begin{aligned}
& 63 \text { op.cit. Briefe und Tagebiicher 1899-1902, s. } 63 \text {. } \\
& 64_{\text {ibid. S. } 63 .}
\end{aligned}
$$


Begeistert äußert er sich im November 1900 in einer Tagebuchaufzeichnung über die Aufführung von Maeterlincks "Tod des Tintagiles". 65 Ähnlicher Enthusiasmus findet sich in einem Aufsatz aus dieser Zeit "Das Theater des Maeterlincks":

Die Sezessionsbühne hat sich...sehr verdient gemacht. Sie ist heute unser zukünftiges Theater, wenigstens ihren Bestrebungen nach, was freilich ihre Gegenwart manchmal gefährdet. Aber vielleicht bestätigt sie das heute Gesagte doch noch einmal durch eine Aufführung der "Schwester Beatrix" und ergänzt es damit. 66

Wichtig ist es anzumerken, daß Rilke Maeterlinck als "Stammvater" der modernen Bühne bezeichnet - und die Sezessionsbühne als das "zukünftige" Theater. Eine Aufführung von Maeterlincks "Pelleas und Melisande" durch den AkademischIiterarischen Verein am 12. Februar 1899 im Neuen Theater zu Berlin hat Rilke dagegen in einem Aufsatz ${ }^{67}$ sehr stark kritisiert als dem Maeterlinckschen Drama nicht gewachsen. Von Maeterlincks Beitrag zum literarischen Jugendstil wird im Kapitel VI. die Rede sein.

Ein letzter Brief aus dem Jahr 1900 an Clara erwähnt die Sezessionsbühne noch einmal, und zwar in Verbindung mit Hofmannsthals "Gestern" und Schönherrs "Bildschnitzer", die

65 op.cit. Tagebücher aus der Frühzeit, S. $373 f$. 66 op.cit. SW V., S. 482.

67 ibid. S. $456-460$. 
"hier auf der Sezessionsbühne oft und oft gespielt werden."68 Ebenso knüpfte Rilke zu der Bremer Sezession damals Kontakte - und zwar während seines Besuches in Worpswede vom 27. August bis Anfang Oktober 1900. Am 16. September ist er bei der Eröffnungsfeier, danach bei Vogeler im 'Lilienałelier.' Die Stimmung, die diese Gelegenheit erzeugt, wird im Tagebuch folgendermaßen wiedergegeben:

Eine gute und reiche Gemeinsamkeit in Gespräch und Schweigen.... wovon die Worte gingen: von Tolstoi, vom Tode, von Georges Rodenbach und Hauptmanns

"Friedenfest", vom Leben und von der Schönheit in allem Erleben, vom Sterbenkönnen und Sterbenwollen, von der Ewigkeit und warum wir uns Ewigem verwandt fühlen....Die Uhr schlug eine viel zu große Stunde und ging ganz laut zwischen unseren Gesprächen umher. Ihr Haar war von florentinischem Golde. Ihre Stimme hatte Falten wie Seide. Ich sah sie nie so zart und schlank in ihrer weißen Mädchenhaftigkeit. Ein großer Schatten ging durch die Stube...erst über mich, den Redenden, über meine wandernden Worte, dann über ihre helle Gestalt und über die glänzenden Dinge alle.69

Auch die Motive entsprechen dem Sezessionstil: Sehnsucht nach dem Tod und der Ewigkeit, und doch das einmalige Erlebnis der schönen Stunde der 'Verklärung' in der Gegenwart, die hier mit mädchenhaften Eigenschaften geschildert wird goldenes Haar, seidenes Kleid, Zartheit und Schlankheit.

Rilkes Interesse an Maeterlinck fand in der Bremer Sezession weiteren Ausdruck. Zusammen mit Gustav Pauli und Heinrich Vogeler führte er "Schwester Beatrix" am 15. Februar 1902 auf. Zur Eröffnungs-Feier der Bremer Sezession

68 op.cit. Briefe und Tagebücher 1899-1902, S. 88 . 69 op.cit. Tagebücher aus der Frühzeit, S. $282 f$. 
1902 schrieb Rilke das Spiel "Zur Einweihung der Kunsthalle"?0 Interessant ist hier sein Vergleich der Malerei mit dem Theater: beide haben "keinen Inhalt", sondern Stimmung und Gefühl und Fülle. Den Inhalt des Alls, eines Frühlingstages... könne man nicht nenken, sondern nur ein Gefühl wiedergeben. Rilkes Verbindung zur Wiener Sezession, die 1897 unter der Führung von Gustav Klimt entstand und Januar 1898 "Ver Sacrum" herausbrachte, wurde von Hans Ankwicz-Kleehoven in der Wiener Zeitung erörtert. ${ }^{71}$ Kleehoven bringt einige noch unveröffentlichte Briefe aus dem Archiv der Sezession heraus. Nachdem Verse aus Advent in einem Heft von "Ver Sacrum" 1898 erschienen waren, und andere Beiträge in den darauffolgenden Heften, fragt Rilke im Juli 1898 aus Zoppot bei der Sezession an, ob sie nicht die Skizze "Fernsichten" und das Gedicht "Der erste Gott", sowie zwei Aufsätze "Über Kunst" haben wollen. Doch nur die beiden Essays wurden gedruckt, ein weiterer folgte später. 72

Eine längere Pause beim Veröffentlichen von Rilkes Beiträgen in "Ver Sacrum" trat darauf ein, weshalb Rilke aus BerIin am 9. Dezember 1899 mahnen mußte:

Was ist denn mit meinem Orlik-Aufsatz geschehen? Ich dachte, Sie wollten ihn in der Oktober-Nummer bringen? Nun dieser Termin längst um ist, frage ich nur bei-

$$
\begin{aligned}
& 70 \text { op.cit. SW III., S. } 403-409 \\
& 7 I_{\text {op.cit. Ankwicz-Kleehoven. }} \\
& 72_{\text {ibid. S. } 8}
\end{aligned}
$$


läufig an, wann er erscheint, auch deshalb, weil ich, wie schon erwähnt, gern correktur lesen möchte. ${ }^{3}$

Erst Im Juli 1900 wurde der Aufsatz mit dem Titel "Ein Prager Künstler" gedruckt. Auch beim Publizieren von Rilkes "Drei Spielen" ist die Sezession nicht sehr pünktlich gewesen. Das waren die letzten Beiträge für "Ver Sacrum", das 1903 sein Erscheinen einstellte.

Darüberhinaus gab es noch andere Beziehungspunkte zur Sezession. Sein Plan, die Wiener Sezession für russische Kunst zu begeistern, gelang ihm, wohl aber nicht in der Form und im Zeitablauf, wie er sich es vorgestellt hatte. Nach der ersten Rußlandreise im Februar 1900 meldet Rilke dem russischen Künstler Leonid Pasternak:

Ich will vieles von Rußland schreiben,......Mit den Wiener Sezessionisten war zunächst auch nichts anzufangen: Dr. Zweybrück trat zurück, und dann wechselte alle Monate die Redaktion. Auf meinen Vorschlag, ein russisches Heft zu veranstalten, ging man zwar begeistert ein, gabe aber so ungenaue Zusicherungen, daß ich nichts beginnen konnte. Und ab 1900 soll "Ver Sacrum" nur für die Mitglieder der "Gesellschaft bildender Künstler" erscheinen... auch mit "Ver Sacrum" wird noch etwas zu machen sein, bis die Verhältnisse sich einigermaßen geklärt haben. Ich hätte schon so gerne etwas veranstaltet, aber es ist wichtig nichts zu überstürzen, wenn man das Fremde hier günstig einführen will: 74

Aus der Absicht, für "Ver Sacrum" über russische Kunst zu berichten, ist nichts geworden. Ein Aufsatz, den Rilke Januar 1900 verfaßte, "Russische Kunst", erschien erst Ok-

\section{$73_{\text {ibid. }}$}

74 op.cit. Briefe und Tagebücher 1899-1902, S. 23. 
tober 1901 in der "Zeit"; ein späterer, "Moderne russische Kunstbestrebungen" von 1902 ebendort. Der Breslauer Kunstprofessor Richard Muther (bei dem Rilke studieren wollte) hatte die Redaktion für bildende Kunst bei dieser Zeitschrift. 75

Rilkes Bemühungen um russische Kunst, die doch im Rahmen der Sezessionsarbeit erfolgreich geworden sind, schlossen auch Mitarbeit an einer Ausstellung ein. Am 22. Oktober 1900 heißt es aus Schmargendorf:

...Keine größere Freude konnte mir werden, als diese zu sehen, wie die "Vereinigung" mit Ernst und Aufmerksamkeit, - mehr noch mit liebe sich dem Plane zuwendet, einer fremden Kunst ihr gastlich-gutes Haus zu öffnen, und damit sie unter seinem Lorbeerdach sich Ruhm und Ruf eiffände. Es hat etwas Rührendes zu sehen, wie selbstlos und opferfroh die Wiener Sezession vom ersten Augenblick an sich gegen andere Kunstgruppen verhält, und ihr Haus ist wie ein reiches Herz, welches gerecht liebt.

Indessen hat sich der Plan einer Ausstellung russischer Bilder in Berlin...als unerfüllbar erwiesen; die Sezessionsbühne will den Termin nicht vom 1. November fortverlegen, bis zu diesem Tag aber ist es möglich, gute russische Bilder, die gerade jetzt sehr zerstreut sind, zusammenzustellen.... Ihren wunsch, daß die Ausstellung später stattfinden soll, kommt also den tatsächlichen Umständen auf das Beste entgegen. 76

Die Ausstellung fand vom November 1901 bis Januar 1902 statt. Im gleichen Brief werden auch die Namen einiger russischer Künstler aufgezählt, deren Bilder ausgestellt werden sollten: Sserow, Somow, und Maljawin, - und die er auf seiner zweiten russischen Reise besuchen will. Interessanterweise

$$
\begin{aligned}
& 75_{\text {op.cit. SW VI. }} \text { S. } 1426 . \\
& 76 \text { op.cit. Ankwicz-Kleehoven, S. } 8 .
\end{aligned}
$$


handelt es sich hier um Vertreter des russischen Jugendstils. Somow hatte sich sogar eine Zeitlang in München aufgehalten und auch dort für die "Jugend" Illustrationen geliefert. Maljiawin gehört zu einer anderen Strömung des russischen Jugendstils, die Anregungen aus der Volkskinst und nicht aus der historischen Ateliertradition erhielt wie Somow z.B. Das Wesentliche an seiner Malerei ist die leuchtende Farbigkeit der buntfleckigen Gewänder, die zu einem die Körperlichkeit auflösenden Flächenmosaik drängen, was typisch für den Jugendstil ist. Des weiteren lesen wir in dem oben angeführten Schreiben:

Es ïnteressiert die Herren vielleicht zu hören, daß ich jetzt dabei bin, die "russische Kunst im 19. Jahrhundert", eine umfangreiche, mit Reproduktionen versehene Kunstgeschichte, deren berufener Verfasser Alexander Benois ist, ins Deutsche zu übertragen. Die sehr mühsame, aber lohnende Übersetzung dürfte schon Mitte 1902 erscheinen...77

Alexander $B_{e}$ nois geht in die gleiche Richtung wie Somow. Seinen Schwerpunkt hat er in der Graphik und erweckt die in Rußland ganz vergessene Buchkunst zu neuem Leben. Selbst der gute Freund Rilkes, Leonid Pasternak, gehört zu diesem Kreis. Allerdings wird ein russischer künstler, der zu dieser Zeit ein starker Vertreter des Jugendstils in Rußland war, von Rilke übersehen: Wassily Kandinsky. Er war es, der 1896 den Jugendstil nach München brachte und damit eine der wesentlichen Voraussetzungen für den Aufbruch der Münchner Kunst 
zum Expressionismus. 78

Der Begitrag, den Rußland um die Jahrhundertwende zur europäischen Entwicklung geleistet hat, ist von nicht zu übersehender Bedeutung. Die zwei erwähnten Richtungen sind: einmal der Jugendstil, der sich aus der historischen Tradltion entwickelt und durch Somow und Benois unter anderen vertreten ist, und der in Volkstradition stehende stil mit Maljawin und Kandinsky als Protagonisten. Die erste Gruppe mit ihrem Zentrum in Petersburg bleibt dem "Schwanengesang" des 19. Jahrhunderts verhaftet, während die zweite Gruppe mit Zentrum in Moskau Neubeginn bedeutet, der auch die westliche Kunst stark ergreifen wird. 79

In dem oben erwähnten Brief Rilkes vom oktober 1900 findet sich auch ein Liob für die Sezession:

Ich bitte Sie, der "Vereinigung" meinen innigsten Dank für diesen Ausdruck von Vertrauen und Teilnahme zu vermitteln ("Ver Sacrum" wurde ihm geschickt), den ich besonders gern empfange, weil er mich einweiht in das, was in Wien geschehen ist, seit ich es zuletzt vom Dache des Sezessionshauses aus gesehen habe. Denn es gibt ein Wien mit wirklichen Ereingnissen! Das wußte ich damals plötzlich, als Herr Roller mich von Bild zu Bild führte im ersten Jahr der jungen Sezession.80

Die Überzeugung, daß die Sezession eine große Arbeit für die moderne Kunst leistet, äußert Rilke in einem Angebot vom Februar 1901: er will bei der Redaktion "Ver Sacrums"

38

op.cit. Hofstätter, S. 239.

79ibid. S. 234

80 op.cit. Ankwicz-kleehoven, s. 9. 
tätig werden.

...der Umstand, daß "Ver Sacrum" wieder breiter und literarischer geworden ist, läßt mich die Vermutung aussprechen, daß vielleicht heute oder morgen die Betätigung einer rein schriftstellerischen Kraft innerhalb der Redaktion erwünscht sein könnte. Sollte dieser Fall eintreten, bitte sidbh dieses Briefes zu erinnern, in welchem ich meine Bereitwilligkeit erkläre, nach wien zu kommen und Ihrer Sache meine Kraft zu widmen, wenn ein entsprechenden posten mir Raum und Möglichkeit dazu gewährt. 81

Doch das Angebot ist nicht akzeptiert worden. Noch im selben Jahr wandte er sich im November an die Sezession mir der Bitte, Plastiken seiner jungen Frau in einer der nächsten Ausstellungen unterzubringen. So konnte Clara im Februar 1902 mit einer männlichen Porträtbüste in Wien debütieren. 82

Es waren wahrscheinlich gerade die starken Beziehungen zur ausländischen Kunst, die Rilke am stärksten zur Wiener Sezession zogen. Schon die erste große Ausstellung von 1899 hatte eine Vertretung sämtlicher neuen Richtungen aus allen europäischen Ländern - England, Frankreich, Belgien, Deutschland und schon damals Rußland. Durch das Zusammenwirken aller Künste bot die Sezession gleichzeitig Ausstellungsbedingungen, die für das moderne Ausstellungswesen vorbildiich wurden. Rilke berichtet am 10.4. 1899, daß er bei der Eröffnung dieser Ausstellung gewesen ist. 83

$81_{\text {ibid. }}$

$82_{\text {ibid. }}$

83 op.cit. Briefe und Tagebücher 1899-1902, s. 8. 
Weitere Zusammenarbeit mit Jugendstil-Künstlern und eine eingehende Beschäftigung mit dieser Richtung läßt sich durch Rilke-Aufsätze, die während dieser Zeit erschienen, feststellen. Die Namen unzählig er Vertreter des Jugendstils in der bildenden Kunst und in der literarischen welt tauchen hier auf. Mehr zu der ersten Gruppe gehören: Vogeler, Segantini, Orlik, Hermoine von Preuschen und Uhde; auch Beardsley, Burne-Jones, Eckmann und Endell, Ludwig von Hofmann, Khnopff, Klinger, Leistikow, Moreau, Munch, Obrist, Riemerschmid, Thoma, Toorop, Van de Velde und Whistler. Eher zur zweiten Grup̈pe gehören: Bahr, Bierbaum, Altenberg, Hugo von Hofmannsthal, Hesse, Dehmel, George, Halbe, Holz, Maeterlinck, Nietzsche, Pater, Salus, Schnitzler, Verhaeren, Vollmoeller, Wassarmann und Wilde. Diese Liste ist nicht einmal vollständig und trotzdem ein Beweis dafür, in welchem Maße Rilke an dieser Richtung teilnahm. 
II. MOTIV-VERGLEICHE ZWISCHEN BILDNERISCHEM

UND IITERARISCHEM JUGENDSTIL

Jost Hermand hat die auffallendsten literarischen

Leitmotive, die eine Entsprechung im bildnerischen Jugendstil haben, zum Einteilungsprinzip seiner Jugendstil-Anthologie gemacht: Tanz und Taumel, Lebensrausch, Der große Pan, Monistisches Verwobensein, Frühlingsgefühle, Blütenzauber, Weiher und Kahn, Schwäne, Traum durch die Dämmerung, Schwüle Stunden, Das wunder des Leibes, Künstliches Paradies. In dieser Arbeit, die sich spezifisch auf den Jugendstil bei Rilke bezieht, eignet sich eine Einteilung folgender Art der Übersicht halber besser: Mystische Versenkung, Das künstliche Paradies, Die Wellenlinie und Das Kunst-Ding. Als Überbegriff für alle Themenbereiche ist die neue Hinwendung zur Natur zu werten. Gerade durch eine Verehrung der Natur und allen organischen Werdens beabsichtigte die Jugendstil-Generation die Versetzung in eine welt, in der alles Geschehen nach dem Vorbild organischer Abläufe bestimmt wurde, damit Geist und Natur nicht Gegensätze bedeuteten, sondern Geist als Steigerung von Natur zu sehen sei. Man glaubte an einen Sieg des Göttlichen im Menschen, der durch Sehnsucht und willen nach Oben - wie das organisch-natürliche Vorbild - wachsen würde. Man glaubte nicht nur an die eigene Verklärung, sondern an eine Evolution der gesamten Welt; für den Jugendstil war somit die Theorie 
der Entwicklung nach Darwins Schrift 1871 "Die Abstammung des Menschen und die geschlechtliche Zuchtwahl" entscheie dend. 84 Die Kunst bedeute die höchste Bewußtwerdung der Natur und der Künstler vollziehe immer wieder das Schöpfungswunder in seinem Schaffen. Die Folgerung sei die Übertragung des evolutionären Denkmodells auf die Funktion der Kunst - die Aufgabe des Künstlers sei die "Entwicklung der Menschheit." Solche Haltungen führen zu totaler Ästhetisierung, denn Verklärung ist nicht möglich in einer technischrationalen Unterwerfung und Nutzbarmachung der Natur durch den Menschen, sondern nur in einer Umsetzung der Natur durch die Kunst in einen Bereich des Ästhetischen. Der Jugendstilbegriff des 'schönen Lebens' und des 'künstlichen Paradieses' ist auf diesen Grundgedanken zurückzuführen.

\section{Mystische Versenkung}

Als Voraussetzung für die Verklärung des Menschen im Sinne des Jugendstils dient die mystische Versenkung in die Natur. Hierdurch wird der Mensch der zeitlichen Endlichkeit entrissen und in einen mystischen Ewigkeitsbezug gestellt. Diesem Vorgang entsprechen die von Entrückung und Trance zeugenden weitoffenen Augen der Mädchen und Jünglinge im bildnerischen Jugendstil. Sie haben den mystischen Blick,

${ }^{83}{ }_{\text {H. Fritz, Literarischer Jugendstil und Expressionismus }}$ (Stuttgart: J.B. Metzlersche Verlagsbuchhandlung, 1969), S.90. 
der Vergangenheit und Zukunft zusammenreißt. 85

Diese Einheitserfahrung ist oft im Jugendstil durch die Figur des Pan, des großen Gottes und Symbols der Allnatur, in dem jede Polarität bildhaft ausgeschlossen ist, da er weder Mann noch Frau ist, versinnbildlicht. 86

Auch der Engel ist ein solches Zwischenwesen, ist Abgesandter des Lichtreichs, der das 'schöne Leben' verkinidet, indem das keimhaft im Menschen wohnende Licht mit seiner Hilfe zur Emanation kommen kann. Eer Engel im Jugendstil ist nichts anderes als die eigene Geistwerdung. 87

Zum Bereich der mystischen Versenkung gehören auch Traum, Phantasie, Sehnsucht und Tod. Der Traum geht über das bewußte mystische Versenken hinaus und ermöglicht einen Ausbruch aus der irdischen Wirklichkeit, besonders im Stadium zwischen Tag und Nacht, also der Dämmerung. Die Phantasie ist die wache Entsprechung des Traumes und ist als Mittel zur Übersteigerung der Realität zu verstehen und nicht als Erfindung unwahrscheinlicher Begebenheiten. Phantasie ist die Gabe der Verwandlung der Realität in Irrealität oder der Irrealität in menschlich faßbare Maße. ${ }^{88}$ Der Tod ist nicht mehr

${ }^{85} \mathrm{E}$. Klein, Jugendstil in Deutscher Lyrik, Diss. Köln 1957, S. 21 .

$$
\begin{aligned}
& 86_{\text {ibid. S. } 116 .} \\
& 88_{\text {ibid. S. }} 118 . \\
& 88_{\text {ibid. S. }} 107 .
\end{aligned}
$$


Anlaß zu Trauer und Klage, nicht das schicksalhaft ins Leben Einbrechende, sondern als höchste Stufe einer individuellen Evolution zu sehen, in der Tod und Verklärung identisch sind. Die Sehnsucht des Lebens wird damit zu einer Sehnsucht des Sterbens. 89

Die mystische Versenkung in die Natur ermöglicht also die Ersetzung der zeitlich und räumlich begrenzten welt durch eine ewige, die, obwohl irreal, sich jedoch im Realen manifestiert. In der kosmischen Natur waren es die wechselnden Erscheinungen, im Menschen die Seele. In beiden Fällen ein Innenraum, dessen näherer Erforschung und Belehnung mit neuen Werten sich die ganze Jahrhundertwende widmete. Es kommt ein Versenken und Einfühlen in das jetzt dem Menschen brüderlich erscheinende Wesen der Dinge zustande. Der Vorgang des Verschmelzens der individuellen mit der Weltseele gehört hierzu. Gott ist nicht mehr der christliche Gott der Offenbarung - ein transzendierender Gott, sondern wird als aus dem Irdischen organisch hervorgehendes wesen betrachtet, wie beim Pantheismus. Hierfür wären die Stundenbuch-"Gebete" Rilkes gute Beispiele. Gott ist der Baum bzw. die Wurzel, die Frucht getragen hat. Die 'Wände' zwischen Gott und Mensch werden niedergerissen - der Mensch ist göttlich und Gott ist menschlich. Stefan Georges Zielsetzung: "den Leib zu vergotten und den Gott zu verleiben" ist eine Formulierung, die das Bestreben des Jugendstils deutlich ausspricht und zur 
Durchdringung der Ur-Widersprüche von Gott-Mensch gehört, sowie zu den schon erwähnten Widersprüchen: Natur-Geist, KunstLeben und Körper-Seele.

Daß Kunst als Religionsersatz betrachtet wird (Rilke: sagt sogar im Florenzer Tagebuch, Religion sei die Kunst der Nichtschaffenden) ist auf dem Hintergrund der geistesgeschichtlichen Wandlung im 19. Jahrhundert zu betrachten: dem Abbau der Gewißheit eines jenseitigen, objektiv existierenden Absoluten durch die Evolutions-Theorie Darwins und Nietzsches 'Gott ist tot' -Philosophie unter anderem. Dochddas religiöse Bedürfnis bleibt bestehen. Hierzu gehört die Grundstimmung des Stundenbuchs: das fragende Ergrifeensein, das Schwanken ohne Halt und Gestalt, das Sich-entzücken an schwebenden Dingen im Leben - dies alles war Gott, der aber zu gleicher Zeit noch nicht war, denn er hätte vom Künstler geplant und entworfen werden müssen. Diese Paradoxie ist als wesentliches Merkmal der Jugendstilanschauungen festzuhalten: einerseits die Anschauung, daß die bisherige religiöse Basis nicht mehr gefühlt wird, andererseits jedoch die Forderung nach einer neuen Form des Religiösen und dem Ersatz des alten Gottes durch die Kunst, die die Gottheit des Menschen erreichen will.90 Verklärung und das 'schöne Leben' ist auch durch die Liebe $z u$ erreichen. Die Erfahrung der Ewigkeit, das Einmünden und sich Aufgeben in das All durch das Medium der oder des Gelliebten ist charakteristisch für das Liebeserlebnis

90 Vergleiche hierzu Nietzsches Begriff des Übermenschen. op.cit. Fritz, S. 91 If. 
im Jugendstil. Das Übersteigern des Endilchen ins Unendliche wird auch hier gefordert, damit aus dem körperlichen, dem dunklen Geheimnis, das Helle, Seelisch-geistige werde und damit wieder ein Baustein zur persönlichen und Weltverklärug geschaffen sei. Daher ist Liebe auch immer Erfüllung und Sehnsucht zugleich, da zwar eine stufe erreicht, aber auch schon die nächste angestrebt wird. ${ }^{91}$ Der Kuß ist das Motiv, durch den die Einheit zweier Personen aus der Vereinzelung heraasführt und die Erfahrung eines Ganzen vermittelt wird. Diese Verbindung offenbart sich als ein bewegtes und zugleich gemessenes Fließen zwischen beiden. Bezeichnungen wie 'fluten' und 'zusammenströmen' vermitteln den Eindruck eines dynamischen, zugleich jedoch wellenförmigen Bewegungsspiels. Die Analogie zum bildnerischen Jugendstil ist augenfällig. Wie in Peter Behrens' Holzschnitt 'Der Kuß' wird die Einheit eines Menschenpaares zum Anlaß, die polare Spannung in ein flächiges Wechselspiel linearer Schwünge umzusetzen. Dabei verselbständigen sich die Bewegungslinien und konstituieren ein sich selbst genügendes ornamentales Gefüge. 92 Wie wir gesehen haben, wird im Jugendstil die Liebe meistens als etwas Einheitliches und Naturverbundenes hingestellt, also als ein ganzheitlicher Erlebnisakt, der sich jenseits aller gesellschaftlichen oder historischen Konkretisierungen abspielt. So verwandelt sich auch das literarische

$$
\begin{aligned}
& 91 \text { op.cit. Klein, s. } 80 . \\
& 92 \text { op.cit. Fritz, s. } 61 .
\end{aligned}
$$


Bild von der Frau immer stärker in ein biologisches Urwesen, das direkt aus dem Schoß der Natur emporzusteigen scheint. Weder die kämpferische Suffragette, die Dirne, die Emanzipierte oder Salonhyäne, wie sie der Naturalismus liebte, noch das süße Mädel, das Lebedämchen oder die verwöhnte Baronesse des Impressionismus interessierte den Jugendstil, sondern lediglich die Frau an sich. Auf diese Weise entwickelt sich ein 'Mythos vom Weibe' als der ursprünglichsten Verkörperung des Elementaren. Hinter diesem Akzent auf dem Biologischen verbirgt sich eine deutliche Abwertung aller geistigen und damit spezifisch humanen Qualitäten.93

In der ersten Phase des Jugendstils stehen Gestalten wie Lulu, Salome und Judith im Vordergrund, da hier das Hauptinteresse noch im impressionistischen Sinne dem Pikant-Erot-m tïschen gilt. Was sich im Umkreis dieser modischen SalomeWelt als steigende Abneigung gegen die gesellschaftliche Realität andeutet, geht in der zweiten Phase dieser Bewegung im Jugendstil immer stärker ins Abstrakte über. Wenn man hier Frauen darstellt, dann oft als nackte Naturwesen: Nymphen, Nixen, Sylphen, Daphnen und Undinen, eine Nacktheit aber, die über das bloße Erotische hinausgeht als Protest gegen die 'Verlogenheit' der großstädtischen Kleiderwelt, die auf die 'naturgegebenen' Formen des menschlichen Körpers keine Rücksicht nimmt. 94

93 op.cit. Hermand, S. 472 . 94 jbid. 
Für dieses Frauenbild beim frühen Rilke gibt es viele Quellen. Welllen küssen hier wie die 'Geliebte', das Meer gleicht einem schönen Weib, manche Mädchen wohnen als 'Wellen im Teiche' - immer wieder erscheinen die Frauen als unartikulierte Natur; sie sind die Namenlosen, die Geheimnisvollen mit dem Urgrunde des Daseins Verbundenen, die jedoch wie die Undinen der Liebe des Mannes bedürfen, um ebenfalls Wort, ebenfalls Seele zu werden. Der Grund, warum gerade Undinen, Nixen, und Meerjungfrauen als Urformen des Weiblichen ausgewählt worden sind, ist auf die formale Ebene zurückzuführen. Diese Geschöpfe ließen sich viel besser in den allgemeinen Linienfluß des Jugendstils einbeziehen als ihre Schwestern auf dem Lande. Die schwimmenden, schwerelosen, rhythmischen Bewegungen eignen sich natürlich für die Wellenlinie des Jugendstils.

Aber die Frau als biologisches wesen wird auch in die Welt der Pflanzen versetzt. Die Pflanzenwelt bietet vielleicht am anschaulichsten in den großen biologischen Vorgängen vom Keimen, Blühen, und Welken eine Analogie für menschliches Werden. So werden Natur- und Menschenseele voll identisch miteinander, da sie den gleichen Lebensprozessen unterliegen 95

In der Pflanzenwelt sind Mädchengestalten am leichtesten als fast geschlechtslose Typen, die in ihrem ganzen Gehabe eine naive Unschuldsgläubigkeit und Daseinsfreudigkeit ausdrücken, darzustellen. Es ist der Typ des fast entfleischten

$$
95 \text { op.cit. Klein, s. } 18 .
$$


Mädchens, das von allem Fleischlichen und Sündhaften aus der Existenz seiner Vorfahren nichts mehr weiß und auch nichts mehr in sich hat. Es ist die reine Kameradin, die den Mann nicht stört, nicht lockt, nicht vom weg ins Licht zieht, sondern leuchtend neben ihm geht in einem ständigen 'Himmelan'. 96 Dieses ideale Frauenbild, die Frau mit großen, starrenden Augen und wuchernden Haaren, c̈die ein Symbol für die schöne Seele war, wurde von den Präraphaeliten übernommen. Außerdem ist die Pflanzenwelt formal gesehen sehr geeignet für die schwungvolle Symmetrie im Jugendstil. Das von Ernst Haeckel seit 1899 herausgegebene luxuriöse Tafelwerk iber die Protisten (Urtiere, Urpflanzen) Kunstformen der Natur wurde sogleich zu einer Fundgrube für neue Formmotive. Haeckel selbst hat im Vorwort diese Tatsache geahnt: "Die moderne bildende Kunst und das moderne, mächtig emporgeblühte Kunstgewerbe werden in diesen wahren 'Kunstformen der Natur' eine reiche Fülle neuer und schöner Motive finden." 97

\section{Das künstliche Paradies}

Die Schöpfung Gottes und die Formung des Lebens durch die Kunst führt zu dem Begriff des 'schönen Lebens', - das künstliche Paradies - wobei das Ästhetische und die Wirklich-

$$
\begin{aligned}
& 96 \text { op.cit. Klein, s. } 74 \text {. } \\
& 97 \text { op.cit. Jost, s. } 6 \text {. }
\end{aligned}
$$


keit miteinander in Einklang gebracht werden. Hier ist ein gewisser Widerspruch zu konstatieren, denn die Kategorie des Ästhetischen läßt sich nicht als Mittel der Lebensformung auf die Wirklichkeit ohne weiteres übertragen. Im Programm der totalen Ästhetisierung muß man an den Widerständen der objek=tiven Wirklichkeit scheitern. Die Folge ist ein Ausweichen vor der Wirklichkeit, das sich im Rückzug und Sich-Verschließen in Bezirke, in denen dem Subjekt noch Möglichkeiten des Verfügens über die Elemente der Wirklichkeit offensteht, äußert. Als Beispiel für diese Möglichkeit kann man die Motive des Gartens mit dem Weiher und der Insel mitten im Meer nennen. Beide Motive stehen für ein Abschließen nach außen hin und werden dadurch zu Bezirken der Exklusivität, die sich der Außenwelt entziehen. Beim Garten ist das Gitter, für die Insel ist das Meer die Grenze. Es sind die Übergangsstellen zwischen Realität und Irrealität, die Grenzen, hinter denen die Welt der Technik, des Kapitals und der Industrie liegt und der Bereich des Seelischen aufhört.

Der Garten ist der feste Bezirk, in dem die Kreisläufe des Lebens sich abspielen. Seine geheimnisvolle Mitte ist der Weiher, der Teich. Wie die Augen des Menschen eine Art transitorischer Punkt sind, in denen das Zusammenfließen von Seele und Außenwelt erkennbar wird, so sind die Weiher solche transitorischen Punkte der Erde, in denen die Geheimnisse der Tiefe und der Höhe sichtbar werden. Von oben her spiegelt sich in ihnen das All, die Farbe des Himmels. 
Die Wolke als Produkt aus Wasser und Äther wird auf dem Teich im Schwan dargestellt. Die Bewegung des Windes läßt die Wellen entstehen, die auch als Gefühlswellen gedeutet werden können. So wie der Schwan das Geheimnis vom Oben symbolisiert, symbolisiert die See-Rose das Geheimnis aus der Tiefe. ${ }^{98}$ Auch die Unterwasserwelt ist ein beliebtes Motiv. Eine Welt des Ahnens und Fühlens, des Geheimnisvollen und seltsam Ergreifenden, des sich Ergreifen-Lassen-Wollen von einem 'ganz Anderen', das nicht zu berechnen, zu messen und zu wägen ist. Diese gefühlte Welt ist auch als Reaktion auf den schal gewordenen Positivismus, auf die Übervernünftelei und 'die drohende Selbstgewißheit der Gründerjahre' zu verstehen. Gabriele D'Annunzio hat den gesamten Art Nouveau auf "die grüne Welt der Algen" festgelegt. 99 Gerade die Unterwasserwelt ist eine weitere Steigerung des Versinkens in immer dunklere Innenbereiche, die von jedem Iichtstrahl abgeschlossen sind. Hier kann die künstlerische Phantasie am besten in die Innenzonen des ästhetischen Unterbewußtseins eintauchen.

Auch das Inseldasein bietet Distanz zur Realität. Die Flucht auf eine Insel ist ein Motiv der Weltentrückung, eines der Abgelöstheit von der Gesellschaft, das länger auszuführen sich hier erübrigt, da dieses Motiv größtenteils mit dem der

98 op:cit:.Klein, S. 125f. 99 op.cit. Jost, s. 17. 
Wasserwelt identisch ist.100

Die Bootsfahrt ist ein beliebtes Motiv im Zusammenhang mit der Wasserwelt: hier ist das Wasser das tragende Element der Sehnsucht nach einem bestimmten Ziel und die Bootsfahrt. das Mittel, es zu erreichen. ${ }^{10 l}$ Wer eine Bootsfahrt unternimmt, ist aus der Alltagswelt herausgelöst und in eine Isolierung gerückt, die ihn offen macht für enge körperliche Verbundenheit mit elementaren Daseinsformen. 102

Der Schwan verbindet beide Bereiche: das Submarine und das Kosmische. Er ist überhaupt das Tier des Jugendstils, sowie die Iilie die Blume. Er ist der Sonnenvogel, der in stolzer Abgekehrtheit die aristokratische Lebensform versinnbildlicht, das paradiesische Leben vollzieht und schließlich noch das 'Sterben in Schönheit' verwirklicht. ${ }^{103}$ Der Schwan eignet sich vor allem für den Rhythmus der JugendstilLinie mit seinem langen, schlanken Hals und seinen sanften gleitenden Bewegungen. Außerdem ist die Farbe des Schwanes weiß - die Farbe der Reinheit und Ursprünglichkeit und als

100 siehe hierzu: Rosenhaupt, Der deutsche Dichter um die Jahrhundertwende und seine Abgelöstheit von der Gesellschaft - besonders darin "Das Inselaasein in der Dichtung", S. 148ff., (Bern-Leipzig: Paul. Haupt Verlag, 1939).

101 op.cit. Klein, S. 156.

102 Roswitha Holler-Keller, Jugendstilelemente in Ricarda Huchs fruher Prosa, Diss. Kiel ig69, S. 136.

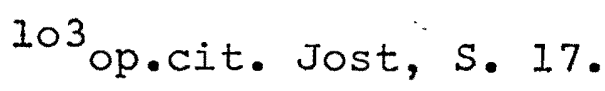


solche eine der beliebtsten Jugendstil-Farben. 104

Die Wellenlinie

Die Wellenlinie im Graphischen und Architektonischen ist im Jugendstil das Stilprinzip an sich. Sie kann Haarwelle, Windbewegung, Wasserwelle, akustische Welle, Wellenkurve bei Pflanzenstengeln, Verlauf von Körperlinien oder auch vollkommen gegenstandslos sein - nur aus dem eigenen Schwung lebende Dekorlinie. Sie ist dem Jugendstil-Künstler praktisch die Grundform für alle Erscheinungen. Sie ist der sichtbarste Ausdruck für Rhythmus und für die Erfahrung des Kreislaufes, des Zueinanderstrebens und der geheimen Identität aller Dinge. Der Wille, der dahinter steckt, ist, die Lebendigkeit alles Lebendigen erneut zu Bewußtsein zu bringen. Durch das Eindringen in Rhythmen und Formen der Natur wurde dabei die menschliche Seele selbst einer neuen Elastizität fähig, die es ihr ermöglichte, ihre eigenen 'Schwingungen' nun in den Schwingungen der Natur wiederzuerkennen. Es kam zur Gleichung: Natur gleich menschliche Seele; was sie beide bewegt, ist die gleiche Welle des Lebensrhythmus und des kosmischen Kreislaufes. 105

Als Beispiel für die akustische Welle im Jugendstil ist die Musik heranzuziehen. Einmal ist die Musik Teil des kreislaufhaften Bezugs zwischen Natur und Geist. Aus der gött-

$$
\begin{aligned}
& 104 \text { op.cit. Madsen, s. } 36 . \\
& 105 \text { op.cit. Klein, s. } 185 .
\end{aligned}
$$


Iichen Sphäre in die Natur hineingelegte 'Melodien' werden als Lieder in diese Sphäre zurückgesandt, ein Vorgang, durch den gleichzeitig 'Gott' organisch wächst und emaniert, denn das Anstreben der Verklärung ist immer gleichzeitig auch deren Konstituierung. In diesem Sinne ist auch die Seele empfindliches Saiteninstrument, worauf die Musik der Sphären erklingt. 106

Daneben hat die Musik im Jugendstil noch eine andere Funktion; durch den Klangreiz der Worte, den Vorgang des feierlichen gehobenen Sprechens, wird die musikalisch-rhythmische Linie besonders zum Stilmittel in der Lyrik. Wichtig dabei ist der Stimmungsgehalt, das direkte Ansprechen des Gefühls, was manchmal dazu führt, daß die Inhalte, Bilder und Vergleiche einander ähneln und austauschbar scheinen. Auch in der bildenden Kunst erkannten Jugendstil-Künstler die Bedeutung der Musik. August Endell sagt, er erziele eine ganz neue Kunst, die durch Form und Linie die Wirkung der Musik anstrebe; er versuche, eine Kunst "mit Formen, die nichts bedeuten und nichts darstellen und an nichts erinnern, unsere Seele so tief, so stark zu erregen, wie er nur immer die Musik mit Tönen vermag."107

Sehr eng verbunden mit der Bewunderung der Musik im Jugendstil ist das Motiv des Tanzes. Der ins Paradies eingedrungene Mensch wird oft im Jugendstil z.B. wie in Bildern von Ludwig von Hofmann, dargestellt als auf blühenden Wiesen,

$$
\begin{aligned}
& 106_{\text {ibid. S. } 221 .} \\
& 107_{\text {op.cit. Holler-Keller, S. } 148 .}
\end{aligned}
$$


wieder zum Kind gewordene, in Reigen und Tanz sich vergnügende, naiv-gläubige Gestalt. 108 In Dichtung und Darstellung ist der Tanz eines der Symbole für das Entrücktsein in die Ewigkeit, sowie Ausdruck für die Besitzergreifung des neuen Paradieses.

Es gibt zwei Grundformen des Tanzes, die 'dionysische' und die 'appollinische' - die eine dem Gott des Rausches und der Ekstase, die andere dem der Ordnung und Überlegung zugeordnet. Der Tänzer kann sich auf zwei Weisen erfahren, einmal ekstatisch, indem die Bewegungssteigerung bis zur Grenze der körperlichen Möglichkeit erfahren wird und eine absolute Gefährdung in sich birgt, "denn die höchste Intensität des Lebendigseins ist Vernichtung der eigenen personalen Existenz"109 - oder in der bewegten Ordnung, die dem Rhythmus als dem ordnenden Prinzip der Bewegung entspricht und in der der Tänzer die sogenannte "Beschwingtheit der Weltordnung" verwirklicht. 110 In diesen beiden Tanzformen realisiert sich die Aufhebung der Grenzen und Gegensätze zwischen dem Ich und der Welt; der Mensch wird zum Gefäß des Unfaßbaren, Unaussprechlichen und Unausdenkbaren.

108 op.cit. Klein, S. 97

${ }^{109}$ I. Deutz, Die dichterische Gestaltung des Tanzes in der deutschen Lyrik, Diss. 1953, S. 12ff.

110 ibid. 
Das Kunst-Ding

Zusätzliche Mosaikteile zur Einrichtung des 'schönen Lebens' im Jugendstil waren die Kunst-Dinge des Kunstgewerbes. Ausgehend von Vasen und Sträußen, Ringen und Harfen gibt es nämlich unzählige Gedichte - ein Beweis dafür, daß durch die Dinge hindurch und aus den Dingen heraus eine andere Realität sprechen kann, als wenn objekt und Subjekt weiterhin wie zwei fremde Welten gegenüber ständen. Auch die späteren Dinggedichte von Rilke leben noch aus dieser Erfahrung. Für die symbolische Bedeutung der Kunsthandwerker im literarischen Jugendstil gibt es viele Beispiele. Im bildnerischen Jugendstil ist das Kunstgewerbe gerade die bedeutendste Richtung - man entwarf Möbel, Besteck, Geschirr- praktisch alles für das tägliche Leben. Der Gedanke dahinter war die Auffassung, daß Kunst nicht mehr in 'reine' und 'angewandte' Kunst geteilt werden könne. Die Kunst fühlte sich näher als je dem Werkstoff verbunden. Die Forderung der 'Materialgerechtigkeit', die uns so selbstverständlich ist, stammt überhaupt erst aus dieser Zeit, aus dieser Bewegung gegen die historische Verkleidung des Stoffes und der Form. Indem jetzt beides unmittelbar hervortrat, gewann das Handwerkliche einen neuen Anspruch und Rang. Handwerk konnte Wagnis und Schöpfung, konnte Kunst werden. 111 


\section{SPRACHMERKMALE}

Die Form der Bildlichkeit

Die Sprache des literarischen Jugendstils hat, genau wie die Linie im bildnerischen Jugendstil, die Tendenz, durch das Vorherrschen erlesener organischer Motive, die einen symbolischen aber vor allem ornamentalen Wert haben, den Inhalt zu überwuchern. Die Auswahl der Seerosen, Schwertlilien und Meerjungfrauen kann in vielen Fällen einfach Vorwand sein für ein schon vorhandenes ornamentales Muster, das in bestimmten Formen der Natur sich annähernd wiederfindet. ${ }^{112}$ Die Betonung des Visuellen im literarischen Jugendstil wird durch ornamentale Wortbildungen und eine Art Bildlichkeit erreicht, die den Status der Gegenständlichkeit in eine qualitative Identität mit dem der Metapher transformiert, was bis zum Aufgehen eines Bildes in die Metapher und zur Lösung des Motives von der wirklichkeit führt. Dazu kommt es zur Koppelung von Bildern, wodurch eine übermäßige Wirkung entsteht. Eine unwirkliche und traumhafte stimmung wird erzeugt, in welcher die Kategorien der Réalität ihre Gültigkeit verlieren zugunsten der Sichtbarmachung eines seelischen Geschehens. Die Stimmung des Gedichtes erwächst indirekt also aus dem Wechselspiel der Bilder und aus dem Stellenwert, der dem ein-

112 . Klotz, "Jugendstil in der Lyrik", Akzente 4; 1957, S. 27. 


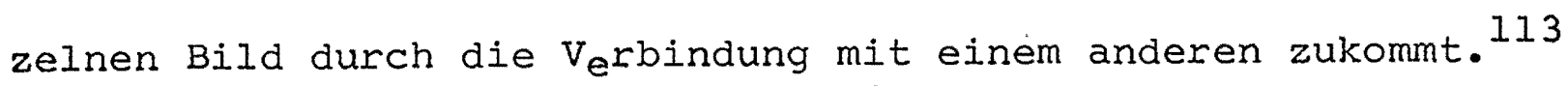
Der Dichter wagt das Unternehmen, einen seèlischen Zustand bzw, Vorgang durch das Medium des Kunstwerkes manifest werden zu lassen, indem er sich einzelner isolierter Wirklichkeitselemente bedient und sie funktional verwendet, d.h. aus ihnen ein bestimmtes Bezugssystem errichtet, das seinerseits als Ganzes den jeweiligen seelischen Zustand spiegelt. Der Realitätsanspruch der jeweiligen Bilder ist zwangsläufig gering, selbst dort, wo eine scheinbar 'reale' Szenerie bildhaft vermittelt wird. Die Wirklichkeit büßt ihren Eigenwert ein, ihr einziger Bezugspunkt ist die in ihr sich objektivierende Subjektivität des Künstlers. Hier sind die Parallelen zur Jugendstilkunst deutlich, in welcher die durch ihre Richtung stimmungshaft wirkenden Linienschwünge dadurch zustande kommen, daß reale Motive stilisiert und in ein ornamentales Lineament umgesetzt werden. 114

Man stößt bei Rilke sehr häufig auf Beispiele für die Stilisierung der Natur, wobei Naturhaftes $z u$ dekorativ-figürlichen Bildern eingeschmolzen wird, die auch mit den Dekorationsmotiven der Zeit übereinstimmen. Das Charakteristische solcher Bilder ist immer wieder, $d a ß$ es sich ohne Ausnahme um ein Zueinander, um Vereinigung, Verschmelzung und Verschlingung handelt, und damit eben wieder um Gebärde, in der die Grundform der alles vereinender Welle als Agens steckt.

$$
\begin{aligned}
& 113_{\text {op.cit. Fritz, S. } 49} \\
& 114_{\text {ibid. S. } 56}
\end{aligned}
$$


Weit über Prag ist riesengroß

der Kelch der Nacht schon aufgegangen.

Der Sonnenfalter barg sein Prangen

in ihrem kühlen Blütenschoß... II5

Der Wechsel von Tag und Nacht wird optisch übersetzt in ein Bild der Vereinigung von Schmetterling und Blüte. Im umgekehrten Verhältnis wird ebenfalls das gleiche Bild gebraucht:

Wie eine Riesenwunderblume prangt

voll Duft die Welt, an deren Blütenspelze, ein Schmetterling mit blauem Schwingenschmelze, die Mainacht hängt.

Nichts regt sich. Nur der Silberfühler blinkt... Dann trägt sein Flügel ihn, sein frühverblaßter, nach Morgen, wo aus feuerroter Aster er Sterben trinkt.

Oder:

Ein Glück löste leuchtend aus Himmeln sich los und hing mit gefalteten Schwingen groß an meiner blühenden Seele...117

Und:

Alles schlürt heil an der stille sich wie da die Seele sich schwellt, daß sie als schimmernde Hüllegsich legt um das Dunkel der Welt.

In diesen Gedichten sind die Jugendstilmotive eindeutig bestimmbar, aber noch nicht als eigentliches symbol anzusehen. Wünsche, Träume und Glück werden Dekorationsmotive und dadurch anschaulich, erreichen aber keine rein geistige Schicht.

$$
\begin{aligned}
& 115_{\text {op.cit. SW I., S. } 25} \\
& 116_{\text {ibid. S. }} 85 . \\
& 117_{\text {ibid. S. }} 88 . \\
& 118_{\text {ibid. S. } 87 .}
\end{aligned}
$$


D. Jost geht so weit zu sagen, daß die Sprache im literarischen Jugendstil nur zur Verzierung, zum Ornament da ist sie ist völlig entmaterialisiert und der wirklichkeit entfremdet. 119 Um solche Ansichten zu verneinen, erforschte $R$. Holler-Keller ${ }^{120}$ den Ornament-Begriff, wie er um die Jahrhundertwende verstanden wurde. Die beliebten Begriffe 'dekorativ' und 'ornamental' im Sprachgebrauch des Künstlers dieser Zeit enthielten eine ungleich höhere Bewertung, denn der Begriff 'ornamental' heiße gleichzeitig auch'symbolisch' und 'gefühlsintensiv'. Die wahre Inbrunst und Leidenschaft, mit der die Natur nach dekorativen Ausdrucksformen untersucht worden sei, sei ein Zeichen für die veränderte geistige Haltung, deren sinnfälliger Ausdruck das neue Ornament wurde: Abkehr von der naturalistisch-objektiven Methode und von der imitierenden Ornament-Behandlung und Bekenntnis zu einem ästhetischen Kunstideal. Die ornamentale Absicht, das Bemühen, kostbare Bilder zusammenzudrängen, um die Darstellung optisch anzureichern und zu schmücken, sei um der Anschaulichkeit wegen geschehen. Die Bildersprache tendiere zum ästhetischen Eigenwert, der Vorgang des Vergleichens selbst werde zum ornamentalen Prinzip erhoben.

Die Frage aber, inwiefern das Ornament symbolisch, und inwiefern es nur dekorativ oder gar beides sei, muß meiner Ansicht nach für die einzelnen Gedichte der verschiedenen

$$
\begin{aligned}
& 119 \text { op.cit. s. } 21 \\
& 120 \text { op.cit. s. } 69 .
\end{aligned}
$$


Vertreter des literarischen Jugendstils gesondert entschieden werden.

\section{Das Verb}

Bei allen Lyrikern des Jugendstils sind charakteristische Verben häufig, die die Wellenlinie der Bewegung darstellen sollen: flechten, schlingen, ranken, fließen, wirren, ringeln, züngeln, schwingen, schwanken, flattern, zittern etc. Alle diese Verben können mit beliebigen Präfixen, etwa um-, ver-, ent-, be- versehen sein und so den Verlauf der Linien präzisieren. Eine andere Gruppe wird repräsentiert durch Verben wie heben, hochreißen, emporblicken, aufraffen, steigen, aufblühen, aufschwingen, entschweben, und ihren Gegenstücken: versinken, senken, fallen, welken, tauchen, fliehen usw. Eine weitere Gruppe besteht aus Durativen: schwellen, glühen, glimmern, blühen, träumen, blicken, sinnen, duften, leuchten, lächeln, rauschen, tanzen usw., die oft durch ihre Umformung in Modaladverbien in ihrer Eigenschaft als Durativa noch verstärkt werden. Die durativen Verben zeigen auch, wie man sich vom Flüchtigen, Impressiven und Zufälligen absetzen möchte, um den Vorstoß in das Immerwährende zu wagen. Ein Versuch also, das Fließende, Verschwimmende und Zerrinnende alles Hiesigen in eine feste Form zu zwängen, die aber gerade erstarrtes Zerinnen selbst ist - angehalten in einem Moment, wo das Fließende das Ewige hindurchscheinen lassen soll. Es handelt sich also um eine Abstrahierung des Figürlichen und um eine Figurierung des Ab- 
strakten. Ent-und Verkörperung treffen sich daher auf einer gemeinsamen Ebene der Entwirklichung, die als 'dekorative Hülle' funktioniert, hinter der sich freilich nicht eigentlich Körperhaftes, Greifbares mehr verbirgt, die aber der Gebärde Leben - und zwar ewiges - verleihen soll. In diesem Zusammenhang kann man von einer Entaktivierung der Verben und einem Substanzverlust der Nomina zugunsten der Gebärde sprechen. ${ }^{121}$ Der Akzent wird vom Ziel auf die Art und Weise verlegt. Verben tauchen auf, deren Subjekt nichts oder sich selbst zum Objekt hat und die auf nichts wirken und nichts verändern. 122

Man versucht im literarischen Jugendstil Gefühlserfahrungen der eigenen Seele dingfest zu machen, indem sie zu gebärdenreichen Figuren werden. Gebärde hier ist ein sichtbares Tun, dessen Zweck vor dem Wie erlischt ${ }^{123}$ Die Gebärde, wie die zeichnerische Linie, ist meistens Ausgangsoder Zielpunkt einer ornamental wirkenden Bewegung, Auslöser einer ornamental wirkenden Dynamik. ${ }^{124}$ So heißt es bei Rilke z.B.:

... und meine weißen wïnsche winken

mir aus dem lodernden Palast.

$$
\begin{aligned}
& 121 \text { op.cit. Klein, s. } 207-9 \text {. } \\
& 122_{\text {op.cit. Klotz, s. } 31 .} \\
& 123_{\text {ibid. S. } 29 f .} \\
& 124_{\text {op.cit. Fritz, s. } 63 .}
\end{aligned}
$$


Wenn wie ein leises Flügelbreiten sich in den späten Lüften wiegtich möchte immer weiter schreiten bis in das Tal, wo tiefgeschmiegt an abendrote Einsamkeiten

die Sehnsucht wie ein Garten liegt.

Und meine nächtebìisse sehnsucht stand, weißbindig. wie der Vesta Priesterin, an deines Seelentempels Säulenrand
und streute lächelnd weiße Blüten hin. 125

Die Gebärde hat vor allem die Funktion, die Zwischenstellung zwischen Wirklichkeit und Unwirklichkeit zu wahren. Hände und Füße und Augen agieren daher 'leise', d.h. traumhaft, schwebend und schweigsam, langsam sich verändernd und bewegend. Hände sind weich, fein, weiß, zart, sanft; Füße wandeln durchweg auf 'leisen Sohlen', Augen sind groß, lächelnd, staunend, fragend, schweigend. Die ganze Haltung bewegt sich zwischen Bewußtheit und Unbewußtheit, also in einer ununterscheidbaren Dämmerzone zwischen Rationalem und Emotionalem einerseits, sowie zwischen Optischem und Emotionalem andererseits. 126

\section{E. Hajeks These der Zeit-Raum-Entsprechung}

Edelgard Hajek gibt sich nicht mit den bisherigen Methoden beim Vergleich des literarischen Jugendstils mit dem bildnerischen zufrieden. Historische Beziehungen, MotivVergleiche und Sprachmerkmale werden bei ihr durch die These der Zeit-Raum-Entsprechungen ergänzt.

$$
\begin{aligned}
& 125_{\text {op.cit. Klein, s. } 204 f} \\
& 126_{\text {ibid. S. } 200}
\end{aligned}
$$


Sie versucht, die Schwierigkeit eines Vergleichs der Künste überhaupt zu überwinden - Schwierigkeiten, die vorhanden sind, weil ein Bild unmittelbar sinnlich erfaßbar ist, während die Dichtung intellektuell vermittelt wird. Lessings Definition, daß das Bild Dinge im Raum, die Dichtung Geschehen in der Zeit darstellt, wird von Hajek als Vergleichsbasis verwendet:

Wenn der Raum das Gebiet des Malers, ̈̈die Zeit das des Dichters ist, so entspricht die Zeit in der Dichtung dem Raum in der Malerei.....Stilistische Übereinstimmungen zwischen Dichtung und Malerei müßten sich also darin manifestieren, daß die Art und Weise der bildnerischen Raumdarstellung und die Art und Weise der lite-
rarischen Zeitdarstellung Gemeinsamkeiten aufweisen.127

Die Jugendstil-Malerei ist gekennzeichnet durch eine plakative Art und Weise, die aus konsequenter Ausschaltung jeder Tiefenillusion, aus absoluter Flächenhaftigkeit resultiert. Die Figuren stehen nicht im Raum, sondern ausschließlich in der Fläche zueinander. Der kontinuierliche Raum, in dem die Dinge sich befinden, wird aufgegeben zugunsten der Kontinuität der Fläche. Die Dinge verlieren ihre Körperlichkeit und damit ihre Individuation, sie werden aneinandergebunden. Diese Gleichartigkeit alles Seienden gehört zu den wichtigsten Zielen des Jugendstils.

Die Möglichkeiten der Zeitstrukturierung in der Dichtung der Jahrhundertwende stellen genaue Parallelen zu der spezifischen Raumstruktur der Jugendstil-Malerei dar. Die Raumlosigkeit bwz. Flächenhaftigkeit entspricht der Zeit127 Edelgard Hajek, Literarischer Jugendstil (Düsseldorf: Bertelsmann Universitätsverlag, 1971), S. 64 . 
losigkeit bzw. Gleichzeitigkeit, dem Verlust der zeitlichen Nacheinanders im literarischen Jugendstil. Hierin ist der Grund zu finden, warum die Lyrik die Dichtungsgattung ist, die bisher am intensivsten auf Jugendstil-Elemente hin untersucht worden ist und wo der Jugendstil am reinsten und deutlichsten ausgeprägt ist. Denn das Lyrische ist von jeher die Zeitentrückteste aller dichterischen Ausdrucksformen. Typisch für den literarischen Jugendstil ist die Absicht, Vergangenheit, Gegenwart und Zukunft in einem Punkt der Zeitlosigkeit zusammenzufassen, die überblendung verschiedener historischer Zeiten, die Konfusionen der Zeitdauer, den Tanz als Symbol der Zeitentrückung usw. Daher der Verzicht auf das zeitwort, also auf den Fortgang in der zeit und die Vorliebe für möglichst zeitindifferente Verbformen wie Infinitiv, Imperativ und Partizip Präsens. 128

128 ibid. S. 66 ff. 


\section{ABGRENZUNG DES JUGENDSTILS ZUM IMPRESSIONISMUS UND ZUR NEOROMANTIK}

Bei einer Analyse der Sprache des Jugendstils fällt man leicht in Versuchung, Merkmale des literarischen Impressionismus anzuwenden, wie sie z.B. von $L$. Thon herausgearbeitet worden sind. ${ }^{129}$ Die Neigung dazu ist deswegen vorhanden, weil der Impressionismus gerade in den gleichen Zeitraum (ca. 1885-1915) fällt und weil die gleiche sprachliche Eigenart von verschiedenen Forschern verschiedenen Stilen zugeordnet wird - jeweils mit gutem Grund. Während L. Thon z.B die Entaktivierung der Verben um 1900 überzeugend mit impressionistischer Passivität erklärt, deutet Volker Klotz sie - ebenso einleuchtend - mit Vorliebe des Jugendstils für Gebärden. 130 Es besteht dennoch die Gefahr, bestimmte Sprachmerkmale der Jahrhundertwende ebenso voreilig dem Jưgendstil zuzuordnen, wie früher dem Impressionismus oder anderen angrenzenden stilen. ${ }^{131}$ Deshalb ist es wichtig, die Unterschiede zwischen dem Impressionismus und dem Jugendstil herauszuarbeiten.

${ }^{129}$ L. Thon, Die Sprache des deutschen Impressionismus (Mưchen: Max Hueber Verlag, 1928)..

${ }^{130}$ Siehe S. 73 dieser Arbeit. 131 op.cit. Hajek, s. 29. 
Im Gegensatz zur impressionistischen 'Hingabe an die Eindrucksflut der Dinge'; die als bloße 'Reizspender' auftreten, herrscht im Jugendstil eine 'kunstvoll arrangierte Atelierwelt', in der sich ein deutlicher Formwille manifestiere, behauptet Volker Klotz. In seinem Forschungsbericht meint Hermand, daß die exotischen Pflanzen z.B. im Jugendstil doch Reizspender bleiben und daß es walerscheinlich besser wäre, von einer Stilisierung und Steigerung der sensualistischen Eindrücke zu sprechen. Denn tatsächlich würden diese Gedichte 'kunstgewerblich bearbeitet' - alle Dinge bekämen wieder 'Kontur'. Man biege sie zurecht, deformiere sie. Kein Ding der Natur behalte seine Gestalt, es werde umstilisiert. Das Ergebnis sei stilisierter Prunk. ${ }^{132}$ Niemals tritt eine kopierende Abbildung der Wirklichkeit ein, wie es beim Impressionismus der Fall ist. Der Impressionismus will das Ding so treffen, wie es zu-dieser stunde, in diesem Augenblick erscheint. Die Gegenwart ist die einzige zeitliche Wirklichkeit. 133

Ein weiteres Merkmal des Impressionismus ist die Definition der Wirklichkeit als eines aus einer unvoraussehbaren Folge von Eindrücken bestehenden Erlebnisses. Die Impressionisten haben eine unüberwindbare Scheu, die Ratio vorauszuschicken und die Dinge aus der Tiefe des Denkens her-

\section{2 op.cit. Hermand, S. 74:E.}

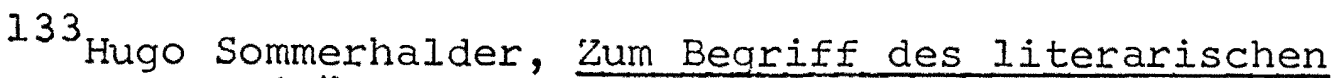
Impressionismus (Zürich: Polygraphischer Verlag AG., 1961), s.8. 
aus zu ordnen und zu binden. Alles Denken stellt Bindungen zwischen den Dingen her; doch das Rationale, insbesondere, ordnet und bindet nach Kategorien, die dem momentanen Eindruck nicht gerecht werden. Im Iiterarischen Jugendstil dagegen werden Bindungen zwischen den Dingen durch den Verhältniswert der Bilder hergestellt, und zwar in symbolhaften Metaphern. 134

Der Impressionist leidet an der Entzweiung der Welt in ein Innen und Außen. Das Gefüge der dem Ich begegnenden Welt wird in stimmungsträchtige Details aufgelöst. Im literarischen Jügendstil wird die Welt wieder zusammengeschlossen, allerdings in einer kunstvoll-arrangierten weise. 135

Auch die sogenannte Neoromantik fällt in dieser Periode; Abgrenzungen zwischen der Neoromantik und dem Jugendstil müssen daher auch getroffen werden. In einer maßgebenden Arbeit setzt Anne Kimmich sich kritisch mit dem Begriff 'Neoromantik' auseinander. ${ }^{136}$ Für sie besteht ohne Zweifel eine Neigung der Künstler der Jahrhundertwende zur alten Romantik. So wurden Werke der Romantiker neu herausgegeben und kommentiert; Kerr schrieb über Brentano, Fr.v. Oppeln-Bronikowski und I. Jakobowski gaben eine Sammlung heraus, "Die

\section{${ }^{134}$ Siehe s. 68 dieser Arbeit.}

135 op.cit. Klotz, s. 28 .

136 Anne Kimmich, Kritische Auseinandersetzung mit dem Begriff 'Neuromantik' in der Literaturgeschichtsschreibung. Diss. Tubingen 1936 (Buchdruckerei Albert Becht.) 
blaue Blume"; in der Kunstzeitschrift "Pan" wurden die Hymnen des Novalis abgedruckt. Schon 1905 begann die Auseinandersetzung mit dem Problem einer neuen Romantik und seither gibt es noch immer Argumente dafür und dagegen, ohne daß der Begriff eindeutig akzeptiert wird. Kimmich referiert die Äußerungen Soergels, Wiegands, Cysarz; Walzels und 25 anderer Literaturhistoriker und kommt zu dem Schluß, daß der Begriff 'Neoromantik' als solcher abzulehnen ist. Romantik, sagt sie, ist die Bezeichnung für eine der wesentlichen Epochen innerhalb der deutschen Literaturgeschichte, sie kann deshalb nicht

gleichzeitig für einen literarhistorischen Abschnitt gebraucht werden, der wirklich 'nur ein kurzes, nicht einmal entscheidendes Entwicklungsstadium trifft'. (Definition von Neoromantik im Reallexikon). Andererseits drückt die Bezeichnung 'Neoromantiker' den so genannten Dichtern wirklich...'den Stempel restaurativen Epigonentums' auf..... Und dies scheint uns nicht.: einmal für die wiener genügend gerechtfertigt zu •

Dennoch, fährt sie fort, ist eine Verwandtschaft mit der Romantik doch die ausgesprochene Rezeptivität und Sensibilität: die Fähigkeit, mit allen Sinnen zugleich zu begreifen, die Synästhesie; aber auch die Betonung des Unbewußten und Unterbewußten, des Traumhaften, dés Symbolischen, und die hohe Würdigung des Künstlers. Trotzdem ist die Neoromantik durch eine zu tiefe Kluft von der Romantik getrennt. Die Weltanschauung der Neoromantiker (die des ausgehenden, verfeinerten Materialismus) ist ein Relativismus mit der Grundüberzeugung 
des Impressionismus, daß die Seele nur ein Etwas sei, durch das die Eindrücke der Außenwelt hindurchfluten, in dem sie sich spiegeln, das aber selbst kein Eigenleben habe. Diese Negierung der Seele ist ganz unromantisch, den tiefsten Überzeugungen der Romantiker durchaus entgegengesetzt. Auch in einem anderen wesentlichen Punkt gibt es einen fundamentalen Gegensatz: Die Romantik umfaßt alle Kulturgebiete, während die Neoromantik sich auf die Domäne des rein Ästhetischen beschränkt. In der Romantik sind wirklich ethische Werte zu erkennen, wogegen die Neoromantik sich in den meisten ihrer Vertreter in reinem Ästhetizismus erschöpft. Die besondere Staatsauffassung der Romantik, ihre Idee der Gemeinschaft überhaupt erlangte Bedeutung weit über die Grenzen der Iiterarischen Romantik hinaus. Die Neoromantik will nichts vom staat wissen und isoliert sich in einem übersteigerten Individualismus. In der Romantik war das religiöse Moment von großer Bedeutung - Die Neoromantik schwankt zwi= schen scharfer Religionsfeindlichkeit und müder Indifferenz. Die Romantik war nur zu einem kleinen Teil weltfremd und todessüchtig und war andererseits fähig, mit dem Leben fertig zu werden. Die Neoromantik verzichtet auf den Willen zum aktiven Leben, sie resigniert in müder Verzweiflung oder sucht in einem letzten Kampf dem Leben alle süße und alle Bitterkeit auszupressen. Die Hypertrophie des Seelischen 1 äßt wenig Raum für das gesunde Körperliche übrig. 138

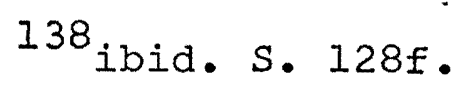


In diesem Abschnitt sollte betont werden, daB die beiden Epochenbegriffe Impressionismus und Neoromantik gewisse Ausdrucksmöglichkeiten für die Iiteratur um die Jahrhundertwende bieten, wobei festzuhalten ist, daß der Ausdruck 'Neoromantik' überhaupt fraglich ist, da man gewiß nicht von Wiederinkraftsetzung der romantischen Idee sprechen kann. Mir scheint der später eingeführte Begriff des literarischen Jugendstils in manchem eine klarere Aussage zu enthalten, weil er von einer bestimmten und ziemlich genau abgrenzbaren Richtung in der bildenden Kunst ausgeht, mit der er formale und ideologische Übereinstimmungen hat. 


\section{KAPITEL \\ RILKES VERHÄLTNIS ZUM JUGENDSTIL, CHRONOLOGISCH GESEHEN}

Nach einer einführenden Beschreibung von Rilkes Stellung zur Malerei und zu Jugendstil-Malern, auch Klärung der für diese Arbeit wichtigen Kunst- und literaturhistorischen Begriffe, nach einer skizzenhaften Charakterisierung des schöngeistigen Schaffens um die Jahrhundertwende zeige ich im folgenden detailliert die Entwicklung auf, die Rilke in seinem Verhältnis zur Jugendstil-Thematik durchschritt; dabei beschränke ich mich auf die Zeit bis 1902, als Rilke durch sein Paris-Erlebnis aus der Jugendstil-Atmosphäre weggerissen wurde und sich neuen Darstellungsformen zuwandt.

\section{DIE PRAGER ZEIT}

Rilkes dichterische Entwicklung während seiner Jugendzeit in Prag war vor allem gehemmt durch das literarische Milieu in dieser Stadt "der tausendjährigen Friedhöfe, der barocken Kirchen, der schwarzen Synagogen, der skurrilen Katakomben und der leidenschaftlich entflammten Brückenheiligen."139 Die 'provinzielle Verspätung' in dieser stadt gab ihm Gelegenheit, als sehr junger Mensch eine öffentliche 
Rolle zu spielen, hinderte andererseits seine Entwicklung, indem er sich mit schon längst vergessenen Lokalgrößen zusammenschloß und ihre Anerkennung erwarb. Es waren vor allem Rudolf Jenny and seine Versuche, den Stil des BerIiner Naturalismus ins Pragerische zu übertragen, die Rilke angeregt haben und deren Nachahmung sich in vielen Dramenversuchen niederschlug. Der Naturalismus blieb aber nicht lange Rilkes Richtung, denn zur gleichen Zeit existierte in Prag eine Mischung aus Neoromantik und einem romantischen, träumerischen Jugendstil, ein Amalgam, das durch den Charakter dieser Stadt gefördert wurde. Erst nachdem Rilke der Stadt Prag den Rücken gekehrt hatte, beschrieb er 1900 die für ihn typische Entwicklung von Künstlern in Prag: die Rolle, die die Vergangenheit für den deutschen Künstler spielt, wird von Rilke klar gesehen. Als überwiegender Einfluß auf ihn wirkt

...die giebelige, türmige Stadt...die große Historie kann in ihr nicht verhallen. Der Nachklar.g tönender Tage schwingt in den welkenden Mauern. Glänzende Namen liegen, wie heimliches Licht, auf den Stirnen stiller Paläste. Gott dunkelt in hohen gotischen Kirchen. In silbernen Särgen sind heilige Leiber zerfallen und liegen wie Blütenstaub in den metallenen Blättern. Wachsame Türme reden von jeder Stunde, und in der Nacht begegnen sich ihre einsamen Stimmen. Brücken sind über den gelblichen Strom gebogen, der, an den letzten verhutzelten Hütten vorbei, breit wird im flachen böhmischen Land. 140

Ein zweiter Punkt ist die Isolierung des deutschen Künstlers und seine Entfremdung von der nationalen tsche$140_{\text {op.cit. SW V. }}$, S. 469. 
chischen Kultur. Verschiedene deutsche Künstlervereine "wie um größerer Wärme willen" schließen sich zusammen und "ihre Mitglieder sind die Vertreter einer unnationalen, uberall möglichen Kunst, die durch nichts auffällt und dem kaufenden Publikum selten Ärgernis giebt". 141 So, behauptet Rilke, ist im deutschen Böhmen die Literatur "Zeitungsgeschrei" und die bildende Kunst das geworden, was dem Journalismus entspricht. Um diese Zustände $\mathrm{zu}$ überdauern, müßte der Künstler "entweder sich auf sich selbst zurückziehen, sich enger an das Land, seine Art und Anmut anschließen... oder in die Fremde...ziehen". ${ }^{142}$ So war Rilke ausgezogen, als er 1896 Prag verließ, um nach München zu gehen.

Charakteristisch für Rilkes Kunst in der Prager Zeit ist dië Jagd nach Beziehungen und Anerkennung, die ihn dazu führte, schon 1894 Mitglied zweier Prager Künstlervereine, von "Concordia" und von dem "Verein bildender Künstler" zu werden, wo er auch mit dem Graphiker Emil Orlik zusammentraf. Diese Vereine, die von Dichtern und Malern gegründet waren, repräsentierten die Tendenz der verschiedenen Künstler, vereint ihrem Kunstideal nachzukommen. Hier beginnen Rilkes Besuche in Künstlerateliers und seine aktive Beschäftigung mit der bildenden Kunst.

$$
\begin{aligned}
& 141_{\text {ibid. S. }} 471 \\
& 142_{\text {ibid. }}
\end{aligned}
$$


Erste Gedichte, die Rilkes Interesse an der Malerei zeigen

Dichterische Umsetzungen seines allgemeinen Interesses an der Malerei damals sind die zwei Gedichte: "St.Peter" und "Wieder einmal Dresden". Im April 1896 schrieb Rilke das Sonett "St. Peter". Es steht in einem Skizzenbuch bei einer Zeichnung: St. Peter nach dem Plane Bramantes. ${ }^{143}$ Noch ehe Michelangelo in Rom die Riesenkuppel seines Ruhmes spannte, hat bei der Grundsteinlegung sich Bramante, wie eine Münze zeigt, gedacht den Dom.

Wenn auch in der Begeisterung Duftarom des Künstlertumes Feuer in ihm brannte, es stieg das Werk, das er sein eigen nannte, erst nach ihm mählich aus der zeiten Strom.

Und wenn ein Künstler oft nicht mit Vollendung mehr krönen darf, was herrlich er begonnen, beweinet nicht sein allzufrühes Sterben.

Ein Enkel fügt sich dann in seine Sendung; und reicher nur und stärker quillt der Bronnen des Geistes fort in gottgeweihten Erben. 144

Das Gedicht zeigt eine deutliche Beschäftigung mit der Kunst der Renaissance. Das Thema ist die Erscheinung des schöpferischen Geistes in der Person Bramantes und seine Fortsetzung in Michelangelo bei der Errichtung vom Petersdom in Rom. Dieses Beispiel wird verallgemeinert in den letzten zwei Strophen: Das Werk eines Künstlers kann manchmal erst durch einen anderen vollendet werden. In diesem Fall war der Plan Bramantes zu überwältigend, um während seines Lebens ausgeführt zu werden. Die Verwendung des Baumaterials der alten

$$
\begin{aligned}
& 143_{\text {op.cit. SW.III., s. } 819} \\
& 144_{\text {ibid. S. } 511}
\end{aligned}
$$


Römer, Beton - statt Stein oder Ziegelstein wie im Mittelalter - ermöglichte solch einen riesigen Bau, der alle Gebäude der römischen Antike mit einer katholischen Kirche übertreffen sollte. Mit seiner Bauweise fing ein neues Kapitel in der Geschichte der Architektur an. Die Möglichkeiten des Materials wurden nach seinem Tode völlig ausgewertet und der Dom konnte erst durch Michelangelos Veränderungen vollendet werden. 145

Dem Rilke-Gedicht gelingt es nur teilweise, die revolutionäre Stellung Bramantes in der Kunstgeschichte zu zeigen. Wichtiger für ihn als die Tatsache, daß Bramantes Genie seiner Zeit voraus war, war Michelangelo, in dem der "Geist" reicher und stärker fortlebte. Rilkes spätere Kunstaufrassungen und Beschäftigung mit der Renaissance im Florenzer Tagebuch und im Stundenbuch sind zum Teil auf diese Zeit zurückzuführen. Hier ist Gott der Dom, woran der Künstler baut, seine Aufgabe ist nicht nur eine künstlerische sondern eine heilige - er erschafft den zukünftigen Gott. Rilke fühlt sich als "Gottgeweihter" und Gott-weihender Erbe der Renaissance.

Das zweite Beispiel für sein Verhältnis zur Kunst in dieser Periode sind die "Verse aus den Briefen an Láska van Oestéren". Sie wurden September 1896 in Dresden verfaßt und berichten von seinem Besuch in der Dresdener Galerie. Die Verse enthalten nichts von künstlerischem

${ }^{145}$ H.W. Janson, History of Art (New York: Harry N. Abrams, Inc., 1962), S. 554-57. 
Wert und sind höchstens interessant, wenn man sie als Inventur der Galerie oder der Rilke bekannten Künstlernamen betrachtet. Oberflächlich und dilettantisch ist sein Versuch, diese ca. 15 Künstler kurz zusammenzufassen.

Wieder einmal Dresden. Galerie, die ich aufzusuchen nie vergesse. Denn ich werde müd zu schauen nie des Teniers bizarre Schenkenspäße und Ostades bunte Bauernmesse und dann Rubens, der den Farben lieh jene Liebeshymnenmelodie. Raphaels verzückte - Madonnie, Rembrandts halblichtschwere, braune Blässe, dran manch Kritikus sich glühend schrie. Cranach auch, dem ich die bunten Pässe in das Fegefeuer nie verzieh. Hier van Dyck, den Freund der Königstrasse, den ich nach den 'Kindern Karls' messe, und Correggio, den ich nie vergesse.... Goya mit der Höllentheorie...Murillos.... Dürer....(usw.)

Rilkes Beitrag zum Kreis der Modernen in der zeit vor München

Für Rilkes spezifisches Interesse und Teilnahme am Jugendstil sind Briefpassagen aus dieser Zeit eine reiche Fundgrube. In den Briefen, die er in den Monaten vor seiner Abreise nach München verschickte, ${ }^{147}$ wird schon der wunsch ausgedrückt, einen neuen moderneren Künstlerverein und eine freie Bühne zu gründen. Mit dem Künstlerverein war ein Ausbruch aus der Abgeschlossenheit des Prager Künstler-Milieus und ein Auflehnen gegen das Provinizielle beabsichtigt. Das Moderne sollte gefördert werden -anders gesagt: Der Bund

146 op.cit. SW III., S. $543 f$.

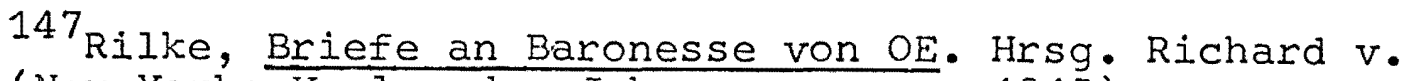
Mises (New York: Verlag der Johannespresse, 1945). 
'moderner Fantasiekünstler' sollte Vorhut 'moderner Zopfverächter' sein. Am 16. März 1896 schreibt Rilke folgende Verse:

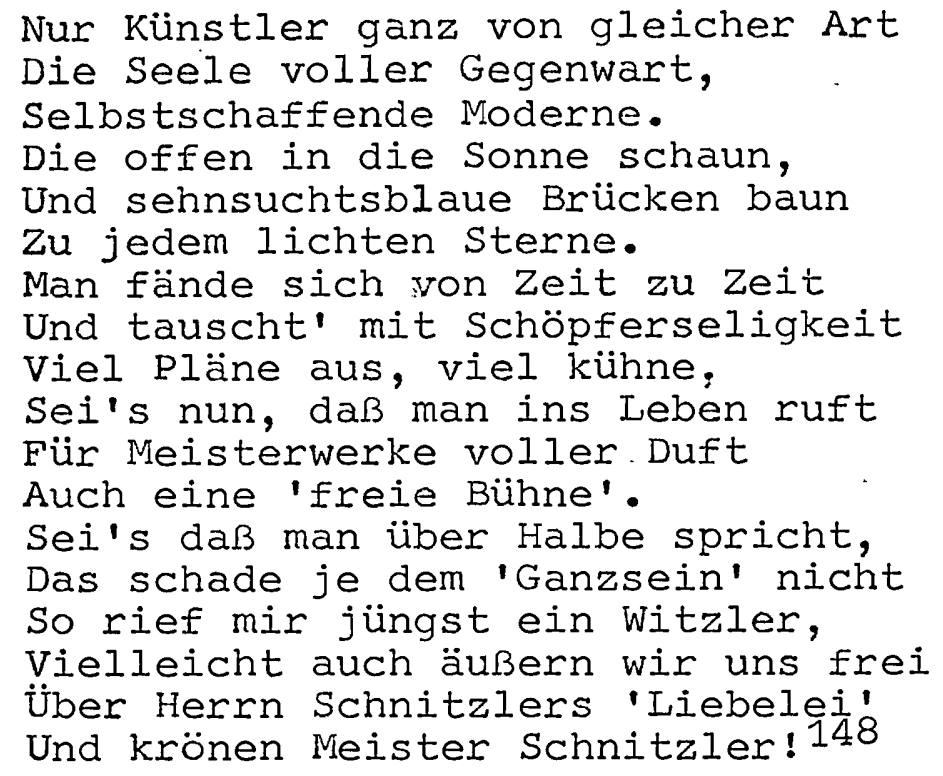

Die Freie Bühne sollte also Halbe, Schnitzler - und an anderer Stelle genannt - auch Maeterlinck aufführen. In Berlin gehörte Halbe zu der Gruppe, aus der später die Sezession geworden ist und lebte seit 1895 in München. Rilke huldigte ihn im September 1895 mit einem Gedicht über sein Drama

'Jugend' :

Als sollte sich mein Herz mit einem Schlag von all dem schalen Alltagsqualm befrein, so griff Max Halbes 'Jugend' tief hinein, wie ein Gewitter in den Spätherbsttagen.

Und wie ihr Innerstes vor sich zerstaubt die Blüte sieht, die rauh ein sturm geknickt, so fuihlt ich meinen heimlichsten Konflikt jetzt aus dem Kunkel meiner Brust geraubt. 149

Das Drama 'Jugend' verkörperte die Jugendstil-Philosophie

$$
\begin{aligned}
& 148 \text { op.cit. SW III., S. } 518 \text {. } \\
& 149_{\text {ibid. S. } 818}
\end{aligned}
$$


der Wiedergeburt des Menschen in Frühling und Liebe. Max Halbe und andere vertraten sogar die Meinung, daß dieser Titel den Begriff "Jugendstil" hervorbrachte. Die Hauptfigur des Stückes ist der "Embryo eines modernen Stimmungsmenschen"; die Betonung liegt auf der Lebendigkeit und Erregung, Naivität und Hingabe eines jungen Paares, die den 'Naturgesetzen' und 'der Macht des süßen Taumels' folgen. Halbes Ausdruck "moderner Stimmungsmensch" erinnert an einen Aufsatz von $\mathrm{H}$. Bahr in dem er die neue Jugendstil-Kunst, als "Überwindung des Naturalismus" so definiert:

Der neue Idealismus drückt die neuen Menschen aus. Sie sind Nerven; das andere ist abgestorben, welk und dürr. Sie erleben nur mehr von den Nerven aus.... Es ist ein geflügeltes, erdenbefreites steigen und Schweben in azurne Wollust, wenn die entzügelten Nerven träumen.150 Hinzugefügt sei, daß auch Schnitzler und Maeterlinck Anhänger dieser Richtung waren.

Als Teil des Vereins sollte die Publikation eines gemeinsamen Organes mit dem Titel "Wegwarten" folgen, worin Beiträge sämtlicher Mitglieder erscheinen sollten. In dem Vorwort zum ersten Heft, das gratis an die Bevölkerung verteilt werden sollte, schrieb Rilke:

Paracelsus erzählt, die Wegwarte werde alle Jahrhunderte zum lebendigen Wesen; und leicht erfüllt die Sage sich an diesen Iiedern; vielleicht waghen sie $\mathrm{zu}$ höherem Leben auf in der Seele des Volkes. 151

150 Dominik Jost, "Zum literarischen Jugendstil" in Jugendstil, Hrsg. Jost Hermand (Darmstadt: Wissenschaftliche Buchgesellschaft, 1971), S. 466.

151 op.cit. Briefe an Baronesse von oE, S. 10. 
Die Wegwarte, die wild wachsende Pflanze, der niemand Beachtung schenkt, die aber der sage nach einmal in hundert Jahren zu höherem Dasein aufersteht, sah Rilke als Sinnbild seines beginnenden Werkes und seiner eigenen Existenz. Hierin ist auch der Jugendstil-Gedanke vorhanden, der den Menschen als Teil der Pflanzenwelt und ihren Gesetzen unterlegen versteht. Tatsächlich war das dritte Heft der Wegwarte am 29. Oktober 1896, das erste und letzte, das als Organ des Vereins erschien, da Rilke vorher schon zwei Ausgaben allein unter seinem Namen publiziert hatte; Beiträge von Hans Benzmann, Gustav Falke, Ludwig Jacobowski, Christian Morgenstern, Bodo Wildberg und Hermoine von Preuschen waren u.a. enthalten. ${ }^{152}$ ob der Bund selbst je in Erscheinung trat, scheint zweifelhaft. Nachdem Rilke nach München übersiedelt war, ist nicht mehr davon die Rede.

Diese Rilke-Briefe bieten auch Information über Rilkes Verbindung mit dem bildnerischen Jugendstil. So bewundert er Orliks Technik der Radierung,

...jener Kunst, die durch Klinger und Liebermann zur 'modernen' gestempelt, von den Jüngern mit Eifer und Begeisterung aufgegriffen wurde, da gerade sie durch den eigentülichen oft unbestimmbaren Reiz ihrer Linien und Formen dem mystisch-schwärmerischen Ruf unserer Kunstrichtung entspricht. 153

Auch findet sich hier die erste Erwähnung von den Jugendstil-Zeitschriften 'Jugend' und 'Simplicissimus',

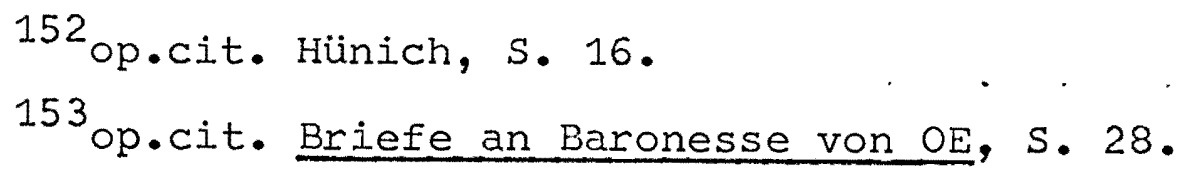


Vertreter der Modernen, zu denen er sich natürlich rechnet. Nachdem Rilke erzählt hat, daß die Hefte in Österreich konfisziert worden sind, meint er voller Überzeugung:

Aber allenthalben, wenn auch die alten Herren mürrisch und ungläubig den Kopf schütteln, und die innerlich Alten ein höhnisches Lächeln in den Mundwinkeln tragen, die "Jugend" rückt auf allen Seiten mit fliegenden Fahnen vor, und - sie wird siegen! Ihr jauchzender Übermut ist doch so viel schöner, als das vergrämte Brummen jener Blasirten war, die immer noch meinten, es sei ein Abendrot, in das sie hineinzögen - während es die schlafrote Wange des erwachenden Morgens war! Heil dem Morgen! 154

Betont lobt er das neue Prinzip des Jugendstils:

Wie viel besser es ist, Stoff und Motiv in der Natur, in flutendem Freilicht zu suchen, als in alten Schartecken, das ward mir jüngst recht bewußt, da ich tageintagaus über staubigen Folianten $s a ß$ : In unserer Familie besteht seit Jahren das Bestreben, wenn auch nicht den alten Ritteradel unseres Stammes wiederzuerringen, so doch die Abstammung von dem uralten Geschlechte derer von Rylke oder Rulico,..... Aber dieser Buicherstaub engt einem die Brust! Fliederduft ist mir lieber, oder schwelender Jasmin! 155

Rilke will scheinbar in diesem Augenblick von einem neuen Anfang und einem neuen Jahrhundert überzeugt sein, wie er es auch später im Stundenbuch zum Ausdruck bringt ${ }^{156}$, und will sogar sein festes Klammern an die Familientraditionen lächerlich machen. Doch durch Selbstanzeigen und Äußerungen

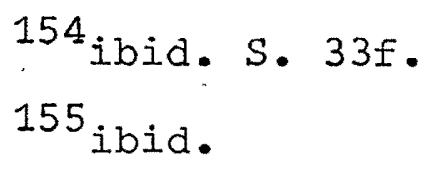

156 op.cit. SW I., S. 256: "Ich lebe grad, da das Jahrhundert geht. Man fühlt den Wind von einem großen Blatt, das Gott und Du und j.ch beschrieben hat und das sich hoch in fremden Händen dreht. Man fühlt den Glanz von einer neuen Seite, auf der noch Alles werden kann." 
aus dieser Zeit wird klar, daß seiner Überzeugung nach der Künstler der verfeinerte und vereinzelte Spätling, in dem ein altes, vornehmes Geschlecht zu Ende geht, seine letzte Blüte erfährt. In diesem Sinne hat Rilke lange seine Herkunft stilisiert und darauf bestanden, Abkömmling einer alten Adelsfamilie zu sein. So steht zum Beispiel in seinem Beitrag zu Franz Brümers "Lexikon der deutschen Dichter":

RILKE, René Maria Cäsar, entstammt einem uralten Kärntner Adelsgeschlecht und wurde am 4. Dezember 1875 in Prag geboren. Mit zehn Jahren verließ er das von Zwietracht zerspaltene Elternhaus, brachte die folgenden fünf Jahre in einer Militärerziehungsanstalt $\mathrm{zu}$ und durchlief dann bis zum Jahre 1894 die obersten Gymnasialklassen unter angestrengtester Arbeit, die für seine Gesundheit von bedenklichen Folgen war. Er lebt nunmehr als Schriftsteller in Prag und leitet seit 1896 die Zeitschrift 'Jung-DeutschIand und Jung-österreich'.....15\%:

Genauso wie Herman Bahr in der "Überwindung des Naturalismus" hat Rilke sein Kunstideal von einem "volksbezogenen" zu einem "ich bezogenen" gewandelt, nämlich zu einem, worin die "entzügelten Nerven" träumen. Hier distanziert er sich auch von der naturalistischen Kunst Rudolf Jennys, in der eine "Tendenz" zu finden sei - ein "Anti", "denn ein wahres Kunstwerk, soll nie im Dienste einer Tendenz stehen, es soll nie um ihretwillen da sein."158

Wir 'Modernen' sind halt doch - ichsüchtig. So sagt man ja wohl 'modern'!

157 .op.cit. SW VI., S. 1204. 158 op.cit. Briefe an Baronesse von OE, S. 29. 
Diese Stelle ist dementsprechend durchaus positiv gemeint. Im ersten Brief, den Rilke aus München schreibt, (November 1896) berichtet er sofort von seinen jüngsten Verbindungen zu dem Kreis der sogenannten Modernen, zu dem Jakob Wassermann (Redakteur des "Simplicissimus") und Max Halbe gehören. Auch das Ehepaar Preuschen'-Telmann habe er kennengelernt und dieRedaktion der "Jugend" besucht, berichtet er.

Beispiele für Rilkes Auffassung der jugendstilhaften Vermischung der Künste

Zum ersten Mal äußert sich Rilke über die Beziehungen zwischen Malerei und Literatur kritisch in seinem frühen Aufsatz "Böhmische Schlendertage" (September 1895) mit einem kurzen Bericht über die Kunstausstellung des Prager "Rudolfinum". Die Bilder des Jugendstil-Malers Ludwig von Hofmann stellen seiner Ansicht nach einen "großen, nachlässigen, müden, naiv scheidenden Zug von träumerischer Verschwommenheit" dar. Rilke kann "diesem Farbensalat keinen Gefallen aboringen."I59 Um seine Abneigung für diesen Naler zu begründen, zieht er Lessings Laokoon-Aufsatz heran, allerdings, in einer ihm günstigen Weise, indem er ihn einseitig auslegt. Da seiner Meinung nach gewisse Arten der Malerei ihre Entsprechung in der Dichtkunst finden könnten (Historienmalerei=Drama und Epos; Genre=Novelle), könnte die Stimmungsmalerei ihre Entsprechung in der Lyrik finden. Dann aber behauptet er, im

$$
159 \text { op.cit. SW V., S. } 292 .
$$


Gegensatz zu Lessing, daß sich die Lyrik ganz und gar des Gegenständlichen enthalte, und somit kein Verhältnis zwischen Malerei und Lyrik existiere. Das sei der Irrtum dieser Richtung. Rilke scheint also zu dieser zeit noch im Unklaren zu sein über die Beziehungen zwischen den Künsten. Ein Vergleich zwischen historischer Malerei und Drama, zwischen Genre und Novelle sei möglich, zwischen Hofmanns Stimmungsmalerei und Lyrik aber nicht. Die Widersprüchlichkeit dieser Auffassung hat er später aufgegeben. Schon im April 1896 vergleicht er in einer Kritik über Hans Benzmanns Buch "Im Frühlingssturm" Gedichte mit Bildern:

Benzmann hat herrliche, leuchtende Farben auf seiner Palette und er nimmt den Pinsel sehr voll. Seine tonsatten Bilder wollen mit Muße und Verständnis geschaut sein. - Diese Gedichte nenne ich Bilder im eigentlichen Sinne des Wortes. Ich habe in diesem Buche geschaut und nicht gelesen.160

Rilkes Mieinung über Hofmann hat sich rasch geändert im Jahre 1898 schreibt er selber Gedichte zu dessen Bildern. Rilkes Bewunderung für und Aussagen über Hermoine von Preuschen sind aber das beste Beispiel für seine Auffassung der Mischung der Künste. Während seiner ganzen Jugendstil-Phase bleibt diese Haltung ziemlich konstant - so z.B. in einem Aufsatz iber Gustav Falkes "Neue Fahrt":

...Falke in seiner heiteren und hellen Anerkennung der Welt, erinnert an die guten deutschen Maler, die ebenso willig den Dingen allen zu ihrem eigensten Ausdruck verhelfen. Das Gedicht 'Die Lie- 
bende' ist wie ein Thoma'sches Bild, schlicht und schön, gerecht gegen Kleines und Großes, still im licht und klar im Schatten....161

Auch Bodo Wildbergs Dichtung wird mit den Thoma'schen Bildern verglichen, und noch 1902 vergleicht Rilke Thomas Manns Stil in den Buddenbrooks mit dem vom Jugendstil-Maler Segantini:

Es ist etwas von der Technik Segantinis hier in das andere Gebiet übertragen: die gründliche und gleichwertige Behandlung jeder Stelle, die Durcharbeitung des Materials, welche alles wichtig und wesentlich erscheinen läßt, die von hundert Furchen durchzogene Fläche, die dem Beschauer einheitlich und von innen heraus belebt erscheint, und schließlich das objektive, die epische Art des Vortrags, welche selbst das Grausame und Bange mit einer
gewissen Notwendigkeit und GesetzmäBigkeit erfült 162

Überhaupt ist die Literatur als solche um die Jahrhundertwende unstetig in ihrer Funktion und vermischt sich mit anderen Kunstgattungen. Gerhart Hauptmann beginnt als Bildhauer, Heinrich Mann als Maler, Oskar Kokoschka und Kurt Schwitters sind Maler und Schriftsteller, Herman Hesse zeichnet, Christian Morgenstern möchte Goldschmied sein, Ernst Barlach ist Bildhauer und Dichter zur gleichen Zeit. ${ }^{163}$ Eine Aussage aus Muzot im März 1922 stellt die Beziehungen zwischen den Künsten in eine andere Perspektive, die Vermischung der Künste hat für den späten Rilke nur noch einen begrenzten wert:

$$
\begin{aligned}
& 161_{\text {ibid. S. } 461 .} \\
& 162_{\text {ibid. S. } 579 .} \\
& 163_{\text {op.cit. Rosenhaupt, s. } 56 .}
\end{aligned}
$$


Es ist natürlich nicht ganz auszuschließen, daß auch die Künste gegenseitig ineinander hinüberwirken und sich beeinflussen; wo aber bewußt ein schon künstlerisch Gestaltetes zum Anlaß wird wiederum für Kunst auf anderem Gebiet, da müßte der so betroffene Künstler außerordentlich viel aus dem Erlebnis Stammendes zu dieser Veranlassung hinzu aufregen, um etwas ganz verantwortliches einem solchen Antrieb aus zweiter Hand abzuringen. Dies ist in den Gedichten des kieinen MarienLebens manchmal geschehen; nicht immer....164

Rilke bezieht sich auf Gedichte, die von den Gemälden El Grecos inspiriert worden waren. Daß noch das Spätwerk Inspiration von Gemälden empfing, wird durch die 5. Elegie und ihrer Quelle Picassos "La Famille des Saltimbanques" jedem Kenner deutlich. Was sich geändert hat in dem Verhältnis der Dichtung zur Malerei hat Rilke mit dem obigen zitat klar machen wollen.

Jugendstil-Motive in Rilkes Dichtung während der Prager Zeit Die Blumen-Motive Hermione von Preuschens. Die Jugendstil Künstlerin Hermione $v$. Preuschen hat Rilkes Dichtung in der Prager Zeit stark beeinflußt, so stark, daß Rilke hier zum ersten Mal Bilder bedichtet: nämlich die Bilder "Evoß Bacche," "Die Pforte der Zukunft" und "Asrael". Auch veröffentlichte er einen Aufsatz über ihre Bücher und Bilder. H.V. Preuschen ist exemplarisch für den neuen Künstler-Typus, bei dem Maler schreiben und Dichter malen. Dieser Gedanke einer $M_{i}$ schkunst ist Rilke sehr sympathisch:

Bei Hermione von Preuschen vertragen sich Dichtkunst und Malerei schwesterlich. Sie findet sich

164 op.cit. Briefe. 2 Bde., Bd. II, S. 342. 
auf dem Gebiet der stimmung.... Sie malt ihre herrlichen Gedichte, deren schwerer reimloser Rhythmenfluß wie geschmolzenes Gold hinströmt, und sie dichtet in farbensatten Allegorien auf die Leinwand. 165

Zu ihrem Bild "Asrael" sagt Rilke in dem Aufsatz, "Hermoine von Preuschen":

-..Asrael, die Gestalt des Todesengels, der mit bang gefaltetem Flügelpaar auf weißer Marmorbank mitten im leuchtenden Mohnfeld hockt und das eine Auge phosphorleuchtend' auf der Seele des Beschauers ruhen läß... (ist das Großartigste dieser Schöpfungen).166

Das Gedicht, das aus diesem Bild entsteht, ist "Asrael":

Hinter dem Duftgeschwel

flammender Blüten

dämmert das Meer....

Da in den prachtdurchgliuten

Frühling trägt er

ewiger Todesmythen

steinernes Brüten...

Schatten fließt schwer

wie eine bange Blütengefahr

aus furchtbar gefaltetem Flügelpaar

dem Asrael.

So starrt er dich an und sein Auge zwingt

dir einen würgenden Reif um die Kehle;

So starrt er dich an und sein Auge trinkt deine Seele...167

Asrael ist in der jüdischen und mohammedanischen Mythologie ein Engel, der die Sterbenden überwacht und deren Körper von der Seele trennt. Schon aus den ersten Zeilen gewinnt man eine Vorstellung vom Bild. Einige Ausdrücke sind sogar aus der Prosa-Bildbeschreibung direkt übernommen. Es ist Früh*

$$
\begin{aligned}
& 165_{\text {op.cit. }} \text { SWV., s. } 310 . \\
& 166_{\text {ibid. S. } 311 .} \\
& 167_{\text {op.cit. SWIII., S. } 544 \text {. }}
\end{aligned}
$$


ling und hinter wuchernden Blüten sieht man ein dämmerndes Meer. Asrael bringt den Tod in dieses Frühlingsbild. Das Jugendstilhafte an Bild und Gedicht ist erstens die Motivauswahl: Frühling, Meer, Engel und Tod, und zweitens das Verflochtensein aller Erscheinungen durch die Wortwahl - worin eine deutliche 'Wellenlinie' festzustellen ist. Wie oft im Jugendstil wird hier keine irdische Wirklichkeit dargestellt, sondern man wird versetzt in einen überirdischen ewigen Bereich - hier den Bereich des Todes: der Todesengel, die flammenden Mohnblüten, das dämmernde Meer und die Todesmythen sind Charakteristika dieser Seelenlandschaft. Eine Seelenlandschaft auch deswegen, weil der körperliche Mensch aus dem Bild ausgeschlossen ist: der Betroffene ("Dich") ist der Zuschauer, der in diese Todesstimmung aufgenommen wird. Der Tod des Menschen wird nur als Teil eines organischen Prozesses erlebt: Mensch wird gleich Blüte gesetzt, indem Asrael einen Schatten darstellt "eine Blütengefahr" in dem lebendigen "f主ammenden" Frühling. Die vielen Verben, die fließende Bewegung evozieren, verbinden alle diese Erscheinungen miteinander; in allen Bereichen ist der organische Prozeß der Verwandlung vorhanden, der im bildnerischen Jugendstil mit der Wellenlinie ausgedrückt wird. Blüten flammen, Schatten fließt, das Meer dämmert, und das Auge trinkt. Der von den Flügeln fließende Schatten erinnert an das Meer im Hintergrund. Und umgekehrt ist die Dämmerung die Vorahnung des Dunkels, das der Schatten des Todes bringt. 
Asraels Auge, das die Seele trinkt, verbindet das Meer noch einmal mit dem Tod. Doch der Augenblick des Todes steht im Gegensatz. zu der lebendigen, wellenähnlichen Bewegung im restlichen Bild. Der entschlossene, unbewegliche Blick Asraels starrt den Zuschauer an und legt ihm einen "würgenden Reif um die Kehle".

Noch weitere Übereinstimmungen zwischen Gedichten Rilkes, die in der Prager Zeit entstanden sind, und Bildern und Gedichten Hermoine von Preuschens sind auffindbar. Vor allem die häufigen Blumenmotive, die so charakteristisch für den Jugendstil sind. In Rilkes Analyse ihres Werks heißt es:

Auf den Bildern und in den Büchern spielen die Blumen eine große Rolle. Aber in beiden Fällen sind die Blumen nicht dazu da, ein farbenfrohes, sinniges Milieu zu bilden. Sie stehen inmer im Mittelpunkte; Hermione von Preuschen hat ihnen Liebe verliehen. Der große Schmerz ihrer Dichterseele fand keinen Raum in der dunkeln Brust, und er brach wie ein rauschender Bergstrom in das Weltall hinaus und erfülte die Herzen der tausend und abertausend Blüten. Und wenn nun die Dichterin klagt, so stimmen all diese tausend Blumen, deren jede ein Stück ihrer Seele trägt, ein großes Mittönen an....und ein Weinen geht durch die Welt.....Der Künstlerin Schmerz ist groß genug, alle diese Blumen zu beseelen. Sie hat gekämpft und gelitten. Ihr kams: 'erst Traum, dann Schicksal'.168

Wichtig für Rilke ist also die Erkenntnis, daß H.v. Preuschen den Blumen eine symbolische Bedeutung gegeben hat, und nicht eine rein ornamentale; ein Beispiel sei auch Asrael, wo die Blumen wirklich im Mittelpunkt stehen und den Tod darstellen. Über alltägliche Anschauungen hinaus werden sie der Dichterin zum traumhaften Erlebnis und zu schicksals- 
hafter Bedeutung. "Ein farbenleuchtend wunderholdes Gift" ist ihr nach Rilke das Leben und sie sehnt sich nach den "Purpurblüten" vom "Lebensgiftbaum". 169 Dieser Aussage nach ist die Jugendstil-Deutung des Todes als Verklärung dem Gedicht "Asrael" hinzuzufügen. Die Mohnblumen im Bild sind gerade das "farbenleuchtend wunderholde Gift" vom "Lebensgiftbaum", wonach sie sich sehnt. Damit schließt sich der symbolische Kreis, der mit Hilfe 'natürlicher' Bilder die Allgegenwart der Natur gerade für eine "großartige Künstlerindividualität" einschließt: Der uns vor Augen liegende Lebensprozeß wird nicht nur allegorisch-beispielhaft dargestellt, sondern Rilke als Empfänger der dichterischen Botschaft sieht die Autorin (wie sich selbst, was aus den nachfolgenden Gedichtzitaten erkenntich werden wird) in diese Beschreibung schicksalshaft hineingerissen.

Eine unendliche Sehnsucht glüht in ihrer Brust. In der Liebe hofft sie Erfüllung. Und die Liebe kommt. Kindischen Jubels voll, geht sie ihr entgegen. Und die ganze Größe des Weibes und der Künstlerin opfert sie ihr. Aber ihr ziel liegt noch jenseits der Liebe und in einer Stunde des Zweifels klagt sie dem Geliebten: "nicht einmal Deine Liebe erlöst mich." Sie ringt nach dieser Erlösung in der Kunst -denn Poesie
ist die' Seele ihres Seins'.170

Diese Gedanken tauchen ebenso in Traumgekrönt auf, die erste Gedichtsammlung Rilkes, die deutlich Jugendstil-Merkmale aufweist. Die vorangehenden Gedichtbände - Leben und Lieder und Larenopfer - enthalten vor allem naturalistische Elendsge-

$$
\begin{aligned}
& 169 \text { ibid. S. } 310 \\
& 170_{\text {ibid. }}
\end{aligned}
$$


dichte und beschreibende Gedichte über die Straßen, Häuser, Kirchen und Brücken des alten Prag, Iyrische Stadtansichten, impressionistische Stimmungsbilder und Huldigungen an die böhmische Heimat und ihre Menschen. Gestalten aus der Sage. und der Geschichte werden besungen, selbst die völkischen Spannungen, die auch im Prag der neunziger Jahre vorhanden waren, bleiben nicht verborgen. In Traumgekrönt dagegen ist die objektive Betrachtung der Außenwelt nicht mehr gegeben, stattdessen eine gefühlvolle Beschreibung einer innerlichen Traumwelt mit jugendstilhaften Merkmalen.

Rilke und H.v. Preuschen versetzen den Künstler in einen heiligen vom Volk getrennten Bereich. Rilke:

$$
\begin{aligned}
& \text { Wenn das Volk, das drohnenträge, } \\
& \text { trabt den altvertrauten Trott, } \\
& \text { Möcht ich weiße Wandelwege } \\
& \text { wallen durch das Duftgehege } \\
& \text { ernst und einsam wie ein Gott. } 171
\end{aligned}
$$

H.v. Preuschen:

$$
\begin{aligned}
& \text {...dem Puppenspiel der zahmen Menschheit, } \\
& \text { deren Herz ein Teich, ein trüber Teich mit } \\
& \text { flachen, engen Ufern (ist). } 172
\end{aligned}
$$

Jugendstilhaft ist Rilkes göttlicher wandelweg durch das "Duftgehege": Der Künstler ist sozusagen Gott. Im Preuschen' Rückzug vom Puppenspiel der Menschheit, deren Herz ein trüber Teich mit engen flachen Ufern ist, kann ein ähnliches Bild vom elitären Schöpfer-Mienschen erkannt werden. Man wird erinnert an das Motiv des Teiches im Jugendstil - ein Symbol

$$
\begin{aligned}
& 171_{\text {op.cit. SW I., s. }} 79 . \\
& 172_{\text {op.cit. SW V., s. } 311 .}
\end{aligned}
$$


der Seele, dessen Klarheit und Reinheit das All widerspiegelt und in dessen Tiefen mystische Geheirnnisse wuchern. Bei der 'nicht-verklärten' dagegen ist das Wasser trüb und seicht. Im ersten Teil der Sammlung Traumgekrönt - "Träumen"versucht der Dichter etwas von der 'naturalistischen' Empfindung des menschlichen Leidens und einer Welt voll Schmerz durch 'Träumen' zu überwinden, aber vergebens erhofft er im zweiten Teil - "Lieben" - Erfüllung und Glück in der Liebe. Verklärung durch die Liebe ist hier noch eine Erfahrung, die nicht andauern kann. Damit ergibt sich bereits eine erste inhaltliche Übereinstimmung mit der oben angeführten Stelle 173 Tatsächlich übernimmt Rilke neben dem Thema Liebe fast alle Themenbereiche, die sich um diesen Begriff ranken: zunächst der Traum eines jungen Lebens, dann die Sehnsucht nach Erfüllung, das Erlebnis einer Leidenschaft, endlich Erkenntnis des vergänglichen Glücks, das nur noch in Erinnerung bestehen bleibt. Am wichtigsten an diesem Vergleich ist, daß dieser Vorgang sowohl bei H.V. Preuschen als bei Rilke in den organischen Lebensprozeß eingebettet ist; und zwar sogar dreifach: nämlich in den jahreszeitlichen Ablauf, in den Tagesablauf und in das pflanzliche Leben an sich. Natürlich lassen sich auch diese drei Bereiche praktisch nicht trennen, maßgebend für die dichterische Darstellung ist das Pflanzliche, insbesondere alles, was mit Blumen zusammenhängt. Die Liebe beginnt an einem Maitag: 
Das war der Tag der weißen Chrysanthemen,-174 mir bangte fast vor seiner schweren Pracht...

Schon in der Frage, wie die Liebe gekommen sei, wird auch die Seele mit einer Blüte verglichen:

Ein Glück löste leuchtend aus Himmeln sich los und hing mit gefalteten Schwingen groß an meiner biuhenden Seele....175

Und die Liebe bringt die Sehnsucht nach höchstem GIück mit sich:

Einen Maitag mit dir beisammen sein, und selbander verloren ziehn durch die Blüten duftqualmende Flammenreihn zu der Laube von weißem Jasmin.

Und von dorten hinaus in den Maiblust schaun, jeder Wunsch in der Seele so still. Und ein Glück sich mitten in Mailust baun,
ein großes, - das ists, was ich will...176

Am Ende des Tages findet er Erfüllung, die Leidenschaft wird in jugendstilhafter Manier vergeistigt durch das Motiv der weißen Lilie, die Symbol für die Reinheit ist.

Schon starb der Tag. Der Wald war zauberhaft, und uñter Farren-blutéten Zyklamen, die hohen Tannen glühten, Schaft bei schaft, es war ein Wind, - und schwere Düfte kamen. Du warst von unserm weiten weg erschlafft, ich sagte leise deinen süßen Namen: Da bohrte sich mit wonnewilder Kraft aus deines Herzens weißem Liliensamen die Feuerlilie der Leidenschaft.177

174 op.cit. SW I., S. 88 .

$175_{\text {ibid. }}$

$176_{\text {ibid. }}$ 177 ibid. S. 93. 
Doch der blühende Frühling kann nicht bleiben, und mit Anbruch des Herbstes stirbt mit den Blumen die Liebe:

Wir gingen unter herbstlich bunten Buchen, Vom Abschiedsweh die Augen beide rot...

'Mein Liebling, komm, wir wollen Blumen suchen'. Ich sagte bang: 'Die sind schon tot.'178

Besonders auffallend in Rilkes Gedichtzyklus ist zunächst die Wortwahl. Ausgehend von einer fülle von Erwähnungen von Blumen ziehen sich verwandte wörter durch den ganzen Text: alle Sinneseindrücke, die er von den Blumen empfängt, gibt er weiter an Menschen und Gegenstände, was umgekehrt ebenso vorkommt. Das Paar sitzt im "Weinblattdämmer" und ist fast nicht von seiner Umgebung zu unterscheiden, und es malt ein "violetter Schatten...ins weiße Kleid ihr Kleckse". I79 Oder es heißt: "Fern drängt sich wie ein Bubenschar: Die Löwenzähne mit blondem Haar..."180 Oder "Die Sonne (ist) in heißen Fieberträumen gestorben" - oder "Die Nacht im Silberfunkenkleid" und "deines Herzens weißer Liliensamen".

Bei H.v. Preuschen bemerkt Rilke: Die Sprache ist ihr zu arm. Sagt sie: 'Der große Schmerz', so scheint ihr das klein und sie verbessert sich 'Der große, meeresgroße Schmerz'. Und die Liebe ist ihr 'die große, wundergroße Liebe'. Die

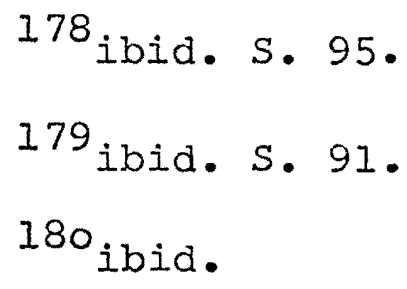


Blumen duften 'schwer, süßeschwer...'; der Frühlingswind weht ihr 'wellenkühl' entgegen, und an den Büschen grüßen sie 'winzig kleine Knospen, deren jede einen Lenz verbirgt'. ${ }^{181}$ Fast wörtlich könnte man diese Bemerkung auf Rilkes Texte übertragen, denn auch bei ihm muß eine übertriebene Sucht nach sinnlichen Ausdrücken. konstatiert werden; z.B. schreibt er nicht bloß "Blütenreihen", sondern "Blüten duftqualmende Flammenreihn"; "...ein Weltmeer voller Lichte", eine "Riesenwunderblume". Alle diese ornamentalen Wortbildungen bedeuten eine typische Vergegenständlichung und Stilisierung; oft wird das Attribut gleichsam in den Gegenstand hineingenommen gerade "Riesenwunderblume", "Abendrotpforte", "Blaunacht" und "Wunderblau". Viele der Gedichte Rilkes aus dieser Periode scheinen diese Blumen H.V. Preuschens darstellen zu wollen - auch "Asrael."

Weitere Jugendstil-Motive. Andere Jugendstil-Motive, die schon in der Prager Zeit auftauchen, sind: Sehnsucht als Ausdruck der mystischen Versenkung, das künstliche Paradies, die Insel, das Teich-Motiv, das Wind-Welle-Motiv, JugendstilLiebe und das Jugendstil-Frauenbild.

Im folgenden Gedicht ist das Sehnsucht-Motiv insofern ein Ausdruck der mystischen Versenkung, als sie gleichgesetzt wird mit der Natur bzw. dem Frühling. Sehnsucht, die "in Sturmestosen" erstarb, wird wiedergeboren - genauso wie die Pflanzenwelt, die im. Winter im "Sturmestosen" stirbt und im

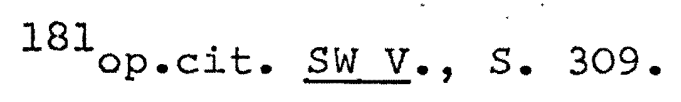


Frühling wiederkehrt. Die Sehnsucht hat "verklärte" Augen wieder einmal ein Beispiel für die Möglichkeit der Verklärung durch die Sehnsucht, einer Verklärung, die aus der Einheit der menschlichen Seele mit der Natur entsteht und die. immer wieder neugeboren wird.

Maudit printemps, reviendras-tu toujours 182

Es liegt so wie ein Duft von schwülen Rosen ob der Geschichte. Auf des Frühlings Spur da geht die Sehnsucht; ihre tränenlosen verklärten Augen fragen immer nur: maudit printemps, reviendras-tu toujours

Und wenn die Sehnsucht einst im Sturmestosen erstarb und an den Brüsten der Natur entschlief...Dann prangt ihr Grab von Sammetmoosen und von dem kindisch-schönen Schmuck der Flur! Maudit printemps, reviendras-tu toujours? 183

In einem Gedicht aus den Briefen an Láska van Oestéren kommt das Motiv des künstlichen Paradieses vor: es ist hier die Rede von dem Schloß der Baronesse, auf das Rilke eingeladen worden war:

Ihr Schloß ist eine blütenvolle Insel der nie verständnislos Vernichtung naht.... Selbst das Brevier schmuickt reicher Randzjerat, Herwegen schuf ihn mit dem Meisterpinsel. 184

Eine Insel der Zuflucht also, für den Künstler und von dem Künstler gemacht. Rilke sieht sich selber in der Rolle des Schloßpoeten:

${ }^{182}$ Refrain eines Liedes von Beranger, hier als Titel einer Erzählung von dem Briefempfänger - Laska van Oestéren; op.cit. SW III., S. 820

183 ibid. S. 525. ${ }^{184}$ ibid. S. 526. 
Und wie ein Tasso geh ich dort und träume was in Veleslavin mir doppelt frommt, weil, mich zu tadeln, kein Antonio kommt, wenn ich von lauter Jubel überschäume.

Wenn ich auch kein Jerusalem befreie....185 ich singe mir ja doch die Seele frei.

Abgeschlossen von den Problemen des Alltags und der politir schen Wirklichkeit kann der Künstler sich seinen eigenen Träumen und Sehnsüchten widmen:

....So hat man dem Dichter Pardon gegeben und hat ihn befreit von der festlichen Norm. Schlicht kam er im Kleide des Alltags eben. Doch eigentlich sollten die Musen weben dem Schloßpoeten - die Uniform. Da müßt ein Gewande den Musen gelingen, das dem festlichen Zwecke diente - genau.... Und da ich modern bin in Sagen und Singen, sollt mein Sang, seit ich Schloßpoet bin, nur als 'Symphonien in Rot und Blau'.186 erklingen

Das ist wieder ein Gedicht mit dem Anspruch, musikalische Wirkung $z u$ erzeugen und damit die Künste zu mischen.

Das Motiv der Liebe als Weg ins Paradies und als Verklärung ist in Traumgekrönt stimmungsgebend:

...und jene Flamme, die uns $j$ äh durchloht, sie leckte an den neidischen Gewanden...

Der Wald war stille, und der Tag war tot. Uns aber war der Heiland auferstanden, und mit dem Tage starben Neid und Not. Der Mond kam groß an unsern Hügeln landen und leise stieg das Glück aus weißem Boot. 187

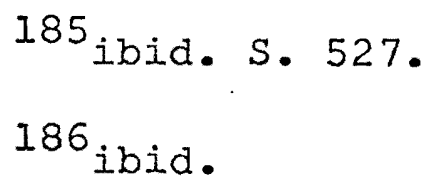


Ein Paradies entstände, in dem der Heiland aufersteht und "Neid und Not" verschwinden. Hintergrund für diese Szene der Vollendung der Liebe ist eine Wasserlandschaft. Die symbolische Bootsfahrt als Mittel, das Ziel der Sehnsucht zu erreichen, wird hier nur perspektivisch umgedreht: das Boot bringt das Glück und die Erfüllung des Traumes. Dieses Motiv wird in dem Gedichtszyklus weiter ausgebaut:

Nach einem Glück ist meine Seele lüstern, nach einem kurzen, dummen Wunderwahn... Im Quellenquirlen und im Föhrenflüstern da hör ichs nahn... Und wenn von Hügeln, die sich purpurn säumen, in bleiche Bläue schwimmt der Silberkahn,dann unter schattenschweren Blütenbäumen seh ich es nahn.188

Die Wellenlinie ist schon während der Prager Zeit ein weiteres beliebtes Motiv. Im folgenden Vers bläst Pan, Symbol der Allnatur, den Wind wie eine Welle:

Dort hockt hinterm Schierling der Riesenpan, der strotzige, lose Geselle. Jetzt sieht er verstohlen die Liese nahn und lacht und wälzt durch den Wiesenplan des Windes wallende Welle...189

Die windeswelle wird auch zur akustisch vernehmbaren welle:

Keine Grille mehr hörst du.... fern im Dorf nach Hundebellen. Stille......Weiche Windeswellen wehen mir das "Ave" zu....190

Auch das licht wird als wellenmäßige Wasserbewegung bildhaft dargestellt:

$$
\begin{aligned}
& 188_{\text {ibid. S. } 95 .} \\
& 189_{\text {ibid. S. } 91} \\
& 190_{\text {op.cit. SW III., S. } 432 .}
\end{aligned}
$$


Es ist ein weltmeer voller Lichte, das der Geliebten Aug umschließt, wenn von der Flut der Traumgesichte die keusche Seele überfließt.191

Die Wasserwelle ist Symbol für das menschliche Schicksal, wie überhaupt die ganze Meereswelt Sinnbild für das menschliche Dasein ist:

Schaltendes Schicksal ist Wellengewiege, -ewiges Ebben, -ewiges Fluten. Siegende Sehnsucht, sehnende Siege wecken und wandeln die toten Minuten. Aufwärts unf abwärts unter der Sonne schwanken wir wie auf der Woge die Kähne. Bald heißt die Muschel Schmerz und bald Wonne, die sie geboren, die perlende Träne. 192

Auch Sehnsucht wird durch die Welle zur Metapher:

Sehnsucht - auch Sehnsucht ist Wellengewiege, wenn sie das Schweigen der Seelen durchbrach; lächelnd in leuchtender Siegerquadrige fährt ihren Spuren der Glückiiche nach. 193

Die Meereswelle ist wie die Geliebte:

Ins Meer! Die Welle naht, die scheue, und zieht mich leise vom Gerüst, und küßt mich zart, so wie die neue Geliebte dich, die bange, küßt.

Wie weich sie mich umfängt! Ich spüre den frischen Odem glückbewußt. Sie legt mir ihre Perlenschnüre mit Schmeicheln um die bleiche Brust. ${ }^{194}$

Umgekehrt ist die Eiebe wie eine Welle:

$$
\begin{aligned}
& 191_{\text {op.cit. }} \text { SWI., s. } 92 . \\
& 192_{\text {op.cit. }} \text { SWIII., S. } 535 f \text {. } \\
& 193_{\text {ibid. S. } 540} \\
& 194_{\text {op.cit. SWI., s. } 432}
\end{aligned}
$$


Liebe auch läßt sich den Wellen vergleichen, Sehnsucht wälzt ihre Wogen zum Ziele, flüchtendes Nahen, nahendes Weichen, heiligster Ernst und doch schönstes der Spiele.

Dieses Erkämpfen mit Raunen und Rosen schon mit der $V_{e}$ nus den Wellen entstiegs, süß vom verstohlenen Augenkosen bis zu dem Kusse, dem Siegel des Siegs. 195

Vielleicht dachte Rilke hier an das Gemälde Botticellis "Die Geburt der Venus", in der die nackte, aus dem Meer gekommene himmlische Venus als Verkörperung der göttlichen Liebe auf einer $M_{\text {uschel }}$ im Meer steht und ans Land getrieben wird durch zwei Windgötter, als Engel dargestellt, deren Atem den Frühling bringt und Blumen streut. 196

Der Kuß, "Siegel des Siegs", wird in dieses Wellenbild eingesetzt: zwei einzelne Personen "fließen" zusammen und erfahren eine durch die Musik erzeugte Einheit miteinander.

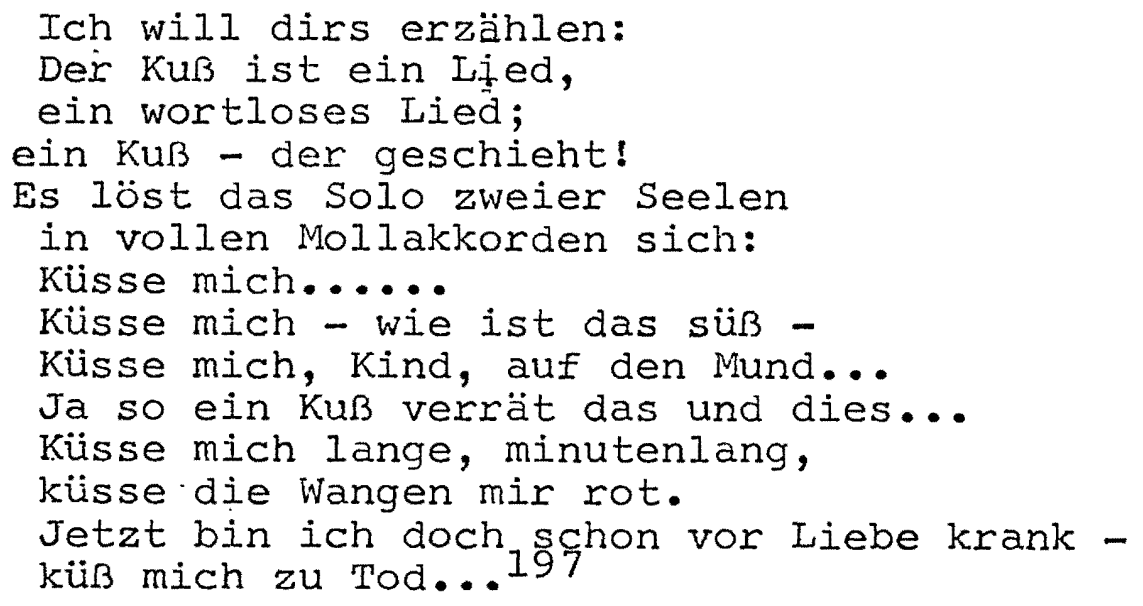


Die Einheit der zwei wird besiegelt durch ein Sich-Aufgeben an das All im Medium des Geliebten. Diese Kombination LiebeTod kommt häufig im literarischen Jugendstil vor.

Bemerkenswert bei der Jugendstil-Haltung Rilkes ist seineSelbstanzeige für Traumgekrönt im Oktober 1896, kurz nach der übersiedlung nach München:

Wieder ein paar Lieder. - Geständnisse, Träume. Ich ewiger Schwärmer! Ich sitz' in meiner stillen Dämmerstube. Und meine Sehnsucht sitzt bei mir. Sie hat abendrotes Haar und seetiefe Augen. Und mit ihren schmalen, durchscheinenden weißen Händen reicht sie mir Orakelblumen. Und ich zerpflücke, halb unbewußt, die sternigen Kelche. Blättchen zu Blättchen sinkt. Und ein frischer wind greift zum Fenster herein und trägt jedes stückchen Frühling über die Dächer.198

Fast alle Jugendstil-Motive kommen hier vor: das Träumen in der Dämmerung - die mystische Versenkung des Dichters, wodurch es ihm möglich wird, "Orakelblumen" zu empfangen, die wiederum den Künstler quasi zum Priester erheben, der durch seine "Lieder" die letzten Wahrheiten des Daseins (Die Blumen mit dem Kelch) empfängt und weitergibt. Der wind als Träger. und Verbreiter der Lieder ist auch jugendstilhaft und übrigens auch die Frau mit großen, starrenden Augen und wuchernden Haaren, die von den Präraphaeliten übernommen wurde als Symbol der schönen seele.

198 op.cit. SW VI., S. 1208. 


\section{DIE MÜNCHENER ZEIT}

Rilkes erster Münchener Aufenthalt dauerte vom September 1896 bis Anfang 1897. Ex stand in losem Kontakt mit der Universität, wo er ein wenig Kunstgeschichte studierte, vor allem die italienische; vorwiegend aber beschäftigte er sich mit seiner eigenen dichterischen Arbeit und mit dem Kunstleben dieser stadt. Er war mit Wilhelm von Scholz und Jakob Wassermann befreundet - beide teilten mit inm den Gedanken an eine neue befreiende Epoche der Kunst. Auch entscheidend für seine Entwicklung während dieser Zeit waren die Entdeckung Jens Peter Jacobsens und das erste vollgültige Liebeserlebnis mit Lou Andreas-Salomé. Mitte Mai 1897 lernte er sie kennen den Sommer verbrachte er mit ihr in Wolfratshausen; im Oktober ging er mit inr nach Berlin, wo er bis 1900 mit Unterbrechungen, unter anderem der Italienreise, bleibt.

\section{München als Zentrum der Moderne}

In München befand Rilke sich im Zentrum der Moderne des deutschen Jugendstils und somit befreit von dem provinziellen Milieu Prags. 199 Das Jahr 1896 war auch ein großes Jahr für München; es war der eigentliche Beginn des deutschen Jugendstils und das erste Erscheinungsjahr der Münchener Jugendstil-Zeitschriften "Jugend" und "Simplicissimus". In

199 Die Flucht aus dieser beklemmenden Atmosphäre hat er in der Novelle Ewald Tragy geschildert. 
München vereinigten sich viele junge Menschen, die oft von weither kamen, um hier zu studieren oder $\mathrm{zu}$ schreiben und das große Erlebnis der Freiheit zu genießen. Sie lehnten sich gemeinsam gegen die Kunstdiktatur auf und bekannten sich zu den neuen Formen des Jugendstils. Peter Behrens, Otto Eckmann, August Endell, Hermann Obrist, Bërnhard Pankok, Richard Riemerschmid und Hans Schmithals waren dabei, auch Hölzel, Jawlensky, Gulbransson, Kandinsky, Klee, Marc und Kubin standen anfänglich mit in der großen Münchener stilbewegung der Jahrhundertwende. 200

Wir wir gesehen haben ${ }^{201}$ war es höchstwahrscheinlich Rilkes Absicht nach München zu gehen, um gerade an dieser Bewegung teilzunehmen, was dann auch geschah. Seine Beschäftigung mit dem Jugendstil während seiner Münchener Zeit wird in den damals geschriebenen Gedichten stark reflektiert. Besonders jugendstilhaft sind die Sammlungen Advent und Mir zu Feier; diese wurde allerdings erst nach dem Aufenthalt in Italien fortgesetzt und beendet. Die stärkste Beeinflussung von Rilkes Werken durch den Jugendstil ist wohl in dieser Periode eingetreten, eben der Zeit in München und Italien und danach in Berlin - 1896 bis 1899. Rilkes spätere negative Einschätzung der Werke aus dieser zeit ist erkennbar aus der Tatsache, daß die meisten Werke zwischen 1904 und 1909 überarbeitet oder gänzlich umgeschrieben worden sind (Mir zu Fei-

$$
\begin{aligned}
& 200 \text { op.cit. Seling, S. } 14 \mathrm{f} \text {. } \\
& { }^{201} \text { Vergleiche S. } 88-94 \text { dieser Arbeit. }
\end{aligned}
$$


er, Die weiße Fürstin, Der Cornet, Das Buch vom mönchischem Leben), - "Ein Bemtihen, das Rilke ausschließlich den Arbeiten dieser ganz im Zeichen des Jugendstils stehenden Übergangsjahre nachträglich zugewandt hat". 202 Bemerkenswert ist, daß - abgesehen von diesen Umarbeitungen bestimmter Jugendwerke - Rilke so gut wie niemals an dem Text der einmal veröffentlichten Bücher noch nachträglich etwas geändert hat. 203 Das soll nicht den Eindruck erwecken, als habe sich Rilke.. später mehr oder weniger von der Thematik und Motivik dieser Werke durch Neufassungen distanziert. Es würde den Rahmen dieser Arbeit sprengen, einen genauen Vergleich der Erstausgaben mit den geänderten Texten anzustellen; doch schon nach einer flüchtigen Einsicht kann gesagt werden, daß Rilkes Varianten höchstens stilistischer Art waren, indem er allzu stilisierte Wortbildungen eliminierte.

Jugendstil-Motive in Rilkes Münchener Lyrik und vor der ItaIien-Reise

Motive aus der Pflanzenwelt. Das Baum-Motiv, das der Pflanzenwelt entstammt, findet sich in einem Gedicht aus der Anthologie Dir zu Feier, in dem die Seele mit einem Baum gleichgesetzt wird:

Wir wissen nicht vom Sinn der Tage. Und unsre kühlen Hände sind

zwei Zweigen ähnlich, die sich zage

$$
\begin{aligned}
& 202_{\text {op.cit. SW I. }}, \mathrm{S} \cdot 785 \text {. } \\
& 203_{\text {ibid. S. } 788 .}
\end{aligned}
$$


entgegenwachsen durch den wind.

Im Alltag tasten unsre Träume

uns mühsam nach und sind in Mühn,

wenn wir schon, schön wie junge Bäume,

dem Sommerlos entgegenblühn. 204

Das unbewußt Natürliche im Menschen weiß mehr als die Träume, die an der Oberfläche des Alltags bleiben - genauso wie die Natur, die von unten den "zagen Zweigen" neues Blühen im Frühling bringt, ohne daß sie es schon wissen. Das Schicksalhafte an der Begegnung zweier Menschen wird als tieferer Sinn der Natur dargestellt.

Das Thema des tief schlummernden Unterbewußtseins, das den Sinn des Seins erfährt, ist auch in folgendem Gedicht angeschlagen:

Ich will nicht langen nach dem lichten Leben

und keinen frágen nach dem fremden Tage:

Ich fühle, daß ich weiße Blüten trage,

die in der Kühle ihre Kelche heben.

Es drängen viele aus den Frühlingserden,

in denen ihre Wurzeln Tiefen trinken,

um, krank und dürstend, in die Knie zu sinken
vor Sommern, die sie niemals segnen werden. 205

Das dichterische Ich setzt sich ab von anderen, die nach dem "lichten" Leben streben, nach dem Sichtbaren, das an der Oberfläche bleibt. Obwohl ihre wurzeln vielleicht auch in die Tiefe tauchen, wolien jene zu schnell zur Blüte - zu schnell sichtbar sein in dem "lichten" Leben. Ihr Schicksal ist es auch, zu früh zu verwelken, ehe sie im Sommer ihre Vollendung erleben. Rilkes spätere Einschätzung der italienischen Re-

$$
\begin{aligned}
& 204_{\text {opcit. SW III. }} \text { S. } 184 . \\
& 205_{\text {ibid. S. } 206 .}
\end{aligned}
$$


naissance wird hieran anknüpfen. 206

Dem pflanzlichen Umfeld entnommen ist auch Rilkes bevorzugter Frauentyp, wie er in einer für die "Jugend" geschriebenen Novelle "Heiliger Frühling" aus dem Jahre 1897 präsentiert wird. "Heiliger Frühling" - "Ver Sacrum" ist das Motto des Jugendstils schlechthin. Hier schenkt ein blasses, krankes Mädchen vor ihrem Tod dem in sie verliebten Jungen durch ihr Wesen einen "heiligen Frühling", "der einem soviel Licht und Glanz in die Brust senkt, $d a ß$ es ausreicht, alle ferneren Tage damit zu vergolden..."207 Das Mädchen ist selbst der heilige Frühling - sie wird als pflanzliches Wesen dargestellt: sie erscheint "unter einem blütenschweren Kirschbaum mitten in dem Blühen", hatte "tiefblaue Augen, die mit ruhiger, schlürfender Seligkeit ins Weite träumten," ihre Lippen waren "zartrot wie kaum erschlossene Blüten", bei ihrem Kuß trinkt er "wie ein Segen,....den heißen Duft (des) keuschen Mundes"; die weißen Hände sind "wie Lilien", die "nach etwas Unsichtbarem zu greifen schienen, (sie) hoben sich hell und durchscheinend von der dunkelgrünen Decke $\mathrm{ab} . . . "$

Neben solchen Stellen, deren gesamte Thematik aus dem Pflanzenbereich hergeleitet ist, gibt es natürlich unzählige Gedichte, in denen vegetative Metaphern verwendet wurden, Metaphern wie z.B. "meine frühlingverliehnen Lieder", "ich

$$
\begin{aligned}
& { }^{206} \text { Siehe S.15If.dieser Arbeit. } \\
& 207 \text { op.cit. SWIV., S. } 496 \text {. }
\end{aligned}
$$


blühte wie ein Lindenast", "ich geh wie im tiefen Garten und weiß: alle Blumen warten demselben Wunder zu", "wie eine Ranke überm Gartengange, will meine Sehnsucht ihre Schwingen schwenken," usw.

Das Motiv der Mystischen Versenkung. Das panthe istische Weltgefühl als eine Form der mystischen Versenkung wird in folgender Weise zum Ausdruck gebracht:

Kann mir einer sagen, wohin ich mit meinem Leben reiche?

$\mathrm{Ob}$ ich nicht auch noch. im Sturme streiche und als Welle wohne im Teiche, und $o b$ ich nicht selbst noch die blasse, bleiche frühlingirierende Birke bin?208

Oder:

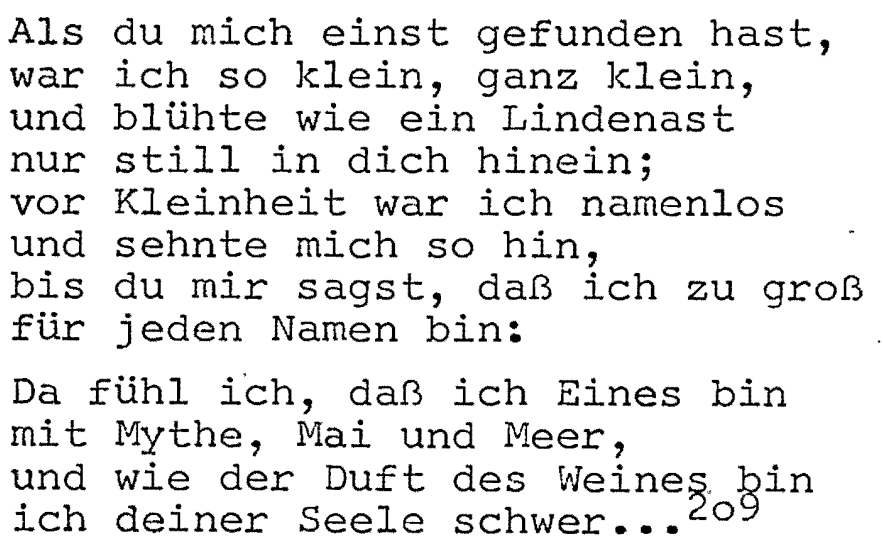

Der Engel als Teil der eigenen Geistwerdung und keineswegs als überirdisches Wesen wird in dem Abschnitt "Engellieder" der Sammlung Mir zu Feier eingeführt: der Engel ist Träger der eigenen Sehnsüchte und Träume, aber auch des eigenen Leidens:

$$
\begin{aligned}
& 208 \text { op.cit. SW III., S. } 258 \text {. } \\
& { }^{209} \text { ibid. S. } 230 f .
\end{aligned}
$$


Ich ließ meinen Engel lange nicht los,

und er verarmte mir in den Armen

und wurde klein, und ich wurde groß:

Und auf einmal war ich das Erbarmen,

und er eine zitternde Bitte bloß.

Da hab ich ihm seine Himmel gegeben, und er ließ mir die leisesten Träume zum Pfand; er lernte das Schweben, ich lernte das Leben, und wir haben langsam einander erkannt...210

Der Engel ist auch Bote des̈ schönen Lebens:

So sah der Engel aus, den ich zu Gast geglaubt, hob er sein helles Haupt über mein Heimathaus:

Sein Angesicht war wie ein Land zu sehn, in Freude halb und halb in Finsternissen, bald ausgesöhnt in einem einzigen Flehn, und wieder dann von einem Weh zemissen, und doch verschönt von diesem weisern Wissen:

- Und morgen schon wird dir der Mai geschehn.; 211

Versenkung und Verklärung durch 'Träumen in der Dämmerung' ist eines der häufigsten Motive:
Das sind die Stunden, da ich mich finde. Dunkel wellen die Wiesen im Winde, allen Birken schimmert die Rinde, und der Abend kommt über sie.
Und ich wachse in seinem Schweigen, möchte blühen mit vielen Zweigen, nur um mit allen mich einzureigen in die einige Harmonie...212

Neben der hier offenliegenden Häufung und Vermischung von Motiv-Bereichen (das Pflanzliche und auch das Wellen-Motiv als Windbewegung) wird das pantheistische Gefühl hier neu durch den Tanz in den letzten Zeilen vergegenständicht. Der Tanz, das sei an dieser Stelle eingefügt, ist symbol für

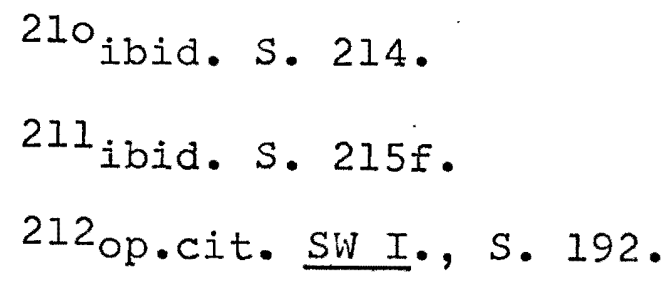


die freie Regung des ursprünglichen und unmittelbaren Lebens, das beim Kind natürlicherweise besonders verkörpert ist. Der Tanz ist Bestandteil eines glücklichen Kinderdaseins:
Wenn wir blonde Kinder haben, schenke ich zu Traum und Tanz eine Krone jedem Knaben, jedem Mädchen einen Kranz. 213

Isadora Duncan schreibt um" die Jahrhundertwende:

Der wahre Tanz sollte nun nichts anderes sein, als eine natürliche Gravitation des Willens im Individuum, der nicht mehr und nichts weniger, als eine Übertragung der Gravitation des Weltalls in das menschliche Individuum ist. 214

Bei Rilke ist der Tanz Ausdruck dieses harmonischen Einklangs mit dem All.

Auch die folgenden Gedichte enthalten die Motive Dämmerung und Traum als Grundstimmungen:

Ich bin zuhause zwischen Tag und Traum. Dort wo die Kinder in die stille stammeln, dort wo die Alten sich im Abend sammeln, und heiße Herde hellen ihren Raum.

Ich bin zuhause zwischen Tag und Traum. Dort wo die Aveglocken grad verklangen und müde Mädchen mit den warmen wangen sich sachte neigen übern Brunnensaum. Und eine Linde ist mein Lieblingsbaum, und alle Sommer, welche in ihr schweigen, erwachen wieder in den greisen Zweigen und leben wieder zwischen Tag und Traum. 215

Oder:

In veratmendes Entzücken klingt des Tages Chorlied aus;

$$
\begin{aligned}
& 213_{\text {op.cit. SW III., S. } 591 .} \\
& 214 \text { op.cit. Rásch, s. } 64 . \\
& 215_{\text {op.cit. SW III., S. } 209 .}
\end{aligned}
$$


meine Sehnsucht baut sich Brücken in die blaue Nacht hinaus.

Und sie lenkt auf monderhellter Spur wie eine Königin ihren goldbezäumten Zelter zu dem Tor der Träume hin... 216

Oder:

Ich möchte einmal wieder lehnen bei dir, im purpurnen Salon. In deines Saitenspieles Sehnen versiegt der letzte Liederton.

Ein rotes Dämmern löst die Wände Aus deines Kleides Seidensaum blühn deine weißen Mädchenhände wie Lilien im Mainachttraum.

Und deine Augen sind wie Sterne, die überm Waldsee blinken blank, drin eine blaue, märchenferne
selige Wunderzeit versank. 217

Und:

Meine Stube, ausgeschlagen

mit lichtsilbernem Mondenschein, trieb von den verlassenen Tagen mit erwachendem Weiterwagen wie ein Kahn in die Nacht hinein. Und schon fern an des Tages scharfen Gestaden standen die Stunden mit den Harfen, und ich sah, wie sie aus ihrem Spielen, ohne zu zielen, ihre teuersten Töne warfen, daß sie auf meiner Fährte Dielen

Die Bootsfahrt wird hier als Metapher für die Erforschung der eigenen Sehnsüchte und Träume verwendet. Isoliert von der Alltagswelt ist der Dichter allein in seiner "Stube";

$$
\begin{aligned}
& 216_{\text {ibid. S. }} 441 . \\
& 217_{\text {ibid. S. }} 446 . \\
& 218_{\text {ibid. S. }} 261 .
\end{aligned}
$$


die wie ein Kahn ihn in die Nacht hinein bringt. Diese Erfahrung des erhöhten Lebens bei einer nächtlichen Bootsfahrt kehrt auch in Dir zu Feier wieder:

Und ich muß denken wie die Nächte nahen, nach denen meine Träume lange schmachten:

Sie fahren an wie diamantne Yachten und tragen frohe Fahnen, hohe Frachten, alle Matrosen sind in Märchentrachten und fremde Vögel, welche Winde brachten, die günstig wehten, rasten in den Rahen. Und aufwärts von der Kühle ihres Kieles bis an der Maste matte Flammenspitzen:

Das Silber in den Rissen, Rillen, Ritzen, Kleinode, die an Bord und Bug erblitzen, die Sehnsucht ihrer Segel - und noch vieles wird alles unsre seligkeit besitzen. 219

Die Wellenlinie. Zum Motiv der Wellenlinie ist voranzuschicken, daß sie manchmal einen bloß dekorativen wert innehat:
Dem Tag ist so todesweh. Müd gießt er aus goldenen Kelchen Wein in den Bergesschnee. Hoch schüchtert, scheu wie ein Reh, ein Stern uiberm Uferschleh, und ziere, zitternde Wellchen gittern den Abendsee. 220

Eine echte Dynamik bekommt die Welle, wenn sie - wie im folgenden Gedicht - sogar kunstgewerbliche Gegenstände mit Leben erfüllt:

.... So bleiben in den Wellen dieses Felles.
Und wie zum Spiel durch müde Liderspalten
den Formen folgen und den samtnen Fälen,
und sachte tasten die damastnen Decken
entlang, mit Fingern fühlen: kühle Becken, 219 ibid. S. 190
220 op.cit. SWI., S. 121 
und mit den Händen ihre Lichte lecken

und raten: Sind sie Silber oder Gold?

Und an den Vasen rütteln, daß ein Wellchen

in ihnen aufwacht, und aus hellen Kelchen

ein Blätterrieseln roter Rosen rollt.

Und denken, denken: was das Klingen ist, und $d a \beta$ ein Duft ist wie von Mandarinen. $O b$ das die Seele von den Dingen ist und über ihnen? 221

Das Verhältnis der Welle zum Meer gleicht dem Verhältnis des Individuums zur Lebensganzheit. Aus der gewissermaßen amorphen Masse des Wassers bilden sich in jedem Augenblick neue Wellen, die sich aber sofort wieder auflösen und in das Meer zurücksinken. Dieser Vorgang erzeugt neue Wellen, so wie der Fortpflanzungsprozeß neue individuelle Gestalten hervorbringt. 22 Das Individuum sucht wie eine Welle die Vereinigung:

\footnotetext{
... Und weißt du was mein Leben will, hast du es schon verstanden? Wie eine Welle im Morgenmeer will es, rauschend und muschelschwer, an deiner Seele Ianden. 223
}

An anderer Stelle wird die Geburt eines Kindes der Wiedergeburt der Erde im Frühling gleichgesetzt; die Wehen sind die Lebens-Wellen:

$$
221_{\text {ibid. S. } 227 .}
$$

222 Wolfdietrich Rasch, "Fläche, Welle, Ornament. Zur Deutung der nachimpressionistischen Malerei und des Jugendstils" in Zur deutschen Literatur seit der Jahrhundertwende. Gesammelte Aufsätze (Stuttgart: J.B. Metzlersche Verlagsbuchhandlung, 1967) S. 201. op.cit. SWI., S. 175. 
...oh, lächle, Weib! Du stehst am Rande des wunders, das dich weihen wird. Fühlst du in dir das scheue Schwellen, und Leib und Seele wird dir weit oh, bete, Weib! Das sind die Wellen der Ewigkeit.224

Auch kann die Welle Bote des Frühlings sein:

Ich geh dir nach, wie aus der dumpfen Zelle ein Halbgeheilter schreitet: in der Helle mit hellen Händen winkt ihm der Jasmin. Ein Atemholen hebt ihn von der Schwelle, er tastet vorwärts: Welle schlägt um Welle der großbewegte Frühling über ihn. 225

Das Ursprünglich-Natürliche und die Reinheit des "Jung-Seins" werden oft durch Meer und Welle dargestellt:

Und einmal lös' ich in der Dämmerung der Pinien von Schulter und vom Schooß mein dunkles Kleid wie eine lüge los und tauche in die Sonne bleich und bloß und zeige meinem Meere: ich bin jung. Dann wird die Brandung sein wie ein Empfang, den mir die Wogen festlich vorbereiten. Und eine jede zittert nach der zweiten, wie soll ich ganz allein entgegenschreiten: das macht mich bang..

Ich weiß: die hellgesellten wellen weben mir einen Wind; und wenn der erst beginnt
so wird er wieder meine Arme heben. 226

Das künstliche Paradies. Das durch Ufer begrenzte Meer ist das "Reich der Schöne", worin der Mensch sich zurückzieht und womit er sich identifiziert, um doch trotz dieses Rahmens das All zu erleben:

$$
\begin{aligned}
& 224_{\text {op.cit. SWI., S. } 140 .} \\
& 225_{\text {op.cit. SWIII. }} \text { S. } 176 . \\
& 226_{\text {ibid. S. } 210 .}
\end{aligned}
$$


Und einmal wach ich auf und bin - das Meer.

Und riesig reck ich meine glatten Glieder

und lege meine Linke, perlenschwer,

an armen Rande blasser Lande nieder.

Und wenn ich auch mit meiner rechten Hand

an andrer Ufer enge Dämme frōhne:

Ich zürne nur an meinem letzten Rand;

tief in mir liegt das stille Reich der Schöne,

und drinnen wohnen die versöhnten Töne, 7
und alle Farben fanden sich verwandt. 227

Folgende zwei Gedichte, die später in die Sammlung Advent aufgenommen wurden, haben alle Requisiten des 'schönen Jugendstil-Lebens' :

Im Schlosse mit den roten Zinken

wär ich so gern des Abends Gast.

Die Fenster glühn, die Falten sinken,

und meine weißen wünsche winken

mir aus dem lodernden Palast.

Ich will durch lange Hallen schleichen

und in die tiefen Gärten schaun,

die über alle Marken reichen.

Und Frauen Iächeln an den Teichen, 228

und in den wiesen prahlen Pfaun...228

Und:

Einmal möcht ich dich wiederschauen,

Park, mit den alten Lindenalleen,

und mit der leisesten aller Frauen

zu dem heiligen weiher gehn.

Schimmernde Schwäne in prahlenden Posen

gleiten leise auf glänzender Glatt,

aus der Tiefe tauchen Rosen

wie Sagen einer versunkenen Stadt.

Und wir sind ganz allein irn Garten,

drin die Blumen wie Kinder stehn,

und wir lächeln und lauschen und warteg,

und wir fragen uns nicht, auf wen...229

227 op.cit. SW III., S. 257.

228

op.cit. SWI., S. 112 .

229 ibid. S. $112 f$. 
In dem ersten Gedicht ist der Pfau, wie der Schwan im zweiten, als Symbol der Schönheit und Eleganz aufzufassen, Ein anderes Mal (in einem Emil Orlik gewidmeten Gedicht) bekommt die Feder des Pfaus sogar magische Kraft zugesprochen:

"Pfauenfeder" -

In deiner Feinheit sondergleichen, wie liebte ich dich schon als Kind. Ich hielt dich für ein Liebeszeichen, das sich an silberstillen Teichen in kühler Nacht die Elfen reichen, wenn alle Kinder schlafen sind.

Und weil Großmütterchen, das gute, mir oft von wïnschegerten las, so träurnte ich, du Zartgemute, in deinen feinen Fasern flute die kluge Kraft der Rätselrute $2 \overline{3}$

und suchte dich im Sommergras. $2 \overline{3} 0$

Noch 1901 beschreibt Rilke in einem Brief an Helmuth Westhoff (auch hier noch Bewunderer der Pfauenfeder und seines Gedichtes aus dem Jahr 1896) die Assoziation, die ihn ergriff, als er auf einem Jahrmarkt in München "andere Leute" mit Pfauenfedern herumgehen und sich damit kitzeln sah - während er mit seiner Pfauenfeder...

...die viel zu stolz war, jemanden zu kitzeln, allein herum(ging) und je länger ich sie so mit mir herumtrug, desto mehr beschäftigte mich die Schlankheit ihrer Form, wie sie sich wiegte auf dem elastischen Stiel, und die Schönheit ihres Hauptes, aus welchem das "Pfauenauge" dunkel und geheimnisvoll mich anschaute...sie schien mir eine ganze Fülle von Schönheiten zu enthalten, die niemand bemerkte als ich.... wieviel Freude... die Harmonie in der Buntheit und der Menge von Farben, die auf einem so kleinen Fleck zusammenstehen, bereiten kann.231

$230_{\text {ibid. S. }} 105$

${ }^{231}$ Rilke, Briefe und Tagebuicher 1899-1902, S. 122. 
Als Rilke dieses Schreiben verfaßte, war er schon lange Freund Heinrich Vogelers gewesen, dessen Lieblingsmotiv auch in seinen Insel-Zeichnungen - der pfauenhafte Märchenvogel war. 232 Vogeler hatte den Pfau aus dem englischen Jugendstil übernommen, wo er besonders als Sinnbild der exotischen Schönheit galt - von Whistlers "Peacock Room" bis Beardsley, der Salome in eine Pfauenschleppe kleidet, und Wilde, der in seinem Salome-Text Herodes von seinen Pfauen schwärmen läßt. Tschudi Madsen erläutert folgendermaßen den Stellenwert der Pfauenfeder im Jugendstil:

In the peacock the feathers, rather than the bird itself, proved of paramount interest. The plumage represented the magnificence of vanity.. with its gorgeous colours and closed oval shapes.233

Entrückt sein aus dem Alltag in den Bereich des Innenlebens wird auch durch das symbol der Insel ausgedrückt. In einem Brief an Lou vom Juni 1897 schreibt Rilke:

Das war eine von den seltenen Stunden. Solche Stunden sind ein dichtumblühtes Inselland: die Wogen athmen ganz leise hinter den. Fruhlingswällen und kein Nachen kommt aus der Vergangenheit nach und keiner will weiter in die Zukunft.

$D a B$ es dann eine Rückkehr in den Alltag gibt, kann diesen Inselstunden keinen Schaden thun. -Sie bleiben losgelöst von allen andern, wie gelebt in einem zweiten höheren Sein.

Ein solches höheres Inseldasein scheint mir die $\mathrm{Zu-}$ kunft der Ganzwenigen.-

Es klingt ein Glück, es blüht von weit und rankt um meine Einsamkeit

232 Robert Schmutzler, Art Nouveau - Jugendstil (Stuttgart: Verlag Gerd Hatje, 1962), S. 261

233 op.cit. Madsen, S. 32. 
und will sich wie ein Goldgeschmied

Um meine Träume weben.

Und ist mein armes Leben

auch Eruhfrostband und leidumschneit

Es muß ihm eine heilige Zeit

den Weihefrühing geben...234

Der Weihefrühling als typisches Jugendstil-Thema wird hier in Zusammenhang mit dem Inseldasein gesehen, mit den Stunden der Verklärung, in denen man wie im Frühling die Weihe für das ganze Jahr bekommt.

Rilkes essayistische Äußerungen zum Jugendstil

Der Münchner Kunstbrief". Die Anteilnahme Rilkes am Münchener Jugendstil wird nicht nur durch die eben besproche- nen Gedichte klar, sondern auch durch seinen Aufsatz, "Wünchner Kunstbrief" (1897). Er spricht von der neuen Tendenz der Münchener Kunst, nicht nur sich selbst Erfüllung zu sein, sondern auch ":Zwecken des Lebens" zu dienen.

Dieses Bestreben stellt sich uns dar als eine Wiederbelebung des Kunstgewerbes und im weiteren Verlaufe als Gründung eines neuen Stiles... (wodurch) die Kunst selbst mit allen ihren Mitteln erziehlich auf das Individuum einwirkt und deshalb von vornhinein nicht als etwas vom Leben Verschiedenes und Fremdes, sondern als natürliche Steigerung und Auswertung desselben empfun-? den wird. Sie muß dann aus den Ausstellungen und Schaufenstern, wo sie so absichtlich und roh wirkt, in unsere nähere und gewohnte Umgebung gebracht werden... sobald es einmal so weit ist, daß wir unsere Stuben nicht mehr im anempfundenen Geschmack vergangener Epochen einrichten, wird diese Wiederbelebung des Kunstgewerbes uns von großer Bedeutung sein. 235

234 Briefwechsel, Rainer Maria Rilke und Lou Andreas Salomé, Hrsg.Ernst Pfeiffer, (Wiesbaden: Insel, 1952),S.19.

$$
235 \text { op.cit. SW V., S. } 322 f \text {. }
$$


Wie. schon erwähnt, wird dieser neue Stil der alten Kunst gegenübergestellt. In der neuen Kunst fallen alle romantischen oder restaurativen Stilformen der Vergangenheit weg. Die Dinge werden nicht historisch aufgeputzt, vielmehr sollen sie mit ihrem Werkstoff unmittelbar ihren Sinn aussprechen, der sich nicht im bloßen Zweck erschöpft. Die neuen kunstgewerblichen Dinge gehören in das Leben hinein sie sind nicht Ausstellungsmaterial, sondern Einrichtungsgegenstände. So ging die Kunst vom Innenraum aus, vom Möbel; das Haus wurde von innen nach außen geformt. 236

Der kunsthistorische Hintergrund ist Rilke bekannt: Die Engländer und die Japaner haben uns den Wert der 'Linie' wieder schätzen gelehrt, und die Anwendung dieser Kenntnis wird dann die Form unserer Möbel und die Zeichnung der Stoffe bestimmen. Die Wiedergewinnungeder 'Linie' hat es auch mit sich gebracht, daß die graphischen Künste in vollstem Umfange gepflegt werden, und ihre Ausnützung für die Illustration und Ausschmückung der Bücher und zu Ausführung von Plakatanschlägen hat der Kunst einen neuen, breiten Weg zum Verständnis der Menge gewiesen. 237

Rilke:war auch gut informiert über die neuen Entwicklungen in der Buch- und Plakatkunst. Eine Renaissance der Graphik als solche ging damals vor sich. In diesem zusammenhang erwähnt Rilke Max Klinger und seine Schrift: "Malerei und Zeichnung" (Leipzig, 1895). Klinger hat die "berechtigte Sonderstellung" der Zeichnung "wiedererobert". Diese Sonderstellung der Zeichnung besteht in der Tatsache, daß sie "alle

$$
\begin{aligned}
& 236 \text { op.cit. Seling, s. } 27 . \\
& 237 \text { op.cit. SW V., S. } 323 .
\end{aligned}
$$


anderen Mittel als Schwarz und Weiß verschmäht und durch diese nicht die Farbenwerte der Natur zu übersetzen, sondern ihren Stimmungsreiz wieder zugeben versucht." Stimmungsreiz heißt: die Freiheit des Künstlers, die Natur subjektiv und phantasievoll nachzubilden, anstatt von Ansprüchen der $\mathrm{Ab}-$ stufung der Materialmittel in der Malerei abhängig zu sein, die eine sichere Entschlossenheit in Form und Farbe verlangen. Form und Farbe eines Gemäldes, behauptet Rilke, müssen eine ruhige Wirkung haben und schließen daher "die Darstellung des Häßlichen oder Furchtbaren" von vornherein aus. Anders die Zeichnung,

... in welcher jede Linie Bewegung hat, mehr transitorisch erscheint und somit befähigt ist, auch dem bis zur Verzerrung gesteigerten Affekt Ausdruck zu verleihen. 238

Der Künstler ist ebenso von den Gesetzen der Perspektive befreit; es steht ihm frei, "Gestalten in einen unbestimmten Raum zu setzen" und dadurch beschäftigt die Zeichnung "die Phantasie des Beschauers...und kann...überaus interessant und anregend werden." 239

Das Aufgeben der Gesetze des Raumes und der Perspektive und die Verfestigung des Flächencharakters der Kunst um die Jahrhundertwende hat w. Rasch folgendermaßen gedeutet:

Die Flächenordnung ist ein Mittel, jenen Zusammenhang der Dinge, die totale Einheit, spürbar zu machen, die den Grundzug der Weltinterpretation jener Epoche ausmacht. Was die Dinge in der Wirklichkeit als iso- 
liert, von einander getrennt und unterschieden erscheinen läßt, ist ihre körperhafte Dreidimensionalität, ihr raumverdrängendes Volumen. Wenn der Maler auf der Leinwandfläche gerade dieses Dreidimensionale und die Raumtiefe mit den Mitteln der Zentralperspektive nachzubilden sucht, so gibt er damit auch das gesonderte, von jedem anderen Gegenstand im Raum scharf abgegrenzte Dasein dieser Dinge wieder..... ürr die Welterfahrung der um 1860 geborenen Generation war das Einzelding eine Konfiguration, eine Verdichtung des einen und immer gleichen "Lebensstromes" der unsichtbaren Kräfte, die sich in Gegenständen manifestieren.....innerhalb der Fläche, als bloße Flächenteile, gewinnen die Einzeldinge einen sehr engen Zusammenhang. Sie bilden zusammen eben die Fläche, deren Einheit als solche anschaubar ist. Der Raum.:trennt, die Fiäche bindet. 240

Bei seiner Analyse der neuen Kunst kommt es Rilke darauf an, daß sie durch die wiedererweckung der Zeichnung dem Künstler die Möglichkeit gibt, den Stimmungsreiz der Natur darzustellen, wie er ihn subjektiv und phantasievoll empfindet. Max Klinger und Hans Thoma sind Beispiele dafür. Sie "dichten" in ihrer Kunst - "einen Abend," "die Einsamkeit". Hier bringt Rilke Zeichner und Dichter zusammen:

Der Umstand, daß die graphischen Künste wieder ei rìg: gepflegt werden und daß Zeichner und Dichter sich darin, daß sie beide die Sehnsucht ihrer Zeit mit den Mitteln ihrer Persönlichkeit geben, oft nahe kommen, hat zur Folge, daß das Bedürfnis zusammenzuwirken da und dort erwacht und zu einer Umgestaltung unseres modernen Zeitschriftenwesens und unserer Buchausstattung geführt hat. 241

In diesem Zusammenhang lobt Rilke die Jugendstil-Zeitschriften "Jugend" und "Simplicissimus" und die modernen Verlage, die "fast jedem Werk ein eigenes künstlerisches Titelblatt ver-

$$
\begin{aligned}
& 240 \text { op.cit. Wolfdietrich Rasch, S. } 192 . \\
& 241 \text { op.cit. SWV., S. } 327 .
\end{aligned}
$$


leihen", auch der Kleinkunst (ex libris), wodurch die Kunst den Weg in das Leben zurückfindet.

"Auch ein Miüchner Kunstbrief" behandelt den neuen Stil weiter. Ganz richtig nennt Rilke Otto Eckmann, Hermann Obrist und August Endell als Vertreter des Dekorativen im Münchener Jugendstil. Rilke kannte August Endell, weil beide gute Freunde Lous gewesen sind. Photographien vom Juni und August 1897 zeigen ihn, Lou und Rilke zusammen in Wolfratshausen. 242 Endell war ursprünglich Naler, ging zum Kunstgewerbe über, und wurde schließlich Architekt. Auch andere Vertreter des Münchener Jugendstils gingen denselben Weg: Behrens, Riemerschmid, Eckmann und Pankok. Die überlieferten Grenzen der Kunst zerflossen. 243

"Moderne Lyrik". Im Frühjahr 1898 hielt Rilke einen Vortrag in Prag über die "Moderne Lyrik". Dieser Vortrag stellt die zentrale reflektierende Äußerung der Anfangsjahre Rilkes dar und bildet den Ausgangspunkt der kritischen An-

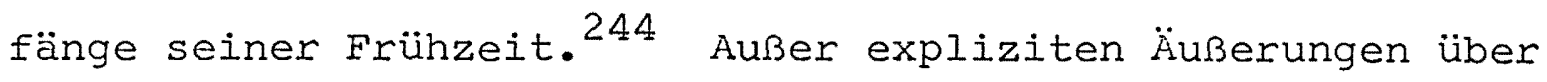
Fragen der Poetik enthält der Vortrag einen Kommentar zu der Kunstbewegung der Jahrhundertwende - eben dem Jugendstil. Über den Pantheismus als Grundgedanken dieser Bewegung sagt Rilke:

$$
\begin{aligned}
& 242 \text { op.cit. Schnack, Nr. } 42 f f \text {. } \\
& 243_{\text {op.cit. Seling, s. } 27} \\
& 244 \text { op.cit. SWVI., S. } 1351 \text {. }
\end{aligned}
$$


Man war ganz unerwartet zu einer Art von Pantheismus gelangt, mit dessen Gottesbegriff man sich immer mehr zu identifizieren geneigt war, und Sie werden begreifen, daß dieses Wachsen, dieses plötzIiche Überallhinreichen, dieses Alleswerden und AIIwerden eine herrliche Befreiung, einen hohen, stür-i mischen sieg bedeutete und in einer großen, lauten Begeisterung seinen Ausdruck suchte. Es kamen Reaktionen hinterdrein, Enttäuschungen und Zweifel, wie hinter jeder unvorhergesehnen Erfolg, aber immerhin blieb diese Empfindung der gefallenen Schranken die Grundstimmung für alles Schaffen und sie ist es heute noch. 245

Aus diesem Vortrag spricht Rilkes Bewunderung für Liliencron, Schlaf, Falke, Salus, Scholz, Bierbaum, Holz, George, Hofmannsthal ind für die Zusammenarbeit der Künste im Jugendstil, für die Zeitschrift "Pan", und Georges "Blätter für die Kunst", und uberhaupt für die neue künstlerische Ausstattung des neuen Buchschmuckes.

Ein freudiges Zusammentun der Künste und Künstler macht sich bemerkbar. Nicht nur der Inhalt ihrer Werke ist freudig und erwartungsvoll, auch ihr äußeres Gewand wird wirdig und feierlich. Und in alle Dinge steigt diese leise sehnsuichtige Schönheit; die Möbel, Teppiche und die kleinsten Dinge täglichen Gebrauches um euch wird sie ganz unvermutet verwandeln. Und plötzlich werdet ihr die einzigen sein, die noch die Nutzkleider des Alltags tragen. Und ihr werdet erschrocken auch eure Seelen schmuicken zu dem festlichen Empfang der neuen Zeit, deren bescheidener, unbeholfener verkünder ich sein will in diesen Worten.246

"Uhdes Christus". Trotz allen Lobs für den Jugendstil als die modernste Kunstrichtung ist nicht anzunehmen, daß Rilke kritiklos alles akzeptierte. Ein Aspekt, der ihn wohl

$$
\begin{aligned}
& 245_{\text {op.cit. SWV. }} \text { s. } 370 \\
& 246_{\text {ibid. S. } 393 f .}
\end{aligned}
$$


gestört hat, war die Bildung von verschiedenen Gruppen Cliquen - innerhalb der Richtung und der damit eventuell verbundenen Gefahr einer pauschalen Beurteilung anderer Tendenzen. 247 Außer den Bildern "im neuen Stil", gibt es "auch noch ein paar Menschen, und vielleicht ist es nicht ganz wertlos, von denen auch mal zu reden." 248 vielleicht geschieht es aus diesem Gedanken heraus, daß er im selben Jahr einen Essay über den Maler Unde publiziert, "Uhdes Christus"; der deshalb für uns interessant ist, da Rilkes Gedichtzyklus "Christus Visionen" von Uhdes Bildern angeregt wurde. 249 Die Anregung besteht aber allerdings in der Hauptsache aus einer Auseinandersetzung mit Uhde, und im Grunde genommen ist der Zyklus eine Bestätigung des Jugendstil-Gedankens, daß Christus nicht die transzendierende Figur ist, die uns von der christlichen Religion präsentiert wird.

Rilke hatte sich in diesen Jahren besonders in bezug auf seine christlichen Ansichten vollkommen gewandelt. Er hat sich besonders gewehrt gegen seine streng katholische Erziehung und die Pseudo-Frömmigkeit seiner Mutter. Er fragte sich damals wie auch noch in späteren Jahren:

...wer ist denn dieser Christus, der sich in alles hineinmischt. - Der nicht von uns gewußt hat, nicht

247. Man lese dazu die Äußerungen in Ewald Tragy, wo seine Jugendstil-Freunde Scholz und Wassermann wegen ihrer Cliquenbildung lächerlich gemacht werden.

$$
\begin{aligned}
& 248 \text { op.cit. SW V., S. } 791 . \\
& 249 \text { op.cit. SW III., S. } 791 .
\end{aligned}
$$


von unserer Arbeit, nicht von unserer Not, nichts von unserer Freude, so wie wir sie heute leisten, durchmachen und aufbringen--, und der doch, so scheint es, immer wieder verlangt, in unserem Leben der erste zu sein...Was will er von uns? Er will uns helfen, heißt es. Ja, aber er stellt sich eigentümlich ratlos an in unserer Nähe. Seine Verhältnisse waren weitaus andere. Oder kommt $\because$ es hier wirklich auf die Umstände nicht an, wenn er hier einträte, bei mir, in mein Zimmer, oder dort in der Fabrik - wäre sofort alles anders, gut?.... Mein Gefühl sagt mir, daß er nicht kommen kann. Daß es keinen Sinn hätte. Unsere Welt ist. nicht nur äußerlich eine andere, - sie hat keinen Zugang für ihn. Er schiene nicht durch. Es ist kein Zufall
umging....250

Schon Nietzsche hatte gesagt "Gott ist tot". Als Ersatz für den christlichen Glauben konnte nur die Aktualisierung der romantischen All-Einheits-Erfahrung und dadurch die Verklärung des Einzelnen erfolgen. Rilkes neue anti-christlichen Anschauungen waren zum $\mathrm{T}_{\mathrm{e}} \mathrm{il}$ auch durch Lou Andreas-Salomé und ihren Aufsatz vorn April 1896, "Jesus der Jude" angeregt. Ein Brief vom 13. Mai 1897 legt davon Zeugnis ab:

Nicht Interesse war es, was mich tiefer und tiefer in diese Offenbarung (ihres Aursatzes) führte, ein gläubiges Vertrauen ging mir auf dem ernsten Wege voran, und endlich wars wie ein Jubel in mir, das, was meine Traumepen in Visionen (die Christus Visionen) geben, mit der gigantischen Wucht einer heiligen überzeugung so meisterhaft klar ausgesprochen zu finden. 251

Die "Christus Visionen" waren radikal anti-christlich und Rilke ließ sie nicht veröffentlichen. Ein Druck ist erst

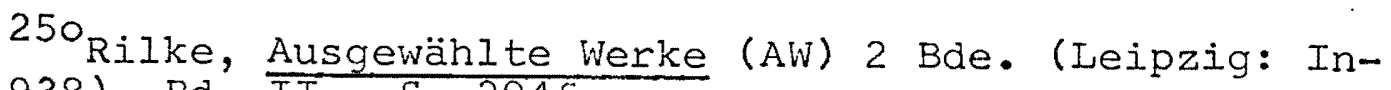
sel, 1938), Bd. II., S. 294f..

251 dreas Salomé, S. 9 . 
1959 nach Rilkes Tod erschienen.

Um Uhdes Rolle in den "Christus Visionen" festzuhalten, ist es notwendig, Rilkes Aufsatz über ihn anzuschauen. Er besteht hauptsächlich aus einer Kritik der Christus-Figur in Uhdes "Himmelfahrt". Rilke lobt das Bild, insofern es

...eine Gruppe von Menschen...zusammengezwungen, geeint und gemeinsam durchzuckt von einer Sensation (zeigt). Und auf allen Gesichtern in feiner Abstufung die Wirkung von etwas Großem, Unglaublichem: bei den Greisen: Erstaunen, bei den Frauen: Entzücken, bei den Jungfrauen: Verklärung und bei den Kindern: Vertrauen, welches dem Verstehen am nächsten kommt....252

Er klagt Uhde an, insofern er

...leider etwas anderes in diesen Raum (stellt), was gar nichts mit der Gruppe zu tun hatte und... aus alter Gewohnheit - Christus (genannt wurde).253

Rilkes Hauptkritik ist, daß Uhde "zahlreichen wünschen entsprechend" Christus hineinmalt, um das Bild "pinakothekfähig" zu machen. So entstand dieser "königlich sanktionierte" Christus, der sogar fliegen können muß! Damit hat er seinen eigenen ursprünglichen Christus, den einfachen Menschen, aufgegeien, um das Publikum zu befriedigen. Uhdes frühestes Christus-Bild, "Lasset die Kleinen zu mir kommen" findet Rilke am besten, weil hier die Kinder eine Rolle spielen und Christus eher als vater erscheint. Obwohl Uhde ihm den Namen "Christus" gab, malte er ihn "zeitlos" und nicht wie in der "Himmelfahrt" in "gewohntem Kostüm und Gehaben."

$$
\begin{aligned}
& 252 \text { op.cit. SWV., S. } 352 . \\
& 253_{\text {ibid. }}
\end{aligned}
$$


Die einzige Vorstellung, die man von Rilkes "Christus Visionen" aus diesem Aufsatz gewinnen kann, wäre Christus als Mensch, der das Wunderbare besitzt, nur insofern es sich in anderen spiegelt; die Verklärung des Menschen durch ein tiefes Erleben ist die Hauptsache und nicht die christliche Botschaft. Christus bleibt Personifizierung des Menschenmöglichen und hat nichts mit dem. Dogma der Kirche zu tun. In den "Christus Visionen" wird dieșe Vorstellung bestätigt und zum Teil erweitert. Der Eindruck, der beim Lesen nach den Christus Visionen haften bleibt, ist Rilkes Kritik an dem menschlichen Versagen Christi. Die gleiche Kritik, die er an Undes Christus geübt hat. Das wichtigste an Rilkes Beschäftigung mit dem Maler Uhde für seine Jugendstil-Entwicklung war vielleicht die Gelegenheit, sich weiter mit dem Christentum seiner Zeit auseinanderzusetzen. Rilke wird sich noch oft mit christlichen Themen in der Malerei beschäftigen, vor allem bei Heinrich Vogeler und bei El Greco. 


\section{DIE ITALIEN-REISE}

Die Wiederentdeckung der Renaissance um die Jahrhundertwende

1898 war ein wichtiges Jahr in Rilkes Leben; im April ging er zum ersten Mal nach Florenz, um die italienische Renaissance-Malerei zu studieren. Dieser Entschluß ist nicht so überraschend wie er scheint. Schon Monate vorher in München und Berlin hatte Rilke sich eingehend zusammen mit Lou und ihrem Freund August Endel $2^{254}$ kunstgeschichtlichen Büchern gewidmet. Jakob Burckhardts "Kultur der Renaissance in Italien" wurde ihm bekannt; er las die Tagebücher des Enea Silvio de' Piccolomini und Leon Battista Albertis Schrift "De re aedificatoria." Er vertiefte sich "in die unendliche Süßigkeit jenes modernsten und innigsten Buches der Renaissance, der "Vita nuove" des Dante. 255 Vor allem interessierte ihn Botticelli und die Frührenaissance. Am 13. August 1897 schreibt Rilke über Botticellis Madonnen,

...(die) mit ihrer müden Traurigkeit, ihren großen nach Erlösung und Erfüllung fragenden Augen, diese Frauengestalten, welche bangen, alt zu werden ohne eine heilige Jugend stehen mitten in der Sehnsucht unserer Zeit. Sandro Botticelli...erkennt in seiner

254 op.cit. Gesammelte Briefe 1892-1904, S. 45.

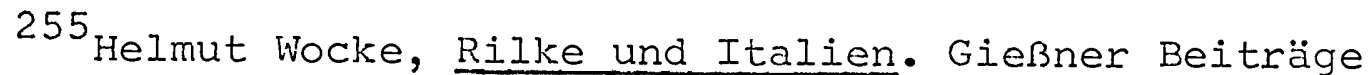
zur deutschen Philologie, Hrsg. Alfred Götze. (Gießen: Münchowsche Universitäts-Druckerei, 1942), S. 7. 
naiven Gottessehnsucht, daß die Madonna in ihrem tiefen, durch die seltsame Mutterschaft veredelten und geheiligten Mitempfinden ganz wohl zur Verkünderin seiner eigenen Traurigkeit und seines iüideseins werden kann... aber sie (ist) überaus zart im 256
Gefühl und (hält) seine Geständnisse beichtheilig..9

Diese Schwermut und Sehnsucht und der bis ins Religiöse gesteigerte Glauben an die Weihe der Kunst wie sie bei Botticelli zu finden ist, sind tatsächlich Merkmale, die die Kunst um die Jahrhundertwende mit der Frührenaissance teilt. Es wäre hier am Platze, den geschichtlichen Hintergrund dieser Wiederentdeckung der Renaissance-Kunst im Jugendstil zu besprechen, die nach Walter Rehm zu einem Renaissancekult geworden ist. 257

Es geschah eigentlich durch Burckhardt, daß die Renaissance als ein besonderer geistesgeschichtlicher und kulturgeschichtlicher Abschnitt der Allgemeinheit im 19. Jahrhundert zugeführt wurde. Nietzsche nimmt dann, an Burckhardt anknüpfend, die Renaissance in sein eigenes Denkgefüge hinein, erhebt sie zu unmittelbarer Gegenwartsbezogenheit und -bedeutung und interpretiert sie weltanschaulich als Gesamtäußerung des Lebensgefühls einer Adelsmenschheit. Die Re.naissance wird hier als durchaus aristokratische Erscheinung gewertet und als Gegensatz zu den demokratischen Tendenzen

256 op.cit. Gesammelte Briefe 1892-1904, s. 45. 257 Walter Rehm, "Der Renaissancekult um 1900 und seine Überwindung" in Der Dichter und die neue Einsamkeit (Göttingen: Vandenhoeck \& Ruprecht, 1969), S. 34-77. 
des Naturalismus. Sie bedeutet das Ringen um eine neue idealistische Weltanschauung. 258 Denn die Renaissance scheint die schönheitliche, aristokratische und individualistische Epoche, die Zeit des gewalttätig ausgreifenden, herrlichgroßen und ruchlos-dämonischen Wesens zu sein. Seit Nietzsche ist der Renaissancemensch als Herrenmensch und Übermensch möglich und Ideal - denn die Renaissance ruht wesentlich auf den Schultern starker Menschen, die den Durchbruch des Natürlichen und Wahren, die höchste Vollkommenheit, den "uomo universale" bedeuten. 259 Diese Vergangenheit wird zum Mythos und zum Kult im 19. Jahrhundert - ein Jahrhundert, in dem Ideal und Leben immer weiter auseinander treten. Nach Nietzsche führt dieser Kult sogar zur Flucht in die Schönheit der Form, in die auserwählten Dinge, wo die Natur vollkommener sei - wie z.B. bei walter Pater in England und bei der ganzen Jugendstilbewegung, die die Ideen der Präraphaeliten in bezug auf ihre Begeisterung für die Frühre-naissance übernommen hatten. Rilke hat schon früh Nietzsche gelesen; er schreibt in Prag 1895:

Ich gehöre zu jener Gruppe von Menschen, die Nietzsche die 'historischen' nennt. - So kehre ich denn, weil die Gegenwart frieren macht, den Blick, zu einer sonnenwarmen Vergangenheit zurück. 260

$$
\begin{aligned}
& 258_{\text {ibid. S. } 37 .} \\
& 259_{\text {ibid. S. } 42 .} \\
& 260_{\text {op.cit. SW V., S. } 294 .}
\end{aligned}
$$


$\mathrm{Zu}$ weiterer Bekanntschaft mit Nietzsches Ideen ist es wohl durch Lou gekommen, die ja eine Zeitlang mit Nietzsche lebte und ein Buch über ihn schrieb. Die Tatsache, daß Rilke das interessanteste Dokument seiner kunsthistorischen Studien in Florenz, das Florenzer Tagebuch, als Reisebericht für Lou schrieb, verbindet noch einmal den Renaissance-Gedanken Nietzsches mit Rilkes Italienreise:

Die im "Florenzer Tagebuch" enthaltene Kunstauffassung Die aristokratische Kunst als Religionsersatz. Das in jugendstilhaftem weißen Kunstleder mit eingeprägten Florentiner Lilien gebundene Florenzer Tagebuch behandelt bereits ein zentrales Thema Nietzsches und des Jugendstils: die Berufung des Künstlers und seine 'übermenschlichen' Kräfte.

Am Anfang des Tagebuchs ist Rilkes Kunstauffassung höchst aristokratisch: der künstler schafft einzig für sich - die Kunst wirkt bildend "nur auf den, welcher sie schafft; denn sie steigert seine Kultur". ${ }^{261}$ Eine volks-bezogene Kunst kann es nicht geben:

'Wir wollen eine Kunst für das ganze Volk.'- Was für eine vorsichtige Überhebung, da das Volk, das dennoch die größere Authorität ist, täglich dekretiert: 'Das Volk will keine Kunst. '262'

Damit sind die "Wegwarten" -Tage für Rilke vorbei, in denen er noch seine Kunst "gratis" an das Volk verteilen wollte. Jetzt ist die Kunst das Mittel Einzelner, Einsamer, sich 261 op.cit. Tagebücher aus der Frühzeit, S. 39. 262 ibid. S. 121 . 
selbst zu erfüllen: "Die Kunst geht von Einsamen zu Einsamen in hohem Bogen über das Volk hinweg." 263

Der Schaffende ist der weitere Mensch, der, über welchen hinaus die Zukunft liegt. Der Künstler wird nicht in aller Zeit neben dem Menschen bestehen. 264

Die Kunst ist also auch die Offenbarung des Zukünftigen, "die Ewigkeit, welche hineinragt in die Tage." Der schöpferische Geist offenbart sich in jeder Generation von Künstlern und setzt seine Entwicklung fort. 265

Ihre Sehnsüchte (vorangehender Künstler) dauern in uns fort. Und unsere Sehnsüchte bleiben... in anderen wach, bis sie sich in irgendwelchen Letzten erfüllen. Diese erst sind dann ein Beginn. Wir sind Ahnungen und Träume.266

Der Gedanke des "zukünftigen Gottes", an dem der Künstler baut, wird hier zum ersten Male formuliert (und im Stundenbuch weiterentwickelt) und bildet den Schluß des Florenzer

\section{Tagebuches:}

Und nun dieses Buches letzter wert ist die Erkenntnis eines Künstlertums, das nur ein Weg ist und in einem reifen Dasein endich sich erfüllt. Mit.jedem Werke, welches Du aus Dir hebst, schaffst Du Raum für irgendeine Kraft. Und der letzte, welcher "nach lange kommt, wird alles in sich tragen, was um uns wirksam und wesenhaft ist; denn er wird der größte Raum sein, erfüllt mit aller Kraft. Das wird nur einer erreichen; aber alle Schaffenden sind die

263

ibid. S. 52 .

$264_{\text {ibid. S. } 38 .}$

265 Siehe Gedicht auf S. 86 dieser Arbeit. 266 op.cit. Tagebücher aus der Frühzeit, S. 41. 
Ahnen dieses Einsamen. Es wird nichts sein außer ihm; denn Bäume und Berge, Wolken und Wellen sind nur Symbole gewesen jener Wirklichkeiten, die er in sich findet. Alles ist in ihm zusammengeflossen, und alle Mächte, die sonst zerstreut einander bekämpften, zittern unter seinem Willen....jeder Gott ist die ganze Vergangenheit einer Welt, ihr letzter Sinn, ihr einheitiicher Ausdruck und zugleich die Möglichkeit eines neuen Lebens. Wie andere ferne welten zu Göttern reifen werden weiß ich nicht. Aber für uns ist die Kunst der Weg; denn unter uns sind die Künstler die DurstigenSie empfangen Stücke des Lebens und geben das LebenIch fühle also: daß wir die Ahnen eines Gottes sind und mit unseren tiefsten Einsamkeiten durch die Jahrtausende vorwärtsreichen bis zu seinem Bèinn. Das fühle ich.267

Später im Tagebuch mildert Rilke die Ansicht, daß Kunst nur für den Künstler da ist: "Es tönt etwas tief aus mir, welches über diese Seiten, über meine lieben Lieder...hinaus zu den Menschen will."268

Rilkes Stellungnahme zur Religion und zum Göttlichen muß in diesem Zusammenhang erwähnt werden.269

Die Religion ist die Kunst der Nichtschaffenden... Der Nichtkünstler muß eine Religion - im tiefinneren Sinn - besitzen, und sei es auch nur eine, die auf gemeinsamem und historischern Vereinbaren beruht. 270

Kunst ersetzt hier also Religion und schafft das Göttliche:

$$
\begin{aligned}
& 267_{\text {ibid. S. } 139 f .} \\
& 268_{\text {ibid. S. } 10 .}
\end{aligned}
$$

269 Der Gottesbegriff des Jugendstils im Allgemeinen und die Auffassung der Kunst als Religionsersatz wurde schon einleitend auf $S$. 55f. dieser Arbeit dargestellt.

$$
\text { 270 op.cit. Tagebücher aus der Frühzeit, s. } 43 .
$$


Gott ist das älteste Kunstwerk. Er ist sehr schlecht erhalten, und viele Teile sind später ungefähr ergänzt. Aber es gehört natürlich zur Bildung, über ihn reden zu können und die Reste gesehen zu haben.271

Aber das Göttliche setzt er plötzlich mit dem weg nach Innen gleich:

Sie (die Künstler der Frührenaissance) haben alle doch nur einen Glauben besessen, und eine Religion hat sie durchglüt: die Sehnsucht nach sich selbst. Ihre höchsten Entzückungen waren die Funde, welche sie in ihrer eigenen Tiefe taten. Zitternd hoben sie sie ins Licht. Und weil das Licht damals des Gottes voll war, so nahm er ihre Gaben an.272

Das Vorbild der Frührenaissance und Kritik an der Hoch-

Renaissance. Bei einer derartigen Betrachtung des Wesens der Kunst spielt Rilkes Studium der Frührenaissance eine große Rolle. Gerade aus seiner Beschäftigung mit Botticelli könnte er auf die neoplatonische Philosophie gekommen sein, die die Tendenz zeigt, den Künstler als souveränes Genie zu betrachten und nicht mehr als ergebenen Handwerker. Platons Auffassung des Dichter-Genies, als jemand, der vom Geist besessen ist, und dadurch gezwungen wird, in einem "seelischen Wahnsinn" zu dichten, wurde durch Marsilio Ficino und die Neoplatonisten erweitert, um den Architekt, den Bildhauer und den Maler einzuschließen. Ein Genie wurde von normalen Sterblichen unterschieden durch die göttliche Inspiration, die ihn leitete und war "heilig", "unsterblich" und "schöpferisch." Dieser "Geniekult" hatte natürlich auch einen Einfluß auf die

$$
\begin{aligned}
& 271_{\text {ibid. S. }} 53 . \\
& 272_{\text {ibid. S. }} 42 .
\end{aligned}
$$


Hochrenaissance und forderte sie zu unmäßigen, fast unerreichbaren Zielen auf.273 Die neoplatonische Philosophie teilte mit dem Jugendstil auch den Gedanken der Einheit zwischen Natur und Geist - hinter der ganzen Schöpfung steht für sie die Weltseele, woher der Mensch und die Natur stammen.

Rilkes erstes Anliegen war die Kunst der Frührenaissance, besonders Fra Bartolommeos und Botticellis, die er in folgender Weise lobt:

Es wechseln immer wieder drei Generationen. Eine findet den Gott, die zweite wölbt den engen Tempel über ihn und fesselt ihn so, und die dritte verarmt und holt Stein um Stein aus dem Gottesbau, um damit kärgliche Hütten zu bauen. Und dann kommt eine, die den Gott wieder suchen muß; und einer solchen haben diese angehört: Dante, Botticelli und Fra Bartolommeo. 274

Um zu verstehen, in welcher Weise Botticelli und Fra Bartolommeo Gott "suchen" mußten, muß man die neoplatonische Philosophie wieder heranziehen. Man versuchte hier, den christlichen Glauben mit der Mythologie der Antike zu vereinigen. Ficino glaubte, daß das Leben des Universums und des Menschen durch eine ständig hinauf- und hinuntersteigende Spirale mit Gott verbunden war und daher alle Offenbarungen - ob aus der Bibel, von Platon oder aus der klassischen Mythologie - eine Einheit bildeten. Auf diese Weise erklärte er Schönheit, Liebe und Seligkeit als eine Sache. Die nackte, aus dem Meer

$$
\begin{aligned}
& 273 \text { op.cit. Janson, s. } 348 \text {. } \\
& 274 \text { op.cit. Tagebücher aus der Frühzeit, s. } 33 \text {. }
\end{aligned}
$$


entsprungene, himmlische Venus konnte dementsprechend mit der Jungfrau Maria als Verkörperung der "göttlichen Iiebe" ausgewechselt werden. Die himmlische Venus bewohnt nur den Geist, während inr Zwilling, die irdische Venus, "men.sch:Iiche Liebe" erzeugt. Botticellis häufige Darstellung der himmlischen Venus entstammt diesem Hintergrund. In seinem berühmtesten Bild "Die Geburt der Venus" z.B. werden zwei Windgötter als Engel dargestellt, und die Personifizierung des Frühlings erinnert an das traditionelle Verhältnis zwischen St. Johannes und Christus bei der Taufe. Dieses Bild einer monumentalen nackten Göttin ist die erste Darstellung seit der Römerzeit, die der klassische venus entspricht.

Über Botticeliis Gottesbegriff sagt Rilke lobend, die Kirche sei nur Vorwand: "Ob Botticelli die Venus oder die Madonna malte; es wurde doch immer seine wunde und verweinte Sehnsucht."275 Botticelli malte aus seinem Inneren und dadurch"göttlich".276 Rilkes einzige Kritik Botticellis bezieht sich auf die Entwicklung am Ende seines Lebens, wo er durch den Einfluß von Savonarola, der einen solchen "Heidenkult" angriff, einige seiner "heidnischen" Gemälde verbrannte, und in der traditionellen Weise seine religiösen Themen weitermalte.

$$
\begin{aligned}
& 275_{\text {ibid. S. } 43 .} \\
& 276 \text { ibid. }
\end{aligned}
$$


Botticelli griff in die Vergangenheit, um das Göttliche zu finden, sein Ausdruck aber ist sein eigener und entspricht nicht dem Ideal der Frührenaissance. Bei ihm liegt die Betonung auf der Dynamik der Linie und nicht der realistischen Darstellung drei-dimensionaler Figuren. Er zeigt kein Interesse für Anatomie - seine, Figuren schweben, sind zart und ihnen mangelt jegliche Kraft. Obwohl "himmlisch", behalten seine Figuren ihre Sinnlichkeit; sie sind echte Akte und genießen eine Bewegungsfreiheit. Seine Kunst ist zugleich fantastisch, dekorativ und mystisch und wurde wegen dieser Stilmerkmale von den Präraphaeliten und Jugendstilmalern verehrt.

Es besteht noch eine Verbindung zwischen Botticelli und der Generation um die Jahrhundertwende. Botticellis Kunst ist ein Ausdruck der Neoplatoniker, die die Wiedererweckung einer zum größten Teil imaginären Antike erstrebten. Sie sehnten sich nach einer irdischen Schönheit, die die ideale Schönheit einer höheren Sphäre wiederspiegelte. Botticelli war der Lieblingsmaler des Medici-Kreises. Diese Gruppe bestand aus allen Scholastikern und Poeten, Literaten und Patriarchen, die sich um das Haupt der Medici-Familie sammelten. Sie führten ein ästhetisches Leben, umgeben von Palästen und Villen und fantastischen Gärten. 277 Auf gleiche Weise suchte Rilkes Generation Flucht von der sozialen wirklichkeit in ein ästhetisches Leben und in Träume von einer glorreichen Vergangenheit, in ihrem Fall eben die Renaissance. 
Es waren also vor allem die Präraphaeliten, besonders Rossetti und Burne-Jones, die Rilke nach Italien geschickt hatten. Durch seine Verbindung zum Jugendstil hatte er sie kennengelernt und wollte ihrer Begeisterung für die Renaissance näher kommen. Die Betrachtungen Rilkes über Botticelli zeigen den Einfluß der Präraphaeliten. In den ersten Seiten des Florenzer Tagebuches verteidigt er die Präraphaeliten gegen diejenigen, die behaupten würden, daß sie einfach eine "Laune" seien, die der "glatten Schönheit müde (Hochrenaissance) ...die mühsame" sucht. 278 Im Gegenteil:

Nicht Zufall und Laune und Mode führte uns zu denen hinter Raffael. Wir sind die fernen Erben, die berufen wurden um der vielen Vermächtnisse willen. 279 .... (und) Der Kunst müde, sucht man den Künstler und will in jedem Werke die Tat erkennen, die den Menschen erhob, den Sieg über etwas in ihm und die Sehnsucht nach sich selbst.280

Die Werke Raphaels und der Hochrenaissance wären eine Höhe der Kunst, aber keine Höhe des Künstlers. Rilke und die Präraphaeliten meinten, daß die Künstler der Hochrenaissance Produkte ihrer zeit und der künstlerischen Tradition gewesen seien, welche sie allerdings zu einer Vollendung gebracht hätten. So habe sich ein monumentaler, aber kein persönlicher Stil entwickelt. Diese Kritik an der Hochrenaissance und die gleichzeitige Inklination für die Frührenaissance ist das

278 op.cit. Tagebücher aus der Frühzeit, S. 33. 279 ibid. S. 72 . $280_{\text {ibid. S. } 33 .}$ 
zweite große Thema des Florenzer Tagebuches. Die Künstler der Frührenaissance schufen nach Meinung Rilkes aus persönlichem Ausdruckswillen, denn - obwohl für sie auch die Tradition der Antike eine Quelle war - ahmten sie "mehr ihrem Mut als ihrer Art" nach und "fanden ja auch nicht zu den Griechen hin, sondern zu sich selbst."281

Bei Werken aus der Hochrenaissance, von Raphael z.B., "ragt doch keine Empfindung mehr über die Reife jenes ersten Genusses hinaus, und das rasche wort wird das richtigste sein." Dagegen bei den Werken der Frührenaissance "gibt es kein erstes wort...es gibt da nur ein erstes Schweigen."282

Deshalb geschieht das Seltsame: das Verhältnis von Bild und Gast bleibt kein einseitiges.....stille Zwiegespräche reißen die Brücken zwischen ihnen nieder und ein versöhnendes Schweigen richtet sie wieder auf.... Wir stehen mit einem Male dem Nienschen gegenüber, der ein Stück seines Glaubens und seiner Sehnsucht in dem dauernden werke mit hastigen oder mit zärtlich zagenden Händen geformt hat. 283

Es kommt Rilke und den Rräraphaeliten also darauf an, wie gefühlvoll der Künstler seinen Glauben und seine Sehnsucht im Bild darstellt, damit im Zuschauer ähnliche Gefühle erregt werden. Die Reizwirkung ist die Urteilsbasis, und nicht die objektive Betrachtung. In seinen eigenen worten ist ihm

$$
\begin{aligned}
& 281_{\text {ibid. S. }} 44 . \\
& 282_{\text {ibid. S. } 31 .} \\
& 283_{\text {ibid. S. } 32}
\end{aligned}
$$


"jeder Stoff (ein) Vorwand zu bestimmten tief intimen Geständnissen."284 Für Rilke ist die Hoch-Renaissance der Höhepunkt einer langen Tradition und Raphael ihr letzter

Vertreter:

Die Zeit hatte gerade noch Kraft, einen Künstler aus sich zu heben, aber sie starb bald in einer Reihe kläglicher Dilettanten ab.285

Aus diesem Zitat wird noch eine abschätzende Beurteilung dieser Epoche klar, die Rilke als zu rasch aufgestiegen und daher nicht "vollendet" sieht:

Sie...bekamen...eine wachsende Kraft, die schon fast Sommer sein wollte: Michelangelo wuchs, Raphael stand in Blüten. Aber es wurde nicht Frucht; es war Juni, heißer, heller Gewitterjuni...Die Blüten krankten und starben, die welche Frucht werden wollten...Die kühlen, köstlichen harrten wie verzaubert der Erlösung, und warten noch. Damals war Mai, und die Welt sollte nicht alles auf einmal haben, Blütezeit und Ernte und...jetzt wird Sommer sein.286

Alle Schlüsselwerke der Hoch-Renaissance sind zwischen 1495 und 1520 entstanden. Aus dieser Tatsache entstand die Theorie (die Rilke mit seinen Zeitgenossen teilte) von einer ballistischen Kurve in der Entwicklung der Kunst, die in der HochRenaissance ihren Höhepunkt hatte und danach absteigen mußte. 287 Evident ist, daß Rilke in die zukunft die Hoffnung der Vollendung dessen, was in der Renaissance "wiedergeboren" war,

$$
\begin{aligned}
& 284_{\text {ibid. S. } 42 .} \\
& 285_{\text {ibid. S. } 45 .} \\
& 286_{\text {ibid. S. } 75 .} \\
& 287_{\text {op.cit. Janson, S. } 348 .}
\end{aligned}
$$


aber sich nicht weiterentwickeln konnte, legte. Um dieses zu erreichen, mußte man zu der "frühlingsumwilderten" Schönheit der Frührenaissance zurückgehen. Die neue Zukunft, den Sommer, sollten die Präraphaeliten herbeiführen. Die Frührenaissance wird in den Augen Rilkes zur Frühlingsrenaissance, $z u$ einem. Aufbruch vegetativer Kräfte:

Und in der ganzen Frührenaissance ist etwas von dem Wesen des blonden Jünglings. Eine keusche Kühle ist in ihren Madonnen und die herbe Kraft junger Bäume in ihren Heiligen. Die Linien sind alle wie Ranken, die in feierlicher Schweigsamkeit irgend etwas ganz Heiliges umschließen, und die Gesten der Gestalten sind zögernd, lauschend, einer zitternden Erwartung voll. Sie sind alle von der sehnsucht geweiht,..... Sie empfinden eine Fülle von Ewigkeiten, und weil sie nirgends bis an die Grenzen gehn, finden sie nirgends Schranken. Sie haben einen stillen und strengen willen in sich, aber es ist derselbe wille, der in den weichen Winden wirkt, und so müssen sie niemals Bewegungen wagen, die heftig und hastig sind. Sie sind so ganz eins mit ihrer Zeit, das macht sie schön. Und sie sind weder hart noch bang; denn weder haben sie sich diese Zeit erzwungen, noch sind sie ihre zufälligen Früchte....Das war der Frühling. Es kam noch kein Sommer seither; und wenn alle recht haben, vielleicht darf unsere Zeit den Sommer beginnen, der zu diesem fernen und festlichen Frühling gehört, und langsam zur Frucht entfalten, was sich damals in der weißen Blüte schon vollendete. 288

Der Hintergrund dieses Gedankens einer Frühlingsrenaissance ist allerdings nicht bei Rilke und der Jugendstil-Generation zum ersten Mal zu finden. Der Kunsthistoriker Vasari, der um 1550 lebte und auch in der Burckhartschen Kunstgeschichte, 
die Rilke kannte, erwähnt wird, ${ }^{289}$ hat schon kunst mit den Gesetzen der Natur gleichgesetzt. Genauso wie die Pflanzenwelt im Frühling mit neuem Leben erfüllt werde, erlebe auch die Kunst eine Blütezeit, nämlich die Renaissance, Vasari hatte auch schon die Befürchtung ausgesprochen, daß die Kunst der Renaissance sich. so weit und so schnell entwickelt habe, daß sie nur noch absteigen könne. Eine Stelle aus dem Stundenbuch drückt genau das aus:

Der Ast vom Baume Gott, der über Italien reicht, hat schon geblüht....

$\overline{\mathrm{doch}}$ er wurde mitten im Blühen müd, und er wird keine Früchte haben. Nur der Früling Gottes war dort....290

Die Bedeutung von Richard Muthers Botticelli-Interpretation für die Jugendstil-Generation

Daß die Jugendstil-Generation und ihre Vorbilder den Sommer herbei führen sollten, wird von Rilke schon vor seiner Italienreise, im März 1898, in dem schon zitierten Vortrag "Moderne Lyrik" formuliert. DiekVerbindung zwischen der Renaissance und den Kunstbestrebungen um die Jahrhundertwende wird folgendermaßen gezogen:

...seit den ersten Versuchen des Einzelnen, unter Flut flüchtiger Ereignisse sich selbst zu finden, seit dem ersten Bestreben, mitten im Gelärm des Tages hineinzuhorchen bis in die tiefsten Einsamkeiten des eigenen Wesens, - giebt es eine Mioderne Lyrik. Und das ist bitte erschrecken Sie nicht - etwa seit dem Jahre 1292.

${ }^{289}$ Rilke über Vasari: "...wie hoch steht er in seiner naiven Anerkennung über dem Gehaben seiner verkrüppelten Nachfahren." ibid. S. 59. 
Dieses ist das Jahr aus dem Advente der großen Renaissance, in welchem Dante die einfache Geschichte seiner ersten, jungen Liebe in der Vita nuova erzählt.291

Dante steht an "der Schwelle" der Renaissance und seine "Lieder" haben die "herrlichen Tage des'Cinquecento"vorausgefühlt, genauso wie das "reiche junge Dichtergeschlecht schön und stark am Rande einer in hundert Sinnen neuen Zeit..." steht. Weiter gibt die Rerıissance Rilkes Generam tion "Kleid und Geste"; "unsere modernsten Gefühle...vereinen (sich) so wunderbar mit der heiteren Tracht des Cinquecento! $222^{2}$ In der Poesie der Jahrhundertwende (Beispiel: Dehmel) ist zum ersten Male in der deutschen Lyrik -

die Peosie des Sommers erkannt und dieser Stimmung mit einem Schlag jene Bedeutung gegeben, welche das deutsche, alte Frühlingsgefühl in Jahrhunderten langsam erlangt hat. 293

Interessant ist in diesem Zusammenhang Richard Muthers Botticelli-Interpretation, die eine deutliche Brücke von den Präraphaeliten zu der deutschen Jugendstil-Dichtung schlägt, indem sie die ornamental empfundene Bewegung und das Blasse des Ausdrucks betont, das dieser "Frühlingsrenaissance" und damit auch dem Jugendstil einen so preziösen Charakter gibt. 294 Botticellis Kunst ist gekennzeichnet durch:

$$
\begin{aligned}
& 291_{\text {op.cit. SW V., S. } 360 f \text {. }} \\
& 292_{\text {ibid. S. } 374 \cdot} \\
& 293_{\text {ibid. S. } 375 \cdot} \\
& 294_{\text {op.cit. Jost Hermand, Ein Forschungsbericht, S. } 79}
\end{aligned}
$$


Stimmungsschwelgerei und Träumen, einer Romantik, die sich in der Sehnsucht nach einem Heimatland der Seele wieder ins glaubenstarke Mittelalter flüchtet und es mit allen Reizen der Mystik umwebt95

Besonders charakteristisch für seine Malerei ist der neue Madonnentypus, der

...von Botticelli selbständig geschaffen,... in der Kunst seinen Einzug (hält). Maria ist nicht mehr die Mutter, sondern ein bleiches, gedankenvolles Mädchen, das nur dazusein scheint, als unaufgegange. Knospe zu verkümmern, von einer stillen Schwermut, als ob man am Ende der Schöpfung stehe. Keine Lebensfreude, kein Sonnenschein, keine Hoffnung. $\mathrm{Bl} \mathrm{a} B$ und bebend die Lippen, ein müder weltschmerzlicher Zug um den Mund.....Auch in der Art, wie er das Kostüm behandelt und Blumen zur Steigerung der Stimmung verwendet,..... Statt der Madonne das modische zeitkostüm anzuziehen, hüllt er sie in blumengeschmückte, mit Gold und Stickereien verzierte Mäntel....Ganze Stilleben von Früchten und Blumen, kunstvolle, aus Cypressenzweigen und dicken Palmblättern errichtete Laubnischen bauen neben und hinter den Gestalten sich auf. 296

Hier haben wir eine Beschreibung des typischen Frauenbildes im Jugendstil. Botticelli hat schon "die ganze Psychologie des Blumenduftes, die wir so gern für das 19. Jahrhundert in Anspruch nehmen..." vorgeahnt, behauptet Muther. Nicht nur "die blasse, mädchenhafte zarte Marie" wird mit Rosen und Lilien und unzähligen Blumen umwölbt zur weihevolle Wirkung," sondern bei allen Gestalten ist "ein Duft von Jugend, Reinheit und Grazie...der Botticelli selbst identifiziert mit jenem Frühling, den er in seinem Hauptwerk verherrlichte."297

295 Richard Muther, Geschichte der Malerei. Bd.II. (Leipzig: G.S. Göschen'sche Verlagshandlung, I899), S. 19.

$296_{\text {ibid. S. } 21 .}$

297 ibid. S. 24 . 
Auch werden die Draperien nach diesem Prinzip behandelt "diese durchsichtigen Schleier und flatternden Bänder. Keiner vor ihm kannte so seine Florgewände, die, eng an die Glieder geschmiegt, deutlich die knospenhaften Formen zeigen." 298

Muther war um diese. Zeit zu einem großen Teil mit dem Jugendstil beschäftigt; er war Herausgeber einer Monographien-Reihe, die unter anderen Bände über Burne-Jones, Aubrey Beardsley und Max Klinger enthielt. Der Schritt von dieser Botticelli-Interpretation zur Motivwelt des Iiterarischen Jugendstils ist nicht weit.

Jugendstil-Motive in Rilkes Italien-Dichtung

Werke Rilkes, die in Italien und unmittelbar danach geschrieben worden sind, werden die Verbindungen zwischen der Botticellinischen Frührenaissance und dem Jugendstil noch einmal deutlich machen. Es handelt sich hier vor allem um die "Mädchen Lieder" und die "Gebete der Mädchen zur Maria" aus Mir zu Feier, "Die weiße Fürstin", "Spiel" und "Die Bilder entlang" und einzelne Gedichte.

Die Frau als Motiv in den "Mädchen Liedern" und "Gebeten". Der Frauentyp in den "Mädchenliedern" und "-Gebeten" erlebt seine Erfüllung - Nutterschaft - im Sommer, dem die Schwangerschaftsperiode des Frühlings vorausgeht. Dieser Vergleich wird im Florenzer Tagebuch schon angestellt und 
und das Ganze als Paralele zur Entwicklung in der Kunst gesehen:

So rein, wie jede Geliebte war in der Frühlingsre:-naissance, so heilig wird jede Mutter sein in dem Sommer, den wir beginnen.299

Unter dem Einfluß von Bildern der Renaissance beschreibt Rilke die Mädchen, die er in Italien sieht:

...nur die Muitter erscheinen müde und früh alt. Solange sie nur Frühling sind, leise, helle, lächelnde Mädchen, - und dann versagt ihre Sommerkkraft an den vielen Kindern und der vielen Arbeit. 300

Botticellis Madonna 301 ist ein "bleiches, gedankenvolles Mädchen...(eine) unaufgegangene Knospe", die vor stiller Schwermut zu verkümmern scheint. Eine Ëntsprechung dieser Sicht in den Gedichten ist die häufige Gleichsetzung der Mädchen mit dem Frühling und der Pflanzenwelt überhaupt:

Ihr Mädchen seid wie die Gärten am Abend im April:

Frühling auf vielen Fährten, aber noch nirgends ein Ziel....

Königinnen seid ihr und reich. Um die Lieder noch reicher als blühende Bäume.

Das emprandet ihr gleich: Königinnen seid ihr und reich.

Die Welle schlug euch nie so seid auch inr niegstill und singt wie sie.

299 op.cit. Tagebücher aus der Frühzeit, S. 73. 300 ibid. S. 108 .

${ }^{301}$ Siehe Zitat S. 155 dieser Arbeit. 302 op.cit. SW I., S. 173. 
Rilke skizziert die Mädchen jugendstilartig nur umrißhaft; wenn sie singen, so sind sie die "um die Lieder noch reicher als blühende Bäume, aus der Frühlingsnatur sich erhebende Stimme" 303 Daraus erklärt sich die Blässe ihrer Gesichter, ihre Lieder wiederholen nur die symbolisch gesehene Bewegung der Wellen, sind unbestimmte Sehnsucht. 304 vollkommen der Wasserwelt zugeordnet-werden die Mädchen so gezeichnet. (bleich, träumend) als seien sie schon ganz vergeistigt.

Ihr Mädchen seid wie die Kähne, und an die Ufer der Stunden seid ihr immer gebunden, darum bleibt ihr so bleich; ohne hinzudenken, wollt ihr den Winden euch schenken: euer Traum ist der Teich. Manchmal nimmt euch der Strandwind mit - bis die Ketten gespannt sind und dann liebt ihr ihn: 'Schwestern, jetzt sind wir Schwäne, die am Goldgesträhne

die Märchenmuschel ziehn.305

Bei näherem Hinsehen aber können sie ihre Zwitterstellung nicht verbergen, wie im folgenden Text, der ähnlich, ja sogar zum Teil identisch in der Wortwahl ist; das Verwobensein dieser Menschen mit der Natur aber ist gleichnishaft auf dem Lande dargestellt. Außerdem weiten die gewählte Farbgebung und die Erntetätigkeit der Mädchen das Bild zu einer Einheit mit der untergehenden Sonne aus. Hierin liegt ihre Einstim-

$$
303_{\text {ibid. }}
$$

${ }^{304}$ Paul Requadt, Die Bildersprache der deutschen Italien$\frac{\text { dichtung von Goethe bis Benn (Bern u. Minchen: Francke, 1962) }}{\text { s. } 179 \text {. }}$

$$
305 \text { op.cit. SW III., S. } 235 \text { f. }
$$


mung zur Erfüllung, die das Tagesende bringt, wie das für den Jugendstil typische Kranzsymbol, das hier als Ährenkranz auf das Ende der frühlingshaften Ungeduld und den Sommer verweist. 306

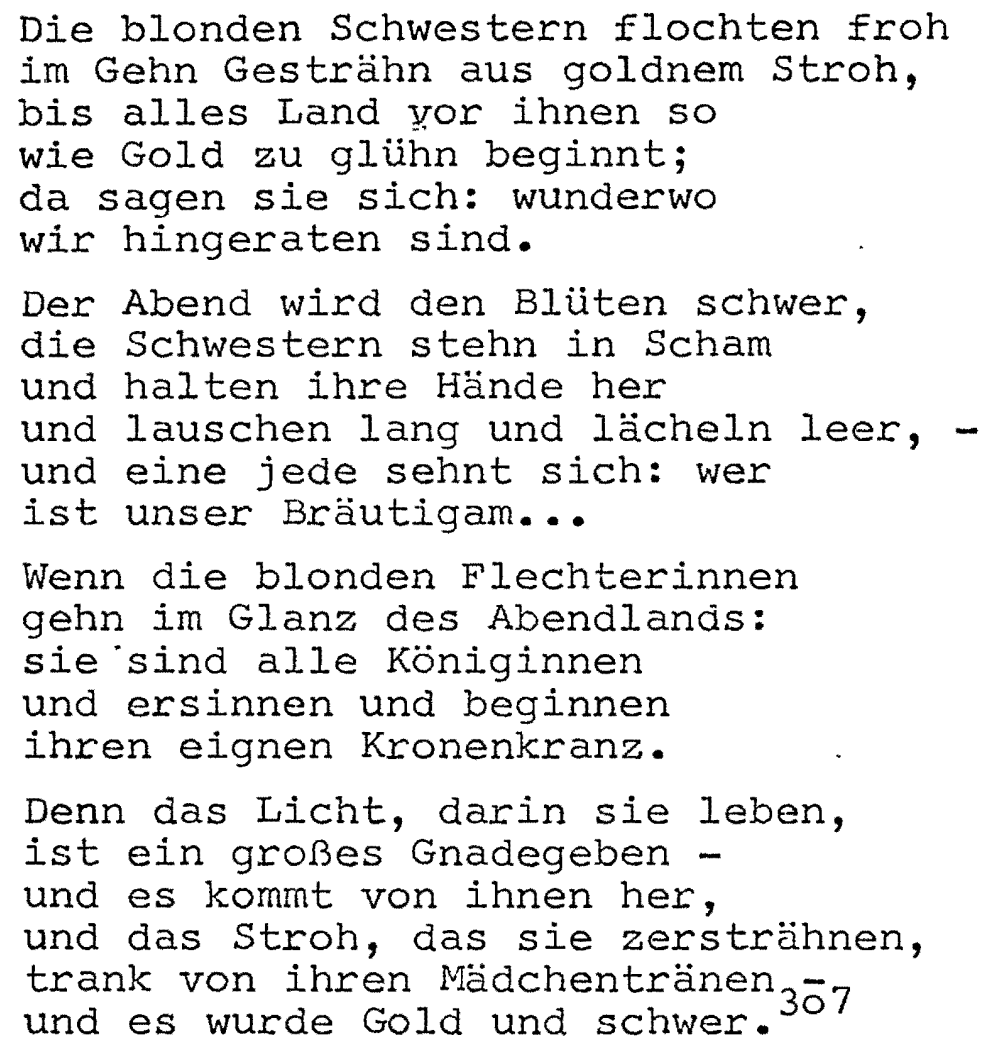

Die "Gebete der Mädchen zu Maria" sind eigentlich Gespräche über das Verlangen nach Verwandlung von Mädchen zu jungfräulichen Müttern: "Mach, das etwas uns geschieht! Sieh, wie wir nach Leben beben." Ihr Beispiel ist Maria selber:

Du wolltest wie die andern sein, die sich scheu in Kühle kleiden; deine Seele wollte seiden ihre müden Mädchenleiden weiterblühn am Lebensrain.

$$
\begin{aligned}
& 306 \text { op.cit. Requadt, s. } 179 \text {. } \\
& 307 \text { op.cit. SWI., s. } 175 \mathrm{f} \text {. }
\end{aligned}
$$




\begin{abstract}
Aber tief aus deinem Kranken wagte eine Kraft zu ranken, Sonnen lohten, Samen sanken: und du wurdest wie der Wein. 308
\end{abstract}

Die Umwandlung von Mädchen zu Müttern korrespondiert mit dem jahreszeitlichen Vorgang: Spätsommer - Herbst. Vor dem Tod (Winter) der Mütter helfen diese den jungen Mädchen noch, ihre Stelle im Früjahr einzunehmen.

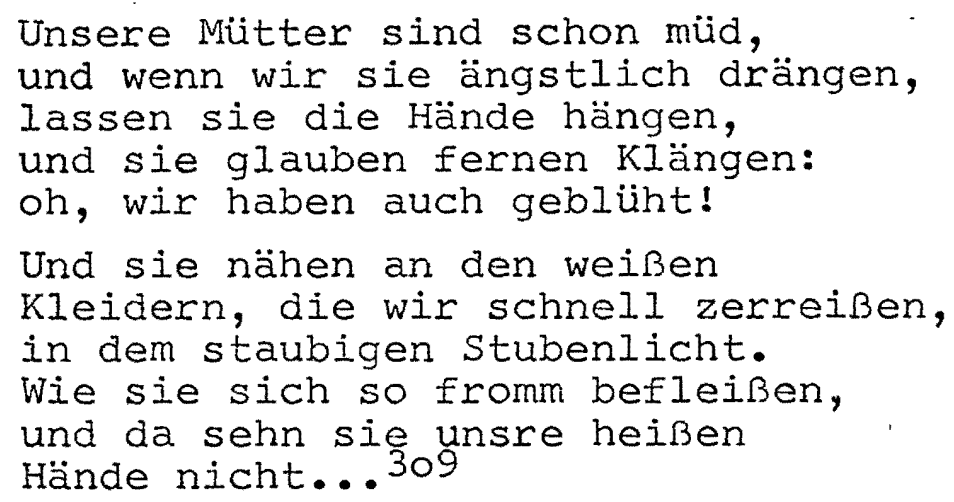

Das Erblühen der Mädchen und ihre kommende jungfräuliche Mutterschaft ist das frühlingshafte Erwachen der Natur, das sie schon in sich keimen fühlen:
Gestern hab ich im Traum gesehn einen Stern in der Stille stehn. Und ich fuhlte: Madonna sprach: Diesem Stern in der Nacht blüh nach. Und ich nahm alle Kraft zu Rat. Grad und schlank aus des Hemdes Schnee streckte ich mich. - Und das Blühen tat mir auf einmal weh...3lo

In dem Blühen ist schon das welken vorausgeahnt:

$$
\begin{aligned}
& \text { Mir wird mein helles Haar zur Last, } \\
& \text { als wäre drin verwühlt } \\
& 308_{\text {op.cit. SW III. , S. } 243 .} \text {. } 309_{\text {ibid. S. } 245 .} \\
& 310_{\text {ibid. S. } 247 .}
\end{aligned}
$$


ein dunkler Limonenast,

der schon in seinem Blühn verblaßt

und schwerer wird, weil er schon fast

exfüllt den Frühling fühlt. 31 I

In diesen Gedichten werden Blühen und Welken vereint - sie können gleichzeitig vorhanden sein. Dies ist der Fall, weil im Jugendstil das Gesamtleben, dessen Einheit in gesteigerten Augenblicken erfahren wird, immer zugleich werden und Vergehen, Schaffen und Zerstören ist. Es enthält den Tod in jedem Augenblick in sich, es besteht als Einheit von Leben und Tod. In der Literatur um die Jahrhundertwende sind Lebenssymbole zugleich Todessymbole. Es besteht ein gesch schärftes Bewußtsein dafür, daßß das Leben jedes Einzelwesens von Anfang an zugleich auch ein immerwährendes Sterben ist. Diese Auffassung ist noch beim späten Rilke vorhanden. "Blühen und verdorrn ist uns zugleich bewußt", heißt es in der vierten "Duineser Elegie." 312

Verschiedene Motive in der "weißen Fürstin". Auch in Rilkes Spiel "Die weiße Fürstin", in Viareggio geschrieben, wird der Tod als in das Leben eingewebt begriffen. Die Frührenaissance ist hier der historische Hintergrund, eine Insel im Meer der geographische, und die Hauptfigur- eine junge "noch nicht geblühte" weiße Fürstin. Sowohl alle Motive als auch die Gattung - das Spiel - sind jugendstilhaft. Auch Hofmannsthal, Stadler, C. Hauptmann und andere haben in diesem Sinne "Spiele" verfaßt.

$$
\begin{aligned}
& 31 I_{\text {ibid. S. } 249 .} \\
& 312_{\text {op.cit. SWI., S. } 697 .}
\end{aligned}
$$


Paul Requadt betrachtet diese Spannung zwischen allgegenwärtigem Leben und Tod als typisch für die Spannung zwischen Lebenswillen und Lebenshingabe im Jugendstil, die in der Farbsymbolik von Rot und Weiß erscheint. "Die Weiße Fürstin" wird im Florenzer Tagebuch als "Vision" zuerst aufgezeichnet. Eines Morgens betritt ein Mönch, in schwarzer Tracht und mit schwarzer Gesichtsmaske den Garten. Dieser Vorgang wird gleich als Farbkontrast konzipiert: der Mönch ist "der Tod selbst", der in den "hellen roten Garten" des Lebens hereinkommt. 313 Ein "weißes junges Mädchen" wird in das Geschehen verflochten, das "vor diesem Sonnenglanz zögerte und nicht Abschied nehmen konnte von der hellen Herrlichkeit". 314 In der ersten Fassung hält sich das Stück an diese Konzeption. Der Frater repräsentiert hier die Pest, wovor das Schloß auf der Insel im Meer und seine Bewohner: die weiße Fürstin, ihr Diener und ihre Schwester lange bewahrt bleiben; die. Insel gewährt bis zum Schluß Abgeschlossenheit und Sicherheit: Das Meer, das "nur in den Augen der Handelnden...auf die Bühne gebracht werden" kann, 315 stellt die Unendlichkeit dar, die Leben und Tod in sich schließt. Einerseits schützt es das Leben auf der Insel- andererseits bringt es den Tod, der in dunkelroten samt gekleidet sich zu-

313 Man erinnere sich hier an das gleiche Thema des Gedichts "Asrael" auf S. 98f. dieser Arbeit.

314 op.cit. Tagebücher aus der Frühzeit, S. 81 ff.

315 op.cit. Briefe und Tagebuicher 1899-1902, S. 18. 
erst verführerisch als Bote des erwarteten Geliebten meldet. Zum Schluß muß die Fürstin - ohne ihr Leben und ihre Liebe zum Geliebten vollendet zu haben - sterben. Das besagen ihr Name, ihre Kleidung und das weiße Schloß. Eine neue umgeschriebene Fassung ist 1904 entstanden, and noch 1906 denkt Rilke daran, die berühmte Duse für die Rolle der weißen Fürstin zu gewinnen, denn ihr hat er das stück gewidmet. 316 Die Allgegenwart des Lebens und des Todes kommt noch stärker in dieser zweiten Fassung heraus:

Sieh, so ist Tod im Leben. Beides läuft
so durcheinander, wie in einem Teppich
die Fäden laufen; und daraus entsteht
für einen, der vorübergeht, ein Bild.
Wenn jemand stirbt, das nicht allein ist Tod.
Tod ist, wenn einer lebt und es nicht weiB.
Tod ist, wenn einer gar nicht sterben kann.
Vieles ist Tod; man kann es nicht begraben.
In uns ist täglich sterben und Geburt,
und wir sind rücksichtslos wie die Natur,
die über beidem dauert, trauerlos
und ohne Anteil...3l7

Hier ist der Teppich ein Symbol für die Verbundenheit der Einzeldinge, für ihre Verwobenheit - in der für Hofmannsthal das Geheimnis bestand, "dieses große Rätselhafte des Lebens, daß alle Dinge für sich sind und doch voller Beziehung aufeinander."318 Der letzte Vers (s.o.) enthält eine sehr eigentümliche, für den Jugendstil typische Anschauung: "Tod ist, wenn einer lebt und es nicht weiß." Das seiner

$$
\begin{aligned}
& 316 \text { op.cit. Br.A. 1906-o7, s. } 96 . \\
& 317_{\text {op.cit. SWI., S. } 225 .} \\
& 318_{\text {op.cit. Rasch, S. } 23 .}
\end{aligned}
$$


selbst unbewußte Leben ist also kein Leben, ist Tod. Den Verkündern des Lebenspathos kommt es demgemäß eigentlich nicht auf das Leben selbst an, sondern auf das gesteigerte Bewußtsein des Lebens. 319

Jugendstil-Symbolik im "Spiel" und in den "Bildern entlang". Das "Spiel" - Ludwig von Hofmann zu eigen - wurde auch unter dem Einfluß der Eindrücke in Italien in Szene gesetzt. Vor seiner Interpretation ein Wort über Iudwig von Hofmann (1861-1945). Hofmann war ein wichtiger Mitgründer der Berliner Sezession. Die Zeitschrift der Sezession, "Pan", enthält viele Beiträge von ihm. Überhaupt steht er an der Spitze der jungen Generation. 1899 schreibt Richard Muther über seine Bilder:

Dieimoderne Sehnsucht nach dem verlorenen Paradies, das Sichzurückträumen in verlorene Schönheitswelten, hat in ihm wohl den reinsten Ausdruck gefunden...Kinder. sind seine Menschen, die vom Bösen nichts ahnen, Kinder, die uiber die Sonnenstrählen, über das Rieseln der Quelle staunen, denen die ganze Natur, ihr eigenes Sein ein Wunder bedeutet...Epheben und Mädchen, nackt und keusch, ruhen wunsch- und leidenschaftslos auf grüner Au oder bieten sich die Hand zum Reigen.320

Hofmanns Bilder sind stilisierend vereinfacht und wurden von ihm als Flächenornamente aufgefaßt. Notive des Badens, des Tanzens oder des Ruhens kehren immer wieder. Die Linien der Menschenkörper sind den Linien der Natur, des wassers, des Baumes nachgeahmt. Der Jugendstil erfüllt sich im Werk Hof-

$$
\begin{aligned}
& 319 \text { ibid. S. } 28 . \\
& 320 \text { op.cit. Hofstätter, S. } 172 f \text {. }
\end{aligned}
$$


manns am besten in den Bildern tanzenden Mädchen, deren arabeskenhaft bewegte Körper von fliegenden Schleiern umgeben sind. 321

Rilkes Bewunderung für Ludwig von Hofmann findet Ausdruck in der Widmung zu dem "Spiel":

Lieber Ludwig von Hofmann, in der Erinnerung sind mir Ihre Bilder wie Freuden und wie Geschenke. Oft wünschte ich Ihnen dessen ein Zeichen zu geben. Keine Gelegenheit kam. Bis mir dieses Lied gelang, das einmal später in einem Buch, "Spiele" stehen sol1. 322

Ludwig von Hofmann hatte Rilkes "Mädchenlieder" im "Pan" illustriert. Die folgende Beschreibung dieser Illustrationen wird dazu dienen, die Hofmannschen Motive mit Rilkes "Spiel" verbinden zu können.

Statt blasser Kantilenen, die im Ungewissen und $\mathrm{Na-}$ menlosen verhauchen, herrscht hier das SchwesterlichVerbundene, der gemeinsame Tanz junger Mädchen, deren luftige Kleider im Winde flattern. Uberall wird das Knospende, Pflanzenhafte dieser zarten Geschöpfe betont, die wie im Blütenregen daherzuwandeln scheinen. Auch die jungen Liebespaare werden in diesen floralen Reigen einbezogen und versinken an "heiligen Weihern", auf denen stolze Schwäne schwimmen, in märchenhafte Melusinenstimmungen, bis sie wünschlos "ineinander münden". 323

In dem "Spiel" wird das Thema der "Weißen Fürstin" umgekehrt. Hier erscheint ein wegen einer Gewalttat leidender

$321_{\text {ibid. }}$
$322_{\text {op.cit. SWIII., S. } 376 .}$

323 Richard Hamann u. Jost Hermand, Stilkunst um 1900. Bd. IV. der Reihe Deutsche Kunst und KuItur von der Gründerzeit bis zum Expressionismus. (Berlin: Akademie-Verlag, 1967), S. 285 . 
"Jüngling im Purpur": im Traum hatte er den Mann seiner geliebten Königin totgeschlagen; und von dessen Blut wurden desnenGewänder rot. Er sucht die heilsame Kraft des Meeres und wird von sieben Mädchen in Weiß am Strand gefunden, die ihn entsühnen, indem sie ihn mit "ihrem weißen Reigen" ganz umranken. Sie neigen sich näher über ihn, bis sie ihn endlich mit ihrem Reigentanz verhüllen. Die rote Farbe symbolisiert hier die leidenschaftliche Liebe zur Königin, die den jungen Mann im Traum dazu führt, den 'König zu töten. Die weiße Farbe wird hier wieder mit dem.frühlingshaften und der leidenschaftslosen Liebe der jungen Mädchen gleichgesetzt. Das lichte und leuchtende Meer im Hintergrund erfüllt einen ähnlichen Stellenwert wie in der "Weißen Fürstin." Das Tanzen der jungen Mädchen|zeigt das Schwesterlich-Verbundene und ihr Einfallen in die Harmonie des Alls, wodurch sie auch eine heilsame Kraft vermitteln können. Ihre Bewegungen werden in Verbindung mit der "breiten landenden Bewegung" der Wellen gebracht, die nach der Bühnenanleitung das vordere Drittel des Schauplatzes ausmachen sollen. 324

Rilke stellte noch zwei andere solche Spiele zu dieser Zeit fertig, aber das geplante Buch ist nicht erschienen. Weiter dichtete er einen Zyklus zu Bildern Iudwig von Hofmanns, der im "Pan" veröffentlicht wurde. Das "Pan" - Heft besteht aus 19 Blättern mit Hofmanns Bildern, Skizzen und Buchschmuck. Gegenüber dem gedruckten Inhaltsverzeichnis 
setzte Rilke "Die Bilder entlang." Die Gedichte sind höchstwahrscheinlich kurz nach Fertigstellung des Heftes entstanden (Juni 1898). Sie sind eindeutige Produkte des Jugendstils. Das erste Gedicht heißt "Schwanenweiher".

Schenke den Schwänen dein Schaun, gieb ihnen dein Vertraun zu tragen :m

weit; bis hin wo die Bäume ragen, bis an die Hügel, die blaun.

Traun:

es legt sich dein $B_{I}$ ick wie ein silberner zügel um sie. Und lenkt sie in ruhigen Ronden. und ihre Flügel, die selten schlagen, sind wie Gefühle von Fraun, von blonden. 325

Aus dem Gedicht spricht ein Gefühl des Vertrauens, das durch die ruhigen, harmonischen Bewegungen der Schwäne ausgedrückt wird. Den Schwänen Vertrauen zu schenken, hei்ßt Vertrauen in das Schöne und Vollkommene zu haben, welches "weit" weg liegt - in einer romantischen Welt. Doch das Schauen, der Blick - die Vorstellung dieser Welt - kann die Schwäne lenken und Schönheit schaffen. Das paradiesische Leben der Schwäne wird dem Jugendstil damit zugänglich. In einem anderen Gedicht dieses Zyklus - "Parzival I" - ist der Schwan das Hauptmotiv und zwar die Heiligkeit seines Sterbens, das Schönheit und Schrecken umschließt und damit eine gewisse Verherrlichung des Todes. Andere Gedichte haben den Teich zum Hauptmotiv: 


\section{Iibelle}

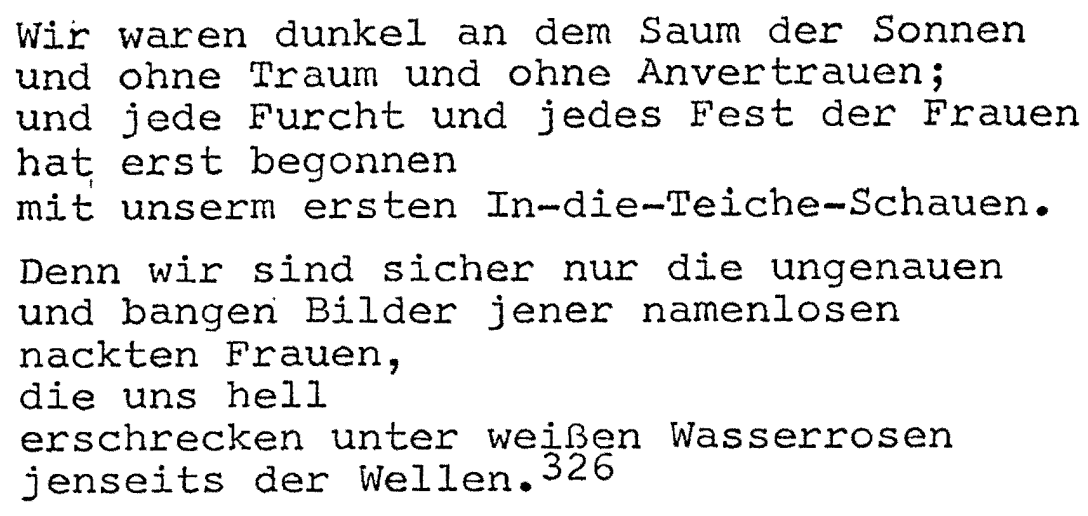

Die Libelle ist ein häufig verwendetes Symboltier im Jugendstil, bestimmt wegen ihrer sinnlichen und wellenförmigen Bewegungen und ihres leichten durchsichtigen Körpers. Der Frauentyp in diesem Gedicht entspricht dem nackten Naturwesen, 327 das die Sinnlichkeit erweckt. Das mystische Erlebnis, das "In-die-Teiche-Schauen", führt zu einer Entdeckung des Urweiblichen und des weiblichen Prinzips an sich durch die Widerspiegelung. Auch in dem Gedicht "Küssendes Paar" ist der Teich Hintergrund für ein sinnliches Erleben der Verbundenheit mit der Geliebten und dadurch mit dem Dasein:

Erst hat die welt sich wandeln müssen im Abendwind, bevor ich fand zu deinen Küssen, die wie ein Fahren auf den Flüssen und wie ein Tag an Teichen sind.

Lang war der Weg und schwer die Wende, die ihn entschied, und tief das Lied: 
Damit wir in einander münden, muß sich ein Riesenreigen ründen den du beginnst, den ich beende. 328

Der Kuß ist die sichtbare Verbindung zwischen zwei Menschen. Das wellenförmige Bewegungsspiel, das parallel zum bildnerischen Jugendstil läuft, wird hier besonders in der letzten Strophe klar. Zwei münden ineinander, sind Anfang und Ende eines Reigens - fließen ineinander und sind untrennbar. 329 Die akustische Welle eines gerade verklungenen Liedes sieht der Dichter noch im Gewand und im Gang, eigentlich im ganzen Körper des Geliebten.

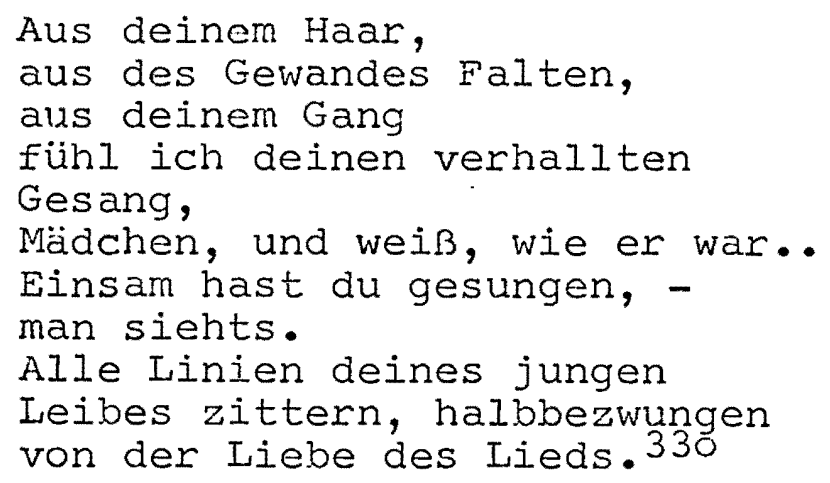

Die Entstehung von Rilkes Ding-Verständnis. Rilke war als Schönheitssucher nach Florenz gegangen. Dort findet er "Dinge", die ihm auf dern wege helfen, "ein Vertrauter alles dessen zu werden, was Schönheit verkündet." 331 Sein ziel ist, den Dingen "immer: mehr ein Jünger" zu werden, "der ihre

328

op.cit. SW III., S. 623

${ }^{329}$ Siehe S. 56f. dieser Arbeit. 330 op.cit. SW III., s. 626.

331 op.cit. Tagebücher aus der Frühzeit, S. $88 \mathrm{f}$. 
Antworten und Geständnisse durch verständige Fragen steigert, der ihnen Weisheiten und Winke entlockt und ihre großmütige Liebe mit der Demut des Schülers leise lohnen lernt." 332 Rilke beschreibt sich als nicht mehr bloßer Bewunderer der Schönheit, sondern er will ihr vertraut sein und durch die "Dinge" von ihr lernen. Mit diesem Ziel für seine Kunst verläßt er Italien. Wie seine für den Jugendstil so wichtige Ding-Auffassung wächst, ist aus Tagebüchaufzeichnungen und Kunstaufsätzen von damals zu ersehen. Schon in einem Gedicht in der Münchener Zeit redet er von dem Singen der Dinge, das er hören will:

Ich fürchte mich so vor der Menschen Wort. Sie sprechen alles so deutlich aus: Und dieses heißt Hund und jenes heißt Haus, und hier ist Beginn, und das Ende ist dort.

Mich bangt auch ihr Sinn, ihr Spiel mit dem spott, sie wollen alles, was wird und war;

kein Berg ist ihnen mehr wunderbar;

Ihr Garten und Gut grenzt grade an Gott

Ich will immer warnen und wehren: Bleibt fern.

Die Dinge singen hör ich so gern.

Thr rührt sie an: sie sind starr und stumm.

Ihr bringt mir alle die Dinge um. 333

Der Gedanke, daß man die "Dinge" nicht besitzen kann, wird

vor der Rußland-Reise im Schmargendorfer-Tagebuch erläutert:

Nicht ein Sarg wollen uns die Hände sein; ein Bett nur, darin di.e Dinge dämmernden Schlafes pflegen und Träume tun, aus deren Dunkel heraus ihre liebsten Verborgenheiten reden. Jenseits der Hände aber sollen die Dinge weiterwandern, stämmig und stark, und wir wollen von ihnen nichts behalten als das 
mutige Morgenlied, das hinter ihren verhallenden Schritten schwebt und schimmert. Denn Besitz ist Armut und Angst; Besessenhaben allein ist unbesorgtes Besitzen.

Bei jedem Ding will ich einmal schlafen, von seiner Wärme müd werden, auf seinen Atemzügen auf und nieder träumen, seine liebe gelöste Nachbarschaft an allen meinen Gliedern spüren und stark werden durch den Duft seines Schlafes und dann am Morgen früh, eh es erwacht, $3 \frac{3}{4}$ allem Abschied, weitergehen, weitergehen...334

Wie wir sehen werden 335 erinnert dieses an Themen des Spätwerks. Rilkes Überlegungen zum "Kunst-Ding" sind auch nicht erst durch Rodin angeregt worden, sondern eben durch seine Verbindung zum Jugendstil, was deutlich werden wird in seinen Kunstaufsätzen vom Jahre 1898 nach der Italienreise. Folgende Aufsätze beschäftigen sich ausschließlich mit den Dingen: "Zur Melodie der Dinge", "Der Wert des Monologs", "Die neue Kunst in Berlin", "Über Kunst", "Impressionisten" und "Die Salon der Drei". In dem zuerst erwähnten Aufsatz wird die Aufgabe des Künstlers in bezug auf die Dinge folgendermaßen dargestellt:

Sei es das Singen einer Lampe oder die Stimme des Sturms, sei es das Atmen des Abends oder das Stöhnen des Meeres, das dich umgiebt - immer wacht hinter dir eine breite Mielodie, aus tausend Stimmen gewoben, in der nur da und dort dein Solo Raum hat. Zu wissen, wann Du einzufallen hast, daß ist das Geheimnis deiner Einsamkeit; wie es die Kunst des wahren Verkehres ist: aus den hohen worten sich fallen lassen in die. gemeinsame Melodie. 336

334 op.cit. Tagebücher aus der Frühzeit, S. 152. ${ }^{335}$ Siehe S. 242 dieser Arbeit. 336 op.cit. SW V., S. 416. 
Die Menschen aber, die diese Melodie nicht hören, sind wie "Bäume, welche ihre Wurzeln vergessen haben und nun meinen, daß das Rauschen ihrer Zweige ihre Kraft und ihr Leben sei." Der Künstler dagegen ist "der Eingeweihte des Lebens" und muß die große Melodie des Lebens hören und das "Bild des tieferen Lebens, des mehr als heutigen, immer zu allen Zeiten möglichen Erlebens" 337 im Kunstwerk manifest machen. In einem weiteren Vergleich tritt die Bedeutung der Wellenlinie noch deutlicher hervor: man müsse die Lebensmelodie in ihren primitiven Formen erkannt haben und...

...aus den rauschenden Tumulten des Meeres den Takt des Wogenschlages ausschälen und aus dem Netzgewirr täglichen Gespräches die lebendige Linie gelöst haben, welche die anderen trägt...338

In dem. Aufsatz "Der Wert des Monologes" stellt Rilke seine Vorstellungen für eine neue Bühne nicht nur in bezug auf den Monolog dar, sondern auch in Bezug auf die Dinge. Für ihn hat "ein Schrank, ein Glas, ein Klang..." so viel Anteil am Leben wie die worte: "Im Leben hat alles denselben Wert, und ein Ding ist nicht schlechter als ein Wort oder ein Duft oder ein Traum." 339 In dem Aufsatz "Die neue Kunst in Berlin" geht er noch weiter in der "Befreiung der Dinge". Hier ist es der Jugendstil-Künstler Van de Velde, der "die Leibeigenschaft der Dinge" aufhebt. Der Künstler sei Messias der Dinge:

$$
\begin{aligned}
& 337_{\text {ibid. S. } 418 .} \\
& 338_{\text {ibid. }} \\
& 339_{\text {ibid. S. } 442 .}
\end{aligned}
$$


Holz darf Holz sein und Eisen - Eisen. Nicht allein das: ein jedes darf sich seiner Eigenart ruhmen. Und wie sie das tun: schlicht und heiter, wie Kinder, die sich über den Bach neigen. 340

Die neue Kunst in Berlin ist natürlich der Jugendstil, insbesondere Torfüllungen, Vitrinen, Tische, alles "in hellem Holz, leicht, ruhig, gesund". Das neue des Jugendstils und auch das Grundprinzip sei die "Bewegung breiten Wellenschlagens, ein rhythmischer Ausgleich von Last und Kraft." 341 Zusammengefaßt läßt sich sagen: Rilke ist zu: einer Ding-Auffassung gekommen, die dem Jugendstil entspricht. Der Künstler muß die Melodie in den Dingen hören und in seinem Kunstwerk das Bild des tieferen Lebens, das er in den Dingen findet, nachschaffen. Es sind die Jugendstil-Künstler, die das Verdienst haben, die Dinge gehört zu haben und selber sprechen zu lassen - Van de Velde, Riemerschmied, Endell, Leistikow, Thoma, Habermann, und Max Klinger werden in diesem Zusammenhang besprochen. Das Kunstwerk bekommt natürlich die gehobene Stellung des "Dinges":

Das Kunstwerk möchte man also erklären: als ein tiefinneres Geständnis, das unter dem Vorwand einer Erinnerung, einer Erfahrung oder eines Ereignisses sich ausgiebt und, losgelöst von seinem Urheben, allein bestehen kann. Diese Selostständigkeit des Kunstwerkes ist die Schönheit. Mit jedem Kunstwerk kommt ein Neues, ein Ding mehr in die Welt. 342

Gott ist das größte Kunstwerk, das vom Künstler geschaffen

$$
\begin{aligned}
& 340_{\text {ibid. S. } 443 .} \\
& { }^{341_{i b i d}} \\
& 342_{\text {ibid. S. } 429}
\end{aligned}
$$


wird. Der bisher nur angedeutete Gedanke an diesen zukünftigen Gott findet hier eine klare Formulierung: ...der Künstler (ist) der Mensch des letzten Zieles, der jung durch die Jahrhunderte geht, mit keiner Vergangenheit hinter sich. Die andern kommen und gehen, er dauert. Die anderen haben Gott hinter sich wie eine Erinnerung. Dem Schaffenden ist Gott die letzte, tiefste Erfüllung. Und wenn die Frommen sagen: "Er ist" und die Traurigen fühlen "Er war", so lächelt der Künstler: "Er wird sein." Und sein Glauben ist mehr als Glauben; denn er selbst baut an diesem Gott. Mit jedem Schauen, mit jedem Erkennen, in jeder seiner leisen Freuden fügt er ihm eine Macht und einen Namen zu, damit der Gott endlich in einem späten Urenkel sich vollende, mit allen Mächten und allen Namen geschmückt. 343

Rilkes spätere Italien-Kritik und sein Abrücken vom

Renaissancekult. Als Rilke später in seinem Leben Abstand von der Jugendstil-Tradition nahm, änderte er auch seine Auffassung von der Frïhrenaissance. Schon nach seinen russischen Reisen wird man ein gewisses Abrücken davon endecken und 1902 äußert sich Rilke schließlich kritisch dem "Renaissancekult" gegenüber:

In Deutschland war inzwischen jenes verfrühte Reanaissancegefühl, jene leichtsinnige künstlerische überhebung, die nun alle beherrscht und mitreißt, zu einer gefährlichen Höhe angewachsen, so daß ich, der voll zustimmung von den demütigen und zukünftigen Menschen der großen Wolga $\mathrm{kam}$, machtlos und zusammenhanglos, wie ein Schweigender unter Geschwätzigen stand, überzählig und unzeitgemäß in jedem Sinn. 344

In einem Brief vom 12. Mai 1904 geht Rilke so weit zu sagen, daß "der italienische Einfluß nicht zu dem gehört, was mich wirklich weiter bringt" und daß er italienische Dinge

$343_{\text {ibid. S. } 427 .}$

344 op.cit. Briefe und Taqebücher 1899-1902, S. 147. 
wie einen "Rückfall in den Bilderbogenunterricht" empfinde. Der blumenreiche italienische Frühling bringt für ihn "nichts Neues...nichts Weites und Unabsehbaresy:

Die große Armut fühlte ich, die im Reichsein liegt: wie bei uns eine Blume, eine kleine erste Blume, die ringt und kommt, eine Welt ist, ein Glück, an dem teilzunehmen unendlich gut macht - und wie hier Herden von Blumen kommen, ohne daß etwas sich rührt in einem, ohne daß etwas teilnimmt und sich verwandt fühlt....Frühlingsausstellung ist es, was hier geschieht, nicht Früling....Es ist gut, daß ich das alles so langsam und leibhaft erfahren habe; denn Italien war immer noch ein Ruf für mich gewesen und eine unabgeschlossene Episode. Nun aber kann ich es getrost verlassen, denn der Abschluß ist da. ${ }^{345}$

1907 mildert er diese Ansicht: die frühe italienische Kunst Benvonuto di Giovanni ist "licht und leicht wie Beete mit Frühsommerblumen." Weiter heiBt es

...diese Zeit (die Renaissance) war in allem gewaltig; und soviel man gegen sie als Kunstperiode aufbringen mag, mit mancher Berechtigung, - das Leben hat Raum in ihr und wuchs nach allen Seiten. 346

Rilke hatte ein großes Interesse an den Gedichten Michelangelos während dieser Zeit entwickelt - Briefe von 1906-1912 bezeugen dies. Zwischen 1913 und 1921 übersetzte er sehr viele von ihm. Er scheint seine kritische Meinung von der Hochrenaissance während der Florenzer Tage geändert zu haben, wo er noch gesagt hatte: Michelangelos Kunst "wurde im Blühen müd" und konnte "keine Früchte haben." 347 Die beginnende $\mathrm{Zu-}$

$$
\begin{aligned}
& 345 \text { op.cit. Br.A. 1902-06, s. } 150-3 . \\
& 346 \text { op.cit. Br.A. 1906-07, s. } 331 . \\
& 347 \text { op.cit. SW III, S. } 330 .
\end{aligned}
$$


neigung zu Michelangelos Werk wird eigentlich schon 1899 deutlich in einem Kapitel aus den Geschichten vom lieben Gott - "Von einem, der die Steine belauscht." 348 Michelangelo als Vertreter der Hochrenaissance ist jetzt nicht mehr ein zufälliges Produkt der Geschichte, sondern einer der lauscht und werkt - seine Schöpferkraft befreit Gott, der im Stein verborgen ist und macht ihn zur Gestalt.

${ }^{348}$ RiIke, Sämtliche Werke. Bd. IV. (Wiesbaden: Insel, 1961), S. 345ff. 


\section{DIE RUBLAND-BESUCHE}

Rilkes nächstes Kunststudium fand statt vor seiner ersten Rußland-Reise und während seines Aufenthaltes dort vom 25. April bis Ende Juni 1899 und wieder vom Mai bis August 1900. Seine Reiseführerin in beiden Fällen war Lau. Zusammen mit ihr verbrachte er Tage und Wochen dabei, die russische Kunst zu studieren. ${ }^{349}$ Dieses erwähnt er in den Briefen an die Freundin von Lou, Frieda von Bülow; leider gibt es keine Tagebucheintragungen und sonst nur zwei Aufsätze über russische Kunst aus den Jahren 1901 und 1902 . Seine Eindrücke sind auch in den Werken, die zu dieser Zeit entstanden sind, zu finden. Im Herbst 1899 nach der ersten russischen Reise wurde geschrieben: der erste Teil des Stundenbuches, Die Geschichten vom lieben Gött, Die Weise von Liebe und Tod des Cornets Christoph Rilke und einzelne Gedichte. Mit diesen Werken beginnt sein Ruhm als Dichter. Um die Entwicklung seiner Kunstauffassung zu beurteilen, die diese "reiferen" Werke ermöglicht hatte, muß man sein Kunsterlebnis in Rußland schildern.

349 Aleksis Rannit führt die folgenden werke an, die von Rilke zur Vorbereitung in Russisch gelesen wurden: J. Sabélin: "Russische Kunst", Moskau, 1900; A.P. Nowitzki: "Die Geschichte der russischen Kunst," Moskau, 1899; "Allgemeine Kunstgeschichte" von P.P. Gnjéditsch, St. Petersburg, 1897. In Aleksis Rannit, "Rilke und die Slawische Kunst." Das Kunstwerk: Eine Zeitschrift über alle Gebiete der bildenden Kunst. 5. Jahr. Heft 4, 1951. (Waldemar Klein Verlag: Baden-Baden), S. 14. 
Mit Lou, und von ihrer Liebe zu Rußland und zum russischen Volk beeinflußt, ging Rilke nach Osten und fand ein Land und eine Kunst, die für ihn in völligem Gegensatz zu Italien stand. Hier dachte er seine seelische Heimat gefunden zu haben, so beeindruckt war er von der Weise des russischen Volkes - ihrer Kunst, Religion und der Iandschaft. Rilkes russische Kunstaufsätze.

Was ihn besonders daran fesselte, ist aus den zwei Kunstaufsätzen zu ersehen. Sehr einleuchtend ist seine Aussage: Rußland sei "das weite Land im Osten, das einzige, durch welches Gott noch mit der Erde zusammenhängt..." 350 In Rußland dauert noch "der erste Tag....der Tag Gottes, der Schöpfungstag" denn "neben den fieberhaften Entwicklungen der nachbarlichen Kulturen bleiben ihm breitere Atemzüge, und in langsamen, immer wieder zögernden Schlägen geht seine Entwicklung vor sich." In Rußland meint Rilke das Ursprüngliche noch erhalten gefunden zu haben, während im Westen es in der zu raschen Entwicklung "in der Renaissance, in der Reformat: tion, in Revolutionen und Königreichen" verloren ging •

Rilkes Beurteilungen über Ost und West sind ziemlich subjektiv und intuitiv. Seine Mythologisierung ist wichtig, weil er hier in eine Diskussion über Kunst des Ostens und des Westens übergeht. Das russische Volk wolle nämlich ein Künstler-Volk werden und die Aufgabe des Künstlers sei es, das Volk zum Künstlertum zu erziehen. Das bedeutet wieder eine

$$
350 \text { op.cit. SW V., S. } 494
$$


völlige Abkehr von der These der Florenzer Tagebuches. Die einzige Bedingung des russischen Künstlers ist, daß er sich an die Heimat hält und den "bestechenden, glänzenden Einfluß fremder Schönheit, der ihn seinem Volke entfremdet", vermeidet. Die traditionelle Form muß den Künstler bilden, ehe er das Volk bildet. Diese Form ist die "Gebärde des Gebets", die das Volk mit dem Inhalt seines ganzen Erlebens fühlt - für den Künstler, das alte Heiligenbild, die Ikone, worin alle Erlebnisse der russischen Natur ausgedrückt sind. Diesem Bild der Einheit zwischen Volk und Kunst stellt Rilke die Kunst des Westens, besonders die der Renaissance gegenüber.

Atemlos kam die Renaissance auf den Gipfeln ihrer Entwicklung an, verstiegen in der steilen Einsamkeit ihrer Ziele, wie jener Kaiser auf der Martinswand, den nur ein Engel wieder zurück zum Volke führen kann. Der Renaissance kam kein solcher Engel. 351

Die Werke der Renaissance hatten "eine halb hoffnungslose, halb übermütige Kraft aufgetürmt... an den Grenzen des Lebens" und haben das italienische Volk weit hinter sich gelassen und ihre Aufgabe des "Erziehens" nicht bewältigt. Er schaut auf Rußland in der Erwartung, daß ein langsamer Aufstieg dort die Erfüllung "jenes jagenden Traumes, von dem Italien noch zittert" sein wird, insofern die russische Kunst dem Volk, verbunden bleibt. - Rußland also an Stelle der Jugendstil-Generation. 352

$351_{\text {ibid. }}$

${ }^{352}$ Siehe S. 152f. dieser Arbeit. 
In dem späterem Kunstaufsatz, "Moderne russische Kunst" von 1902, hat er seine naive, idealistische Haltung der russischen Kunst gegenüber gemildert. Dieses Mal setzt er sich mit den Problemen dieser Kunst auseinander. Das besonders Russische istjjetzt seiner Meinung nach die Fähigkeit des tiefen Nachdenkens:

Viel zu nahe kommt dem Auge des russischen Menschen das Gesicht seines Nächsten; er sieht es und erlebt und erleidet es, als sähe er sein eigenes Gesicht in einer schweren Stunde. Diese Fähigkeit hat die großen Schriftsteller gebildet; sie alle, Gogol und Dostojewskij und Tolstoj wären nicht ohne sie Aber sie ist dicht imstande große Maler zu erziehen.

Rilke nennt es Rücksichtslosigkeit, was dem Russen fehlt. Rücksichtslosigkeit, ein Gesicht malerisch "das heißt ruhig, leidenschaftslos, wie eine Sache $z u$ sehen, nicht daran teilzunehmen im menschlichen Sinne; sein Schauen geht leise in ein Mitleiden, in Lieben und Helfen über, also über das Bildliche hinaus zum Stofflichen." 354

Hier widerspricht Rilkes Meinung seiner früheren, daß das russische Volk geboren war, um das Künstler-Volk der Zukunft zu werden. Diese Wandlung ist vielleicht mit seinem Besuch in Paris zu erklären und vor allem durch seine Bekanatschaft mit Rodin. Obwohl der Aufsatz vermutlich schon bis Ende 1901 (vor Rodin) abgefaßt wurde, wurde er erst im November 1902 bei der Korrektur in Paris unterzeichnet. Zu dieser Zeit schrieb Rilke schon an dem ersten Teil seiner Rodin-

$$
\begin{aligned}
& 353_{\text {op.cit. SWV., S. } 613} \\
& 354_{\text {ibid. S. } 614 .}
\end{aligned}
$$


Monographie. Hier sucht er nicht die subjektive, religiöse, intuitive Kunst Rußlands, sondern die objektive, dinghafte Rodins. Die Pólarität zwischen ost und west ist darin ausgedrückt.

Rilkes russische Kunstkritik war in erster Linie themabedingt und nicht ästhetisch-formalistisch. Einige größere Maler der Zeit waren für ihn nur. Nebenerscheinungen: Lewitan, Wrubel und Rjepin. Rilke hatte aber mit diesem Aufsatz seine Liebe für russische Kunst nicht aufgegeben. Er hat noch die Hoffnung, daß die jüngere Generation, die in Paris gewesen ist und sich mit der modernen Kunst befaßt hatte, "mit ungestörtem Gleichgewicht nach Hause und zu ihrer Arbeit zurückkehrt...um gerecht sein zu können gegen ihre heimische Kunst und ihre Vergangenheit." 355

Ganz zum Schluß wendet sich Rilke einem ganz anderen Thema zu - nëmlich dem russischen Kunstgewerbe und dem Interesse der neuen russischen Generation dafür. Hier zeigt sich seine und ihre Teilnahme am Jugendstil. Alte Stickereien, Schnitz- und Tischlerarbeiten, Ausschmückungen von Kinderbüchern wurden von den Russen studiert und nachgearbeitet. Nach Rilke ist hier einer von den Wegen, auf welchem "die russische Seele versucht hat, zur Kunst zu gehen". Was sie im Grunde sucht, ist "ein Bild"; "...nach einem Bilde, das nicht Schicksale und Gesichten erzählt wie ein menschliches Gesicht, sondern das einfach da ist, damit man es anschaue: 
also nach einer großen Kunst." 356 Dieses ist eine Ahnung der Dinghaftigkeit, die Rilke bei Rodin fand und in seiner ei- genen Kunst suchte. "Der Pather", das früheste Gedicht in seinen dinghaften Neuen Gedichten, wurde kurz hiernach verfaßt. Weitere Beziehungen Rilkes zum russischen Jugendstil wurden schon in Verbindung mit der Wiener Sezession bespro $=$ chen. 357

Hier muß erwähnt werden, daß Rilke den Kontakt mit Rußland sein ganzes Leben lang aufrecht erhalten hat durch die Freundschaft mit dem Maler Leonid Pasternack und dessen Sohn Boris.

Die im'stundenbuch'sichtbaren russischen Einflüsse

Um den Einfluß der Kunst auf Rilkes Werk bis in seine russische Zeit zu zeigen, sind die Werke, die im Herbst 1899 nach seiner ersten Rußlandreise geschrieben wurden, zu besprechen. Der erste Teil des Stundenbuches (UDie Gebete," später das "Buch vom mönchischen Leben" genannt) ist für uns am wichtigsten in bezug auf Rilkes bisherige Erlebnisse im Jugendstil, in der italienischen Renaissance und in der russischen Kunst.

Die überwiegende Stimmung in diesem Werk resultiert aus dem russischen Kunst-Erlebnis. Der Dichter nimmt die Person eines russischen Mönches an, der Ikonen malt; die

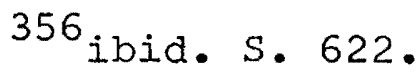

${ }^{357}$ Siehe S. 46ff dieser Arbeit. 
Verse sind seine "Gebete" - Rilkes Kenntnisse der IkonenKunst kommen in vielen Versen zum Ausdruck:

Nichts ist mir zu klein, und lieb es trotzdem und mal es auf Goldgrund und groß, und halte es hoch, und ich weiß nicht - wem, löst es die seele los. 358

\section{oder}

Wir dürfen Dich nicht eigenmächtig malen,

Du Dämmernde, aus der der Morgen stieg.

Wir holen aus den alten Farbenschalen

die gleichen striche und die gleichen Strahlen,

mit denen Dich der Heilige verschwieg. 359

Das ist eine Wiedergabe der russischen Tradition, in der viele von den Ikonenmalern Heilige waren und sonst hauptsächIich Mönche. Das Wort "Ikone" ist griechisch fur"Ebenbild" oder "Widerspiegelung", und in diesem Sinne mußten Ikonen nach der alten griechischen Art gemalt werden in dem Glauben, daß diese bildliche Darstellung dem Urbild nahe sei und daß man dadurch den Dargestellten (den Heiligen selber) sehe. Dieser Glaube gibt der Ikone wunderwirkende, heilende Kräfte. Die innerliche Heiligkeit dieses Stoffes verlangte, daß der Künstler, der dafur verantwortlich war, von so einem reli= giösen und frommen Charakter wie nur möglich sei.

Die Worte "...mal es auf Goldgrund und groß" erzählen vom traditionellen goldenen Hintergrund bei der Ikone, der den Glanz des Himmels darstellen sollte. "Ich weiß nicht. wem, löst es die Seele los" ist eine Andeutung auf die wunderwirkende Macht der Ikone und ihrer Fähigkeit, die Heiligen

$$
\begin{aligned}
& 358 \text { op.cit. SW III., S. } 307 . \\
& 359 \text { ibid. S. } 308 .
\end{aligned}
$$


zu personifizieren. Die Verse: "Wir dürfen Dich nicht eigenmächtig malen" beziehen sich auf die Tatsache, daß die Ikonen kein persönlicher Ausdruck des Künstlers sein durften; sie mußten genau dem griechischen Urbild entsprechen daher: "Wir holen aus den alten Farbenschalen die gleichen Striche und die gleichen Strahlen".

Immer wieder kommt auch die Dunkelheit der russischen Kunst zum Vorschein und damit das Unbewußte und Intuitive. Der Mönch liebt seines "Wesens Dunkelstunden, in welchen seine Sinne sich vertiefen."

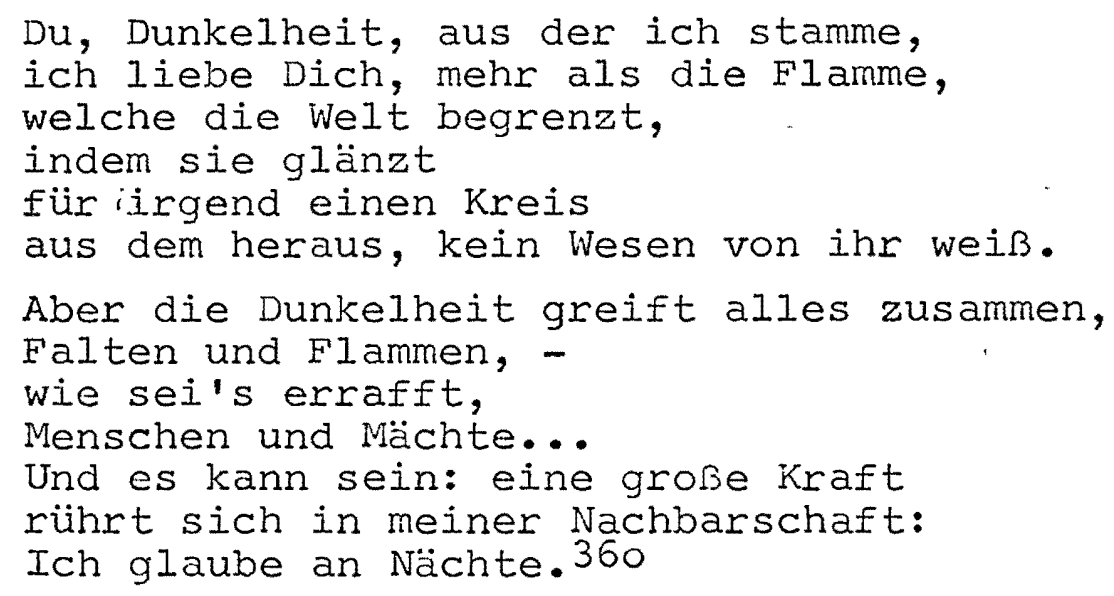

Die hier vorhandene nächtlich-dunkle Stimmung entspricht der der Ikonen rnit ihren dunklen, dämmernden Farben. Das findet seinen Kontrast in der Renaissancekunst, die selbstbewußter ist und sich hauptsächlich mit Licht beschäftigt. Der Mönch liest davon in fremden Büchern und erinnert sich erregt daran. Hier werden Madonnen "geplant", das heißt, eigenmächtig gemalt: "Ich weiß wie menschlich sie Madonnen planen, und 
träume oft von jungen Tizianen, durch die der Gott in Gluten geht."361 Tizian kann für einen "eigenmächtigen" Künstler der Hoch-Renaissance gehalten werden. Fast tausend Jahre lang, seit dem Jahre 787, dem zweiten Konzil zu Nicaea, hatte die Kirche über die Kunst bestimmt: "It is not the painter but the Holy Fathers who have to invent and dictate. To them manifestly belongs the composition. To the painter remains only the execution." Die Leistung Tizians liegt darin, đaß er Kunst von der Bestimmung der Kirche befreit hatte. 362 Durch ihn geht der Gott "in GIuten." In Tizians Werken ist eine gewisse Lebenslust (GIut) festzustellen: seine Gemälde sind voll von hellen frohen Farben;auch diejenigen mit religiösen Themen. Damit steht seine Kunst in direktem Gegensatz zu der des Mönches, der spricht: Döch, wie ich mich auch in mich selber neige... Mein Gott ist dunkel und wie ein Gewebe von hundert Wurzeln, welche schweigsam trinken. Nur, daß ich mich aus seiner wärme hebe, mehr weis ich nicht, weil alle meine Zweige tief unten ruhn und nur im winde winken. 363

In diesem Bild des Baumes, dessen Wurzel aus dunklem Ursprung dem sichtbaren Baum Leben gibt, stellt der Mönch (jugendstilhaft) seine unmittelbare Verbindung $\mathrm{zu}$ Gott fest. Gott ist aber das selbst - er findet Gott nur, wenn er sich in sich selber vertieft.

$$
\begin{aligned}
& 361_{\text {ibid. S. } 308 .} \\
& 362_{\text {op.cit. Janson, s. } 380 .} \\
& 363_{\text {op.cit. SW III., S. } 508}
\end{aligned}
$$


Rilke bleibt bei der These im Florenzer Tagebuch:

Italien war eine Höhepunkt, aber keine Vollendung der Kunst und damit keine der Offenbarung Gottes:

Der Ast vom Baume Gott, der über Italien reicht, hat schon geblüht. $\overline{\mathrm{doch}}$ er wurde mitten im Blühen müd, und er wird keine Früchte haben. Nur der Frühling Gottes war dort.... 364

In der Urfassung sind diese Verse eingeleitet mit den folgenden Worten:

Der Mönch hat in einem großen Buche den "Moses" des Michelangelo im Bilde gesehen. Er kennt auch die unvollendete Pieta, welche sich in Florenz hinter dem Hauptaltar des Domes befindet, aus einer $\mathrm{Zeich}-$
nung.

Die Vollendung der Kunst und Verkündigung Gottes liegt in RußIand:

Mit einem Ast, der jenem niemals glich, wird Gott, der Baum, auch einmal sommerlich verkündend werden und aus Reife rauschen. In einem Lande, wo die Menschen lauschen, wo jeder ähnlich einsam ist, wie ich.366,

Diese zeilen werden so eingeleitet:

Aus seinen Bildern, meint der Mönch, ist die Maria unterwegs auf ihrem weiten Weg. Sie ist vor Jahrhunderten aus den silbernen Ikonen fortgegangen und geht durch die welt in Gestalten und Werken. Und wird, wenn sie müde ist, in die Ikone wiederkehren, und ihr Kind wieder in diese silbernen Wiegen legen und bei ihm sitzen und singen....Denn die zeiten sind

$$
\begin{aligned}
& 364_{\text {ibid. S. } 330 .} \\
& 365_{\text {ibid. }} \\
& 366_{\text {ibid. S. } 332 .}
\end{aligned}
$$


wie ein Kreis, und festlich ist der Tag da ein Reifes in seinen wartenden Anfang fällt. 367

Daraus ersieht man noch deutlicher, daß die Maria der Renaissance nur eine vorübergehende Verwandlung der russischen Maria war. Wenn die Zeit reif sein wird, wird ihre Vollendung in der Ikone liegen.

Hiermit taucht das Problem einer Definition des Gottesbegriffs im Stundenbuch auf. Durch ein Heranziehen des Jugendstils kann man vieles erläutern. Bert Herzog behauptet in einem Aufsatz: "Der Gott des Jugendstils in Rilkes'Stundenbuch"':

Anscheinend wußte Rilke damals selbst noch nicht, was Gott für ihn war. Er schien erst zu wissen, was Gott nicht mehr war: kein christlicher Gott mehr, kein persönlicher Gott, kein Gott der Offenbarung. Es war alles noch ein Tasten im Nebel, ein irgendwie noch Ausgespartes, eine Erweichung der alten Substanz ins Gefühlige, ein Sich-entzücken an schwebenden Dingen, ein religiösen Lyrismus, der sich enthusiasmierte, der aber,.... weder vor Lebenskraft noch LebensIust überschäumte, sondern einem müden zug nôschgab, aus der Sehnsucht nach dem Leben geboren. 368

Diese Grundstimmung der nebulösen Sehnsucht nach dem Leben, eines Sich-Entzückens an schwebenden Dingen, ist die "Theologie" des Jugendstils überhaupt. Gott ist eben ein Vorwand für den Ausdruck des Gefühls, wie Rilke im Florenzer Tagebuch erklärt. Er ist die sich verwandelnde Gestalt; ist der Schmied, das Lied der Jahre, das große Morgenrot über den Ebenen der Ewigkeit, der Hahnenschrei nach der Nacht der Zeit, 367 ibid.

${ }^{368}$ Bert Herzog, "Der Gott des Jugendstils in Rilkes Stundenbuch". In Schweizer Rundschau, IX, 21, S. 1238 . 
der Tau, die Maid, der fremde Mann, die Mutter und der Tag. Diese Bilder zeigen ein fragendes Ergriffensein und ein Schwanken ohne Halt und Gestalt, was auch vom Jugendstil gesagt werden kann.

Wenn Gott nicht der Gott der Offenbarung ist, ist er der "offenbarte" Gott. Gott ist, was der Künstler aus sich hebt, was er macht, malt oder baut:

Wir bauen an dir mit zitternden Händen und wir türmen Atom auf Atom. Aber wer 6 kann dich vollenden,
du Dom. Ein anderer Aspekt dieser Abhängigkeit Gottes von dem Menschen, der Rilkes anti-christliche Neigungen zeigt, ist, daß Gott ohne den Menschen seinen Sinn verliert:
Was wirst du tun, Gott, wenn ich sterbe?
Ich bin dein Krug (wenn ich zerscherbe?)
Ich bin dein Trank. (wenn ich verderbe?)
Bin dein Gewand und dein Gewerbe, mit mir verlierst du deinen Sinn. 370

E.C. Mason drückt einen solchen Gottesbegriff so aus: "Man ist nicht Atheist, denn man glaubt, daß das Leben göttlich ist; man ist aber ebensowenig Theist, denn dasjenige, an dessen Göttlichkeit man glaubt, ist eben das Leben." 371 Schopenhauer nennt einen solchen Menschen einen höflichen Atheisten, denn man sagt noch Gott, aber man meint ihn nicht mehr; man spricht noch "Gebete", aber sie sind an niemanden

$$
\begin{aligned}
& 369 \text { op.cit. SWIII., s. } 316 . \\
& 370_{\text {ibid. S. } 334 .} \\
& 371_{\text {op.cit. Herzog, s. } 1239 .}
\end{aligned}
$$


gerichtet. "Religion ist eine Art und Weise des Fühlens, aber ihr Gegenstand ist imaginär und nur ein Vorwand, um den Aufschwung des Herzens zu erleben, um zum Fühlen zu kommen, um ergriffen zu sein." 372

Weitere Jugendstil-Themen im 'Stundenbuch' und in einzelnen Gedichten

Jugendstil-Motive, die im Stundenbuch und in anderen werken nach den RuBland-Reisen wiederzufinden sind, sind: die Liebe, das künstliche Paradies und die Wellenlinie, allerdings nicht mehr in dem Maß wie in München und nach Italien.

Die Liebe ist Teil des pantheistischen Weltgefüls und somit Teil der neuen Religion. Ein "Gebet", das schon im Schmargendorfer Tagebuch aufgeschrieben worden ist (1899) und dann noch in den zweiten Teil des Stundenbuches eingeschoben wurde, ist eben kein Gebet sondern ein Liebesgedicht. Von Gott war nicht die Rede, sondern nur von Lou, und damals stand Lou wohl sogar neben Gott und beide waren vertauschbar. Bert Herzog will sogar behaupten, daß der Gott des Stundenbuches gar nicht war, oder nur etwas Vorgeschobenes, und daß immer wieder Lou gemeint war und in Lou das Leben, das All, die Natur und die Göttlichkeit des Lebens. ${ }^{373}$ Das Liebesgedicht lautet folgendermaßen:

Lösch mir die Augen aus: ich kann dich sehn, wirf mir die Ohren zu: ich kann dich hören,

$372_{\text {ibid. }}$

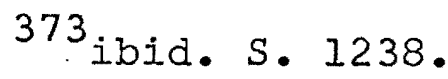


und ohne Füße kann ich zu dir gehn, und ohne Mund noch kann ich dich beschwören. Brich mir die Arme $a b$, ich fasse dich mit meinem Herzen wie mit einer Hand, halt mir das Herz $z u$ und mein Hirn wird schlagen, und wirfst du in mein Hirn den Brand, so werd ich dich auf meinem Blute tragen. 374

Das künstliche Paradies. Bereits die Handlung des Stundenbuches ist an sich typisch für das künstliche Paradies im Jugendstil. Ein russischer Mönch - ein Ikonenmaler zieht sich von der welt zurück und betet in Versen, die einen Anflug von Raffinement und Luxus haben, denn seine Worte sind ausgesucht, die Metaphern exquisit. Vor allem in Schönheit besteht der Sinn des Seins:

Und um der Schönheit willen sind wir beide und wundersam zu einem Werk geweiht. Wie Bilder sind wir, tief in alter seide. Und ob ich male, träume oder leide, ich hange wie ein glänzendes Geschmeide um Deiner Schultern Dunkelheit.

Die Schönheit ist von allem Sein der Sinn. Sie nahm zuerst von den verhehlten Lenden die falschen Falten einer schlechten Scham, die rohe Freude wurde von ihr zahm, und von ihr trägt die Sehnsucht und der Gram die schmalen Kronen, welche blenden. 375

Dieser Haltung entspricht der Wunsch, mit Kostbarkeiten seine Ideal-Welt auszustatten:

Ihr vielen unbestürmten städte,

tut auf die Tore von Topas.

Die Gassen sind verstummt von Gras, aber in eurer Wände Glätte sieht sich der Tag wie Gold und Glas...376

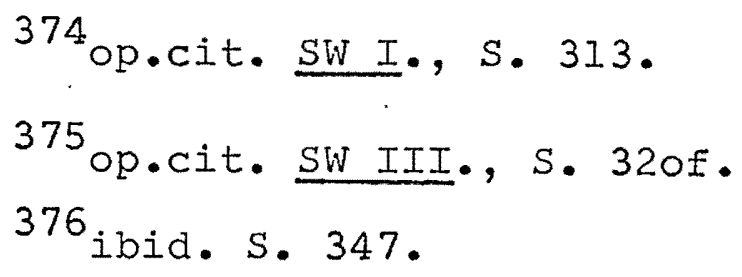


Die Welle ist eine der häufigsten Motive im Stundenbuch. Gott geht durch die Schöpfung "wie eine Welle"; sein Wille "geht wie eine Welle und jeder Tag ertrinkt darin"; er ist auch die Windeswelle, die von ihm und von den Engeln durch den Mönch zu den Menschen geht:

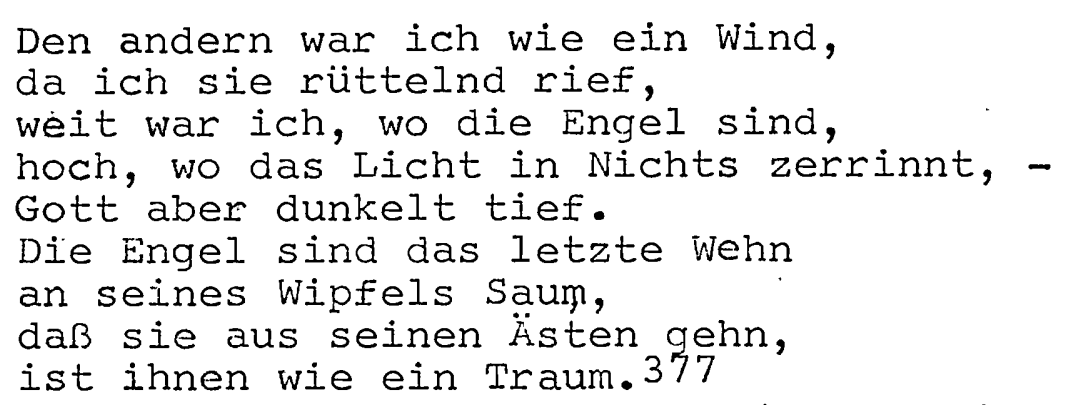

Rilkes pantheistische Weltanschauung findet - wie bereits früher - ihren adäquaten Ausdruck, indem das Motiv der Wellenbewegung innerhalb der Natur in Ringen und Kreisen wiedergegeben wird:

Ich lebe mein Leben in wachsenden Ringen, die sich über die Dinge ziehn.

Ich werde den letzten vielleicht nicht vollbringen, aber versuchen will ich ihn:

Ich kreise um Gott, um den uralten Turm, und ich kreise jahrtausendelang -

und ich weiß noch nicht: bin ich ein Falke, ein Sturm oder ein großer Gesang...378

Die im Tanz enthaltenen Wellen kehren ebenso wieder: "...so wird euch eine Nacht beginnen die, wie der Traum der Tänzerinnen, von Linien und Ringen lebt;"379 oder "Du bist nicht mehr

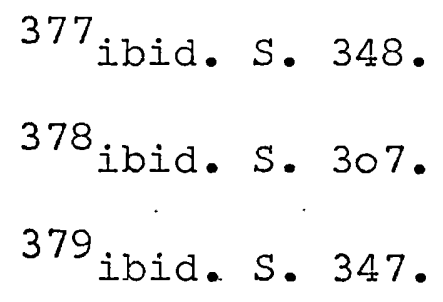


inmitten deines Glanzes, wo alle Iinien des Engeltanzes die Fernen dir verbrauchen wie Musik...". Hier wird Stimmungszauber sprachlich sichtbar gemacht. Vorstellungen von bestimmten Bewegungen scheinen von untergeordneter Bedeutung zu sein. Die Zeilen entziehen sich dem Faßbaren vollkommen. 380

Auch kann der Tanz Bild für das Leben überhaupt und dem Tod gegenüber gestellt sein:

Und statt Bacchanten, die berauscht und, rot von Wein und Abend, durch den Taxus tanzen, kommen zwei Jünglinge mit schwarzen Lanzen und stillen Stirnen, die wie hinter Schanzen geborgen denken an den großen Tod.381

Im folgenden Gedicht wird der Tanz als optisches Bild auf eine rein akustische Bewegung übertragen und der Eindruck einer Wellenbewegung im Optischen als auch im Akustischen entsteht:

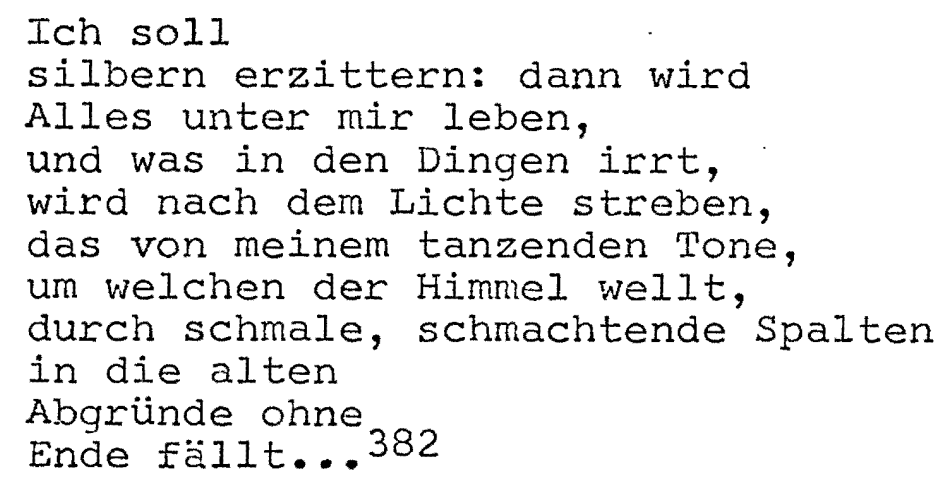

Neben diesen Motiven erscheint der Ding-Begriff erneut im Stundenbuch; besonders bezeugt er die allgegenwärtige An${ }^{380}$ Dietgard Kramer-Lauff, Tanz und Tänzerisches in Rilkes Lyrik (Niunchen: Wilhelm Fink VerIag, 1969), S. 73. 381 op.cit. SW III., S. 649.
$382_{\text {op.cit. SWI., S. } 401 .}$ 
wesenheit Gottes: Gott ist das Ding der Dinge, ist in den Dingen - ist das "wundersame Spiel der Kräfte" und die Melodie der Dinge ist die Inspiration für den Mönch. 383

Die Suche nach einem neuen Stil

Die wendung in Rilkes Kunst, die nach der ersten russischen Reise eintritt und bis ungefähr 1903 dauert, wird von ihm in vielen Gedichten und Tagebucheintragungen ausgedrïckt. Die entsprechenden Stellen zeigen insbesondere die Problematisierung seines Ding-Bewußtseins und eine damit notwendige Stil-Änderung. Schon im Dezember 1897 deutet sich die neue Entwicklung an:

Ich möchte werden wie die ganz Geheimen: Nicht auf der Stirne die Gedanken denken, nur eine Sehnsucht reichen in den Reimen.....
Nicht mehr verraten und mich ganz verschanzen.... 384 Rilke will seine gefühlvolle Lyrik, die er später als oberflächlich bezeichnete, etwas bändigen - er sucht einen ernsthafteren Ton. E.C. Mason weist darauf hin, daß eine Begegnung mit $\mathrm{S}$. George nur wenige wochen, bevor dieses Gedicht geschrieben wurde, die Inspirationsquelle gewesen sei. Denn gerade George hatte eine solche von Rilke ersehnte unpersönliche, monumentale und disziplinierte stilhaltung entwickelt. Nach der ersten Rußlandreise will er scheinbar sich erneut um einen neuen stil bemühen:

Noch ist vieles an mir, was ich hasse; aber ich fühle doch schon, daß das Fremdes ist, Zufälliges, das nicht

$$
\begin{aligned}
& 383_{\text {op.cit. SW III. }} \text { s. } 323 . \\
& 384_{\text {op.cit. SWI., S. } 154 .}
\end{aligned}
$$


mit mir zusammenhängt. Daraus kommt mir dieses Vertrauen und diese Kraft. Ob ich es einmal erreichen werde, ganz in eigenen Kleidern zu gehen ich weiß es nicht. Jedenfalls will ich erst mal
nackt werden, dann läBt sich das Weitere finden.

Der Wunsch, tiefer in sich selbst einzudringen und sich nicht beeinflussen zu lassen von "modernen" Richtungen - hier ist bestimmt der Jugendstil gemeint - heißt gleichzeitig aber, in die Dinge tiefer einzutauchen, was immerhin auch ein Bemühen des Jugendstils gewesen war und eine Erkenntnis, die er aus Italien und RuBland mitgebracht hatte. Er will einerseits weniger ich-bezogen in das wesen der Dinge vordringen und andererseits gerade dadurch seine Gefühle erforschen und auch "Bilder" für sie finden. Was wegfallen muß, sind die überflüssigen Gebärden und Worte:

$\mathrm{Zu}$ vieler Weisheit bin ich noch zu jung, mein Blut vergeudet sich noch in Gebärden; doch will ich reif zu solchen Worten werden, daß ich fast wie ein Schweigender erscheine und wie ein Haus am Rande der Ukraine und wie ein Bild aus stillem Elfenbeine und wie ein wunder in dem heiligen Weine 386

In diesem Sinne meint er ebenfalls Ende 1899:

Du mußt ein Bild für das Gefühl erfinden, das du verschenken willst an viele Fremde, denn fest muß man umfassen, was man reicht; Du darfst nicht sagen, was du heimlich hast,... Du mußt Blüten tragen wie ein Ast, dann werden alle winde Dich verkünden. 387

385 op.cit. Tagebücher aus der Frühzeit, S. 156. 386 op.cit. SW III., S. 645 . 387 op.cit Tagebücher aus der Frühzeit, S. 204. 
Die bereits im Herbst 1899 entstandenen Werke sind allerdings auch ein Beleg dafür, daß Rilke den erwünschten Stil noch nicht verwirklichen konnte. Auch viele Gedichte aus dem Buch der Bilder, die gleichzeitig verfaßt wurden, besitzen nur eine oberflächliche Bildhaftigkeit. Aber trotz aller unvollkommenen Versuche, eine Dinghaftigkeit in seiner eigenen Kunst $z u$ verwirklichen, sind die eben zitierten Zeilen jedenfalls ein Beweis für sein Bemühen, den Dingen vertrauter zú werden. ${ }^{388}$ Auch die Kunstdinge sind damit gemeint:

Die Dinge aber müssen willig halten,
was einer ihnen in die Hände legte;
da sagt ein Glas, was meinen Ahn bewegte,
ein Buch verrät mir, was er heimlich hegte,
und dieser Atlas, der um die Gestalten
vergangner Frauen rauschend sich erregte,
fält immer wieder in die alten Falten.
Was in uns schläft, bleibt in den Dingen wach,
aus ihnen schaun uns dnnkel Augen nach,
die unsere Gebärden weit begleiten:
Die Ersten dauern, und wir sind die Zweiten. 389
Im Früjahr 1900 erkennt Rilke, daß die Entwicklung ejajes eigenen Stils nur dann erfolgreich zustande kommen kann, wenn er seine Beziehungen zu "modernen" Richtungen abbricht. Am 6. März 1900 heißt es in einem Brief an Frieda von Bülow: "Ich habe fast keine literarischen Beziehungen mehr und vermeide jeden Anlaß, solche zu begründen." 390 vielleicht hat

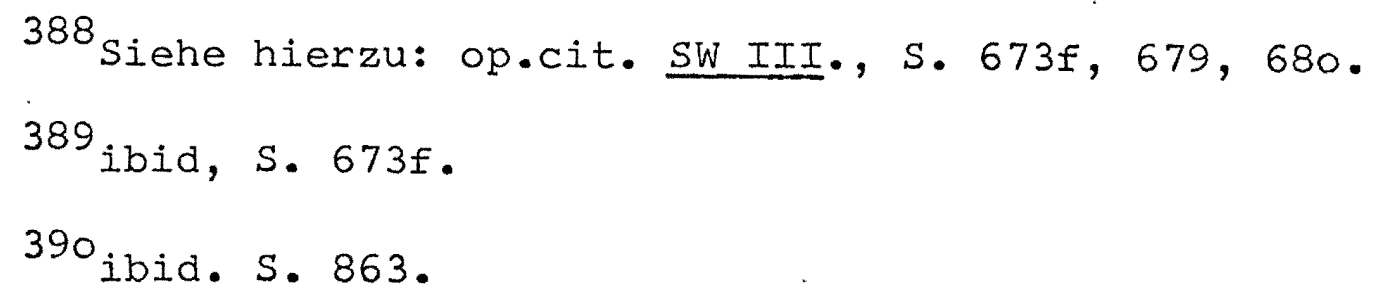


Rilke damals seine Fähigkeit zur Zurückgezogenheit etwas überschätzt; denn schon ein Aufenthalt bei H. Vogeler in Worpswede im Herbst dieses Jahres läßt ihn enge Beziehungen zum Jugendstil durch die Kunst Vogelers und seine Gäste, unter anderen Heymel und Schröder, die Herausgeber der "Insel", schließen. Seine Suche nach Ausdruckssteigerung wird immer dringender:

Alles Gefuihl, in Gestalten und Handlungen wird es unendlich groß und leicht. Ich ruhe nicht, bis ich das eine erreicht: Bilder zu finden für meine Verwandlungen. Vir genügt nicht das steigende Lied. Einmal muß ich es mächtig wagen, weithin sichtbar auszusagen 391
was im Ahnen kaum geschieht.

Und schon im Herbst 1900 spricht er von einem "Fortschritt":

Und wieder rauscht mein tiefes Leben lauter, als ob es jetzt in breitern Ufern ginge. Immer verwandter werden mir die Dinge und alle Bilder irnmer angeschauter. Dem Namenlosen fuhl ich mich vertrauter: Mit meinen Sinnen, wie mit Vögeln, reiche ich in die windigen Himmel aus der Eiche, und in den abgebrochnen Tag der Teiche sinkt, wie auf Fischen stehend, mein Gefühl. 392

Die Tagebucheintragung, die diesem Gedicht vorausgeht, zeigt ebenfalls eine neue Gewißheit seines entwickelteren Stadiums. Doch seine große Subjektivität Gott und den Dingen gegenüber und die Ornamentalität der Bilder zeigen, daß er immer noch der Jugendstil-Tradition zugewandt bleibt:

Alle Kräfte steigen in mir. Alles Leben versammelt sich zu meiner Stimme. Ich sage alles reich. ileine

$$
\begin{aligned}
& 391_{\text {ibid. S. } 699 .} \\
& 392 \text { op.cit. SW:I., S. } 402 .
\end{aligned}
$$


Worte sind wie bestickt mit dunklen Steinen. Ich spreche oft von wenigen Dingen und fühle: "Von großen Dingen sollst du groß reden oder schweigen", und ich sehe es ihnen manchmal ani ich habe groß geredet. O daß nicht Hochmut wäre, was ich da sage, $\mathrm{da \beta}$ es wie Demut klänge und wie Dankbarkeit. Aber es gibt Tage, da ich von mir nicht reden kann, ohne Gott zu nennen, den einsamen Gott, in dessen Schatten meine Worte dunkeln und glänzen. 393 


\section{WORPSWEDE}

Die Verbindung zu Heinrich Vogelers Version des Jugendstils Rilkes Reise nach Florenz war aus noch einem anderen Grund für ihn bedeutend. Hier lernte er den Maler Heinrich Vogeler kennen. Nach seiner Rückkehr besucht er Vogeler im Dezember 1898 und sieht Worpswede und die Künstlerkolonie, von der Vogeler ein Mitglied ist, zum ersten Mal. Er ist wieder Vogelers Gast im Herbst 1900. Ab Ende März 1901 bis August 1902 wohnt Rilke in Westerwede bei Worpswede.

Worpswede ist typisch für die im Jugendstil vorhandene "Kleinraumkunst" 394 - der Rückzug in das künstliche Paradies. Worpswede liegt nördlich von Bremen und war um 1900 ein kleines Dorf, das mitten im Moor ziemlich allein stand und bewohnt war von einigen Bauern, Handwerkern und Torfstechern. Fritz Mackensen war der erste der Künstler, die das Dorf entdeckten, und allmählich entstand eine Kolonie. Als Mittelpunkt der "Kleinraumkunst" war Worpswede in gewisser Weise eine Flucht aus der Wirklichkeit und ein Versuch, "aus dem Vollbesitz kreativer Kräfte eine standhaltende Gegenwirklichkeit (auf kleinen Raum) zu erzeugen." 395 Durch H. Vogeler, der mehr im typischen Jugendstil malte als die anderen, die sich hauptsächlich mit Landschaftsmalerei abgaben, kam Rilke

$$
\begin{aligned}
& 394 \text { op.cit. Rosenhaupt, s. } 39 . \\
& 395 \text { op.cit. D. Jost, Literarischer Jugendstil, S. } 8 \text {. }
\end{aligned}
$$


jetzt also auf den Jugendstil zurück. Wie die Präraphaeliten war Vogeler eine Poetennatur, der Lieder und Gedichte schrieb, war mehr Stimmungsmensch als die anderen Maler. Er pflegte eine feinkultivierte Lebensführung, trug Biedermeier,Kleidung und gestaltete sein Haus und Garten ebenso. ${ }^{396}$ Er war also der Beardsley-Typ, der "Dandy" im Jugendstil. Seine Gemälde sind sehr farbenreich, und in die idealisierte Landschaft des Moores setzt er die Gestalten seiner meist literarisch angeregten Fantasie. Seine Themen sind Personen und Szenen aus Märchen, aus der Bibel oder die der Präraphaeliten. Vogeler war auf fast allen Gebieten des Kunstgewerbes tätig. Als Graphiker illustrierte er jugendstilmäßige Bücher, nicht nur von Rilke, sondern auch von Hauptmann, Wilde, Hofmannsthal, Bierbaum, Jacobsen, R. Huich und anderen. 397 Er war Architekt, bemalte Festräume, entwarf Möbel, Parkanlagen und baute Häuser. 1914 meldete er sich als Kriegsfreiwilliger. 1917 wurde er aus Idealismus Kommunist und ging nach Rußland. Die Bilder dieser Zeit gehören nicht mehr zum Jugendstil, sondern zum Expressionismus. 398

Einige Gedichte für Vogeler verfaßte Rilke schon nach seiner Rückkehr aus Florenz 1898. Aus dem Jahre 1899 gibt es unter anderen ihm gewidmeten Gedichten das "Gebet zu

396 Hans Wohltmann, Worpswede (Worpswede: Verlag Haus am Weyerberg, 7. ergänzte Auflage 1967), S. 27.

397 op.cit. Petzet, s. 49 f. 398 op.cit. Wohltmann, s. 27. 
Sankt Georgs Macht und Namen", welches Rilkes und Vogelers märchenhaftes Weltbild zeigt. Rilke hatte sich schon seit seiner Kindheit mit Rittern beschäftigt, und seine frühen Visionen einer militärischen Zukunft spielen eine Rolle noch im "Coronet." Die Mischung von Heldentum und Poesie, Blut und Gesang bewundert Rilke in der Dichtung Liliencrons. Seine Teilnahme an dieser Art Dichtung in "Sankt Georg" drückt sich so aus: er rettet "ein sanftes Mädchen in blassem Taft...ihr lichtblaues Gewand ist noch...voll Sand und von Angst gerafft". Zum Schluß preist er St. Georg:

$$
\begin{gathered}
\text { Deine fromme verkündende Kraft } \\
\text { Deine tiefe silberne Ritterschaft: } \\
\text { Komme all über uns. } \\
\text { Wohne bei uns wohne. } \\
\text { Amen.399 }
\end{gathered}
$$

Die übersentimentale Haltung wird in den Gedichten fortgesetzt, die Rilke 1900 in Worpswede zu Vogleers Bildern schrelbt. Ein Gedicht "Aus einem Marienleben" zeigt Vogelers und Rilkes Vorliebe für Engel. Hier ist der Engel noch der des Jugendstils und der der Präfaphaeliten. In einem Aufsatz von 1902 heißt es zu Vogelers "Verkündigung" - "etwas von der Stille des Himmels (ist) in dem singend-sangenden Engel, der sich zu ihr niederneigt...Die Verkündigung ist...eine Stimmung". ${ }^{400}$ Später schreiot Rilke darüber:

$$
\begin{aligned}
& 399 \text { op.cit. SW III., S } 644 . \\
& 400 \text { op.cit. SW V., S. } 573 .
\end{aligned}
$$


Er hat es nicht auf den Knieen gemalt; denn er hat nicht an den Himmel gedacht, sondern an seinen Garten.....Er (Vogeler) ist der Meister eines stillen, deutschen Marienlebens, das in einem Garten vorgeht. 40 ?

Hier gibt es auch andere Erwähnungen von Engeln in Vogelers Bildern:

Und hinter ihnen (Liebespaar) erklingt der Liebe Lied, von einem Engel auf hoher Harfe gespielt: vor ihnen aber liegt der Liebe Land, in welchem Frühling ist, tief und aufgetan. Und wenn sie weitergehen, so treten Engel in langen Kleidern hinter 402 den Bäumen hervor und umgeben sie mit ihrem Gesang...02

Aus diesen Aussagen ist klar zu ersehen, daß Vogelers Engel eher ein Einwohner seines Gartens ist, der das schöne Leben verkündet, als ein überirdisches Wesen, das seine Verkündi: gung sowohl Maria als auch Liebespaaren mit der Harfe singt. Daß durch Vogeler Rilkes Engel-Vorstellungen einen mehr märchenhaften, idyllischen Zug und eher dekorativen Charakter bekommen, ist auch in seinem Gedicht "Verkündigung über den Hirten" 403 deutlich. Rilke schrieb uibrigens noch einen Gedichtzyklus im Herbst 1900 zu den Bildern Heinrich Vogelers. ${ }^{404}$

Neben den Gedichten gibt es von Rilke drei Kunstaufsätze über Vogeler..Der erste wurde Januar 1902 geschrieben und erschien in einem Sonderheft für Voceler der Jugendstil-

$$
\begin{aligned}
& 401_{\text {ibid. S. } 135 .} \\
& 402_{\text {ibid. }}
\end{aligned}
$$

403 op.cit. SWII., S. 699:"Zu zwei Blättern v. H. Vogeler" 4.04 Es sind die Gedichte "Das Haus", "Ritter, welt und Heide", "Der Kahn" und "Widmung". op.Cit. SW III, S. 707-7II. 
Zeitschrift "Deutsche Kunst und Dekoration." Nach einer Darstellung von Vogêers "Kunst-Dingen" meint Rilke, uns die dahinter verborgene Geisteshaltung erklären zu müssen. Wichtig scheint ihm Vogelers "Verhältnis zu dem Fremdartigen." Und zwar als Erklärung dafür, daß Vogèler zu der Zeit als spät-romantischer Märchenmaler berühmt war. Vogeler schuf seine "Phantasie-Centauren und Ungetüme" als Verkörperungen des feindläch Unharmonischen, der immer zu großen Fremde. Endlich, um sich zu. schützen, baute er Mauern um seine welt, und seine Malerei nahm weniger gespenstische züge an und ging dafür in die. Märchenmalerei über:

Ein Mensch mit einer schon ganz bestimmten, aber sehr eng begrenzten Wirklichkeit um sich, zu der alles in Widerspruch stand, was er als Erlebnis oder Stimrnung empfand, dem alles so fremd und unwahrscheinlich war, daß er es nur als Märchen erzählen und als einmal gewesen empfinden konnte. So entstanden diese Märchen, seine eigene Märchen, irlebnisse, die über seine wirklichkeit hinausragten, und die er mit den wenigen Mitteln dieser Wirklichkeit auszusprechen sich bemühte.05

Diese Abkehr von der Wirklichkeit erläutert D. Jost:

Dem Jugendstil liegt die Urangst vor der Wirklichkeit mit ihren Forderungen zugrunde. Die Wirklichkeit ist in der Jugendstilzeit das Fremde schlechthin, das Andere, das essentiell Feindliche; eine Auseinandersetzung und Kraftprobe mit ihr kann nur in eine vernichtende Niederlage münden. Wer nicht aus dem Vollbesitz kreativer Kräfte eine standhaltende Gegenwirklichkeit zu erzeugen vermag, ist ihr erbarmungslos ausgeliefert und damit allen tödlichen Verwundungen anheimgegeben, welche die Realität dem sensitiven Menschen, dem kindlichen "fuilenden Herzen" zu schlagen fähig ist. 406

$$
\begin{aligned}
& 405 \text { op.cit. SWV., s. } 561 \\
& 406 \text { op.cit. Jost, Literarischer Jugendstil, s. } 8 \text {. }
\end{aligned}
$$


Bestätigend nimmt Rilke zu Vogelers Abgelöstheit von der großen Wirklichkeit und zu seinem Rückzug in seine kleinere Märchenwelt Stellung. Sogar, wenn vielleicht "alle letzten großen Dinge außerhalb dieser Wirklichkeit" (bleiben), vervollkommnet diese sich ohne ihre Hilfe. Denn
\#zu dieser angesiedelten, still umfriedeten Wirk- lichkeit...die wie eine kleine Stadt mit Mauern und Zinnen und Toren und allem Nutz- und Schmuck-Werk großer Städte im Tale liegt, können die allerletzten großen Wahrheiten und Tiefen, obwohl sie dort nie eintreten werden und gleichsam außerhalb des Bildes liegen, doch Beziehung haben: sie können ruhig und stetig auf sie einwirken, wie entfernte sterne mit ihrem Licht und mit ihrer Anziehung auf Dinge wirken, die von ihnen nicht wissen. 407

Rilke geht weiter, um diese Welt mit Beschränkungen und Mauern zu loben, dieses aus Schönheiten gebaute Leben, das in Vogelers Garten verkörpert ist. Hierin hat Vogeler das ästhetische Leben begründet. Rilke erklärt den ganzen Menschen aus dem Wesen seines geschaffenen Gartens. "Geschaffen", denn Rilke sagt von Vogelers Garten, die Bäume seien nicht "irgendwo fern in der Heide...Waisen, vom Winde gepflanzt und vom Zufall erzogen", es wären "seine" Bäume. Diese Bäume und andere "versammelte, gepflanzte Dinge" wären wiederum der Stoff seiner Inspiration:

Über diesen Garten war ein sehr seltsamer Gärtner gekommen, ein Dichter, der in seinen Garten einen Gedicht-Anfang setzte, und es der Natur überließ, nachdem er den Rhythmus angedeutet, das Gedicht fortzuführen; und ein Maler, der von dem wild wachsenden Gedicht angeregt, ein Bild schuf, darin es nachgebildet war, und den dieses Bild, das er gemalt, wieder zu einem neuen Versuch anleitete, bei dem er wieder wirklich Gürtner wurde. Es ist schwer zu sagen, und

$$
407 \text { op.cit. SW V., S. } 562 \text { f. }
$$


man sucht umsonst Bilder dafür, anzudeuten, was für eine Kette von Anregungen und Wechsel-Wirkungen dieşen Garten mit Heinrich Vogelers Kunst verbindet. 408

Damit besitzen wir nicht nur ein Beispiel für die Kleinraumkunst des Jugendstils, sondern auch für die Vermischung der Künste (ein Bild wird von einem Gedicht angeregt), und vor allem für das Verhältnis zwischen Natur und, Kunst: es wachsen sozusagen Gedichte und Bilder aus dem Garten, und wiederum wird der Garten (die Natur) - wie in Vollendung eines Kreislaufes - wieder neu nach seiner Vorstellung gestaltet und trägt damit zur Tendenz im Jugendstil bei, die Natur zu stiIisieren.

Abschließend kann über das Verhältnis zu Vogeler gesagt werden, daß Rilke dadurch besonders in der Kleinraumkunst geEangen blieb. Positiv daran wäre nur, daß er die Vollendung der Kunst noch nicht erlebt zu haben meint, denn er ersehnt eine "ganz große Kunst" eines neuen zukünftigen Lebens. Was er genau im Sinne hat, ist noch nicht klar.

Kunstiberlegungen in der Worpsweder Monographie

Rilkes Interesse an der Worpsweder Kunst war nicht auf Vogeler beschränkt. Da Rilkes Vater nach der Heirat mit Clara Westhoff (1901) aufhörte, ihn zu unterstïtzen, und da das Ehepaar bald darauf eine rochter bekam, war Rilke unter Druck, einen Auftrag von Gustav Pauli anzunehmen, eine Monographie über die Worpsweder Maler zu schreiben. Daß diese Arbeit

$$
408 \text { ibid. S. } 567 \text {. }
$$


eine "Brotarbeit" für ihn war, hat Rilke wiederholt betont. 409

Das Verhältnis zwischen Kunst und Landschaft ist Rilkes Hauptinteresse; ein Thema, das inm wichtig ist seit dem gewaltigen Eindruck von der russischen Landschaft, deren Weite er in Worpswede wiederzufinden meint. Rilke vertiefte sich in die Geschichte der Iandschaftsmalerei und entdeckte eine frühe Tendenz, die Landschaft als Vorwand für ein menschliches Gefunl abzubilden. Damit legt Rilke fest, wohin die Kunst sich entwickeln muß: "...man durfte sie nicht mehr stofflich empfinden auf die Bedeutung hin, die sie für uns (besitzt), sondern gegenständiich als eine große' vorhandene wirklichkeit. 40 Hiermit ahnt Rilke, was seine Aufgabe sein wird. Die Dinge der Natur sind nicht mehr nur Stimmungsreiz, sondern Wirklichkeit an sich. Die Worpsweder Landschaft war das große Erlebnis für Rilkes Dingbewußtsein:

...wir leben im Zeichen der Ebene und des Himmels. Das sind zwei Worte, aber sie umfassen eigentlich ein einziges Erlebnis. Die Ebene ist das Gefühl, an welchem wir wachsen. Wir begreifen sie und sie hat etwas Vorbildliches für uns; da ist uns alles bedeutsarn: der große Kreis des Horizontes und die wenigen Dinge, die einfach und wichtig vor dem Himmel stehen...4II

Aus seinem Worpsweder Tagebuch von 1900 wird $k l a r$, daß er von der Ehrfurcht dieser Maler vor der Natur und vor den Dingen

$$
\begin{aligned}
& 409 \text { op.cit. SWVI., s. } 1272 . \\
& 410_{\text {op.cit. }} \text { SWV., S. } 521 \text {. } \\
& 411_{\text {ibid. S. } 26 .}
\end{aligned}
$$


beeindruckt ist und selber die Natur abbilden will, wie sie "wirklich" ist und ihr nicht nur eine stimmung entziehen möchte. Zum ersten Mal lebt er unter Künstlern, beobachtet sie bei der Arbeit, redet über Kunsttheorie mit ihnen und will auch Abbildungen von der Wirklichkeit erschaffen, so wie die Maler sie porträtieren konnten.

Die Bedeutung Worpswedes für Rilkes Dingbegriff ist durch einen Vergleich des ersten Stundenbuches mit dem zweiten, "Buch von der Pilgerschaft", das im Herbst 1901 geschrieben worden ist, leicht herauszuarbeiten. Im ersten Stundenbuch findet der Mönch Gott in den Dingen und redet von dem wundersamen Spiel der Kräfte, die durch die Dinge gehen. Er will die Melodie der Dinge hören, die ihn inspiriert. In dem zweiten Stundenbuch dagegen wird das Ding ein großes Vorbild für den Menschen; es bedeutet vor allem Gesetzmäßigkeit und Ruhe - ein sich dern allgemeinen Gesetz der Natur Einfügen. Der Mensch muß werden wie das Ding

$$
\begin{aligned}
& \text { Da muß er lernen von den Dingen, } \\
& \text { anfangen wieder wie ein Kind, } \\
& \text { weil sie, die Gott am Herzen hingen, } \\
& \text { nicht von ihm fortgegangen sind. } \\
& \text { Eins muß er wieder können: fallen, } \\
& \text { geduldig in der Schwere ruhn, } \\
& \text { der sich vermaß, den Vögeln allen } \\
& \text { im Fliegen es zuvorzutun. } 412
\end{aligned}
$$

Rilkes Überzeugung, daß die Weise des Daseins in ihrer Reinheit in den Dingen verwirklicht ist, entwickelt sich in den Neuen Gedichten. Rilke gibt sein "Kreisen um Gott" vollkom-

$$
412 \text { op.cit. SWI., S. } 321 \text {. }
$$


men auf, um sich den einfachen Dingen zuzuwenden.

Die Begegnung mit Clara Westhoff und Paula Becker.

In Worpswede lag der Kern für Rilkes Zukunft in zwei

weiteren Punkten: in seiner Verbindung mit Clara Westhoff und Paula Becker. Den jungen Frauen liest er im "weißen Saal" Vogelers bei Kerzenlicht vor und stellt fest: "Wieviel näher fühl ich mich jetzt wieder allem Unbewußten und Wunderbaren, wie in den Tagen der Mädchenlieder". Paula ist die "blonde Malerin" - die "blonde Blüte" 413 und Clara ist die Jungfrau in Person, "ganz in weiß":

Ein Mädchen, weiß und vor der Abendstunde und immer wieder fühl ich sie wie Funde; nicht was sie sind, ist mir so wunderbar: Die leisen Linien von Hals und Haar
und wie sie grenzen vor dem Hintergrunde. ${ }^{414}$

Für Rilke sind sie Mädchen, "wie wachsende Blumen" bilden sie einen Teil des märchenhaften Gartens von Vogeler:

Eigentlich ist das wie ein Märchen. Ich sitze in einem ganz weißen, in Gärten verlorenen Giebelhaus unter schönen und würdigen Dingen, in Stuben, die voll von der Stimmung eines Schaffenden sind. Ich sitze in seinen träumerischen Stühlen, freue mich an seinen Blumen, schaue mich in seinen Spiegeln,... (ich) empfange im weißen Saal bei zwölf Kerzen, die in hohen silbernen Leuchtern stehn, die ernstesten Männer der Gegend und sehr schöne, schlanke Mädchen in Weiß, die wenn ich sie bitte, Lieder spielen und singen und sich zusammensetzen, in feinen Empirestühlen, und die vornehmste Bilder sind und der köstlichste überfluß und die süßesten Stimmen dieser flüsternden Zimmer...415

$$
\begin{aligned}
& 413 \text { op.cit. SW III., s. } 710 . \\
& 414_{\text {ibid. S. } 697 .} \\
& 415 \text { op.cit. Tagebücher aus der Frühzeit, S. } 259 \mathrm{f} \text {. }
\end{aligned}
$$


Außer in vielen Gedichten wird dieser Frauentyp in Rilkes Worpsweder Tagebuch beschrieben:

(Ich) sehe die rührende schlanke Gestalt eines jungen Mädchens, dessen Gefühl ganz an die Oberfläche ihres Körpers getreten ist, blüht. Unendliche Düfte um ihren Leib. An ihren jungen Brüsten blüht das Gefühl wie mit Rosen, harten gefüllten Rosen, - ihre Finger 41 die tastenden, gehen in unsichtbare Lilien

Das waren Gedanken zu einem Drama, das Rilke verfassen wollte, und zwar "in die Sehnsucht hinein" mit dem Titel "Die Blinde." Darin beschreibt ein blindes junges Mädchen sein Gefühl der Einsamkeit und Sehnsucht, das durch die Blindheit verursacht worden ist: "Ich bin von allem verlassen. Ich bin eine Insel al7 Ein Fremder, der mit ihr spricht - offensichtlich ein junger Mann - will durch seine Anwesenheit ihr Alleinsein beseitigen; er ist "über das Meer gekommen..." auf die Insel:

Ich bin noch im Kahne.

Ich habe ihn leise angelegt

an Euch. Er ist bewegt, seine Fahne weht landein. 418

Auch die Wasserwelt kann Hintergrund sein für kostbare Stunden mit der Frau. In folgendem Gedicht, das ein Erlebnis vom Herbst 1900 schildert, 419 ist der Schwan Symbol für eine geheimnisvolle Kraft, die ein gemeinsames Gefühl in einem Menschenpaar erweckt:

$$
\begin{aligned}
& 416_{\text {ibid. S. } 387 .} \\
& 417_{\text {ibid. S. } 401 .} \\
& 418_{\text {ibid. }} \\
& 419_{\text {op.cit. Briefe und Tagebücher } 1899-1902, \text { S. } 346 .}
\end{aligned}
$$


Erinnern Sie sich jenes schönen Schwanes?

Aufeinmal wurden Nacht und Alster weit:

Und er verhieß uns viel Nochnichtgetanes, sein zu uns steigendes Gefüh (wir sahn es)

ermunterte uns zur Gemeinsamkeit.

Und diese stunde, da wir unbewegt

und tief und still und Vieles wissend waren,

hat leisen Keimes Kraft in uns gelegt.

Und wenn es blühen wird, vielleicht nach Jahren, komm ich zu dem gemeinsam schönen Tag,

zu dieser Stunde köstlichem Ertrag

mit allem was ich habe hingefahren -

an welchen wassern ich auch wohnen mag. 420

Joachim Rosteutscher ${ }^{421}$ sieht den Rilkeschen Frauentyp

(hier Clara und Paula) sogar als Übersteigerung des "entfleischten Mädchens" - das ästhetische Hauptidol im werke Rilkes sei das tate Mädchen. Seiner Meinung nach beruht die ganze Geschichte des Rilkeschen Mädchenidols auf der biographischen Tatsache des frühen Todes seiner Schwester, den seine Mutter so sehr als Verlust empfand, daß sie ihren bald darauf geborenen Sohn, der den Namen René Maria bekam, fünf Jahre lang als Mädchen erzog. Selbstidentifizierung mit der verstorbenen Schwester ist dann die Wurzel von Rilkes besonderer Art des seelischen Verhältnisses zu Wesen weiblichen Geschlechtes. Als Beispiel hierfür sei ein Gedicht aus dem Worpsweder Tagebuch vom 28. Oktober 1900 herangezogen; die Verse richten sich an Clara und Paula:

Ich bin bei euch. Bin dankbar bei euch beiden, die ihr wie Schwestern meiner Seele seid; op.cit. SW III., S. 711 .

421 Joachim Rosteutscher, Das ästhetische Idol im werke von Winkelmann, Novalis, Hofmann, Goethe, George und Rilke 
denn meine Seele hat ein Mädchenkleid, und auch ihr Haar ist seiden anzufühlen, Ich sehe selten ihre kühlen Hände, denn hinter (vielen) Wänden wohnt sie weit, wohnt wie im Turm, noch nicht von mir befreit, kaum wissend, daß ich einmal kommen werde.

Ich aber geh durch die Winde der Erde (immer) auf die wachsende Mauer zu, hinter welcher in unbegriffener Trauer

meine seele steht. Ihr kennt sie genauer, ihr habt sie näher a'ls ich geschaut, ihr seid die Schwestern meiner Braut. Seid gut zu ihr.

Habt sie lieb, die Schwester, die blonde. Sprecht zu ihr im steigenden Monde. Sagt ihr von euch. Sagt ihr von mir.422

Rosteutscher behauptet auch, daß ein deutlicher weg von diesem toten Kind zu dem in seinem Werk häufigen Symbol der Puppe oder Marionette führt. 423

Neben dieser Abstrahierung des Fraulichen nehmen Clara und Paula aber auch natuirlich eine wichtige Stellung als Künstler-Persönlichkeiten ein. Aus Rilkes Worpsweder Tagebuch ersehen wir, daß Clara als frühere Schülerin von Rodin viele begeisterte Gespräche mit ihm über den großen Bildhauer hielt. Durch Clara angeregt, wendet sich Rilke im Herbst 1900 hier schon Rodin zu. Clara bleibt nach der Heirat weiterhin seine "Mentorin" in bezlug auf die bildende Kunst. Wenn er in den nächsten Jahren sich zur Kunst brieflich äußert, schreibt er hauptsächlich an sie. Es gibt unzählige Briefe aus den Jahren 1902-06, die das belegen.

422 op.cit. Tagebüicher aus der Frühzeit, S. 363. 423 op.cit. Rosteutscher, S. 232. 
Bei Paula Becker liegt ein Fall von Freundschaft und gegenseitiger Verehrung vor, die erst in Paris vertieft wurde. Zur Worpsweder Zeit hat Rilke viel Gutes über sie persönlich zu sagen, gibt aber keine Stellungnahme zu ihrer Kunst ab, die um 1900 auch noch nicht vollkommen ausgereift war. Rilke rechnete sie nicht zu den eigentlichen Worpsweder Malern, die er in seiner Monographie behandelte, obwohl ihre Moorlandschaften auch schon 1899 in der Bremer Kunsthalle ausgestellt wurden, ohne allerdings für wertvoll gehalten zu werden. Selbst ihr Mann, Modersohn - auch ein Worpsweder Malerkommentierte, die Bilder seien "nicht intim, zu plakatmäßig! Stelzer faßt das so zusammen:

Das ist es also. Die Abwendung von der lyrischen Heimatkunst im Sinne von Worpswede... ist erkannt und ziemlich präzise umschrieben. "Nicht intim genug", also mit jenem Willen zum Monumentalen, zum Vereinfachten gesehen, der die beginnende Stilwende in Europa kennzeichnet! "Zu plakatmäßig", also im Sinne eines starken Anrufs gemeint, dem die impressionistische Kleinfarbigkeit und die in der bisherigen Landschaftsmalerei gesuchte unbegrenzte Tiefenräumlichkeit geopfert wurde, zugunsten eines wiederkommenden Respekts vor der Bildfläche und ohne Rücksicht auf die bis dahin wissenschaftliche Perspektive. 424

Der Kern ihrer zukünftigen Entwicklung trat schon offen zutage, als Rilke ihr begegnete. So weit war seine Kunstanschauung nicht gediehen, um ihre Bedeutung für die Malerei des 20 . Jahrhunderts zu erkennen. Denn ihre frühen Landschaftsbilder zeigen eine ganz neue "künstlerische Optik, eine neue Bildform auf einem ganz ähnlichen Wege...wie kurz zuvor (bei)

424 Otto Stelzer, Paula Modersohn-Becker (Berlin: Rembrandt-Verlag GmbH, $195 \overline{8})$, S. 10. 
Cézanne, von dem sie indessen damals noch nicht einmal den Namen kannte." 425

Später verließ Paula Becker inehrere Mala Worpswede, um nach Paris zu fahren und dort Kunst zu studieren. Und 1900 erkennt sie die bedeutende Stellung Cézannes, obwohl er selbst in Paris damals unbekannt war. Sie wird sein deutscher Entdecker. Clara wußte von ihrer Begeisterung für Cézanne, und man kann annehmen, daß Rilke hier durch sie von Cézanne das erste Mal hörte. Die nachfolgende entscheidende Rolle Cézannes für Rilke ist bekannt; seine an Clara gerichteten Briefe über Cézanne (1906-07), sind die erste deutsche Publikation über den berühmten Franzosen. 426

Paula Becker starb schon 1907 im Kindbett; Rilkes Verehrung für sie als künstlerin und als Frau ist vor allem im "Requiem für eine Freundin" verewigt. Daß sie tief in seinem Gedächtnis weiter lebte, bezeugt folgender Brief aus dem Jahr 1913:

...das Schicksal ihres Heimganges (hat) an mir gerüttelt....es mögen einige andere Umstände bedeutend mitgewirkt haben, aber daß sie, die über die Maßen Liebliche in ihrem Herzen, uns so früh und erschütternd verließ: das war wohl der erste Anlaß, daß mir durch mehrere Jahre hin der Tod das Leben überwog, größer war, mehr im Recht und drängender mich angehend als die Fülle des diesseitigen Antriebs, die uns sonst so beschäftigt. 427

$$
\begin{aligned}
& 425_{\text {ibid. }} \\
& 426_{\text {ibid. S. } 15 .} \\
& 427 \text { op.cit. Br.A. 1907-14, S. } 286 .
\end{aligned}
$$


Rilkes letzte essayistische Beschäftiqung mit ausgesprochenen Jugendsti1-Themen

Drei Aufsätze aus dem Jahr 1902 bestätigen noch Rilkes aktives Verhältnis zum Jugendstil. Es sind Aufsätze über Maurice Maeterlinck, Giovani Segantini und Walter Pater. Rilkes Maeterlinck-Rezeption. Maurice Maeterlinck gilt wie Verhaeren - als Vertreter des literarischen Jugendstils in Belgien. Seine Werke wurden von den Jugendstil-Malern L.v. Hofmann, Melchior Lechter und Georg Minne illustriert; er selber ist befreundet mit F. Khnopff, J. Toorop und G. Minne. Maeterlincks süße, weltfremde Träumereien, sind voller Empfindung, Wehlaut und Resignation. Seine Gestalten vermögen nicht zu handeln, sie verstehen nicht, was mit ihnen geschieht, sie folgen den Leidenschaften ihrer Seele und Ieben in ständiger Furcht vor dem Schicksal. Seine Marionetten sind keine Menschen - darum schreibt er Spiele für Puppen sie sind Empfindungen und Gefühle, die Gestalt genommen haben und sich verselbständigt haben. Leben heißt für sie, das Unbegreifliche zu dulden und $z u$ erleiden. Die Beziehung $z u$ den englischen Präraphaeliten wird dadurch deutlich. ${ }^{428}$ Der Jugendstil-Maler Leistikow ist von Maeterlinck tief beeindruckt und widnet ihm in der "Freien Bühne" eine ausführliche Besprechung, nachdem er in Paris "Pelléas und Mélisande" gesehen hatte:

Ich wïßte niemand, der besser malte als dieser Dichter. Seine Werke sind gesprochene Malerei. Und diese 428 op.cit. Seling, s. 127. 
Aufführung ist eines der größten malerischen

Kunstwerke, die die Neuzeit hervorgebracht hat." 429

Maeterlinck gelang es also anscheinend, mit Hilfe von Sprache Bilder vor dem Auge des Zuschauers erstehen zu lassen; noch jugendstilmäßiger ist die Figurendarstellung. E. Hajek zieht zur Begründung dieser These in ihrer Analyse des Wildeschen Stücks "Salome" Alfred Kerr heran, der das Theater der Jahrhundertwende folgendermaßen beschreibt:

Maeterlinck, Wilde, Hofmannsthal, d'Annunzio, Wedekind schaffen ja keine Gestalten mehr. Eher Dinge. Seelenreize. Sie verkörpern tragische Farbenspiele; oder komische Linienspiele;.... Sie schaffen vielleicht etwas Verglühendes oder Dahinklingendes statt einer Gestalt. Vielleicht ein Lächeln statt einer Kömodie. Vielleicht einen Rausch für eine Begebenheit. Aber keine Menschen. Sie geben die Furcht: nicht einen furchtsamen Charakter... Sie malen eher den Prophetismus als einen Propheten. 430

Nicht als lebendige, plastische Menschen, ausgestattet mit einem bestimmten Charakter und in einer bestimmten Situation leben, denken, fühlen, zweifeln, handeln sie - wandeln sich und entwickeln sich, sondern um die Jahrhundertwende sind die Gestalten keine Menschen - höchstens Wortmotiv und Arrangement. Ähnlich verhält es sich in der Entwicklung der Malerei des Jugendstils um die Jahrhundertwende. Auch hier findet = sich in der Figurendarstellung ein Verzicht auf jede Wirklichkeitsillusion. Im bildnerischen und literarischen Jugendstil wird es vermieden, der Gestalt einen gegenständlichen Eigen-

429 op.cit. Hofstätter, S. 170.

430 A. Kerr, "Neue Schauspielkunst" in Neue Rundschau, 1904 , S. $94 f$. 
wert, den Anschein vom lebendigen Menschen zu verleihen. Die Gestalt ist praktisch mit einer Formulierung identisch, sie besteht nur aus Worten, genau wie im bildnerischen Jugendstil die Gestalt nur aus Papier und Tusche entsteht. In beiden Fällen ist das künstlerische Medium primär, ohne die Bindung an den Gegenstand zu verlieren. Doch sind diese Gestalten nicht außerhalb des Kunstwerks vorstellbar. ${ }^{43}$ Auf eine allgemeine Formel gebracht, läßt sich die strukturelle Ähnlichkeit zwischen dem literarischen und dem bildnerischen Jugendstil folgendermaßen zusammenfassen: "Das Dargestellte emanzipiert sich nie vom Darstellungsträger, es ist mit ihm identisch." Dies ist ein Merkmal der dekorativen Kunst: "das Darzustellende wird idealisiert, d.h. der Wirklichkeit, der es selbst angehört, weiter und weiter entrückt. Aber eben. damit rückt das Kunstwerk weiter....in die Wirklichkeit des Materials." 432

Rilkes Bewunderung für Maeterlinck reicht bis. ins Frühjahr 1896 zurück, wie aus einem Brief an Láska van Oestéren hervorgeht. 433 Sçhon zu dieser Zeit wollte er Maeterlinck aufführen. Rilke schreibt im Dezember 1901, er habe "allen Maeterlinckaufführungen, die bislang in Deutschland versucht worden sind, beigewohnt" und habe sich mehrfach mit dem bel-

$$
\begin{aligned}
& 431_{\text {op.cit. Hajek, s. } 50 .} \\
& 432_{\text {ibid. S. } 51 .} \\
& 433_{\text {Siehe s. } 89 \text { dieser Arbeit. }}
\end{aligned}
$$


gischen Dichter beschäftigt. ${ }^{434}$ Seine Abhandlungen aus den Jahren 1898 und 1900 beweisen das: "Pelleas und Melisande," "Maurice Maeterlinck", Der Tod des Tintagiles" und "Das Theater des Maeterlinck." Der letzte Aufsatz von 1902, "Maurice Maeterlinck", wurde als Vortrag in Bremen gehalten, kurz bevor Rilke zusammen mit H. Vogeler am 15. und 16. Februar 1902 Maeterlincks "Schwester Beatrix" zur Neueröffnung der Bremer Kunsthalle aufführte. Seit Ende August 1901 wurde in Rilkes Briefen an A. Holitscher, Gustav Pauli und andere der Plan zur Aufführung des Stückes erörtert. ${ }^{435}$ Er will vor allem eine starke Stilisierung bei der Auffuhrung:

Starke Stilisierung, die sich unterstützen läßt durch ein dreifaches oder doppeltes, perspektivisch ineinandergeschobenes Rahmenwerk, welches die Bühne umfaßt und gleichsam hinausschiebt, indem im letzten kleinsten Rahmen die Maeterlinckische Handlung sich vollzieht. Das Rahmenwerk jedem Stücke entsprechend: Bei I'Intruse Laub- und Blätterrahmen, bei Schwester Beatrix gotisches Gewölbe usf. Dieses Rahmenwerk spielte etwa dieselbe Rolle wie der Rahmen bei stark stilisierten Bildern (etwa bei. Ludwig von Hofmann), der über die Entfernung von Bild und Umgebung langsam, in leisen Übergängen, hinweghilft. 436

Hier haben wir die erste bewußte Beziehung zwischen dem literarischen und dem bildnerischen Jugendstil in Rilkes Betrachtung der Maeterlinckschen Kunst. In Äußerungen Rilkes über sein Theater lobt er vor allem die schwerelosen Gestalten: Sie können nur aneinander vorübergehen, und keine vermag die andere zu halten. Sie sind Düfte, allein

$$
\begin{aligned}
& 434 \text { op.cit. SW VI., S. } 1178 \text {. } \\
& 435_{\text {op.cit. Briefe und Tagebücher 1899-o2 }} \text {, S.113,162, } 172 \text {. } \\
& 436_{\text {ibid. S. } 113 .}
\end{aligned}
$$


man sieht den Garten nicht, aus dem sie aufsteigen...

(er füllt) die ganze Bühne mit Worten und Gesten

aus... Seine Mystik (geht) tiefer und rätselhafter

hinter den Dingen auf. 437

Bei Maeterlinck ist die Vermittlung eines Gefüls beabsichtigt, womit eine "Verlegung des Schwerpunktes aus der eigentlichen äußeren Handlung auf das seelische Gebiet" ${ }^{438}$ stattfindet, was im Drama um die Jahrhundertwende eine Iyrische Wirkung hat und Zeitlosigkeit ausdrückt. ${ }^{439}$ Alle diese Betrachtungen bestätigen die These von Hajek, daß die Figurendarstellung im Jugendstil eine Entmaterialisierung erlebt - nicht die Gestalt ist das Wichtigste, sondern das Wort bzw. die Linie und die Farbe. Rilkes ÄuBerungen über Maeterlincks Marionetten bestätigen die These noch eindeutiger:

Die Puppe hat nur ein einziges Gesicht, und sein Ausdruck steht für immer fest. Es gibt entsetzte Puppen und fromme und einfältige. Jede hat nur ein Gefühl im Gesicht, aber dieses ganz, in seiner höchsten Steigerung. Und außerdem verfügt jede über einen abbiegbaren Leib. Ihrer Bewegungen sind nicht viele; sie spielen sich auch nicht in den Handgelenken oder den Schultern ab, sondern konzentrieren sich an wenigen schlanken Stellen der Figuren....sollte das nicht Aufgabe der Bihne sein: einfache, große, weithin erkennbare Gebärden zu geben? 440

Die Personen werden auf einen Begriff reduziert - auf ein Ge-

437 op.cit. SW V., S. 438

438 ibid. S. 477 .

${ }^{439}$ Siehe die These von Hajek S. 74 dieser Arbeit. 440 op.cit. SW V., S. 479 f. 
fühl - sie sind eher Gefühle, als daß sie eins haben. 441

Es ist Rilke bewußt, daß Maeterlincks Theater mit den Entwicklungen in der modernen Malerei verwandt ist:

Maeterlinck tut hier einen Schritt, der in andern

Künsten...schon damals geschah, als man sich von

dem Joch des Genre- und Hintorienbildes befreite, als man emprand, daß nicht im Thema des Bildes sein Inhalt liege, sondern in etwas anderem, das an allen Stellen diesen Inhalt durchdringt und durchleuchtet, über sich selbst hinaus erhebt und verklärt. 442

Auch die Motive bei Maeterlinck sind typisch für den Jugendstil; seine welt ist eine mit "hohen gotischen Schlössern an weiten Meeren, schweigenden Parken, düsteren Weihern und geheimnisvollen Grotten...Königen, Prinzessinen...."443 - was Rilke sehr sympathisch ist. Maeterlinck wird bis 1904-o5 von Rilke bewundert. $444 \mathrm{Zu}$ anderen Künstlern, wie Vollmoeller und Verhaeren, hatte Rilke während seiner Pariser-Zeit Kontakt. Seine Briefe beweisen seine Verehrung für ihre Werke:45 Giovanni Segantini. Der zweite Aufsatz aus diesem Jahr hat den Jugendstil-Künstler Segantini zum Thema. Segantini,

441 Iop.cit. Hajek, S. 44 .

442 op.cit. SWV., S. 534 .

${ }^{443}$ pAN, III. (Berlin: Fontane \& Co, 1897), S. 256.

${ }^{444}$ Siehe hierzu BR.A. 1902-06, S. 184, 195, 272.

445 Siehe hierzu Br.A. 1902-06, S. 275. Br.A. 1906-07, S. $16 ; 39,234,309$. Briefe 2 Bde.: Bd.I, S. $174 \dot{1}, 439,479$; Bd.II, $118 \mathrm{E}, 123 \mathrm{f}$. 
der zeitweise beim "Pan" mitgearbeitet hatte, entwickelte eine Technik, die meist aus einem plastisch durchfurchten Netz von Linien bestand, das so porös und durchsichtig war, daß die Grundierung immer wieder hindurchschimmerte. Seine Themen versuchten die Einbettung des Menschen in die Natur darzustellen, was den Jugendstil-Einfluß seiner Kunst deutlich macht. Auch der Einfluß der Präraphaeliten auf seine Bilder wird klar: schwebende Gestalten, deren Gewänder sich mit der Luft und den Haaren vermischen, sind häurig. ${ }^{446}$ Eine Sonderkollektion von 22 Werken Segantinis wurde im Frühjahr 1902 in Bremen, anläßlich der im Maeterlinck-Abschnitt erwähnten Neueröffnung der Kunsthalle, gezeigt. Rilke nennt Segantini in seinem Aufsatz eine "große, revolutionäre Persönlichkeit"; er bewundert die "Reinheit und Erhabenheit" seiner Bilder und "die großen, ruhigen Linien." 447

Walter Pater. Es liegt noch ein wichtiges Kunstdokument von Rilke aus dem Sommer 1902 vor: ein Artikel über ein Buch von Walter Pater, einer der größten Figuren des englischen Jugendstils. Paters Buch "Studies in the History of the Renaissance", erschienen 1873, kam 1902 zum ersten Mal in deutscher Sprache heraus. ${ }^{448}$ In einem Schlusparagraphen charakterisiert Pater das LebensgefühI des deutschen Jugendstils. Pater

$$
\begin{aligned}
& 446 \text { op.cit. Horstäter, s. II6F. } \\
& 447 \text { op.cit. SW V., s. } 550 f f . \\
& 448 \text { op.cit. SW VI., s. } 1420 \text {. }
\end{aligned}
$$


mahnt seine Leser, den schönen, vergehenden Augenblick mit all ihren Sinnen festzuhalten; er sehnt sich zur Renaissance zurück, denn hier gäbe es die größte Schönheit und die Blütezeit der Malerei. Rilkes Kommentar zu dem Buch: er findet es ausgezeichnet; es sei eines der "besten und lebendigsten," welche sich mit Kunstwerken beschäftigen. Er sieht in Paters Einblick eine bedeutende Annäherung an die Meister der Renaissance und in das "Geheimnis der Kunstschaffens." 449

Diese Aussagen und andere zeigen, daß Rilke noch zu dieser Zeit Paters Begeisterung für die Renaissance teilt wahrscheinlich auch seine ästhetizistische Einstellung. Allerdings hatte Rilke sich Anfang 1902 von einem "verfrühten Renaissancegefuhl" distanziert. 450 Es ist etwas schwierig, diese widersprüchliche Äußerungen zu vereinbaren.

E.C. Mason meint, daß Rilkes spätere Bewunderung und beinahe Anbetung der Miona Lisa höchstwahrscheinlich von Paters Gedicht über sie stammt. In der Worpsweder Monographie bespricht er das Gemälde auf Grund eben dieses Gedichtes, das heibt also, ohne das Original gesehen zu haben, welches er erst im Herbst in Paris erblickt. Auch sein Interesse an Michelangelos Gedichten wurde durch Pater und dessen Aufsatz, "Die Gedichte Michelangelos" höchstwahrscheinlich geweckt, der in seinem Renaissance-Buch abgedruckt war. ${ }^{451}$

449 op.cit. SW V., S. 600 . 450 Siehe S.174f. dieser Arbeit. $45 I_{E}$.C. Mason, Rilke, Europe and the English Speaking World (Cambridge: University Press, 1961), S. $76 f$. 


\section{RILKES ABKEHR VOM JUGENDSTIL}

... Ich habe gar keine Verbindungen mit Menschen, nehme an keinem Kreis, keiner Bewegung anteil: ich bin mein eigener Kreis und eine Bewegung nach Innen: So lebe ich. $45 \overline{2}$

Diese lakonische Aussage Rilkes drei Tage vor der Abreise nach Paris scheint im Gegensatz zu ähnlichen früheren diesmal der Tatsache zu entsprechen; sie leitet Rilkes Abkehr von der Jugendstil-Bewegung ein.

Doch seine Pläne, nach Paris zu gehen, waren lange unbestimmt. Noch im Juli 1902 dachte er "im Oktober zu Muther nach Breslau zu gehen, in der Absicht, so bald als möglich den Doctor zu machen." 453 Muther war Professor fur Kunstgeschichte dort und Herausgeber einer Sammlung illustrierter Monographien unter dem Namen "Die Kunst." Rilkes Studienpläne die er immer wieder aufgeben mußte, gingen auch dieses Mal nicht in Erfüllung. Stattdessen bekam er einen Auftrag, von Muther eine Monographie über Rodin für "Die Kunst" zu schreiben. Muther war damals zu einem großen Tejil mit dem Jugendstil beschäftigt; andere Bände in der Reihe behandelten Burne-Jones, Max Klinger, Aubrey Beardsley und den modernen Impressionismus. Als zehnte Ausgabe erschien dann im Frühjahr 1903 Rilkes Band über Rodin.

$$
\begin{aligned}
& 452 \text { op.cit. SW III., S. } 863 . \\
& 453 \text { op.cit. SW VI., S. } 1435 .
\end{aligned}
$$


Im August 1902 verließ Rilke Familie und Haus in Westerwede und fuhr nach Paris zu Rodin. Damit geht seine Jugendstil-Phase zu Ende und die Prägung seiner "eigenen" Kunst beginnt. Das "schöne Leben" kann nicht in der Großstadt Paris gedeihen - man kann in Malte die Angst und das Erschrecken vor den Grausamkeiten der modernen Großstadt nachempfinden, die das paradiesartige Dahinleben des Jugendstils zerstören. Diese Abkehr vollzieht sich relativ schnell; schon im nächsten Jahr schreibt er an Lou während eines kurzen Besuches im Haus des alten Freundes Vogeler:

Und es wird immer kleiner um Heinrich Vogeler, sein Haus zieht sich um ihn zusammen und füllt sich mit Alltag aus, mit Conventionen und mit Trägheiten, so daß nichts Unerwartetes mehr geschieht... Und Heinrich Vogelers Kunst wird unsicher, verliert immer mehr an Anschauung und Sicherheit und ist ganz auf den Zufall einer spielerischen Erfindung gestellt, die sich von den Dingen entfernt... Und es kann keine Kunst kommen daraus, denn Kunst kann sich nicht wiederholen. Und mir, der ich wieder aus der Fremde kam, bangt bei dieses Lebens leichter Bescheidenheit. 45

Zum letzten Mal versuchte Vogeler 1912, zu Rilke Verbindung aufzunehmen, ein gemeinsames "Marienleben" herauszugeben. Rilke ging zunächst darauf ein, um den ehemaligen Freund nicht zu beleidigen; doch als er Vogelers Bilder zu seinen neuen Versen erhielt, lehnte er enttäuscht ab, weil er feststellte, wie weit sich seine eigene Kunst vom Jugendstil fortentwickelt hatte.

Das einzige Mal, wo Rilke überhaupt ausdrücklich den Namen Jugendstil verwendet, ist 1904 in einem Brief an Clara 454 op.cit. Petzet, S. 84. 
aus Schweden - wobei daran zu denken ist, daß dieser Name sich erst nach der Jahrhundertwende durchsetzte. Auch hier steht er diesem Stil kritisch gegenüber:

Die Möbel, die auch nach ihren (Frl. Larsson; seine Gastgeberin) Angaben hergestellt sind, haben, obwohl sie sichtlich nordische und altertümliche Motive zu verwenden bernuht sind, etwas Altertümelndes und zugleich Jugendstilhaftes, so daß man ihrer nicht froh werden kann und die Räume nicht irgendwie empfindet. Schade! 455

Noch vier Jahre davor aber hatte $\mathrm{H}$. Vogeler Jugendstil-Möbel für Rilkes Hausstand in Westerwede entworfen. ${ }^{456}$

Zehn Jahre später endlich fand die ziemlich endgültige Absage der Jugendstil-Welt statt. Der aufziehende Krieg ließ Rilke voraussehen, daß die paradiesartige Periode mit ihm zusammenbrechen würde. Wie ein wehmütiger Abgesang auf die allmählich verblassende welt der Weiher und Teiche im Jugendstil wirk folgender Text.

Waldteich, weicher, in sich eingekehrter-, draußen ringt das ganze lieer und braust, aufgeregte Fernen drücken Schwerter jedem Sturmstoß in die Faust -, während du aus dunkler unversehrter 457 Tiefe Spiele der Libellen schaust.

$$
\begin{aligned}
& 455_{\text {op.cit. }} \text { Br.A.1902-o6 }, \text { S. } 175 . \\
& 456 \text { op.cit. Petzet, s. } 55 . \\
& 457 \text { op.cit. SWII., S. } 78 f .
\end{aligned}
$$




\section{RILKES WEITERE VERBINDUNGEN ALIGEMIEINER}

UND KÜNSTLERISCHER ART ZUM UTFELD DES JUGENDSTIIS

\section{Seine elitäre Lebensweise}

Man kann keineswegs behaupten, daß der Einfluß des Jugendstils auf Rilkes Gedankenwelt und spätere werke nach 1902 vollkommen verschwindet. Eine Vertiefung ins $\ddot{A}$ sthetische lag seiner ganzen Lebensweise überhaupt, denn sie bedeutete gleichzeitig Zurückgezogenheit von der Wirklichkeit und vom Leben. Die große Welt brauchte er, um sich vorübergehende Seßhaftigkeiten und gute Arbeitsbedingungen $z u$ verschaffen, und er reiste wieder ab, sobald er seine "Einsamkeit" bedroht glauben mußte. Das künstliche Paradies als Motiv in seinen frühesten Gedichten - und seine Rolle als Schloßpoet - hatte er sein ganzes Leben lang versucht zu realisieren. Viele Namen aus den vornehmsten Adelsgeschlechtern Europas finden sich unter den Adressaten seines Briefwechsels; auf Schlössern und in Familien ersten Ranges war er der bewunderte Gast. Holthusen schreibt, Rilke sei der Günstling einer gesellschaftIichen Ordnung gewesen, die seine geselischaftslose Lebensführung ermöglichen konnte, ehe sie in den Erschütterungen des Zeitalters der Weltkriege zusammenbrach: einer ordnung, die eine radikale Vereinsamung und Verlorenheit des Menschen in der Anonymität der Großstädte in sich schloß und noch das Luxusleben einer für ̈̈sthetik empfänglichen Oberschicht er- 
laubte - einer Welt aus Hotelzimmern und Adelsschlössern 458 Die in der Jugendstil-Epoche geforderte Stilisierung des Lebens, die Forderung der Einheit von Kunst und Leben hat Rilke deshalb verwirklichen können.

\section{Rilkes Bekanntenkreis in Paris: Rodin, Zuloaga}

Nicht nur sein Lebensstil, sondern auch sein Bekanntenkreis besteht weiterhin zum Teil aus Künstlern, die vom Jugendstil geprägt worden sind. Seine Freundschaften mit verhaeren und Vollmoeller, mit orlik, mit Muther und Meier-Graefe bleiben erhalten. Ebenso seine Beziehungen zu Graf Kessler, Heymel, Wassermann und George.

Auch Rodin gehört in gewisser Weise zu der JugendstilTradition. Rodins Werk ist voller Bewegung, voller Wellenlinien. Bei ihm nimmt die Figur nicht mehr isoliert und aufrechtstehend den zentralen Platz ein. Es entsteht ein bewegten Formenfluß nicht nur zwischen den verschiedenen Gestalten mehrfiguriger Gruppen, sondern auch zwischen einzelnen Teilformen untereinander. Zerissene Oberflächen fließen im Spiel der Lichter und Schatten ineinander. Die vibrierende Kontur der menschlichen Gestalt "steckt...oft noch halb in ungeformter Substanz - Sinnbild des Zusammenhanges zwischen allen Formen und Stufen des Lebens." 459 Die Bewegung der modellierten Oberfläche hebt Rilke immer wieder als das Beson-

$$
\begin{aligned}
& 458 \text { op.cit. Holthusen, S. } 8 \text {. } \\
& 459 \text { op.cit. Schmutzler, S. } 124 \text {. }
\end{aligned}
$$


dere der Rodinschen Plastiken hervor. Am "Mann mit der gebrochenen Nase" erkennt er:

Es war das Gesicht eines Lebendigen, und als er (Rodin) es durchforschte, da zeigte sich, daß es voll Bewegung war, voll von Unruhe und Wellenschlag. In dem Verlauf der Linien war Bewegung, Bewegung war in der Neigung der Flächen, die Schatten rührten sich wie im Schlafe, und leise schien das Licht an der Stirne vorbeizugehen. Es gab also keine Ruhe, nicht einmal im Tode, denn mit dem Verfall, der auch Bewegung ist, war auch das Tote dem Leben noch untergeordnet. Es gab nur Bewegung in der Natur; und eine Kunst, die eine gewissenhafte Ausdeutung des Lebens geben wollte, durfte nicht jene Ruhe, die es nirgends gab, au ihrem Ideal machen...46\%o

Dies könnte genausogut eine Aussage über die Bedeutung der Wellenlinie im Jugendstil sein. ${ }^{461}$

Noch zwei Künstler, für die Rilke sich sehr stark während der Pariser Zeit und danach engagiert und die in der Jugendstil-Tradition stehen, sind Zuloaga und Hokusai. Der spanische Maler Igantio Zuloaga, den Rilke in Paris (der Stadt, in der Zuloaga seinen Ruhm begründete) kennenlernte und dessen Kunst er bewunderte, ist 1870 geboren und im Verhältnis zu den meisten Jugendstil-Künstlern relativ jung. Nachdem Rilke erst einen Monat in Paris gewesen ist, erfährt er, daß Zuloaga in Paris wohnt - mit Begeisterung meldet er seine $\mathrm{Ab}$ sicht, sich alle wïhe zu geben, seine Adresse zu erfahren und

$$
460 \text { op.cit. Br.A. } 1907-14 \text {, S. } 319 .
$$

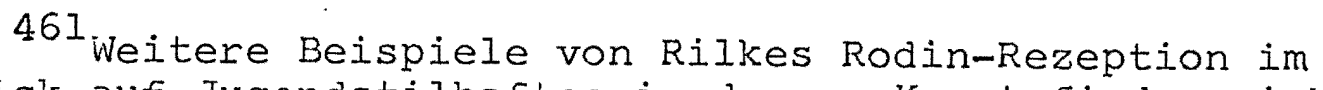
Hinblick auf Jugendstilhaftes in dessen Kunst finden sich in einem Aufsatz, der nach Fertigstellung dieser Arbeit erschien und besonders auf Rilkes Rodin-Vionographie Bezug nimmt: Karl E. Webb, "Rilke, Rodin, und Jugendstil: The Poet as an Art Critic" in: Orbis Litterarium, Vol. XXVII, No. 4. (Copenhagen: Munksgard, 1972), S. 254-263. 
zu ihm gehen zu können. 462 August 1903 bewundert er "ein großes Bild (des) Freundes, den wir uns in Paris gewonnen haben" - es ist Zuloagas Stierkämpfer-Familiє. Während einer beabsichtigten Reise nach Venedig hat Rilke vor, Bilder von Zuloaga zu sehen, "vielleicht als die einzige Wirklichkeit in dieser traumhaften stadt..."463 später schreibt er, die Bilder Zuloagas wären das Wichtigste für ihn in Venedig gewesen. Im Mai 1904 erzählt er Lou von seinem Plan, eine Monographie über Zuloaga zu verfassen. Dazu wollte er nach Spanien reisen, um näheres über diesen Maler, der "neben Rodin der einzige Mensch (ist), mit dem ich mich während des Pariser Aufenthaltes tief und lange berührte und dessen wichtigkeit und wert ich fühle und sagen kann", zu erfahren.64 Rilke reiste aber zuerst nach Schweden, unterwegs sah er Bilder Zuloagas und Hokusais. Ein Zuloaga-Heft hatte er mitgenommen und seinen schwedischen Maler-Freunden, die auch der Jugendstil-Tradition verwandt waren, gezeigt. ${ }^{465}$ Als Rilke dann wieder 1905-06 in Paris ist, berichtet er von verschiedenen Besuchen bei Zuloaga selbst. Zuloaga war ein Sammler von Greco-Bildern, die er auch Rilke zeigte; Rilkes spätere Spanienreise und sein Studium der Kunst El Grecos ist auf Zuloaga zurückzuführen.

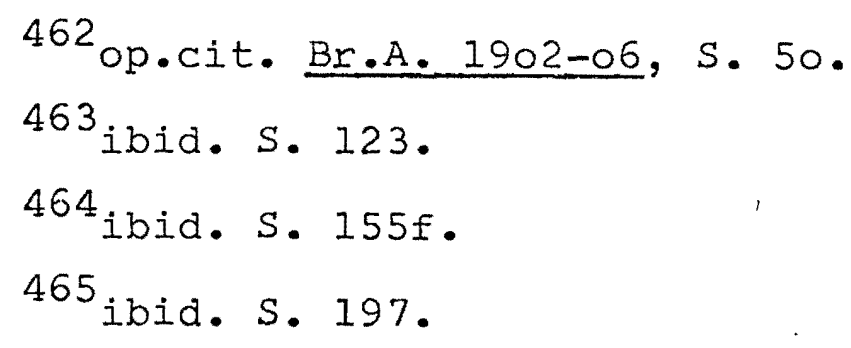


Rilkes Studium Hokusais

Rilke muß auf den japanischen Maler Hokusai gerade durch seine Verbindung zum Jugendstil gekommen sein, denn ihm war schon lange der japanische Einfluß auf diese Richtung bekannt. ${ }^{466}$ Die Hauptwerke Hokusais wurden zwischen 1799 und 1834 geschaffen, dem goldenen Zeitalter des japanischen Holzschnitts. Mitte des 19. Jahrhunderts wurde dieser Meister des Farbholzschnitts im westen bekannt. Seine Flächentechnik und seine Motive wurden yon Jugendstil-Künstlern studiert und übernommen. In seiner Kunst sind alle Elemente des Jugendstils vorhanden: Labilität, Tendenz zu asymme0 trischer Dekoration, Mustern und Ornamenten. Wassermotive sind typisch für ihn: Tintenfische und Polypen, Unterseegeschöpfe, Wasserfälle und Meereswogen sind Gegenstände seiner Arbeit. 467

Rilke erwähnte Hokusai schon in der Worpsweder Monographie; er kannte ihn aus Muthers Geschichte der Nialerei im XIX. Jahrhundert (1893). Doch erst in Schweden kam 1904 ein näheres Studium zustande. Auf der Reise dahin hatte er in Düsseldorf im Hause eines Japansammlers einen lag über den 13 Bänden von Hokusais Skizzenbuch "Mangwa" verbracht. Einige Tage später hörte Clara von ihm:

...Jeden Augcnblick sehe ich etwas. isuch ich habe eine Menge von Hokusai gelernt in diesem Vorubergehen an der Mangwa. Ein Weg, dunkel von Grund, mit den Zwil-

$$
\begin{aligned}
& { }^{466} \text { Siehe S. } 130 \text { dieser Arbeit. } \\
& 467 \text { op.cit. Schmutzler, S. } 15 \text {. }
\end{aligned}
$$


lingsfrüchten eines Ahornbaumes rhythmisch überstreut -: das wäre eines von seinen tausend Blättern geworden. Der Goldregenstrauch mit seinen Fruchtschoten, die wie altmodische Ohrgehänge aufgehängt sind, der Jasmin, der nicht aufhören will zu blühen und dessen Sterne ganze Milchstraßen bilden im dunkelnden Grün...468

Die Naturbeschreibung fährt fort in einer Weise, die Rilke von Hokusai gelernt zu haben meint. Rilke ist hier wie die Maler, welche die Welt betrachten, "die Motive suchen, Maler, die aus dem großen Mosaik fünf kleine Steine herausbrechen, um sie zu einer Harmonie zusammenzustellen." 469 So hatte Hokusai die "Mangwa" zusammengestellt aus Zeichnungen von tausenden Aspekten der wirklichen Welt: Männer, Frauen, Kinder und Tiere werden von allen möglichen Standpunkten - in jeder Gestik und Tätigkeit dargestellt. Das Bemühen des Künstlers, das Leben in seiner Ganzheit wiedergeben zu wollen - und dem künstlerischen Umsetzungsprozeß gemäß zu gestalten, trifft allerdings wieder auf den unüberbrückbaren Gegensatz zwischen Kunst und Wirklichkeit. Rilkes Erkenntnis darüber wird in dem Brief über Hokusai deutlich, indem er die Maler und die Welt gegenüberstellt, und dann doch zu dem Schluß kommt, daß "das wirkliche Leben... wie die wirkliche Welt" ist. 40 Eine echte Lebensweise erzeugt eine echte Kunstauffassung, die die Wirklichkeit hinter den Dingen erfahren läßt. Hokusais Leben und

$$
\begin{aligned}
& 468_{\text {op.cit. Br.A. } 1902-06} \text {, S. } 206 \mathrm{f} \text {. } \\
& 469_{\text {ibid. }} \\
& 470_{\text {ibid. }}
\end{aligned}
$$


Kunst blieb für Rilke beispielhaft für die Realisierung dieser Lebensanschauung. Besonders betonte Rilke die Tatsache, daß Hokusai sich unermüdich um das wahre Sein in der Kunst bemühte, erst mit 60 Jahren seine Reife erlangte und unaufhörlich einen Gegenstand bildlich zu treffen versuchte. Seine "36 Ansichten des Fudjibergs" und auch seine späteren "loo Ansichten" des gleichen Berges sind typisch dafür; auch sind sie Thema von Rilkes Gedicht aus dem Jahr 1906, "Der Berg":

Sechsundreißig Mal und hundert Mal hat der Maler jenen Berg geschrieben, weggerissen, wieder hingetrieben (sechsunddreiBig Mal und hundert Mal)

zu dem unbegreiflichen Vulkane, selig, voll Versuchung, ohne Rat, während der mit Umriß Angetane seiner Herrlichkeit nicht Einhalt tat:

tausendmal aus allen Tagen tauchend, Nächte ohne gleichen von sich ab fallen lassend, alle wie zu knapp; jedes Bild im Augenblick verbrauchend, von Gestalt gesteigert zu Gestalt, teilnahmslos und weit und ohne Meinung -, um auf einmal wissend, wie Erscheinung, sich zu heben hinter jedem Spalt. 471

Hermann Pongs 472 weist darauf hin, daß der Berg, diese Mächtigkeit des Urgesteins, in Kontrast zum Künstler gesetzt wird, der sich immer wieder bemüht ( $36 \mathrm{Mal}$ und $100 \mathrm{Mal}$ ), ihn zu "begreifen" und zu malen. Die Herrlichkeit des Berges läßt sich nicht fassen, obwohl jeder Gestaltungsversuch sich bis zum höchsten Grảu steigert. Erst in den letzten zwei zeilen

471 op.cit. SWI., S. 638 .

472 Hermann Pongs, Das Bild in der Dichtung, Bd. II (Marburg: N.G. Elwert-sche Verlagsbuchhandlung, 1963), S. 483. 
kommt er dem Künstler entgegen - wird Erscheinung für ihn, hinter jedem Pinselzug seiner zahlreichen vergeblichen Umrisse. Wie in den "Ding-Gedichten" kommt der Künstler zu einer tiefen Erkenntnis der Dinge.

Als Hokusai 75 Jahre alt war, sagte er über sich selber:

Since the age of 6 I have had the habit of drawing forms of objects. Although from about 50 I have often published my pictorial works, before the 7oth year none is of much value. At the age of 73 I was able to fathom slightly the structure of birds, animals, insects and fish, the growth of grasses and trees. Thus perhaps at 80 .my art may improve greatIy; at 90 it may reach real depth, and at 100 it may become divinely inspired. At 110 every dot and stroke may be as if living. I hope all great men will feel that what I have said is not absurd. 473

Rilke kannte diese Aussage Hokusais und wies in seinen Briefen öfter darauf hin. ${ }^{474}$ Für seine Arbeitsweise in der Pariser Zeit blieb sie sein Leitmotiv. 1904 schreibt er an Lou, gerade bevor er Hokusai in einem der nächsten Briefe erwähnt: ...meine Arbeitsweise (ebenso wie mein viel aufnehmenderes Schauen) hat sich geändert, so daß ich wohI nie mehr dazu kommen werde, ein Buch in zehn Tagen (oder Abenden) zu schreiben, vielmehr für ein jedes lange und ungezählte zeit brauchen werde; das ist gut, es ist ein Fortschritt nach dem Immerarbeiten
hin, das ich um jeden Preis mir erringen will...475 Sogar 1910 ist Hokusai noch Vorbild:

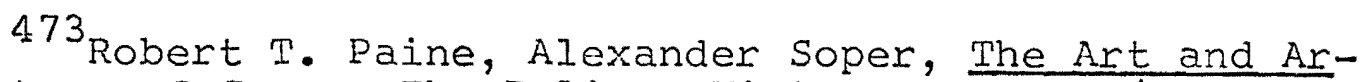
chitecture of Japan. The Pelican History of Art, (London: Penguin Books Ltd., 1955) S. 153.

${ }^{474}$ Siehe insbesondere op.cit. Br.A. 1902-06, S. 84. 475 ibid. S. 145 . 
Ich mußte an etwas denken, was der alte Hokusai (der so weise geworden war, wie man es nur als Maler werden kann) an seinen Verleger schrieb. "Die Bilder der Dinge...neigen dazu hin, Schriftzeichen werden zu wollen; unsere Aufgabe ist es, sie immer wieder im Bildbereich, im Bildlichen zurückzuhalten."476

Dieses war eine Warnung gegen die "Flächensprache" der modernen Kunst, die nur mit Schwierigkeit der "Welt gerecht" werden konnte. Damit wird die stilisierte Welt im Jugendstil auch angegriffen.

\section{Die Stilwendung im Spätwerk}

Rilkes Bemühung, Dinghaftigkeit in seinen Gedichten zu verwirklichen, und sein Kampf gegen die gefühlvolle Lyrik, die einfach aus ihm herausstrümte, bleiben Hauptziele während der Pariser Zeit. Das wird auch erreicht, indem er (vor und nach den Rußland-Reisen und während der Worpsweder Zeit) eine neue Art des Schauens anstrebt, die - wie schon gezeigt worden ist - mit seinen Verbindungen zum Jugendstil zusammenhängt. Von der Verwirklichung dieser Fähigkeit, die Dinge zu "sehen", wird in einem Brief an Clara vom 6.7. 1906 berichtet. Eine neue Schaffensperiode hatte für Rilke begonnen; nach' Reisen nach Viareggio, Rom und Schweden war er wieder in Paris als Privatsekretär bei Rodin bis zum Mai 1906 gewesen, und gleich danach hatte er wieder zeit für seine eigene Kunst. In der Periode von 1906-09 schrieb er den größten Teil der Neuen Gedichte, die Requien und brachte 'Malte' zu Ende. Im

$$
476 \text { op.cit. Br.A. 1907-14, S. 102-3. }
$$


gerade erwähntem Brief erzählt Rilke von einem Besuch im Louvre, wo er Bilder "nur Bilder und viel zu viele Bilder $(s a h)$, und überall stand jemand und alles störte" ${ }^{477}$ - dabei empfindend,

daß alles durch mich durchging wie wasser durch ein Spiegelbild, meine Umrisse in Fließendes auflösend. Und ich sagte mir: ich, will nicht mehr das Spiegelbild sein, sondern, was oben ist. Und ich drehte mich um, so daß ich nicht mehr auf dem Kopf stand, und machte einen kleinen Augenblick die Augen zu und zog mich um mich zusammen und spannte meine Konturen, wie man Violinsaiten spannt, bis man sie fest und klingend fühlt, und auf einmal wußte ich mich ganz im Umriß wie eine Dürersche Zeichnung, und so trat ich vor die liadonne Lisa: und sie war ohnegleichen....daß ist es, was man einmal wird können müssen. Und wird dann nicht alles Arbeit sein? Denn was ist in diesem Zustand unfruchtbar? 478

"Nicht mehr Spiegelbild zu sein, sondern das was oben ist" bleibt Rilkes Absicht auch während seiner Beschäftigung mit Van Gogh und besonders Cézanne, der ihm die Lehre des "sachIichen Sagens" - Ausdruckskunst statt Eindruckskunst - brachte. Nach dieser Schaffensperiode in Paris (bis 1910) unternahm Rilke Reisen nach Algerien, Tunesien und Ägypten, verbrachte einige zeit in Duino und Venedig und machte eine Spanienreise. 1914 kommt es zu einer neuen Einsicht in seiner Kunstauffassung, die durch seinen eigenen Vorwurf entsteht, er habe in den letzten Jahren nichts geschafft. Es waren tatsächlich Jahre voller Rückschläge: die Elegien wurden angefangen aber nicht beendet, und das "Marienleben" be-

$$
\begin{aligned}
& 477_{\text {op.cit. Brd. } 1906-17} \text {, s. } 45 f \text {. } \\
& 478_{\text {ibid. }}
\end{aligned}
$$


zeichnet er als Rückfall in eine alte Schreibweise. Auch sein persönliches Leben brachte Enttäuschungen, denn seine vielen Beziehungen zu Frauen ließen seine Vorstellungen der besitzlosen Liebe nicht verwirklichen. Im großen und ganzen waren das frühere "Immerarbeiten" und das "sachliche Sagen" nicht mehr möglich - er erkannte, daß er doch auf seine "Inspiration" angewiesen war. Er schreibt 1914 an Lou, daß das folgende Gedicht eine "Wendung" darstellt, die wohl auch kommen muß, wenn er leben wolle.

Lange errang ers im Anschaun. Sterne brachen ins Knie unter dem ringenden Aufblick. Oder er anschaute kniend, und seines Instands Duft machte ein Göttliches müd, daß es inm lächelte schlafend. Türme schaute er so, daß sie erschraken: wieder sie bauend hinan, p̈lötzlich, in Einem! Aber wie oft, die vom Tag überladene Landschaft ruhete hin in sein stilles Gewahren, abends. Tiere traten getrost in den offenen Blick, weidende,....

Vögel durchflogen ihn grad, den gemütigen....

Und das Gerücht, daß ein Schauender sei, rührte die minder, fraglicher Sichtbaren, rührte die Frauen.

Schauend wie lang?

Seit wie lange schon innig entbehrend, flehend im Grunde des Blicks?

Wenn er, ein Wartender, $\mathrm{SaB}$ in der Fremde; das Gasthofs zerstreutes, abgewendetes Zimmer mürrisch um sich, und im vermiedenen spiegel wieder das Zimmer und später vom quälenden Bett aus wieder: da bereits in der Luft, unfaßbar beriet es über sein fühlbares Herz, 
über sein durch den schmerzhaft verschütteten Körper dennoch fühlbares Herz beriet es und richtete: daß es der Liebe nicht habe. (und verwehrte ihm weitere Weihen.)

Denn des Anschauns, siehe, ist eine Grenze, und die geschautere welt will in der Liebe gedeihen.

Werk des Gesichts ist getan, tue nun Herz-Werk an den Bildern in Dir, jenen gefangenen; denn du überwältigtest sie; aber nun kennst du sie nicht. Siehe, innerer Mann, dein inneres Mädchen, dieses errungene aus tausend Naturen, dieses erst nur errungene, nie noch geliebte Geschöpf. 479

Dies ist ein eindeutiges Bemühen, sich von der früheren Sachlichkeit und Dinghaftigkeit zu distanzieren; zugunsten der inneren Bilder fällt das Anschauen als Wiöglichkeit der Eroberung der Dinge weg. Die neue Schaffensweise verbindet das Anschaun mit einem unbewußten, inspirierten Niederschreiben. ${ }^{480}$ Als Hauptergebnis dieser Bemühung sind die Elegien und Sonette zu sehen.

Jugendstil-Notive im Spätwerk

Vorhandene Jugendstil-Motive erfahren im Spätwerk zum größten Teil eine Umdeutung. Innerhalb des gewandelten Stiles wird das rein Ornamentale zurückgedrängt, so daß Bildlichkeit zumeist als direkter Ausdruck für innere Vorgänge dient. Ein Blick auf die Elegien und Sonette wird dieses bestätigen.

$$
479 \text { op.cit. SW II., S. } 82 f f \text {. }
$$

${ }^{480}$ Siehe S. 6f. dieser Arbeit, "Die Worte des Herrn an Johannes auf Patmos". 
Diese Werke werden als exemplarisch für das Spätwerk betrachtet, indem sich in ihnen Rilkes reife Zeit, ästhetisch umgestaltet, komprimiert wiederfindet.

Das pantheistische Weltgefühl, das noch 1914 klaren Ausdruck im folgenden Gedicht findet, wird in den Elegien Objekt einer großen "Infragestellung":

Durch alle Wesen reicht der eine Raum: Weltinnenraum. Die Vögel fliegen still durch uns hindurch. 0 , der ich wachsen will, ich seh hinaus, und in mir wächst der Baum. Ich sorge mich, und in mir steht das Haus. Ich hüte mich, und in mir ist die Hut. Geliebter, der ich wurde: an mir ruht der schönen Schöpfung Bild und weint sich aus. ${ }^{481}$

In den Elegien befindet sich der Mensch nicht mehr innerhalb der Umarmung der Natur, er ist heimatlos, der Erde und dem Himmel entfremdet. Ihm gegenüber gestellt ist der Engel, der nun nicht als "Bote des schönen Lebens" erscheint, sondern als Symbol der höchsten Vollkommenheit, für die der Mensch noch nicht reif ist und die er als schrecklich empfindet, indem er dessen Anblick noch nicht gewachsen ist. Der Engel ist also nicht Ereundicher Begleiter des Menschen, sondern "reiner Geist" und eine gewaltige Kraft und eine Glanz, die den Menschen blendet.

Wer, wenn ich schriee, hörte mich denn aus der Engel Ordnungen? und gesetzt selbst, es nähme einer mich plötzlich ans Herz: ich verginge von seinem stärkeren Dasein. Denn das Schöne ist nichts als des Schrecklichen Anfang, den wir noch grade er- 
und wir bewundern es so, weil es gelassen verschmäht, uns. zu zerstören. Ein jeder Engel ist schrecklich. 482

Der Mensch befindet sich außerhalb des Paradieses, das ihm noch im Jugendstil gerade durch den Engel erreichbar war. Während das Tier sicher und wohlbehutet in der Natur geborgen ist, ist der Mensch dem Rhythmus der Natur entrissen. Die Anfangsstrophen der "Vierten Elegie" machen diesen Unterschied deutlich durch Vergleiche aus dem pflanzlichen und aus dem Wasserbereich; die Elegie ist vom Motiv her jugendstilhaft, in der Aussage aber nur teilweise; man denke an die Erühere Kombination 'Tod' und 'Leben' im Jugendstil.

O Bäume Lebens, o wann winterlich?

Wir sind nicht einig. Sind nicht wie die Zugvögel verständigt. Überholt und spät, so drängen wir uns plötzlich winden auf und fallen ein auf teilnahmslosen Teich. Blühn und verdorrn ist uns zugleich bewußt. Und irgendwo gehn Göwen noch und wissen, solang sie herrlich sind, von keiner ohnmacht.

Die Möglichkeiten der Verklärung durch die Liebe werden im Spätwerk auch in Frage gestellt. Zwar sieht der Dichter noch in den Liebenden eine heilige Erscheinung der Natur, die den Ausbruch aus aller Mittelmäßigkeit bedeutet und den Einbruch in die hohen Bezirke des Seins. Liebe ist noch Kraft der Hoffnung und das Geheimnis der Welt, doch eine lange Dauer ist den Liebenden nicht gegeben:

O und die Nacht, die Nacht, wenn der Wind voller Weltraum uns am Angesicht zehrt-, wem bliebe sie nicht, die ersehnte,

$$
\begin{aligned}
& 482_{\text {op.cit. SW I., S. } 685 .} \\
& 483_{\text {ibid. S. } 697 .}
\end{aligned}
$$


sanft enttäuschende, welche dem einzelnen Herzen mühsam bevorsteht. Ist sie den Iiebenden leichter? Ach, sie verdecken sich nur mit einander ihr Los. 484

Ich weiß, ihr beruhrt euch so selig, weil die liebkosung verhält, weil die Stelle nicht schwindet, die ihr, Zärtliche, zudeckt; weil ihr darunter das reine Dauern verspürt. So versprecht ihr euch Ewigkeit fast von der Umarmung. Und doch, wenn ihr der ersten

Blicke Schrecken besteht und die Sehnsucht am Fenster, und den ersten gemeinsamen Gang, ein lvial durch den Garten: Liebende, seid ihr dann noch? Wenn ihr einer dem andern euch an den Nund hebt und ansetzt-: Getränk an Getränk: o wie entgeht dann der Trinkende seltsam der Handlung. 485

In der "Achten Elegie" meint der Dichter sogar, daß die Liebenden einander den Weg "ins Offene" - zur Verklärung und zur Einheit mit der Natur - verstellen, indem einer dem anderen seine Seligkeit verdankt und somit das Grenzenlose durch das "Du" begrenzt: 486 "Iiebende, wäre nicht der andre, der die Sicht verstelit, sind nah daran und staunen...."487

Mit diesem Motiv verbunden ist die jugendstilhafte Nädchengestalt, die auch in den Elegien noch zu finden ist. In der "Ersten Elegie" ist Gaspara Stampa das Vorbild dafür, eine Italienerin aus der Renaissance, die zur großen Iiebenden geworden war und deren Liebe zu einem untreuen Geliebten

$$
\begin{aligned}
& 484 \text { ibid. S. } 685 . \\
& 485_{\text {ibid. S. } 691 .} \\
& 486 \text { Rilke, Duineser Elegien, Die Sonette an Orpheus, mit } \\
& \text { Erläuterungen von Katharina Kippenberg (Zurich: Conzett \& } \\
& \text { Huber, 1951), S. } 119 .
\end{aligned}
$$

$$
487 \text { op.cit. SWI., S. } 714 .
$$


unvollendet blieb und die in der "Blüte der Jugend" starb488

Aber die Liebenden nimmt die erschöpfte Natur in sich zurück, als wären nicht zweimal die Kräfte, dieses zu leisten. Hast du der Gaspara Stampa denn genügend gedacht, daß irgend ein Mädchen, dem der Geliebte entging, am gesteigerten Beispiel dieser Liebenden fühlt: daß ich würde wie sie? Sollen nicht endlich uns diese ätesten Schmerzen fruchtbarer werden? Ist es nicht Zeit, daß wir liebend uns vom Geliebten befrein und es bebend bestehn: wie der Pfeil die Sehne besteht, um gesammelt im Absprung mehr zu sein als er selbst. Denn Bleiben ist nirgends. 489

Die Idee des opferbereiten jungen Mädchens wurde schon im "Grabmal eines Mädchens", "Alkestis" und im "Tod des Geliebten" und "Euridike" in den Neuen Gedichten entwickelt aus dem früher ähnlichen Motiv während Rilkes Jugendstil-Zeit. Auch im für Paula Becker geschriebenen "Requiem" findet man den Gedanken, daß das Opfer des Mädchentums in der Ehe dem Tode gleichkomme; hier ist es eine Künstlerin, die durch eine the in ihrer Entwicklung und in ihrem Schaffen aufs schwerste gehindert wurde, schließlich nach vergeblicher flucht aus ihrer Verstrickung ihr Leben zur Erfüllung ihrer Aufgabe als Gattin und Mutter opfern mußte. 490

Auch die Möglichkeit, im Tanz sich in die Harmonien des Alls einzufügen und dadurch die Ewigkeit und das Entrücktsein aus der Zeit zu erfahren, bleibt in den Elegien dem Menschen fern. Der Tänzer ist nicht länger die wieder zum Kind gewor-

$$
\begin{aligned}
& 488 \text { op.cit. Kippenberg, s. } 68 f \text {. } \\
& 489 \text { op.cit. SWI., S. } 686 f . \\
& 490 \text { op.cit. Rosteutscher, S. } 246 \text {. }
\end{aligned}
$$


dene, sich vergnügende naive Gestalt, sondern ein tanzender Akrobat - ein artistisches Kunststück - der von einem "niemals zufriedenen willen" beherrscht wird:

Wer aber sind sie, sag mir, die Fahrenden, diese ein wenig Flüchtigern noch als wir selbst, die dringen von früh an wringt ein wem, wem zu Liebe niemals zufriedener Wille? Sondern er wringt sie, biegt sie, schlingt sie und schwingt sie, wirft sie und fängt sie zurück; wie aus geölter, flatterer Luft kommen sie nieder auf dem verzehrten, von ihrem ewigen Aufsprung dünneren Teppich, diesem verlorenen Teppich im Weltall.491

Auch das Teppich-Symbol hat in den letzten Zeilen seine Bedeutung als magische Verwobenheit aller Lebensbestandteile verloren und ist nur noch dünn, ohne tieferen Sinn und "verloren" im Weltall.

In dieser eben erwähnten "Fünften Elegie" wird der Tänzer: auch in die Pflanzenwelt einbezogen - an und für sich ein typisches Jugendstil-Element. Der Tänzer ist ein Baum der Bewegung, der sich entwickelt und vollendet, bis er fest und reif dasteht. Doch in einem gewagtem sprung fällt er wie eine unreife Frucht $\mathrm{ab}$ :

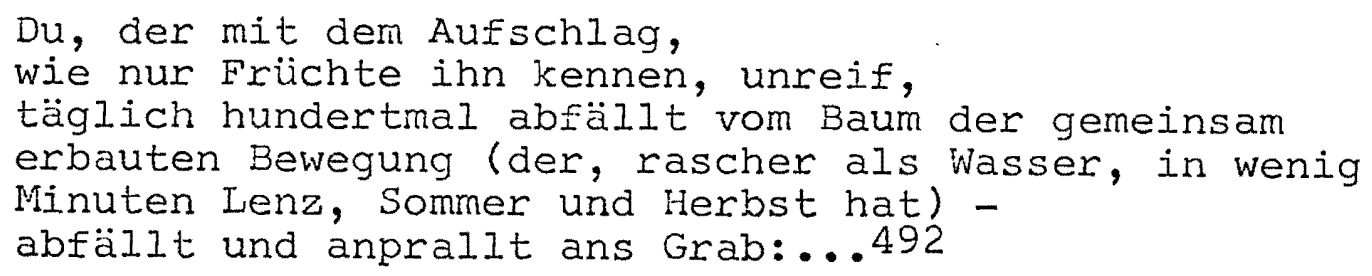

Man wird wieder an die "Vierte Elegie" erinnert - der Mensch kann sich nicht in die Gesetze der Natur einfügen; er ist ent$491_{\text {op.cit. SW. I. }}$ S. 701.
$492_{\text {ibid. S. } 702 \mathrm{~F} .}$ 
weder überholt und spät oder unreif und kommt zu keiner Vollendung. 493

Ein weiteres Motiv, das eine Umwandlung erfährt, ist die Gebärde des'Entgegenreckens', die sich oft im bildnerischen Jugendstil findet; Jünglinge oder Mädchen recken ihre Arme der strahlenden Sonne entgegen in einer Gebärde der Sehnsucht. In der "Siebten Elegie" ist die ausgestreckte Hând Zeichen für die Abwehr vor dem Engel:

...mein Anruf ist immer voll Hinweg; wider so starke Strömung kannst du nicht schreiten. Wie ein gestreckter Arm ist mein Rufen. Und seine zum Greifen oben offene Hand bleibt vor dir offen, wie Abwehr und Warnung, Unfaßlicher, weitauf. 494

Der Mensch ruft das All an, seine offene Hand greift aber nicht nach dem Himmel, sondern weist auf das Irdische und feiert das menschliche Sein.

Rilke hatte bereits die schöpferischen Leistungen des Menschen in dieser Elegie dargestellt: es sind vor allem Kunstwerke, die das tiefste Zeugnis unseres Selbst sind - das Werk unserer Hände und Herzen, das in diese Dinge eingegangen ist. 495 Solche Produkte sind Ansatz für höhere "Verwandlungen", denn die Dinge schwinden und der. Mensch muß sie retten und sie verwandeln! Die Dinge erleben und doch nicht besitzen, sondern

493 ̈̈hnliche Gedanken finden sich in Rilkes Interpretation der Hochrenaissance, Siehe S. I5off. dieser Arbeit.

$$
\begin{aligned}
& 494 \text { op.cit. SWI., s. } 713 . \\
& 495_{\text {op.cit. Kippenberg, S. } 139 .}
\end{aligned}
$$


sie in uns zu verwandeln, war das Jugendstil-Thema, das im Frühwerk tonangebend war und eher als alle anderen im Spätwerk erhalten bleibt:

Und diese, von Hingang lebenden Dinge verstehn, daß du sie rühmst; vergänglich, traun sie ein Rettendes uns, den Vergänglichsten, zu. Wollen, wir wollen sie ganz im unsichtbarn Herzen verwandeln in - o unendlich - in uns! 496

Das Schlafen mit den Dingen - innig sein mit ihnen - behandelt die XIV. Sonette an Orpheus, Teil II:

Nähme sie einer ins innige Schlafen und schliefe tief mit den Dingen-: o wie käme er leicht, anders zum anderen Tag, aus der gemeinsamen Tiefe.

Oder er bliebe vielleicht; und sie blühten und priesen ihn, den Bekehrten, der nun den Ihrigen gleicht, 497

Ein Vergleich mit der Eintragung im Schmargendorfer-Tagebuch (siehe Seite 170f.) ergibt eine fast wörtliche Übereinstimmung. Rilkes Lob der Dinge - vor allem auch kunstgewerblicher hängt eng mit der Jugendstil-Abneigung gegen die aufsteigende industrielle Entwicklung und die Überhandnahme der Maschine und der Technik zusammen. Dieses Problematik wird in der "Siebten" und "Neunten Elegie" besonders betont. Die X. Sonette an Orpheus, II. Teil, macht uns Rilkes standpunkt deutlich:

Alles Erworbne bedroht die Maschine, solange sie sich erdreistet, im Geist, statt im Gehorchen, zu sein. Daß nicht der herrlichen Hand schöneres zögern mehr prange, zu dem entschlossenern Bau schneidet sie steifer den Stein Nirgends bleibt sie zurück, daß wir ihr ein mal entrönnen und sie in stiller Fabrik ölend sich selber gehört.

$$
\begin{aligned}
& 496 \text { op.cit. SWI., S. } 719 . \\
& 497_{\text {ibid. S. } 760 .}
\end{aligned}
$$


Sie ist das Leben, - sie meint es am besten zu können, die mit dem gleichen Entschluß ordnet und schafft und 498

Noch ein Jugendstil-Motiv im Spätwerk ist die Welle. In einem Brief aus dem Jahr 1923 heißt es:

Daß alles Leere, alle Abwesenheit, alles scheinbare Verlassensein nichts anderes sein kann, im natürlichen unverfälschten Dasein, als ein Nachinnenschlagen dessen, was verloren oder vergangen scheint, Besinnung und Zusammennehmung, und leise innerste Arbeit, die dabei ist, das augenblicklich nicht sichtbare, fast Unbeweisliche zu erneuen, mit der nächsten steigenden Welle des Jahres, wieder wie neu, wie zum ersten Mal, unerschöpflich hervorzubringen....499

Das Wellen-Motiv ist eng mit Rilkes Auffassung des Steigens und Fallens verbunden, mit dem Kreislauf des Daseins, der immer wieder neue Kraft für den Menschen wie für die Natur bringt. In der "Zweiten Elegie" verbindet die Welle beide Bereiche; doch hier ist von der Vergänglichkeit des Menschen die Rede: jeder Atemzug bringt ihn dem Tod näher:

Wie Tau von dem Frühras hebt sich das Unsre von uns, wie die Hitze von einem heißen Gericht. O Lächeln, wohin? O Aufschaun: neue, warme, entgehende welle des Herzens -: weh mir: wir sinds doch. Schmeckt denn der Weltraum, in den wir uns lösen, nach uns? Fangen die Engel wirklich nur Ihriges auf, ihnen Entströmtes, oder ist manchmal, wie aus Versehen, ein wenig unseres Wesens dabei...500

In der I. Sonette an Orpheus, II. Teil, ist das gleiche Thema allerdings etwas anders ausgelegt: dort ist der Mensch durch seinen Atem mit dem Kosmos verbunden, - statt aber Vergäng-

$$
\begin{aligned}
& 498 \text { ibid. S. } 757 . \\
& 499 \text { op.cit. Briefe. } 2 \text { Bde., Bd. II, S. } 425 \text {. } \\
& 500 \text { op.cit. SWI., S. } 690 .
\end{aligned}
$$


lichkeit des Menschen bedeutet der Atemzug Gewinn und Verwandlung in Sprache, in Gesang und Gedicht, und dadurch die Selbstverwirklichung des Menschen.

Atmen, du unsichtbares Gedicht!

Immerfort um das eigne

Sein rein eingetauschter Weltraum. Gegengewicht, in dem ich mich rhythmisch ereigne.

Einzige Welle, deren

allmähliches Meer ich bin;

sparsamstes du von allen möglichen Meeren, -

Raumgewinn.

Wieviele von diesen Stellen der Räume waren schon

innen in mir. Nianche Winde

sind wie mein Sohn.

Erkennst du mich, Iuft, du, voll noch einst meiner Orte? Du, einmal glatte Rinde,

Rundung und Blatt meiner worte. 501

501 ibid. S. 751 . 
SCHLUSSBETRACHTUNG

Die knappe Motiv-Analyse des Spätwerks im vorangegangenen Kapitel sollte nur als exemplarischer Versuch gewertet werden, Rilkes immerwährende Jugendstilbezogenheit darzustellen. Es würde den Umfang dieser Arbeit sprengen, noch mehr jugendstilartige Charakteristika detaillierter für das werk nach 1902 anzuführen. Auch müßte noch eine eingehendere Untersuchung weiterer Stilmerkmale und ihrer $A b-$ leitung aus der bildenden Kunst im Frühwerk geleistet werden, möglicherweise ausgehend von E. Hajeks These der ZeitRaum - Entsprechung. Von gleicher Bedeutung wäre es, die langsame Abkehr Rilkes vom rein ornamentalen Gebrauch der Bilder zu immer tiefergehender Symbolik aufzuzeigen. Eine andere Möglichkeit der Ausweitung meines Ansatzes bestände darin, mit Hilfe vergleichender Arbeitsweise Rilkes "JugendStil" noch mehr aus dem Geist seiner Zeit zu erklären. Ich hoffe, für solche oder ähnliche weiterführende Themen mit der vorliegenden Arbeit eine Grundlage geschaffen zu haben. 


\section{AUSGEWÄHLTE BIBLIOGRAPHIE}

Bibliographien

Hünich, F.A. Rilke Bibliographie. Erster Teil. Leipzig: Insel, 1935 .

Mises, Richard v. Katalog der Rilke-Sammlung. Wiesbaden: Insel, 1966.

Ritzer, Walter. Rainer Maria Rilke Bibliographie. Wien: 0. Kerry, 1951.

\section{Primärliteratur:}

Ausgewählte werke. (A.w.). Hg. vom Rilke-Archiv in weimar. Besorgt durch Ruth Sieber-Rilke, Carl Sieber und Ernst Zinn. Bd. I., II. Leipzig: Insel, 1938.

Sämtliche werke. (S.w.). Hg. vom Rilke-Archiv. In Verb. mit Ruth Sieber-Rilke besorgt durch Ernst Zinn. 6 Bde. Wiesbaden: Insel, 1955-1966.

Briefe, Verse und Prosa aus dem Jahre 1896. Hg. Richard von Mises als drittes B̈̈ndchen der Reihe "RMR im Jahre 1896." New York: Verlag der Johannespresse, 1945.

Briefe an Baronesse von OE. Hg. Richard von Mises als zweites Bündchen der Reine "RIR im Jahre 1896." New York: Verlag der Johannes-Presse, 1945.

Gesammelte Briefe. Hg. von Ruth Sieber-Rilke und Carl Sieber. Bd. 1-5. Leipzig: Insel, 1936-1939. 1. Briefe aus den Jahren 1892-1904. 2. Briefe aus den Jahren 1904-07. 3. Briefe aus den Jahren 1907-14. 4. Briefe aus den Jahren 1914-1921. 5. Briefe aus liuzot 1921-26. 6. Briefe an seinen Nerleger.

Briefe. Hg. vom Rilke-Archiv in Weimar, in Verb. mit Ruth Siejer-Rilke besorgt durch Karl Altheim. Bd. I. 2 . Wiesbaden: Insel, 1950.

Briefe. (Br.A.). Hg. von Ruth Sieber-Rilke und Carl Sieber. Leipzig: Insel, 1931-1937.

Briefe und Tagebücher 1899-1902. (1931)

Briefe 1902-06. (1930) 


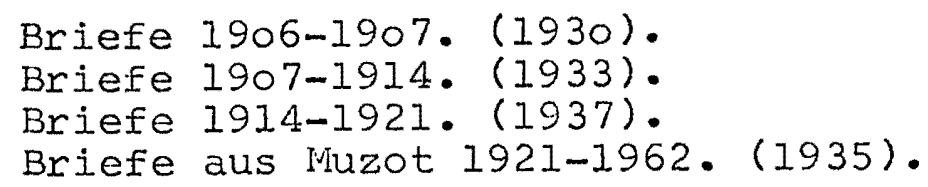

Briefwechsel, Rainer Maria Rilke und Marie von Thurn und Taxis-Hohenlohe. Hg. Ernst Zinn. 2 Bde. Zürich: Niehans \& Rokitanksy und Wiesbaden: Insel, 1951.

Rainer Maria Rilke und Lou Andreas Salomé. Briefwechsel. Hg. Ernst Pfeiffer. Wiesbaden: Insel, 1952.

Tagebücher aus der Frühzeit. Hg. Ruth Sieber-Rilke und Carl Sieber. Leipzig: Insel, 1942.

Duineser Eleqien, Die Sonette an Orpheus. Mit Erläuterungen von Katharina Kippenberg. Zürich: Conzett Huber, 1951.

Sekundärliteratur: Bücher

Ahlers-Hestermann, Friedrich. Stilwende. Aufbruch der Jugend um 1900. Berlin: Mann, 1941.

Becker, Paula Modersohn. Briefe und Tagebuchblätter. München: Paul List, 1917.

Benjamin, Walter. Schriften Bd. II. Frankfurt: Suhrkamp, 1955. S. 323-330.

Berendt, H. Rilkes Neue Gedichten. Bonn: H. Bouvier Verlag, 1957.

Bollnow, Otto Friedrich. Unruhe und Geborgenheit. Stuttgart: Kohlhammer Verlag, 1958.

Demetz, Peter. René Rilkes Prager Jahre. Düsseldorf: Eugen Diedrichs Verlag, 1953.

Deutz, I. Die dichterische Gestaltung des Tanzes in der deutschen Lyrik, Diss., 1953.

Falk, W. Leid und Verwandlung. Salzburg: Otto Muiller Verlag, 1961 .

Fritz, Horst. Literarischer Jugendstil und Expressionismus. Stuttgart: J.B. Metzlersche Verlagsbuchhandlung, 1969.

Gebser, Jean. Rilke und Spanien. Zürich: Verlag Oprecht, 1940.

Haeckel, Ernst. Kunstformen der Natur. 1899-1904. Leipzig und Wien: Verlag Bibliographisches Institut, 1899 . 
Hajek, Edelgard. Literarischer Jugendstil. Düsseldorf: Bertelsmann Universitätsverlag, 1971.

Hamann, Richard u. Hermand, Jost. Stilkunst um 1900. Bd. IV. der Reihe Deutsche Kunst und Kultur von der Gründerzeit bis zum Expressionismus. Berlin: Ak ademie-Verlag, 1968 .

Hamilton, G.H. The Art and Architecture of Russia. Penguin History of Art. London: Penguin Books Ltd., 1954.

Hartt, Fredrick. Sandro Botticelli. St. Louis: Washington University Press.

Heerikhuizen, F.W. R.M.Rilke. His Life and Work. London: Routledge \& Kegan Paul Itd., 1951.

Hermand, Jost. Ein Forschungsbericht. Jugendstil 1918-1964. Stuttgart: J.B. Metzlersche Verlagsbuchhandlung, 1965.

Lyrik des Jugendstils. Eine Anthologie. Universal-Bibliothek Nr. 8928. Stuttgart: Reclam, 1964.

Jugendstil. Darmstadt: Wissenschaftliche Buchgesellschaft, 1971. Enthält u.a. folgende Aufsätze: "Der literarische Jugendstil" v. Walter Lennig (1958); "Stefan George und der Jugendstil" v. C. David (1963); "Lyrik des Jugendstils v. Jost Hermand (1964); "Thomas Manns Erzählung 'Tristan' v. Wolfdietrich Rasch (1964); "Zum literarischen Jugendstil" v. Dominik Jost (1968); "Undinen-Zauber v. Jost Hermand (1969).

Hofstätter, Hans. Geschichte der europäischen Jugendstilma-Ierei. Reihe III. KuItur und Geschichte, Duiriont Dokumente. Köln: Verlag i. Duliont Schauberg, 1963.

Holler-Keller, Roswitha. Jugendstilelemente in Ricarda Huchs früher Prosa, Diss. Kiel, 1969.

Holthusen, H.E. Rainer Maria Rilke in Selbstzeugnissen und Bilddokumenten. Hamburg: Rowohlt, 1958.

Hunt, John D. The Pre-Raphaelite Imagination 1848-1900. London: Routledge \& Kegan Paul Ltd., 1968.

Janson, H.W. History of Art. New York: Harry N. Abrams, Inc., 1962 .

Jost, Dominik. Iiterarischer Jugendstil. Stuttgart: J.B. Metzlersche verlagsbuchhandlung, 1969 . 
Kimmich, Anne. Kritische Auseinandersetzung mit dem Begriff ' Neoromantik' in der Literaturgeschicht'ss:chreibung. Diss. Tübingen, 1936 .

Kirchgraber, Jost. Meyer, Rilke, Hofmannsthal. Dichtung und bildende Kunst. Bonn: Bouvier Verlag, 1971 .

Klein, E. Jugendstil in Deutscher Lyrik, Diss. Köln, 1957.

Koreska-Hartmann, Jugendstil - Stil der 'Jugend'. Nördlingen: DTV., 1969 .

Kramer-Lauff, Dietgard. Tanz und Tänzerisches in Rilkes Lyrik. München: Wilhelm Fink Verlag, 1969.

Madsen, S. Tschudi. Art Nouveau. New York: MicGraw-Hill Book Co., 1967.

Mason, E.C. Rilke and the Enqlish Speaking World. London: Cambridge Univ. Press, 1961.

Exzentrische Bahnen. Göttingen: Vandenhoeck u. Ruprecht, 1963 .

Rilke. London: Oliver and Boyd Ltd., 1963.

Muther, Richard: Geschichte der Malerei. Bd. II. Leipzig: G. S. Göschen'sche Verlagshandlung, 1899.

Narazaki, Muneshige. Masterworks of Ukiyo-E Hokusai. Tokyo and Palo Alto: Kodansha International Ltd., 1968.

Paine, R.T. and Soper, A. The Art and Architecture of Japan. The Pelican History of Art. London: Penguin Books Ltd., 1955.

Peters, H.F. Rainer Maria Rilke: Masks and the Man. Seattle: University of Washington Press, 1960.

Petzet, H.W. Das Bildnis des Dichters. Paula Becker-Modersohn, Rainer Maria Rilke. Frankfurt/M.: SocietätsVerlag, 1957.

Von Worpswede nach Moskau: Heinrich Vogeler, ein Künstler zwischen den Zeiten. Köln: Verlag M. Duriont Schaugerg, 1972 .

Pongs, Hermann. Das Bild in der Dichtung. Bd. II. Miarburg: N.G. Elwert'sche Verlagsbuchinalung, 1963. 
Ramseger, Dr. Georg. Literarische Zeitschriften um die Jahrhundertwende unter besonderer Berücksichtigung der "Insel". Germanische Studien. Berlin: Verlag Dr.E. Ebering, 1941. S. 3-179.

Rasch, Wolfdietrich. Zur deutschen Literatur seit der Jahrhundertwende. Gesammelte Aufsätze. Stuttgart: J.B. Metzlersche Verlagsbuchhandlung, 1967.

Bildende Kunst und Literatur. Beiträge zum Problem ihrer Wechselbeziehungen im neunzehnten Jahrhundert. Studien zur Philosophie und Literatur des neunzehnten Jahrhunderts, Bd. 6. Frankfurt/M.: Vittorio Klostermann, 1970 .

Rehm, Walter. Der Dichter und die reue Einsamkeit. Göttingen: Vandenhoeck \& Ruprecht, 1969. S. 34-77.

Requadt, Die Bildersprache der deutschen Italiendichtung von Goethe bis Benn. Bern und Wiunchen: Francke, 1962.

Roh, Franz. German Art in the 2oth Century. London: Thames \& Hudson, 1968.

Rosenhaupt, Hans w. Der deutsche Dichter um die Jahrhundertwende und seine Abgelöstheit von der Gesellschaft. Bern, Leipzig: Paul Haupt Verlag, 1939.

Rosteutscher, Joachim. Das ästhetische Idol im Werke von Winkelmann, Novalis, Hofmann, Goethe, George und Rilke. Bern: Francke Verlag, 1956.

Rud, Einar. Vasari's Life and Lives. Princeton: D Van Nostrand Co., 1961 .

Ryan, Lawrence. "Die Krise des Romantischen bei R.M.Rilke". In: Nachleben der Romantik in der modernen deutschen Literatur. Hg . Wolfgang Paulsen. Heidelberg: Stiehm, 1969 .

Schmalenbach, Fritz. Jugendstil. Ein Beitrag zur Theorie und Geschichte der Flächenkunst, ijüzburg, 1935 .

Schmutzler, Robert. Art Nouveau - Jugendstil. Stuttgart: Verlag Gerd Hatje, 1962 .

Schnack, Ingeborg. Rilkes Leben und Werk im Bild. Wiesbaden: Insel, 1956.

Schneditz, W. Rilke und die bildende Kunst. Graz: Kienreich, 1947. 
Schneibel, Gertrud. Rainer Maria Rilke und die bildende Kunst. Diss. Gießen, 1933.

Seling, H. Jugendstil. Der Weg ins 20. Jahrhundert. Heidelberg: Keysersche Verlagsbuchhandlung, 1959 .

Sieber, Carl. René Rilke. Leipzig: Insel, 1932.

Skrobuche, Heinz. Icons. Edinburgh, London: Oliver \& Boyd, 1963.

Soergel-Hohoff. Dichtung und Dichter der Zeit. Bd. I, II. Hamburg: Bagel Verlag, 1963.

Sommerhalder, Hugo. Zum Begriff des literarischen Impressionismus. Zürich: Polygraphischer Verlag AG., 1961.

Stelzer, Otto. Paula Modersohn-Becker. Berlin: Rembrandt-VerIag GmbH, 1958.

Thon, L. Die Sprache des deutschen Impressionismus. Miünchen: Max Hueber Verlag, 1928.

Wandel, J. Rilke und die Maler. Diss. Evanston, Illinois: Northwestern University, Typoscript, 1965.

Wocke, Helmut. Rilke und Italien. Gießener Beiträge zur deut schen Philologie, Hg. Alfred Götze. Gießen: Münchowsche Universitäts-Druckerei, 1942 .

Wohltmann, Hans. Worpswede. Worpswede: Verlag Haus am Weyerberg, 1967.

Zimmermann, Horst. Dresden Gallery. London: Peter Owen, 1966.

Zeitschriften-Artikel

Ankwicz-Kleehoven, "Rainer Maria Rilke und die Wiener Se:ession", Wiener Zeitung, Nr. I, I. Januar 1947, S. 8f.

Comerford, M. J. "Rilke in English: 1946-1966." Germanic Review, Vol. XlII., 1967. S. 301-309.

Gronicka, A.v. "Rilke and the Pasternaks". Germanic Review, Vol. XXVII., 1952. S. 260-271.

Herzog, B. "Der Gott des Jugendstils in Rilkes Stundenbuch." Schweizer Rundschau, LX, 21. S. 1237-1241.

Kerr, A. "Neue Schauspielkunst". Neue Rundschau, 1904,S. $94 f$. 
Klotz, V. "Jugendstil in der Lyrik", Akzente 4, 1957. S. $27-34$.

Kronegger, M.E. "Impressionist Tendencies in Lyrical Prose", Revue de Litterature comparé, Vol. 43, 1963. S. 528-

PAN, Nr. I., Berlin: Fontane \& Co., 1895.

Rannit, Alexis. "Rilke und die slawische Kunst". Das Kunstwerk. 5. Jahr. Heft 4, 1951. S. 13-24.

Webb, Karl E. "Rilke, Rodin, und Jugendstil: The Poet as an Art Critic". Orbis Litterarium, Vol. XXVII, No. 4.

S. $254-263$. 